UNIVERSIDAD POLITÉCNICA DE VALENCIA

DEPARTAMENTO DE TECNOLOGÍA DE LOS ALIMENTOS

\title{
"Influencia de la adición de glicosidasas sobre el potencial aromático del tomate (Solanum lycopersicum L.)"
}

\section{Tesis Doctoral}

Presentada por:

Josefa Ortiz Serrano

Dirigida por:

Dr. José Vicente Gil Ponce

Valencia, 2008 


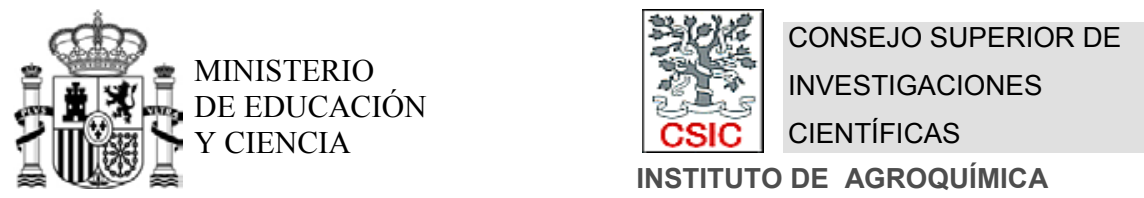

INSTITUTO DE AGROQUÍMICA

Y TECNOLOGÍA DE ALIMENTOS

D. José Vicente Gil Ponce, Doctor en Ciencias Biológicas, Profesor Contratado Doctor de la Universitat de València, e investigador en el Instituto de Agroquímica y Tecnología de Alimentos (IATA) del Consejo Superior de Investigaciones Científicas (CSIC):

HACE CONSTAR QUE: $D^{a}$. Josefa Ortiz Serrano, Ingeniero Agrónomo por la Universidad Politécnica de Valencia, ha realizado bajo su dirección en el Instituto de Agroquímica y Tecnología de Alimentos (IATACSIC) el trabajo que, con el título "Influencia de la adición de glicosidasas sobre el potencial aromático del tomate (Solanum lycopersicum, L.)", presenta para optar al grado de Doctor.

Y para que así conste a los efectos oportunos, firman el presente certificado en Burjassot, a 29 de Mayo de 2008.

Fdo. Dr. José Vicente Gil Ponce 

A mis

padres, a mi hermano,

$y$ a Fred 



\section{AGRADECIMIENTOS}

El momento de mirar hacia atrás y agradecer los apoyos recibidos durante el desarrollo de esta Tesis Doctoral ha llegado. En primer lugar quiero dar las gracias al Instituto de Agroquímica y Tecnología de Alimentos (IATA-CSIC) y a los Drs. Daniel Ramón Vidal y José Vicente Gil por haberme dado la oportunidad de descubrir y participar del mundo de la ciencia y de la investigación, particularmente al Dr. José Vicente Gil, director de este trabajo, por haberme permitido hacerlo de su mano. A él tengo que agradecer además, su profesionalidad, su disponibilidad, y la inmensa mayoría de todo lo que he aprendido, que no ha sido poco.

Mi agradecimiento a la Dra. Ma Carmen Bolarín del Centro de Edafología y Biología Aplicada del Segura (CEBAS-CSIC), al Dr. Vicente Moreno y a sus ayudantes del Instituto de Biología Molecular y Celular de Plantas (IBMCP) por habernos suministrado el material necesario y suficiente para llevar a cabo esta investigación.

Este documento es el resultado del trabajo realizado con ilusión y esfuerzo, un documento que nunca hubiera visto la luz $\sin$ el acompañamiento, educativo, generoso y sin condiciones, de mi director y de tod@s I@s compañer@s con los que he compartido los pasillos, las comidas, los almuerzos, la bancada en el laboratorio, o los equipos. Recuerdo con cariño a la Dra. Empar Chenoll enseñándome a preparar medios de cultivo, o al Dr. Pedro Martínez mostrándome cómo trabajar con cepas de hongos liofilizados, a Juan Antonio Tamayo o a Óscar Herrero siempre pacientes, siempre dispuestos a compartir sus saberes, siempre compañeros, o a la Dra. Berta Alquezar aconsejándome en la maquetación. No me atrevo a nombrarlos a todos por miedo a olvidar a alguien, el camino recorrido hasta aquí ha sido largo.

A tod@s, gracias, gracias, gracias. 



\section{RESUMEN}

El sabor y el aroma del tomate son el resultado de las interacciones que se establecen, principalmente, entre sus azúcares, ácidos orgánicos, aminoácidos libres, minerales y compuestos volátiles, jugando estos últimos un papel muy relevante en la apreciación sensorial final. Una parte de estos compuestos se encuentran en forma libre, constituyendo la fracción volátil libre (FVL) pero otra parte se encuentra en forma glicosilada y los componentes que la forman no pueden ser percibidos por los receptores olfativos, constituyendo la denominada fracción volátil glicosilada (FG). Los precursores glicosilados constituyen, por tanto, una fuente potencial para incrementar el aroma final si se consigue la hidrólisis de los enlaces glicosídicos y la consiguiente liberación de los aglicones. El objetivo de este estudio fue determinar la composición de ambas fracciones en el tomate para, seguidamente, evaluar la capacidad de determinadas actividades glicosídicas para liberar los compuestos volátiles que se encuentran en forma glicosilada.

Se ha caracterizado el perfil aromático de cinco variedades de tomate. Los resultados han mostrado una gran influencia de la variedad sobre la composición tanto de la FVL como de la FG del tomate, estableciéndose el potencial de esta última para incrementar los compuestos volátiles libres. Se ha estudiado la influencia de la maduración en el perfil aromático del tomate, observándose que los componentes de la FVL y de la FG tienden, en general, a aumentar sus concentraciones a medida que avanza la maduración del fruto, aunque con relevantes excepciones. Este estudio avala la posibilidad, propuesta por otros autores, de utilizar el perfil aromático del tomate como una herramienta para la identificación de las variedades.

Se han producido extractos enriquecidos en distintos enzimas glicosídicos de origen fúngico. La incubación de zumo de tomate en presencia de estos enzimas, de forma individual o combinada, ha demostrado su capacidad para liberar varios de los aglicones 
particularmente relevantes en el aroma del tomate de acuerdo con la bibliografía. A partir de extractos de la FG del tomate y su incubación con los enzimas glicosídicos o sus combinaciones, se han determinado los compuestos volátiles y los azúcares liberados. Los resultados indican que en la composición de los glicósidos del tomate participan los azúcares glucosa, xilosa, ramnosa, y arabinosa, y entre los aglicones volátiles se encuentran aldehídos, alcoholes, y terpenos. La cantidad de ramnosa detectada así como el papel relevante de la ramnosidasa en el aumento de compuestos volátiles del zumo de tomate, sugiere la abundancia de glicósidos de este azúcar. Estos resultados pueden suponer un punto de partida para abordar la mejora biotecnológica del aroma del tomate. 


\section{RESUM}

El sabor i l'aroma de la tomaca són el resultat de les interaccions que s'establixen, principalment, entre els seus sucres, àcids orgànics, aminoàcids lliures, minerals i compostos volàtils, jugant estos últims un paper molt rellevant en l'apreciació sensorial final. Una part d'estos compostos es troben en forma lliure, constituint la fracció volàtil lliure (FVL) però una altra part es troba en forma de glicósids i els components que la formen no poden ser percebuts pels receptors olfactius, constituint la denominada fracció volàtil glicosilada (FG). Els precursors glicosilats constituïxen, per tant, una font potencial per a incrementar l'aroma final si s'aconseguix la hidròlisi dels enllaços glicosídicos i el consegüent alliberament dels aglicons. L'objectiu d'este estudi va ser determinar la composició d'ambdós fraccions en la tomaca per a, a continuació, avaluar la capacitat de determinades activitats glicosídiques per a alliberar els compostos volàtils que es troben en forma de glicósids.

S'ha caracteritzat el perfil aromàtic de cinc varietats de tomaca. Els resultats han mostrat una gran influència de la varietat sobre la composició tant de la FVL com de la FG de la tomaca, establint-se el potencial d'esta última per a incrementar els compostos volàtils lliures. S'ha estudiat la influència de la maduració en el perfil aromàtic de la tomaca, observant-se que els components de la FVL i de la FG tendixen, en general, a augmentar les seues concentracions a mesura que avança la maduració del fruit, encara que amb rellevants excepcions. Este estudi avala la possibilitat, proposta per altres autors, d'utilitzar el perfil aromàtic de la tomaca com una ferramenta per a la identificació de les varietats.

S'han produït extractes enriquits en distints enzims glicosídics d'origen fúngic. La incubació de suc de tomaca en presència d'estos enzims, de forma individual o combinada, ha demostrat la seua capacitat per a alliberar alguns dels aglicons particularment rellevants en l'aroma de la tomaca d'acord amb la bibliografia. A partir d'extractes de la FG de la tomaca i la seua incubació amb els enzims glicosídicos o les seues 
combinacions, s'han determinat els compostos volàtils $i$ els sucres alliberats. Els resultats indiquen que en la composició dels glicósids de la tomaca participen els sucres glucosa, xilosa, ramnosa, i arabinosa, i entre els aglicons volàtils es troben aldehids, alcohols, i terpens. La quantitat de ramnosa detectada així com el paper rellevant de la ramnosidasa en l'augment de compostos volàtils del suc de tomaca, suggerix l'abundància de glicósids d'aquest sucre. Estos resultats poden suposar un punt de partida per a abordar la millora biotecnològica de l'aroma de la tomaca. 


\section{SUMMARY}

The tomato taste and aroma is the result of the interactions established, mainly, between its sugars, organic acids, free amino acids, minerals, and volatile compounds, the latest playing a relevant role in the final sensory appreciation. A part of these volatile compounds are found in free forms, forming the free volatile fraction (FVF), but another part is found in glycosidically bound forms and its constituents can not be perceived by the olfactory receptors, constituting the named volatile glycosidically bound fraction (GBF). The glycosidically bound precursors, therefore, make up a potential source to increase the final aroma if the hydrolysis of the glycosidic linkage and the consequent release of aglycons are achieved. The aim of this work was to determine the composition of both fractions in the tomato to, next, evaluate the ability of certain glycosidic activities to release the volatile compounds from their respective glycosidic precursors.

The aromatic profile of five cultivars has been characterised. The results have shown a strong influence of the cultivar on the composition of the FVF event of the GBF of the tomato, establishing the potential of the latest to increase free volatile compounds. The influence of fruits maturation on the aromatic profile of the tomato have been studied, observing that the dominant trend of the FVL and GBF components was, in general, to increase its concentration as the fruit maturation move, although with relevant exceptions. This study supports the possibility, reported by other authors, of using the aroma profile of the tomato as a tool for cultivar identification.

Extracts enriched in different glycosidic enzymes of fungal origin have been produced. The incubation of the tomato juice added with these enzymes, individually or in combinations, has demonstrated its ability to release several of the particularly relevant aglycons for the tomato aroma according to the literature. From extracts of the GBF of the tomato and its incubation with glycosidic enzymes or its combinations, the volatile compounds and sugar units released were determined. The results show 
that the tomato glycosides composition involves the sugars glucose, xilosa, rhamnose, and arabinose, and the volatile aglycons aldehydes, alcohols, and terpenes. The quantity of rhamnose detected and the relevant role of the rhamnosidase in the enhancement of volatile compounds of the tomato juice, suggest the abundance of glycosides of this sugar. These results can be the starting point in order to address the biotechnological improvement of the tomato aroma. 


\section{ÍNDICE GENERAL}

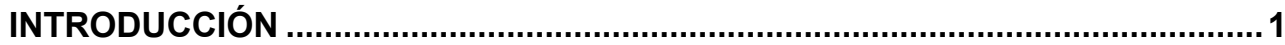

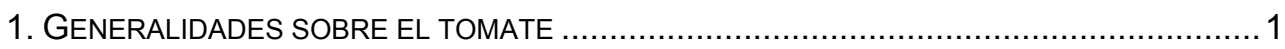

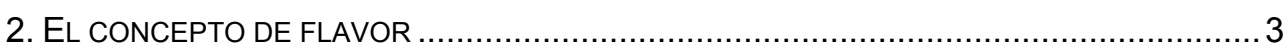

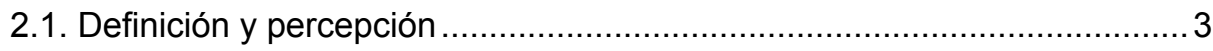

2.2. El aroma, componente fundamental del flavor de los alimentos ...............6

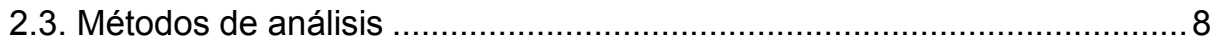

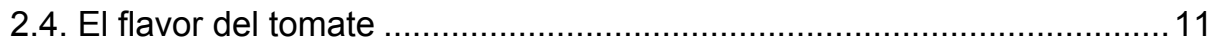

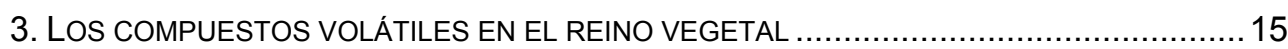

3.1. Perfil de compuestos volátiles en tomate ........................................... 16

3.2. Rutas generales de biosíntesis de compuestos volátiles en tomate ....... 19

3.3. Efecto del etileno en la biosíntesis de compuestos volátiles en tomate.. 23

4. PRECURSORES DE COMPUESTOS VOLÁTILES EN PRODUCTOS VEGETALES: LOS

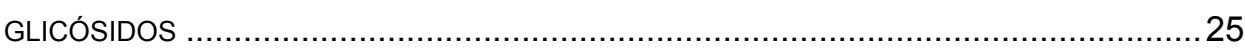

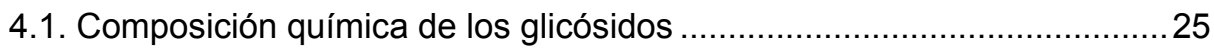

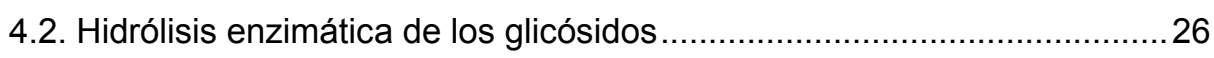

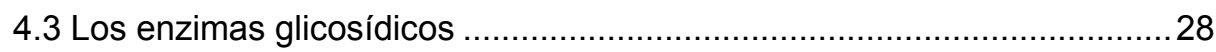

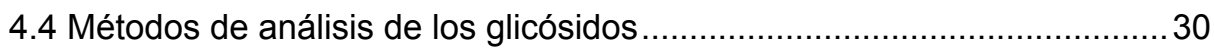

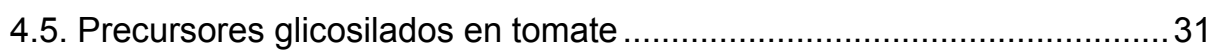

5. BIOTECNOLOGÍA Y MEJORA DEL FLAVOR EN EL ÁREA DE LA TECNOLOGÍA DE LOS

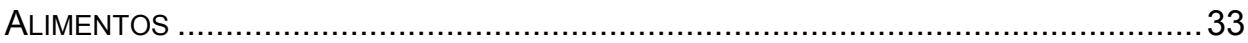

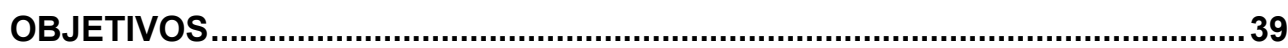

MATERIALES Y MÉTODOS ..........................................................................43

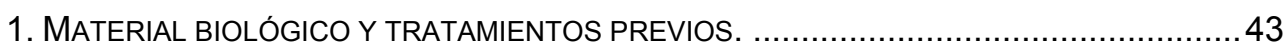

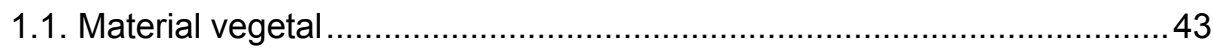

1.2. Cepas de levadura y su crecimiento en condiciones de laboratorio ........44

2. PRODUCCIÓN DE EXTRACTOS ENRIQUECIDOS CON LOS ENZIMAS GLICOSÍDICOS BGLN,

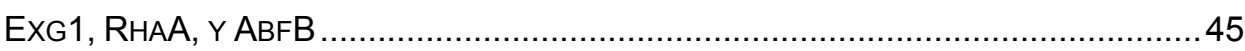

2.1. Producción de extractos enriquecidos con el enzima BgIN .....................46

2.2. Producción de extractos enriquecidos con los enzimas Exg1 y AbfB .....46

2.3. Producción de extractos enriquecidos con el enzima RhaA.....................47 
2.4. Producción de los enzimas BgIN y Exg1 adicionados al zumo extraído de las variedades $p 73$, Jorge y Durinta ........................................................ 47

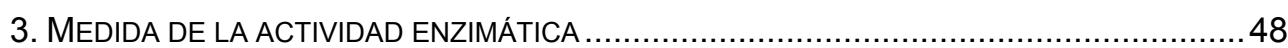

4. EXTRACCIÓN DE LA FRACCIÓN GLICOSILADA DEL TOMATE....................................48

5. HIDRÓLISIS ENZIMÁTICA DE LA FRACCIÓN GLICOSILADA DE TOMATE ..........................49

5.1. Caracterización de la fracción glicosilada .................................................... 49

5.2. Análisis de la composición de los glicósidos ........................................49

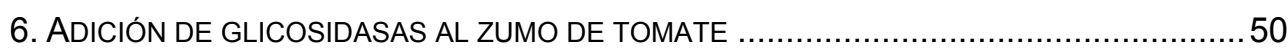

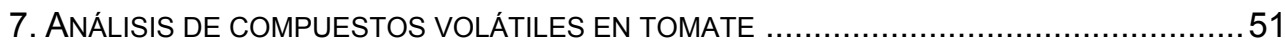

7.1. Detección: microextracción en fase sólida en espacio de cabeza y

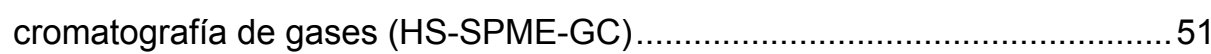

7.2. Identificación: cromatografía de gases acoplada a espectrometría de

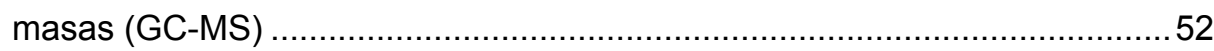

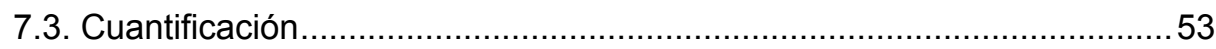

8. ANÁLISIS DE AZÚCARES: CROMATOGRAFÍA LÍQUIDA DE ALTA RESOLUCIÓN (HPLC) ....55

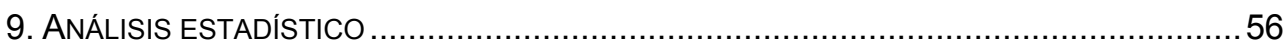

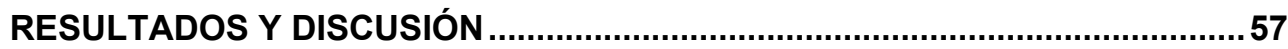

\section{CAPÍTULO 1. CARACTERIZACIÓN DEL PERFIL AROMÁTICO DEL TOMATE}

1. CARACTERIZACIÓN DE LA FRACCIÓN VOLÁTIL DEL TOMATE ...................................59

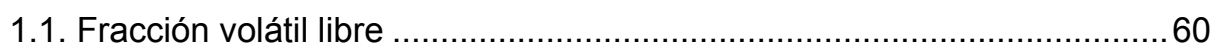

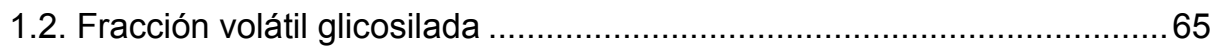

1.3. Potencial aromático de la fracción glicosilada ..........................................68

2. INFLUENCIA DEL ESTADO DE MADURACIÓN EN EL PERFIL AROMÁTICO ….....................70

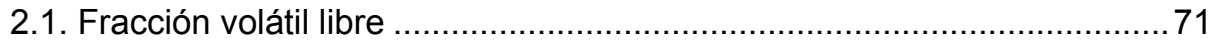

2.1.1. Comparación entre las variedades MM y Raf en el estado de maduración

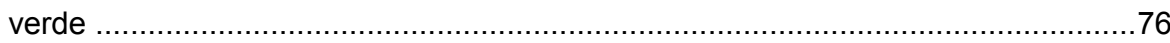

2.1.2. Comparación entre las variedades MM y Raf en el estado de maduración

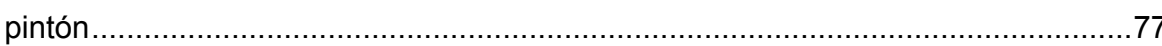

2.1.3. Comparación entre las variedades MM y Raf en el estado de maduración maduro

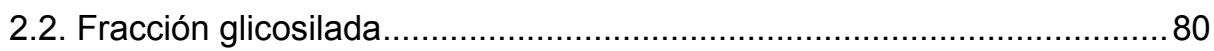

2.2.1. Perfil de compuestos volátiles ....................................................... 80

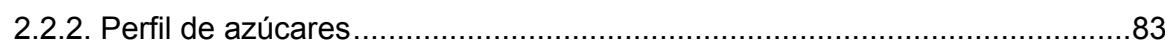


2.2.3. Comparación entre las variedades Moneymaker y Raf ...............................84

2.3. Potencial aromático de la fracción glicosilada ................................... 87

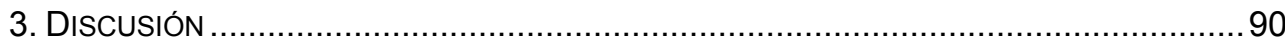

3.1. Caracterización de la fracción volátil del tomate .................................90

3.1.1. Caracterización de la fracción volátil libre ................................................91

3.1.2. Caracterización de la fracción glicosilada.................................................99

3.1.3. Potencial aromático de la fracción glicosilada ...................................... 102

\section{CAPÍTULO 2. EMPLEO DE GLICOSIDASAS PARA LA LIBERACIÓN DE} COMPUESTOS VOLÁTILES GLICOSILADOS DEL TOMATE.

1. PROducción de EXTRACTOS ENRIQUECIDOS CON LAS ACTIVIDADES BgLN, EXg1, RHAA, Y ABFB 107

2. EFECTO DE LA ADICIÓN DE LOS ENZIMAS BGLN Y EXG1 AL ZUMO DE LAS VARIDADES DE TOMATE P73, JORGE, Y DURINTA (ORTIZ-SERRANO Y GIL, 2007) . 110

3. EXPERIMENTOS DE ADICIÓN DE ACTIVIDADES GLUCOSIDASA, RAMNOSIDASA, Y ARABINOSIDASA AL ZUMO DE TOMATE EN DISTINTOS ESTADOS DE MADURACIÓN .......117

3.1. Tratamientos enzimáticos en la variedad Moneymaker ........................ 122

3.2. Tratamientos enzimáticos en la variedad Raf............................... 129

3.3. Efecto global sobre la fracción volátil libre......................................... 135

4. ANÁLISIS DE LA COMPOSICIÓN DE LOS GLICÓSIDOS ..................................... 138

4.1. Perfil de aglicones en el estado de maduración verde ...........................59

4.2. Perfil de aglicones en el estado de maduración pintón .......................... 141

4.3. Perfil de aglicones en el estado de maduración maduro ....................... 144

4.4. Perfil de azúcares en distintos estados de maduración ....................... 147

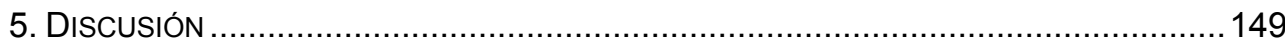

5.1. Empleo de glicosidasas para la liberación de compuestos volátiles

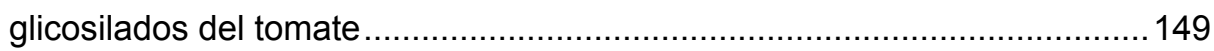

5.1.1. Efecto de la adición de $\beta$-glucosidasas al zumo de tomate .......................150

5.1.2. Efecto de la adición de mezclas de glicosidasas al zumo de tomate en distintos estados de maduración ....................................................................153

5.1.3. Análisis de la composición de los glicósidos ......................................160

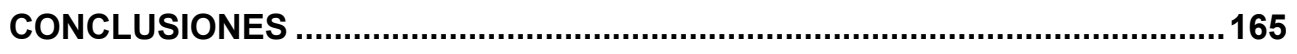

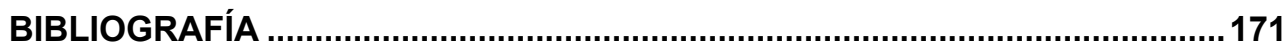





\section{ÍNDICE DE FIGURAS}

Figura 1. Esquema de las vías de percepción del flavor a través de nariz y boca.

Figura 2. Ruta de biosíntesis de los terpenoides. 21

Figura 3. Estructura de los precursores de compuestos volátiles glicosilados. _ 26

Figura 4. Esquema de la hidrólisis enzimática de los precursores de compuestos volátiles glicosilados.

Figura 5. Frutos de las variedades de tomate estudiadas, p73, Jorge, Durinta, Moneymaker, y Raf, en el estado de maduración pintón. 60

Figura 6. Cromatograma de gases (HS-SPME-GC) representativo de la fracción volátil libre del tomate obtenido a partir del zumo de la variedad p73. 60

Figura 7. Cromatograma de gases (HS-SPME-GC) representativo de la fracción glicosilada del tomate, en este caso, previamente extraída de la variedad Raf, obtenido tras hidrólisis enzimática de la misma con AR2000. 65

Figura 8. Concentración en forma libre (barras en negro) y en forma glicosilada (barras en blanco), expresada como la media \pm error estándar de 3 repeticiones, en las variedades p73, Jorge, Durinta, Moneymaker (MM) y Raf. Los valores numéricos señalados corresponden a la razón entre la concentración en forma glicosilada y libre, para cada compuesto y variedad.

Figura 9. Frutos de las variedades Moneymaker y Raf en los 3 estados de maduración considerados, $\mathrm{V}, \mathrm{P}, \mathrm{y} \mathrm{M}$. 70

Figura 10. Suma ponderada de las concentraciones de 7 de los 10 compuestos cuya mezcla reproduce el aroma del tomate fresco maduro. Diferentes letras indican diferencias significativas entre los 3 estados de maduración considerados para cada variedad según el Test de Tukey's HSD aplicado con un intervalo de confianza del $95 \%$ a 3 repeticiones.

Figura 11. Concentración de los compuestos volátiles identificados en la FVL que mostraron diferencias significativas entre las variedades MM (barras en azul oscuro) y Raf (barras en azul claro) en el estado de maduración $\mathrm{V}$, según el Test de Tukey's HSD aplicado con un intervalo de confianza del $95 \%$ a 3 repeticiones. 77

Figura 12. Concentración de los compuestos volátiles identificados en la FVL que mostraron diferencias significativas entre las variedades MM (azul y verde 
oscuros) y Raf (azul y verde claros) en el estado de maduración $\mathrm{P}$, según el Test de Tukey's HSD aplicado con un intervalo de confianza del $95 \%$ a 3 repeticiones. Barras en azul para concentraciones entre 100-1800 $\mu \mathrm{g} / \mathrm{L}$, y en verde para concentraciones entre 0.2-180 $\mu \mathrm{g} / \mathrm{L}$.

Figura 13. Concentración de los compuestos volátiles identificados en la FVL que mostraron diferencias significativas entre las variedades MM (azul y verde oscuros) y Raf (azul y verde claros) en el estado de maduración M, según el Test de Tukey's HSD aplicado con un intervalo de confianza del $95 \%$ a 3 repeticiones. Barras en azul para concentraciones entre 290-6000 $\mu \mathrm{g} / \mathrm{L}$, y en verde para concentraciones entre $0.8-350 \mu \mathrm{g} / \mathrm{L}$.

Figura 14. Concentración de glucosa, xilosa, arabinosa, y ramnosa detectada tras la hidrólisis enzimática del extracto de glicósidos de las variedades MM y Raf en los estados de maduración $\mathrm{V}$ (verde), P (burdeos), y M (azulado). Diferentes letras para cada estado de maduración representan la existencia de diferencias significativas entre los azúcares según el el Test de Tukey's HSD aplicado con un intervalo de confianza del $95 \%$ a 3 repeticiones. 83

Figura 15. Concentración de los aglicones que mostraron diferencias significativas, tras hidrólisis enzimática de la $F G$, entre las variedades $M M$ (barras en azul y verde oscuros) y Raf (barras en azul y verde claros) en el estado de maduración $V$, según el Test de Tukey's HSD aplicado con un intervalo de confianza del $95 \%$ a 3 repeticiones. Barras en azul para concentraciones entre 19-500 $\mu \mathrm{g} / \mathrm{L}$, y en verde para concentraciones entre 0.1$14 \mu \mathrm{g} / \mathrm{L}$. 84

Figura 16. Concentración de los aglicones que mostraron diferencias significativas, tras la hidrólisis enzimática de la FG, entre las variedades MM (barras en azul y verde oscuros) y Raf (barras en azul y verde claros) en el estado de maduración P, según el Test de Tukey's HSD aplicado con un intervalo de confianza del $95 \%$ a 3 repeticiones. Barras en azul para concentraciones entre 3-1200 $\mu \mathrm{g} / \mathrm{L}$, y en verde para concentraciones entre 0.1 $5 \mu \mathrm{g} / \mathrm{L}$. 85

Figura 17. Concentración de los aglicones que mostraron diferencias significativas, tras la hidrólisis enzimática de la FG, entre las variedades MM (barras en azul y verde oscuros) y Raf (barras en azul y verde claros) en el 
estado de maduración M, según el Test de Tukey's HSD aplicado con un intervalo de confianza del $95 \%$ a 3 repeticiones. Barras en azul para concentraciones entre $0.4-40 \mu \mathrm{g} / \mathrm{L}$, y en verde para concentraciones entre 25$8000 \mu \mathrm{g} / \mathrm{L}$.

Figura 18. Concentración en la FVL (barras en negro) y en la FG (barras en blanco) en los estados de maduración verde $(v)$, pintón $(p)$, y maduro $(m)$ de las variedades MM y Raf, expresada como la media \pm error estándar de 3 repeticiones. Los valores numéricos señalados corresponden a la razón entre la concentración en forma glicosilada y libre, para cada compuesto y variedad. nd: compuesto no detectado. 89

Figura 19. Actividad $\beta$-glucosidasa del enzima BgIN medida en las 5 fracciones cromatográficas. 109

Figura 20. Actividad de los enzimas Exg1, AbfB, y RhaA medida en las sucesivas fracciones cromatográficas. La fracción 1 resultó de eluir con $10 \mathrm{~mL}$, y el resto con $5 \mathrm{~mL}$. 109

Figura 21. Concentración de los compuestos volátiles que aumentaron significativamente tras la incubación de los zumos de las variedades p73, Jorge, y Durinta en presencia de BgIN y/o Exg1. ${ }^{*} p<0.05$, ${ }^{* *} p<0.01,{ }^{* * *} p<$ 0.001, según el Test de Tukey's HSD aplicado con un intervalo de confianza del $95 \%$ a 3 repeticiones. Barras en blanco para el zumo incubado sin enzima (BLC), barras con rayas diagonales para el tratamiento con BgIN, y barras con rombos para el tratamiento con Exg1.

Figura 22. Concentración de los compuestos volátiles que disminuyeron significativamente tras la incubación de los zumos de las variedades p73, Jorge, y Durinta en presencia de BgIN y/o Exg1. X $p<0.05$ según el Test de Tukey's HSD aplicado con un intervalo de confianza del 95\% a 3 repeticiones. Barras en blanco para el zumo incubado sin enzima (BLC), barras con rayas diagonales para el tratamiento con BgIN, y barras con rombos para el tratamiento con Exg1. 115

Figura 23. Concentración de los compuestos volátiles que aumentaron significativamente tras la incubación del zumo extraído de la variedad Moneymaker en presencia de los enzimas BgIN, Exg1, RhaA, y AbfB, individualmente y combinados, según el Test de Tukey's HSD aplicado con un 
intervalo de confianza del $95 \%$ a 3 repeticiones. ${ }^{*} \mathrm{p}<0.05$ respecto al zumo incubado sin adición de enzimas o blanco (BLC). 124

Figura 24. Aumentos $\left(^{*}\right)$ y disminuciones $(X)$ significativas de la concentración del salicilato de metilo tras la incubación del zumo extraído de la variedad Moneymaker en presencia de los enzimas BgIN, Exg1, RhaA, y AbfB, individualmente y combinados, según el Test de Tukey's HSD aplicado con un intervalo de confianza del $95 \%$ a 3 repeticiones. $X,{ }^{*} p<0.05$ respecto al zumo incubado sin adición de enzimas o blanco (BLC). 126

Figura 25. Disminuciones significativas de la concentración del hexanal tras la incubación del zumo extraído de la variedad Moneymaker en presencia de los enzimas BgIN, Exg1, RhaA, y AbfB, individualmente y combinados, según el Test de Tukey's HSD aplicado con un intervalo de confianza del $95 \%$ a 3 repeticiones. $X p<0.05$ respecto al zumo incubado sin adición de enzimas o blanco (BLC). 128

Figura 26. Concentración de los compuestos volátiles que aumentaron significativamente tras la incubación del zumo extraído de la variedad Raf en presencia de los enzimas BgIN, Exg1, RhaA, y AbfB, individualmente y combinados, según el Test de Tukey's HSD aplicado con un intervalo de confianza del $95 \%$ a 3 repeticiones. ${ }^{*} p<0.05$ respecto al zumo incubado sin adición de enzimas o blanco (BLC). 130

Figura 27. Aumentos $\left({ }^{*}\right)$ y disminuciones $(X)$ significativas de la concentración del salicilato de metilo y del octanal tras la incubación del zumo extraído de la variedad Raf en presencia de los enzimas BgIN, Exg1, RhaA, y AbfB, individualmente y combinados, según el Test de Tukey's HSD aplicado con un intervalo de confianza del $95 \%$ a 3 repeticiones. $X,{ }^{*} p<0.05$ respecto al zumo incubado sin adición de enzimas o blanco (BLC). 132

Figura 28. Disminuciones significativas de la concentración del hexanal y del nonanal tras la incubación del zumo extraído de la variedad Raf en presencia de los enzimas BgIN, Exg1, RhaA, y AbfB, individualmente y combinados, según el Test de Tukey's HSD aplicado con un intervalo de confianza del $95 \%$ a 3 repeticiones. $X p<0.05$ respecto al zumo incubado sin adición de enzimas o blanco (BLC). 134

Figura 29. Suma ponderada de todos los compuestos volátiles identificados en los estados de maduración $\mathrm{V}, \mathrm{P}$, y $\mathrm{M}$ tras la incubación del zumo extraído de las 
variedades Moneymaker y Raf en presencia de los enzimas BgIN, Exg1, RhaA, y AbfB, individualmente y combinados, según el Test de Tukey's HSD aplicado con un intervalo de confianza del $95 \%$ a 3 repeticiones. ${ }^{*} p<0.05$ respecto al zumo incubado sin adición de enzimas o blanco (BLC). 137

Figura 30. Concentración de glucosa (GLU), ramnosa (RAM), y arabinosa (ARAB) detectadas tras la incubación del extracto de glicósidos de las variedades Moneymaker (MM) y Raf en los estados de maduración V (negro), P (rojo), y M (verde) en presencia de BgIN, RhaA, BgIN+ RhaA, BgIN+ RhaA+AbfB. Diferentes letras para cada estado de maduración indican diferencias significativas entre los azúcares según el Test de Tukey's HSD aplicado con un intervalo de confianza del $95 \%$ a 3 repeticiones. 148 



\section{ÍNDICE DE TABLAS}

Tabla 1. Concentración de los compuestos volátiles presentes en tomate a una concentración $>10^{-3} \mathrm{ppm}$, y su LogU. En negrita y entre paréntesis la concentración en agua de los 10 compuestos cuya mezcla reproduce de forma aproximada el aroma del tomate fresco maduro troceado, según Buttery (1993).

Tabla 2. Cepas de microorganismos utilizadas en este trabajo. 44

Tabla 3. Volumen de solución enzimática y tampón Mcllvain 75 mM pH5 ( $\mu \mathrm{L})$ adicionado a $1 \mathrm{~mL}$ de extracto de glicósidos.

Tabla 4. Volumen de enzima y agua ( $\mu \mathrm{L}$ ) adicionado a cada muestra de $3 \mathrm{~mL}$ de zumo.

Tabla 5. Estándares comerciales, factores de respuesta FR $(\mathrm{L} / \mu \mathrm{g})$, y $\mathrm{r}^{2}$ de las curvas de calibrado obtenidas para la cuantificación de los compuestos volátiles en el espacio de cabeza. 54

Tabla 6. Estándares comerciales, curvas de calibrado, y $r^{2}$ de las curvas de calibrado obtenidas para la cuantificación de los monosacáridos. 55

Tabla 7. Concentración $(\mu \mathrm{g} / \mathrm{L})$ de los compuestos volátiles identificados en la FVL de las variedades de tomate, p73, Jorge, Durinta, Moneymaker (MM), y Raf. 61

Tabla 8. LogU de los compuestos volátiles identificados en la FVL de las variedades de tomate p73, Jorge, Durinta, Moneymaker (MM), y Raf. 64

Tabla 9. Concentración $(\mu \mathrm{g} / \mathrm{L})$ de los aglicones detectados tras la hidrólisis enzimática del extracto de glicósidos de las variedades de tomate p73, Jorge, Durinta, Moneymaker (MM), y Raf. 66

Tabla 10. Concentración ( $\mu \mathrm{g} / \mathrm{L})$ de los compuestos volátiles identificados en la FVL de las variedades MM y Raf en los estados V, P y M. 72

Tabla 11. LogU de los compuestos volátiles identificados en la FVL de las variedades MM y Raf, en los estados de maduración $\mathrm{V}, \mathrm{P}$, y M. 75

Tabla 12. Concentración $(\mu \mathrm{g} / \mathrm{L})$ de los aglicones detectados tras la hidrólisis enzimática del extracto de glicósidos de las variedades MM y Raf en los estados de maduración $\mathrm{V}, \mathrm{P}, \mathrm{y} \mathrm{M}$. 81

Tabla 13. Actividad enzimática $\left(\mathrm{mU}_{\mathrm{enz}} / \mathrm{mL}\right)$ de las fracciones utilizadas en los posteriores experimentos. 110

Tabla 14. Concentración $(\mu \mathrm{g} / \mathrm{L})$ de los compuestos volátiles detectados tras la incubación de los zumos extraídos de las variedades p73, Jorge, y Durinta sin 
adición de enzima (BLC), con adición de BgIN (BGLN), y de Exg1(EXG1).

Tabla 15. LogU de los compuestos volátiles detectados tras la incubación del zumo extraído de las variedades p73, Jorge, y Durinta sin adición de enzima (BLC), con adición de BgIN (BGLN), y de Exg1 (EXG1). 116

Tabla 16. Concentración $(\mu \mathrm{g} / \mathrm{L})$ de los compuestos volátiles detectados tras la incubación del zumo extraído de la variedad Moneymaker sin adición de enzimas (BLC), y en presencia de los enzimas BgIN, Exg1, RhaA, y AbfB, individualmente y combinados. 119

Tabla 17. Concentración $(\mu \mathrm{g} / \mathrm{L})$ de los compuestos volátiles detectados tras la incubación del zumo extraído de la variedad Raf sin adición de enzimas (BLC), y en presencia de los enzimas BgIN, Exg1, RhaA, y AbfB, individualmente y combinados. 121

Tabla 18. Concentración $(\mu \mathrm{g} / \mathrm{L})$ de los aglicones detectados tras la incubación del extracto de glicósidos de las variedades Moneymaker (MM) y Raf en el estado de maduración $V$ en presencia de BgIN (E1), RhaA (E2), BgIN+ RhaA (E3), $B g I N+R h a A+A b f B(E 4)$, y sin adición de enzimas (BLC). 139

Tabla 19. Concentración $(\mu \mathrm{g} / \mathrm{L})$ de los aglicones detectados tras la incubación del extracto de glicósidos de las variedades Moneymaker (MM) y Raf en el estado de maduración $P$ en presencia de BgIN (E1), RhaA (E2), BgIN+ RhaA (E3), $\mathrm{Bg} I \mathrm{~N}+\mathrm{RhaA}+\mathrm{AbfB}(\mathrm{E} 4)$, y sin adición de enzimas (BLC). 142

Tabla 20. Concentración $(\mu \mathrm{g} / \mathrm{L})$ de los aglicones detectados tras la incubación del extracto de glicósidos de las variedades Moneymaker (MM) y Raf en el estado de maduración $M$ en presencia de BgIN (E1), RhaA (E2), BgIN+ RhaA (E3), $B g I N+R h a A+A b f B(E 4)$, y sin adición de enzimas (BLC). 145 


\section{ABREVIATURAS}

$\begin{array}{ll}\text { ADH } & \text { Actividad alcohol deshidrogenasa } \\ \text { BLC } & \text { Blanco o muestra sin tratamiento } \\ \text { FAOSTAT } & \text { Base de datos estadísticos de la Organización de las Naciones } \\ & \text { Unidas para la Agricultura y la Alimentación } \\ \text { FG } & \text { Fracción glicosilada } \\ \text { FVL } & \text { Fracción volátil libre } \\ \text { GC } & \text { Cromatografía de gases } \\ \text { GC-FID } & \text { Cromatografía de gases con detector de ionización de llama } \\ \text { GC-MS } & \text { Cromatografía de gases acoplada a espectrómetro de masas } \\ \text { HPLC } & \text { Cromatografía líquida de alta resolución } \\ \text { LogU } & \text { Logaritmo de las unidades de olor de un compuesto } \\ \text { LOX } & \text { Actividad lipoxigenasa } \\ \text { M } & \text { Estado de maduración maduro } \\ \text { M.A.P.A } & \text { Ministerio de Medio Ambientey Medio Rural y Marino } \\ \text { MM } & \text { Variedad Moneymaker } \\ \text { P } & \text { Estado de maduración pintón } \\ \text { HS- SPME } & \text { Microextracción en fase sólida de espacio de cabeza } \\ \text { V } & \text { Estado de maduración verde } \\ \text { U } & \text { Unidad de olor } \\ \text { Uenz } & \text { Unidad de actividad enzimática }\end{array}$



INTRODUCCIÓN 



\section{INTRODUCCIÓN}

\section{Generalidades sobre el tomate}

El tomate (Solanum lycopersicum L.) pertenece a la familia de las Solanáceas $y$, como otras especies de esta misma familia (patata, pimiento, berenjena, tabaco, etc.), es oriunda de las zonas templadas de América, concretamente de la región andina que se extiende desde el sur de Colombia al norte de Chile, aunque parece que fue en México donde se domesticó. Fue introducida en Europa en el siglo XVI como planta ornamental y su cultivo se inició en 1880 en Inglaterra (http://www.infoagro.com/hortalizas/tomate.htm). Actualmente, el tomate es la hortaliza más consumida a nivel mundial, tanto en fresco como en conserva, y la de mayor valor económico. El gran éxito del tomate radica en que es una hortaliza que ha alcanzado una extensa variedad de tipos, y en que posee excelentes cualidades para integrarse en la preparación de infinidad de alimentos, ya sean cocinados 0 crudos (http://www.siea.sagarpa.gob.mx/InfOMer/analisis/antomate.html).

En el contexto mundial, el cultivo del tomate representa el $16,3 \%$ de la producción total de hortalizas, y el 9,6\% del área total dedicada a la producción hortícola (FAO-FAOSTAT, 2006). A nivel nacional, el tomate es un producto básico del sector hortícola español, ocupa el $18 \%$ de la superficie de cultivo del sector y aporta el $37 \%$ del valor de la producción hortícola nacional. En España es tan importante la utilización del producto en fresco, $50 \%$ de la producción dedicada al mercado nacional en 2005 , como su carácter de materia prima industrial, al que se destina un $48 \%$ de la producción (Anuario de estadística agroalimentaria M.A.P.A, 2006).

El tomate contiene importantes metabolitos para la nutrición y la salud humana. Destaca su alto contenido en antioxidantes como la provitamina $A$ ( $\beta$-caroteno), las vitaminas $C$ y $E, y$ especialmente el licopeno (Canene-Adams et al., 2005), que es además el pigmento 
responsable del color rojo brillante del fruto (Lewinsohn et al., 2005a). Evidencias experimentales y epidemiológicas han asociado el elevado consumo de tomate, y por tanto de licopeno, con una disminución del riesgo de padecer enfermedades crónicas, como el cáncer y las enfermedades cardiovasculares (Weisburger, 1999).

La situación actual del mercado del tomate, y en general de muchas hortalizas, es de una fuerte competencia. Dada la gran importancia económica del cultivo del tomate, tradicionalmente, se han dedicado importantes recursos a investigar la obtención de nuevas variedades que den una mejor respuesta a las exigencias agronómicas (rendimiento, resistencia a plagas y enfermedades, producción de frutos partenocárpicos, resistencia a la salinidad, etc.), y comerciales (uniformidad de color, tamaño, y forma, ausencia de defectos externos, firmeza, "larga-vida", etc.) (de Prado Ruíz-Santaella, 2002). Sin embargo, se han descuidado los aspectos relacionados con su calida nutricional y organoléptica.

El concepto de calidad de un alimento está íntimamente ligado a la percepción que de él tiene el consumidor, y a sus preferencias. La percepción de un alimento se basa en la aplicación de los 5 sentidos (gusto, vista, olfato, oído, y tacto), por eso la máquina más precisa para medirla es el propio ser humano, aunque la percepción de cada individuo dependerá de su propia sensibilidad al estímulo recibido (Plotto et al., 2006). Por otro lado, las preferencias por un tipo de alimento determinado son muy variadas y cambian en función del país, tipo de población, factores socio-económicos, uso al que se destina el alimento, etc. (Ruíz et al., 2005). Por ejemplo, los japoneses y chinos gustan de tomates con baja acidez porque los suelen consumir como fruta, pero en la mayoría de países tropicales, donde los tomates se usan cocinados, se acepta una alta acidez (de Prado Ruíz-Santaella, 2002). Aunque en un primer 
momento la decisión de compra por parte del consumidor está altamente condicionada por la apariencia externa del producto (Serrano-Megías y López-Nicolás, 2006), la posterior frecuencia e intensidad de compra dependen ampliamente de las propiedades sensoriales, especialmente del flavor y de la textura (Baldwin y Scott, 2002). El flavor del tomate se puede dividir a través de una serie de descriptores en dos grandes grupos: el de los atributos a tierra, a cerrado, a la planta, a verde, y el de los atributos frutales, florales, tropicales, a tomate maduro, y dulce. Siendo los atributos a tierra, a ambiente cerrado, a la planta, y a verde los más frecuentes entre las variedades de tomate comerciales (Baldwin y Scott, 2002; Baldwin et al., 2004). En las últimas décadas, el creciente descontento del consumidor hacia los tomates que encuentra en el mercado, carentes del flavor característico de este fruto, y el hecho de que esté dispuesto a pagar un valor añadido por un producto que cumpla con sus expectativas (Bruhn et al., 1991), han impulsado los trabajos dirigidos a mejorar el flavor del tomate, y en particular su aroma.

\section{El concepto de flavor}

\subsection{Definición y percepción}

El flavor es la respuesta integrada a la compleja mezcla de estímulos que un individuo percibe durante la ingesta de un alimento, resultado de la interacción de los compuestos químicos del alimento con los receptores del gusto (sabor), trigeminales (dolor), y olfativos (olor y aroma) (Fisher y Scott, 2000). Tanto el gusto como las sensaciones trigeminales son consecuencia de interacciones con moléculas polares, solubles en agua, y no volátiles. Los compuestos volátiles se unen a los receptores olfativos de forma análoga a la unión que se establece entre enzima y sustrato. La interacción puede ser vía nasal directa (olor) o retronasal, desde la boca (aroma), desencadenando las sensaciones olorosas (Figura 3). El olfato es 
el más sensible de los 5 sentidos, superando incluso a los actuales instrumentos analíticos. Puede detectar compuestos volátiles a una concentración del orden de partes por trillón, mientras que la lengua sólo detecta partes por cien (Baldwin et al., 2000; Fisher y Scott, 2000).

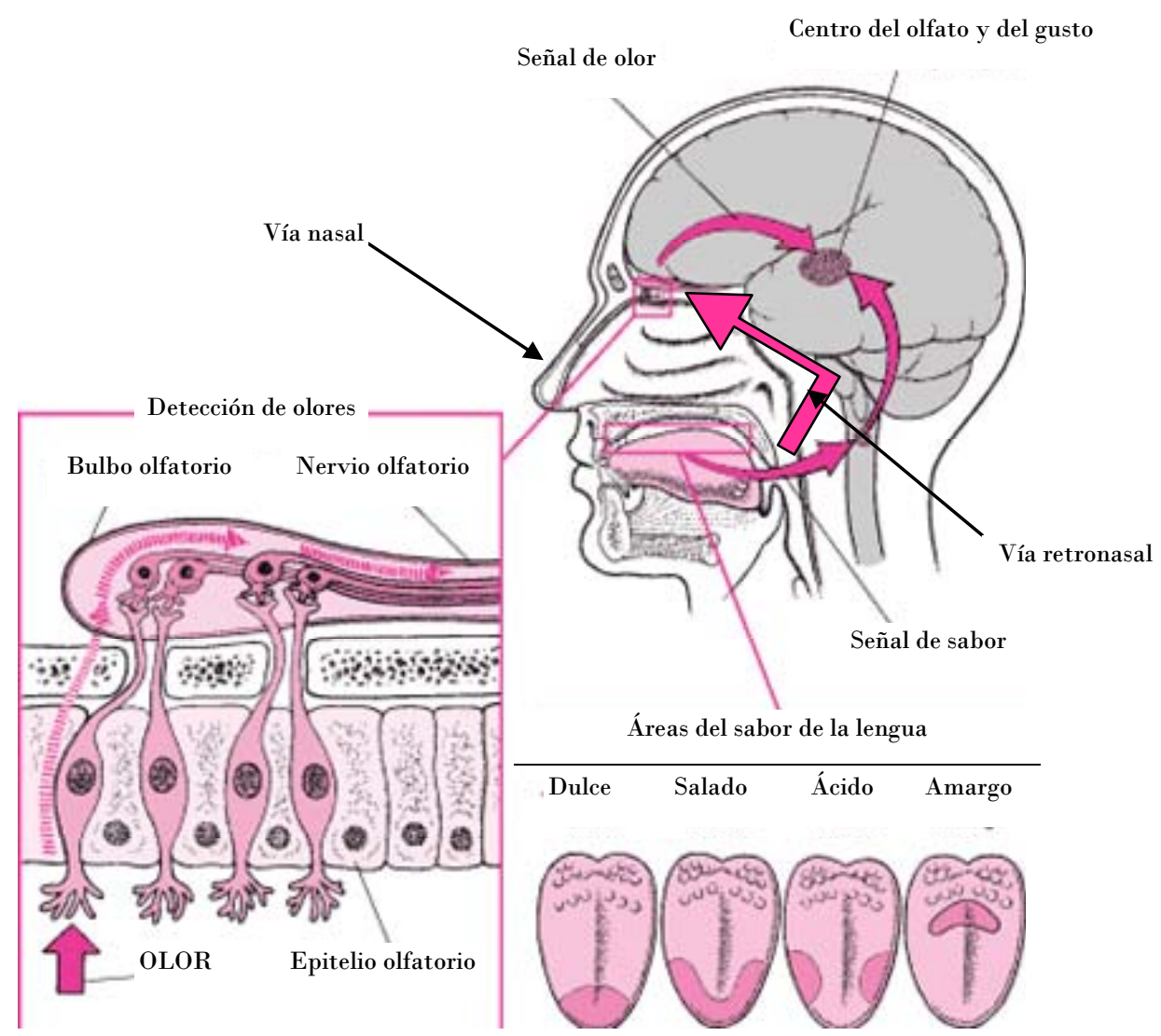

Figura 1. Esquema de las vías de percepción del flavor a través de nariz y boca.

La respuesta integrada que da el cerebro a los estímulos del flavor hace difícil atribuir a cada uno de ellos su importancia relativa. Sin embargo, aunque los sabores juegan un papel muy importante, sin olvidar el de la textura, son los aromas los que marcan las diferencias fundamentales que permiten distinguir entre los distintos alimentos (Leland, 1997). Por ejemplo, cuando se elimina temporalmente el sentido del olfato es muy difícil distinguir entre cebollas y peras (Fisher y Scott, 2000). 
Para que contribuyan a la percepción del flavor, las moléculas deben ser primero liberadas desde los alimentos. Este proceso es especialmente limitante en el caso de los aromas, y en él intervienen distintos factores. En primer lugar, es importante si las moléculas se encuentran libres o conjugadas con alguna otra molécula, por ejemplo glicosiladas, así como su propia volatilidad (Williams, 1993; Baldwin et al., 2000). Por otro lado, en la emisión de compuestos volátiles desde los alimentos son decisivos tanto los factores humanos como los que dependen del propio alimento (Brauss et al., 1998). Entre los factores humanos se encuentran los hábitos de masticación, y la cantidad y composición de la saliva. Los principales factores derivados de la naturaleza del alimento son su composición y estructura (Leland, 1997). En efecto, recientes estudios han puesto de manifiesto que la estructura o matriz del alimento afecta a la liberación de ciertos compuestos volátiles, reteniéndolos en el alimento (Bezman et al., 2003; Plotto et al., 2004). En cuanto a la composición, las interacciones entre los componentes volátiles y no volátiles de los alimentos han sido ampliamente descritas en trabajos previos. La formación de uniones entre ciertos compuestos volátiles y lípidos, proteínas, o carbohidratos, reduce la tasa de liberación de los primeros (Godshall, 1997; Rogacheva et al., 1999; Hansson et al., 2002). En algunos casos las pequeñas moléculas de azúcares simples y los ácidos pueden adsorber compuestos volátiles disminuyendo su liberación, mientras que en otros casos se ha descrito que favorecen el paso de ciertos compuestos volátiles a la fase gaseosa ("salting-out effect"), desde la que serán percibidos (Nahon et al., 1998). Por otro lado, los fenoles, compuestos abundantes en las plantas y presentes en alimentos de origen vegetal como zumos de frutas o vino, interactúan inter- e intramolecularmente con ciertos compuestos volátiles reduciendo su tasa de liberación (Vasserot et al., 1995; Jung et al., 2000). Todas estas interacciones dependen de la estructura del compuesto y su 
intensidad es función de la hidrofobicidad y de los coeficientes de partición y difusión, así como de las propiedades reológicas de la fase acuosa del alimento. Finalmente, en la bibliografía se han descrito múltiples interacciones, tanto de antagonismo como de sinergismo, entre los distintos compuestos volátiles de mezclas complejas, que caracterizan el aroma del alimento (Lawless, 1986; Brossard et al., 2007).

\subsection{El aroma, componente fundamental del flavor de los alimentos}

Mientras que el sabor característico de los alimentos normalmente se relaciona con una sola clase de compuestos, un abrumador número de compuestos volátiles pertenecientes a distintas familias de la química orgánica han sido identificados en los alimentos, aunque no todos contribuyen a la percepción del flavor (McGorrin, 2002). Entre ellos se encuentran hidrocarburos (terpenos -limoneno), compuestos con uno o varios grupos funcionales (alcoholes -linalol-, aldehídos -benzaldehído-, cetonas - $\beta$-ionona-, ésteres -acetato de butilo-, lactonas -4-decanólido-, óxidos de éter -cineol), diversos heterociclos (fenoles -4-vinilfenol, furaneol), compuestos azufrados (disulfuro de metilo), etc. En general, los aromas sólo representan una ínfima parte del alimento. Su concentración en carnes, frutas, y verduras oscila en torno a las 50 partes por millón (ppm). Mientras que su presencia en hierbas aromáticas y especias es mayor, oscilando entre el 0.1 y el $1 \%$, y entre el 1 y el $20 \%$ del producto, respectivamente (Richard, 1992).

En general, es una mezcla de compuestos volátiles, más o menos compleja, la que caracteriza el flavor final de los alimentos (Leland, 1997; Fisher y Scott, 2000; Baldwin, 2004). En esa mezcla no todos los compuestos juegan el mismo papel. Existen aromas primarios que definen olores individuales al unirse a un único receptor olfativo. Son como letras de un alfabeto, y combinados pueden definir otro aroma, por ejemplo el 
salicilato de metilo. Los aromas secundarios son como sílabas, y se unen a más de un receptor olfativo (Baldwin et al., 2000). En la percepción del flavor de un alimento se distinguen igualmente notas principales y notas de fondo. Las notas principales son aportadas generalmente por compuestos de bajo peso molecular y alta volatilidad, termolábiles y polares, que se perciben en primer lugar. Mientras que las notas de fondo corresponden a moléculas volátiles de bajo peso molecular, termoestables, y apolares, que ejercen un efecto más sutil que las notas principales sobre el flavor final de un alimento (Baldwin, 2004).

Múltiples esfuerzos se han dedicado a intentar elucidar la importancia relativa que cada compuesto ejerce en el flavor global de los alimentos. Para este propósito se revela especialmente útil el logaritmo de las unidades de olor de un compuesto (LogU). La unidad de olor (U) fue definida por Guadagni et al. (1966) como la concentración de cada compuesto en el alimento dividido por su umbral de percepción, generalmente calculado en agua. Valores de LogU positivos corresponden a compuestos que se encuentran en el alimento a una concentración por encima de su umbral de percepción, y por tanto se considera que contribuyen claramente en la percepción final del flavor del alimento. Mientras que los compuestos con valores de LogU negativos, o no contribuyen, o quizá lo hacen de manera mucho más sutil (Buttery et al., 1988b; Buttery, 1993). Aunque de gran utilidad práctica, el LogU es una simplificación de un sistema complejo y como tal encierra ciertas limitaciones. A la hora de otorgar la importancia relativa a un compuesto, el LogU no considera el efecto de retención que ejerce la propia matriz del alimento, ni las interacciones que se establecen entre los componentes volátiles y no volátiles de los alimentos. Se trata de un parámetro estrictamente analítico que tampoco refleja el cambio en la calidad del olor de un compuesto volátil con su concentración, absoluta o relativa (Fisher y 
Scott, 2000). Tampoco tiene en cuenta las múltiples interacciones, de antagonismo o sinergismo, que pueden surgir entre los distintos compuestos volátiles de mezclas complejas (Lawless, 1986; Brossard et al., 2007). Por ejemplo, en el té verde de jazmín ha sido descrito recientemente el importante papel que juegan los compuestos volátiles que se encuentran por debajo de su umbral de percepción gracias al sinergismo que entre ellos se establece, incluyendo el cis-3-hexenol (Ito y Kubota, 2005), compuesto también presente en el tomate.

\subsection{Métodos de análisis}

El análisis del flavor y de la calidad de los alimentos se puede llevar a cabo mediante técnicas analíticas y sensoriales. Ambas aproximaciones son complementarias y su integración nos ofrece una información más completa del flavor. Los métodos analíticos están basados en las propiedades químico-físicas del alimento e informan aisladamente acerca de sus diferentes constituyentes. La evaluación sensorial consiste en evaluar del alimento todo lo que se puede percibir por los sentidos, y en determinar su aceptación por parte del consumidor, utilizando como instrumento de medición al ser humano (Costell y Durán, 1981; Costell, 1983).

Se habla de tres grandes grupos de análisis sensorial, descriptivo, discriminativo, y del consumidor (Parolari, 1996). El análisis descriptivo consiste en la descripción y medición de las propiedades sensoriales de un producto. Requiere de un panel de degustadores, llamados jueces, bien entrenado. El análisis discriminativo es utilizado para comprobar si hay diferencias entre productos. Se emplean como mínimo 20 ó 25 personas, dependiendo del tipo de ensayo, aunque no requieren un gran entrenamiento. Por último, en el análisis del consumidor, o test hedónico, se trabaja con al menos 80 evaluadores no entrenados, y la pregunta es si 
les agrada o no el producto (Wittig de Penna, 2001). Los métodos de evaluación sensorial tienen limitaciones. Implican el uso de técnicas específicas perfectamente estandarizadas, con el objeto de disminuir la subjetividad en las respuestas y permitir su reproducibilidad, y se requiere de mucho tiempo y material para llegar a resultados válidos.

La nariz electrónica (NE) es una tecnología de aparición reciente que intenta imitar a la nariz humana, y resulta un excelente complemento para el análisis sensorial. Se trata de un instrumento de olfato artificial que permite distinguir y reconocer aromas utilizando sensores de gas, aunque no determina la composición de dicho aroma (Gardner y Bartlett, 1999). Los estudios realizados hasta el momento han demostrado su gran aplicabilidad en el campo del control rutinario de la calidad de los alimentos (Berna et al., 2004; Hernández-Gómez et al., 2006). En los últimos años, ha aparecido en el mercado un nuevo tipo de NE basado en la espectrometría de masas de espacio de cabeza (MS-HS), mediante la cual se consigue obtener un espectro más completo que equivaldría a un multisensor (Berna et al., 2005a; Berna et al., 2005b).

En cuanto a los métodos analíticos, su validez depende enormemente de las fases iniciales de manejo y preparación de las muestras, así como de las técnicas de extracción y separación previas a las determinaciones, durante las cuales los componentes del flavor pueden sufrir cambios químicos de distinta naturaleza (Werkhoff et al., 2002). Las técnicas más conocidas para la extracción de compuestos orgánicos de una muestra son "purge-trap" o métodos "head-space" para concentración de volátiles, y extracción líquido-líquido, extracción en fase sólida y extracción por fluido supercrítico para semi-volátiles o no volátiles (Fisher y Scott, 2000). Estos métodos presentan varios inconvenientes, incluyendo su alto costo y tiempos de preparación excesivos. La técnica de micro extracción en fase sólida (SPME), cuya idoneidad para el análisis de 
alimentos ha sido demostrada en múltiples trabajos previos (Ibáñez et al., 1998; Song et al., 1998; Volante et al., 2000; Riu-Aumatell et al., 2004; Markovic et al., 2007), elimina la mayoría de estos inconvenientes (Beltran et al., 2006). La SPME no requiere solventes o aparatos complicados, y puede concentrar compuestos volátiles y no volátiles, en muestras líquidas o gaseosas (Yang y Peppard, 1994).

Entre los métodos analíticos más habituales en el análisis de alimentos destaca el cromatográfico. La cromatografía incluye una gran diversidad de técnicas de separación basadas en el reparto o distribución de una muestra (soluto) entre una fase móvil y otra fija o estacionaria. En general, los compuestos volátiles del flavor se analizan por cromatografía gaseosa (GC) (Lamparsky, 1992b) y los que no son volátiles por cromatografía líquida de alta resolución (HPLC) (Morin y Richard, 1992). Los alimentos son sistemas tan complejos que suele ser necesaria una pre-separación, acoplando más de una de estas técnicas en un mismo análisis (Fisher y Scott, 2000).

La última fase del análisis es la identificación y cuantificación. Las siguientes técnicas acopladas permiten la identificación y cuantificación de los componentes del flavor y de sus estructuras químicas: cromatografía de gases acoplada a espectrometría de masas (GC-MS) (Bricout, 1992), cromatografía líquida de alta resolución acoplada a espectrometría de masas (HPLC-MS), cromatografía de gases acoplada a espectroscopia de infrarrojos por transformada de Fourier (GC-FTIR) (Paul, 1992), y resonancia magnética nuclear (NMR) (Lamparsky, 1992a). Otras técnicas como la cromatografía de gases con detección olfatimétrica (GC-O) han permitido cuantificar los componentes volátiles $\mathrm{y}$, además, identificar aquellos que aportan alguna nota aromática al alimento en cuestión (Buttery, 1993; Imre, 2002). Es decir, la GC-O podría considerarse un punto intermedio entre el análisis sensorial y las técnicas cromatográficas. 
A pesar de los enormes avances conseguidos en las últimas décadas, las técnicas cromatográficas siguen adoleciendo de una falta de rapidez analítica (menor por la reciente aparición de los sistemas de cromatografía ultrarápida), de un alto coste, y de la necesidad de personal cualificado.

Uno de los grandes retos que plantea actualmente la investigación sobre el flavor de los alimentos es establecer la relación entre las medidas analíticas y los análisis sensoriales, pues hacerlo proporcionaría herramientas cuantitativas concretas para mejorar la calidad de los alimentos. La quimiometría utiliza métodos estadísticos multivariantes para determinar la correlación entre el análisis sensorial y el instrumental. Algunas de estas técnicas, como el análisis de compuestos principales (PCA), el análisis de conglomerados o cluster, y el discriminante (DA), reducen el número de variables. Otras sirven para clasificar muestras por comparación con otras conocidas previamente, como el análisis del vecino más próximo; las técnicas del análisis clique y de la escala multidimensional, pueden sugerir categorías cuando éstas son desconocidas de antemano; y el análisis factorial, puede proporcionar claves de las variables desconocidas (Dijksterhuis, 1997; Fisher y Scott, 2000). Aunque muchos esfuerzos se están dirigiendo en establecer la relación entre las medidas analíticas y los análisis sensoriales los resultados obtenidos hasta el momento en alimentos son sólo indicativos.

\subsection{El flavor del tomate}

El característico flavor del tomate es fruto de las interacciones que se establecen entre los azúcares reductores (principalmente fructosa, y también glucosa), los ácidos libres (principalmente cítrico, y también málico), los aminoácidos libres (principalmente ácido glutámico, y también ácido aspártico), los minerales (principalmente fosfato y potasio), y los cientos de compuestos volátiles presentes en este fruto. Algunos autores 
han otorgado mayor importancia relativa a los azúcares y ácidos (Stevens et al., 1979; Jones y Scott, 1984; Malundo et al., 1995), y otros a los compuestos volátiles (Buttery et al., 1987; Krumbein y Auerswald, 1998; Brauss et al., 1998; Berna et al., 2005b). En general, se ha constatado que los tomates más dulces son mejor aceptados, siempre que se encuentren dentro de un nivel de acidez óptimo (Malundo et al., 1995) y que existe una alta correlación entre el perfil aromático del tomate y la aceptabilidad por parte del consumidor (Berna et al., 2005b). Aminoácidos y minerales ejercen una contribución más sutil sobre el flavor. Los aminoácidos pueden realzar el sabor y tener un efecto tampón (Bucheli et al., 1999), mientras que los minerales ejercen un efecto tampón, e influyen fundamentalmente sobre el $\mathrm{pH}$ y la acidez titulable (TA) del tomate.

A pesar de que el tomate ha sido objeto de numerosos estudios, tanto analíticos como sensoriales, actualmente no se dispone de una definición exacta y cuantificable del que sería su flavor típico o deseable (Bucheli et al., 1999; Baldwin et al., 2000). Esta situación es reflejo de las dificultades que entraña el estudio del flavor de los alimentos, y en particular del tomate. Uno de los factores que aumenta la variabilidad de los datos publicados sobre el flavor del tomate es que la naturaleza de su matriz disminuye la concentración de varios compuestos aromáticos detectados en el espacio de cabeza (Bezman et al., 2003). Además, la percepción de las moléculas volátiles varía no sólo con la concentración relativa (Tadmor et al., 2002) sino también con el medio de evaluación. En efecto, el umbral de percepción de los compuestos volátiles en un triturado de tomate es mayor que el calculado en agua, incluso cambian los descriptores sensoriales (Tandon et al., 2000). Por otro lado, establecer la relación entre los datos instrumentales y sensoriales del tomate es todavía hoy una de las asignaturas pendientes del estudio del flavor (Watada y Aulenbach, 1979; Abegaz et al., 2000; Tandon et al., 2003; Thybo et al., 
2005; Serrano-Megías y López-Nicolás, 2006). Los ensayos analíticos se pueden realizar sobre muestras representativas de tomates de una misma variedad, sin embargo, los consumidores juzgan la calidad de frutos individuales, entre los que existe una gran variabilidad (Brauss et al., 1998). Así mismo, las preferencias de los consumidores por unos atributos sensoriales determinados también varían con el segmento de la población y el área geográfica consideradas (Ruíz et al., 2005). Distintos trabajos han relacionado ciertos compuestos volátiles con atributos sensoriales del tomate (Krumbein y Auerswald, 1998; Tandon et al., 2003; Baldwin et al., 2004; Abegaz et al., 2004; Krumbein et al., 2004). Sin embargo, estos resultados son sólo orientativos, y las distintas recomendaciones que de ellos se derivan para mejorar el flavor del tomate son, a veces, contradictorias. Por ejemplo, los análisis químicos y las técnicas sensoriales descriptivas aplicadas sobre líneas comerciales de tomate han mostrado como un incremento de compuestos que aporten notas florales (6-metil-5-heptén-2-ona y $\beta$-ionona), frutales (cis-3-hexenal y geranilacetona), y frescas (3-metilbutanol y 1-penten-3-ona) o una disminución de compuestos que aporten sensación de estancamiento o de ambiente viciado (hexanal, trans-2-hexenal y 3-metilbutanal), de acre o picante (2-isobutiltiazol), y de alcohol (2-feniletanol), sería beneficiosa para el flavor global del tomate (Tandon et al., 2000). Estos resultados no están de acuerdo con el aumento del nivel de aldehídos C6 (hexanal, trans-2hexenal y 3-metilbutanal) sugerido por Wang et al. (1996) y por Gray et al. (1999) para mejorar el flavor. Recientemente se ha definido un tomate con pleno flavor como aquel con un alto nivel de azúcares y sólidos solubles, un menor nivel de ácidos orgánicos, y un nivel medio-alto, aunque sobre todo equilibrado, de hexanal, cis-3-hexenal, 2- y 3- metil-1-butanol, trans-2hexenal, cis-3-hexen-1-ol, geranilacetona, $\beta$-ionona, y 1-penten-3-ona (Tandon et al., 2003). Est'os resultados apoyan las indicaciones sugeridas 
previamente por Malundo et al. (1995), por Baldwin y Scott (2002), y por Baldwin et al. (1998). Otro de los factores que complica la investigación sobre el flavor del tomate es la falta de una mejor comprensión sobre las interacciones que se establecen entre sus componentes. Se ha constatado que la concentración de ciertos compuestos volátiles en el alimento influye sobre la percepción dulce o amarga del mismo. Los compuestos que aportan notas "florales" o "frutales", como las cetonas, aumentan la sensación de dulzor del tomate sin aumentar su contenido en azúcares; mientras que algunos de los compuestos asociados con notas "verdes", como los aldehídos C6, aumentan la sensación de amargor (Baldwin et al., 1998; Baldwin et al., 2004). No sólo los compuestos volátiles pueden afectar la percepción del sabor dulce o amargo, los azúcares también influyen sobre la percepción global del aroma. Baldwin y Thompson (2000), constataron que el aumento de azúcares, especialmente de sacarosa y fructosa, se traducía, a partir de una cierta concentración, en una disminución de la percepción del aroma global.

Los factores que influyen sobre el flavor del tomate son bien conocidos (Baldwin et al., 2000; Thybo et al., 2005), sin embargo, su efecto y modo de acción sobre los componentes del flavor no han sido todavía descritos. Sobre el flavor del tomate influye la variedad (Stevens, 1972; Stevens et al., 1977; Stevens et al., 1979; Baldwin et al., 1991a; Baldwin et al., 1991b; Langlois et al., 1996; Brauss et al., 1998; Berna et al., 2004; Ruíz et al., 2005; Carbonell-Barrachina et al., 2006), el clima durante el cultivo, el estado de maduración del fruto (Baldwin et al., 1991b; Buttery, 1993; White, 2002; Tieman et al., 2006; Prasanna et al., 2007), las prácticas culturales (Dalal et al., 1967; Besford y Hobson, 1975; Wright y Harris, 1985; Thybo et al., 2006), y el manejo postcosecha (Kader et al., 1978; Buttery et al., 1987; Buttery, 1993; Servili et al., 2000; Krumbein et al., 2004). Entre estos factores, la falta de madurez en el momento de la 
recolección (Kader et al., 1977; Watada y Aulenbach, 1979; Buttery et al., 1987; Maul et al., 1998; Yilmaz et al., 2002b), la baja temperatura de almacenamiento (Stern et al., 1994; McDonald et al., 1999), y el pobre potencial genético de las variedades comerciales (Baldwin et al., 1991a; Baldwin et al., 2000), se consideran las principales causas de la baja calidad organoléptica que presentan actualmente los tomates comerciales (Baldwin y Scott, 2002).

\section{Los compuestos volátiles en el reino vegetal}

En la bibliografía existen múltiples evidencias de las distintas y diversas funciones que cumple la emisión de compuestos volátiles por parte de las plantas, si bien, todavía no se dispone de suficiente información para comprender toda su complejidad. Por un lado, los compuestos volátiles juegan un papel fundamental en las interacciones ecológicas (Piechulla y Pott, 2003), y en diversos procesos fisiológicos (Pichersky y Gershenzon, 2002), como sugirió el descubrimiento de la emisión del etileno en la primera mitad del siglo XX. Por otro lado, los compuestos volátiles determinan el aroma $y$, por tanto, son esenciales en la definición de la calidad (Piechulla y Pott, 2003).

El perfil de compuestos volátiles emitidos por las plantas cambia cualitativa y cuantitativamente ante situaciones de estrés biótico y abiótico (Paré y Tumlinson, 1997), y también en función del estado de desarrollo de la planta y de la hora del día (Dudareva et al., 2000). Se han descrito compuestos volátiles implicados en la polinización que atraen, dirigen, y seleccionan el tipo de polinizador (Dudareva et al., 2004). Igualmente se ha comprobado la existencia de compuestos volátiles que participan en los mecanismos de defensa directa de la planta con su actividad antimicrobiana, como por ejemplo el geraniol y el linalol (Pattnaik et al., 1997), y antiherbívora (Kessler y Baldwin, 2001), repeliendo o intoxicando 
al agresor. Otros participan en las estrategias de defensa indirecta. Por ejemplo, existen plantas que tras haber sufrido daños por un depredador emiten compuestos volátiles que repelen a los herbívoros o que atraen a sus enemigos (Pichersky y Gershenzon, 2002). La comunicación plantaplanta a través de la emisión de compuestos volátiles también aparece documentada en la bibliografía (Baldwin et al., 2006). Por ejemplo, se han encontrado plantas que sintetizan y almacenan sustancias de defensa cuando son expuestas a los compuestos volátiles emitidos por otras plantas atacadas por herbívoros, como lo es el salicilato de metilo (Dicke y Bruin, 2001). Recientemente, también se ha demostrado que la emisión de compuestos volátiles guía a las plantas parásitas hacia las hospedadoras (Runyon et al., 2006).

\subsection{Perfil de compuestos volátiles en tomate}

El aroma del tomate, como el de otros muchos alimentos de origen vegetal, es el resultado de una compleja combinación de compuestos volátiles. Entre ellos se encuentran aldehídos, alcoholes, cetonas, ésteres, lactosas, terpenos, hidrocarburos, ácidos carboxílicos, sulfuros, o compuestos nitrogenados (Buttery et al., 1971). Estos compuestos se forman tanto en el fruto intacto durante la maduración, como al proceder a la ruptura de los tejidos celulares (Kazeniac y Hall, 1970). Al romper los tejidos se permite la unión entre enzimas y sustratos, previamente compartimentalizados en el fruto, y se aumenta el contacto con el oxígeno (Buttery, 1993). Se ha observado que tras proceder a la ruptura de tejidos celulares algunos compuestos como el trans-2-pentenal y el geranial, aparecen por primera vez; otros, como el cis-3-hexenal, trans-2-hexenal, trans-2-heptenal, y 1-pentén-3-ona, aumentan su concentración; y otros, como el 3-metil-1-butanol, pentanol, 6-metil-5-heptén-2-ona, o 2feniletanol, no experimentan cambios significativos (Baldwin et al., 2000). 
Los mayores niveles de compuestos volátiles en tomate se concentran en la pulpa y en la piel, en el fluido se han encontrado pequeñas cantidades de cis-3-hexenal, mientras que las semillas no aportan cantidades significativas (Buttery et al., 1988a). Generalmente, las concentraciones de los compuestos volátiles en tomate, aumentan con la maduración, alcanzando su máximo en el estado pintón o maduro (Baldwin et al., 1991b; Buttery, 1993). McGlasson et al. (1987) encontraron que los mutantes de tomate que no maduran, nor y rin, eran deficitarios en ciertos compuestos con olor intenso como hexanal, 3-metilbutanol, hexanol, 2isobutiltiazol, etc. En efecto, en la bibliografía se ha descrito que la síntesis de muchos de los compuestos volátiles derivados de la degradación de los lípidos, como son aldehídos y alcoholes, es dependiente del proceso de maduración en tomate (Yilmaz et al., 2002a). Todos los compuestos no aumentan con la maduración. Por ejemplo, en la bibliografía se ha descrito la disminución del salicilato de metilo durante la maduración del tomate, siendo un compuesto propio de los estados inmaduros (Gao et al., 2007).

Aunque más de 400 compuestos volátiles han sido identificados en el tomate y sus derivados (para revisión ver Servili et al., 2000), sólo 30 han sido detectados a una concentración superior a 1 parte por billón (ppb) en el fruto. Buttery (1993) calculó sus LogU, y obtuvo valores de LogU positivos para 16 de estos compuestos (Tabla 1), por lo que se considera que contribuyen significativamente en el flavor del tomate. Los compuestos con LogU negativos pueden participar también en el flavor final del tomate, pero lo harían de manera más sutil, como notas de fondo. Además, Buttery (1993) consiguió reproducir de manera aproximada el aroma del tomate maduro troceado a partir de una combinación de 10 de estos compuestos, a la concentración adecuada, en agua (Tabla 1). Los resultados obtenidos por Buttery insinuaron que un compuesto no tiene que ser necesariamente abundante para ejercer un impacto en el flavor del tomate, pues su 
participación en el flavor no es sólo función de su concentración absoluta sino también de su umbral de percepción. Es el caso de la $\beta$-ionona, un compuesto presente a una de las más bajas concentraciones en tomate pero con el segundo mayor valor de LogU.

Tabla 1. Concentración de los compuestos volátiles presentes en tomate a una concentración $>10^{-3} \mathrm{ppm}$, y su LogU. En negrita y entre paréntesis la concentración en agua de los 10 compuestos cuya mezcla reproduce de forma aproximada el aroma del tomate fresco maduro troceado, según Buttery (1993).

\begin{tabular}{|c|c|c|}
\hline Compuestos volátiles & Conc. (ppm) & $\log U$ \\
\hline cis -3-hexanal & $12.00(\mathbf{3 . 5 0 0})$ & 3.700 \\
\hline$\beta$-Ionona & $0.004(\mathbf{0 . 0 1 0})$ & 2.800 \\
\hline Hexanal & $3.100(\mathbf{0 . 6 0 0})$ & 2.800 \\
\hline$\beta$-Damascenona & 0.001 & 2.700 \\
\hline 1-Pentén-3-ona & $0.520(\mathbf{0 . 2 0 0})$ & 2.700 \\
\hline 2+3-Metilbutanal & $0.027(\mathbf{0 . 2 0 0})$ & 2.100 \\
\hline trans -2-hexenal & $0.270(\mathbf{0 . 1 6 0})$ & 1.200 \\
\hline 2-Isobutiltiazol & $0.036(\mathbf{0 . 0 1 0})$ & 1.000 \\
\hline 1-Nitro-2-feniletano & 0.017 & 0.9 \\
\hline trans-2-heptenal & 0.06 & 0.7 \\
\hline Fenilacetaldehído & 0.015 & 0.6 \\
\hline 6-Metil-5-heptén-2-ona & $0.130(\mathbf{0 . 1 0 0})$ & 0.4 \\
\hline cis-3-hexenol & $0.150(\mathbf{1 . 5 0 0})$ & 0.3 \\
\hline 2-Feniletanol & 1.900 & 0.3 \\
\hline 3-Metilbutanol & 0.38 & 0.2 \\
\hline Salicilato de metilo & $0.048(\mathbf{0 . 0 5 0})$ & 0.08 \\
\hline Geranilacetona & 0.057 & -0.02 \\
\hline$\beta$-Ciclocitral & 0.003 & -0.2 \\
\hline 1-Nitro-3-metil-butano & 0.059 & -0.4 \\
\hline Geranial & 0.012 & -0.4 \\
\hline Linalol & 0.002 & -0.5 \\
\hline 1-Pentén-3-ol & 0.11 & -0.6 \\
\hline trans -2-pentenal & 0.14 & -1.000 \\
\hline Neral & 0.002 & -1.200 \\
\hline Pentanol & 0.12 & -1.500 \\
\hline Pseudo-ionona & 0.01 & -1.900 \\
\hline Isobutil cianuro & 0.013 & -1.900 \\
\hline Hexanol & 0.007 & -1.900 \\
\hline Epoxi- $\beta$-ionona & 0.001 & -2.000 \\
\hline
\end{tabular}

Tabla adaptada de Buttery (1993) 


\subsection{Rutas generales de biosíntesis de compuestos volátiles en tomate}

Es importante diferenciar los mecanismos de biosíntesis de compuestos volátiles de los mecanismos de emisión, pues cada uno de estos procesos tiene su propia dinámica (Peñuelas y Llusià, 2001). Las investigaciones a nivel bioquímico han permitido establecer que los compuestos volátiles son sintetizados en los tejidos desde los que son emitidos. La biosíntesis de compuestos volátiles en los frutos tiene lugar en diferentes compartimentos celulares, tales como los cloroplastos, los cromoplastos, o el citosol (Dudareva et al., 2000). En el reino vegetal los compuestos volátiles son considerados metabolitos secundarios, aunque generalmente sus precursores son compuestos del metabolismo primario (Pichersky et al., 2006). Los componentes volátiles del tomate, tanto en hojas y tallos como en frutos, son sintetizados a partir de una diversa gama de precursores que incluyen lípidos, aminoácidos, carotenoides, terpenoides, y lignina (Baldwin et al., 2000). Aunque muchos compuestos volátiles han sido identificados como componentes importantes del flavor en frutas y vegetales, los enzimas y genes que controlan su producción y su patrón de herencia apenas han sido estudiados $y$, por tanto, el conocimiento sobre sus rutas de biosíntesis es limitado. Profundizar en el estudio de estas rutas se revela fundamental para avanzar en la mejora del flavor de estos frutos (Yilmaz, 2001).

Los componentes volátiles del tomate se clasifican en 6 grupos en función de su biosíntesis: derivados de lípidos, asociados a la ruta de los terpenoides, derivados de carotenoides, formados a partir de amino ácidos, relacionados con la ruta del ácido shikímico, y otros (Yilmaz, 2001).

Se ha observado que hay compuestos que se sintetizan a través de la degradación enzimática de los lípidos cuando se produce la ruptura de tejidos celulares (Baldwin et al., 2000), siendo su nivel en el fruto intacto 
nulo o mínimo (Riley y Thompson, 1998). Es el caso, por ejemplo, de los aldehídos C6 (hexanal y cis-3-hexenal), responsables de la nota "verde" en el aroma del tomate. Hexanal y cis-3-hexenal se forman, respectivamente, a partir de los ácidos linoleico y linolénico, tras la acción de una lipoxigenasa (LOX) seguida de una hidroperóxido liasa (HPL). Hexanal y cis-3-hexenal pueden ser entonces reducidos a sus correspondientes alcoholes, hexanol y cis-3-hexenol, respectivamente, por la acción de una alcohol deshidrogenasa (ADH) (Galliard et al., 1977). Por otro lado, la inestabilidad del cis-3-hexenal ha sido descrita en numerosos trabajos (Buttery et al., 1987; Buttery et al., 1988a), y en especial su amplia isomerización a trans-2-hexenal (Galliard et al., 1977; Buttery, 1993; Riley y Thompson, 1998; Gray et al., 1999).

Hasta el momento sólo se ha identificado un terpenoide volátil en tomate, el $\alpha$-copaeno, y además sólo en frutos verdes (Baldwin et al., 2000). Sin embargo, importantes compuestos volátiles en tomate, como el linalol, se forman a partir de la ruta de los terpenoides (Figura 2). La ruta básica de biosíntesis de terpenoides se puede resumir en 3 etapas (Mahmoud y Croteau, 2002). En primer lugar se forman los terpenos (compuestos formados por unidades de isopreno de 5 carbonos), por la vía del mevalonato (MEV) que tiene lugar en el citoplasma a partir de acetilCoA, o a través de la ruta del metileritritol fosfato (MEP) que tiene lugar en los cloroplastos o cromoplastos a partir de piruvato y gliceraldehído-3fosfato. A continuación, 2 ó 3 unidades de terpenos se condensan para formar otras de 10 ó 15 carbonos, reacción catalizada por preniltransferasas de cadena corta. Finalmente, la acción de las terpeno sintasas da lugar a la conversión de estas moléculas en monoterpenos y sesquiterpenos.

Por otro lado, diferentes trabajos han confirmado la formación de norisoprenoides como la 6-metil-5-heptén-2-ona y la $\beta$-ionona, y de 
monoterpenos como el citral, a partir de la degradación de carotenoides como el $\beta$-caroteno y el licopeno, respectivamente (Stevens, 1970; Simkin et al., 2004; Lewinsohn et al., 2005b). Estas reacciones tienen lugar sólo en el fruto, y en algunos casos dependen de la ruptura de tejidos celulares (Baldwin et al., 2000). Sin embargo, la naturaleza bioquímica de estos mecanismos de oxidación degradativa (enzimática o no), y los enzimas y genes que en ella intervienen deben ser revisados en cada caso particular (Lewinsohn et al., 2005a).

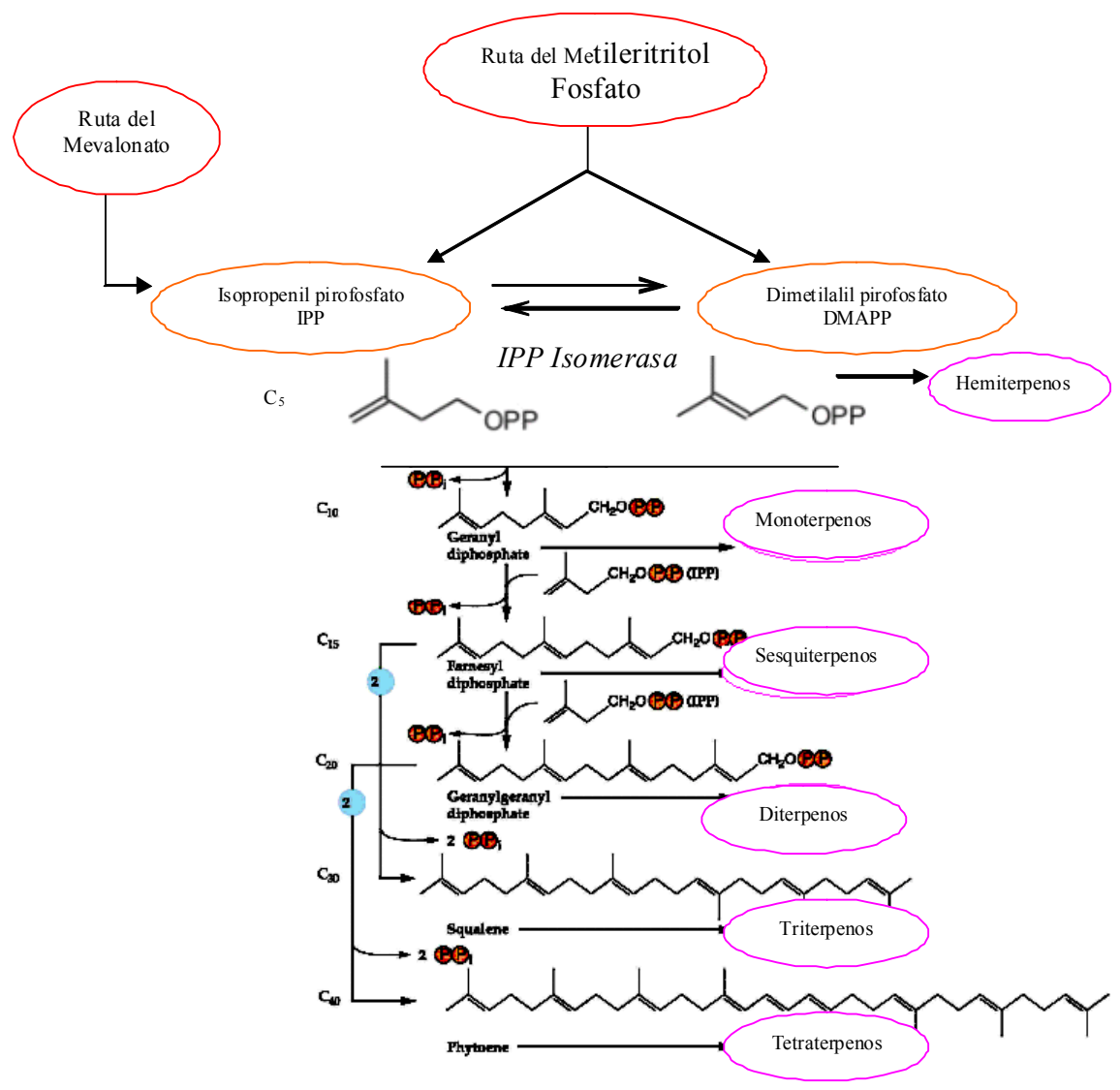

Figura 2. Ruta de biosíntesis de los terpenoides.

Otros compuestos se originan a partir de aminoácidos que pueden ser transformados en alcoholes y posteriormente en ésteres, a través de 
diferentes etapas que incluyen desaminación, descarboxilación, reducción, y esterificación (Crouzett, 1992). Algunos de los aminoácidos precursores de compuestos volátiles en tomate son la alanina (acetaldehído), leucina (3-metil-1-butanol), isoleucina (2-metil-1-butanol), valina (1-nitro-2metilpropano), y la fenilalanina (2-feniletanol) (Baldwin et al., 2000). El tomate contiene compuestos nitrogenados inusuales (1-nitro-2-feniletano, 1-nitro-2-metilpropano, 1-nitro-3-metilbutano) que no se encuentran en otras frutas o verduras, pero sí en ciertas flores. Se ha sugerido que estos compuestos pueden formarse en el fruto vía la fenilalanina, quizá con la mediación de algún sistema enzimático (Buttery, 1993).

Otros compuestos volátiles como el eugenol, bencilaldehído, 2feniletanol, y guaiacol son derivados de la ruta del ácido shikímico. Esta ruta conduce a la formación de lignina, cumarina, taninos, fenoles, y fenilpropanoides/bencenoides, a partir de los cuales se producen alcoholes, aldehídos, y ésteres (Dudareva et al., 2004; Pichersky et al., 2006).

Por otro lado, la hidrólisis química o enzimática de los glicósidos, moléculas en las cuales un azúcar se une a otro compuesto de diferente naturaleza química mediante un enlace O-glicosídico, puede dar lugar directamente a compuestos volátiles (linalol, $\alpha$-terpineol, 2-feniletanol, furaneol, etc), y también a compuestos hidrófilos de baja volatilidad, a menudo polihidroxilados. La hidrólisis de estos compuestos puede, a su vez, dar lugar a alcoholes, a partir de los cuales pueden formarse aldehídos como el 3-metilbutanal o el fenilacetaldehído (Williams, 1993; Baldwin et al., 2000). 


\subsection{Efecto del etileno en la biosíntesis de compuestos volátiles en} tomate

La maduración es un fenómeno complejo, altamente coordinado, genéticamente programado, e irreversible que implica grandes cambios fisiológicos, bioquímicos, y organolépticos que confieren al fruto su pigmentación, textura, aroma, flavor, y calidad nutricional (Prasanna et al., 2007).

El tomate es un fruto climatérico, de manera que al inicio de la maduración experimenta un incremento brusco de la respiración y de la producción de etileno (pico climatérico), que desciende posteriormente. El efecto del etileno sobre los componentes del flavor del tomate, y en particular sobre las principales rutas de biosíntesis de los compuestos volátiles, ha sido abordado desde distintas aproximaciones (uso de inhibidores de su biosíntesis o de su acción, aplicaciones exógenas, desarrollo de plantas transgénicas con la biosíntesis de etileno alterada), y se ha observado que, si bien en ciertos casos existe una clara implicación del etileno, también existen actividades enzimáticas o rutas de biosíntesis independientes de esta fitohormona (White, 2002; Zhu et al., 2005). Sirviéndose de la ingeniería genética, Gao et al. (2007) han descrito que en tomate el metabolismo de los azúcares es independiente del etileno, mientras que el de los ácidos cítrico y málico está regulado por etileno. Además, sugirieron que como el etileno afecta a los aminoácidos precursores de compuestos volátiles, excepto en el caso de la alanina, también afectaría a los compuestos volátiles derivados de estos aminoácidos. Su trabajo demostró que el etileno regula la producción de algunos de los aldehídos y alcoholes derivados de la degradación enzimática de los lípidos (hexanal, hexanol, trans-2-heptenal, cis-3hexenol), pero no la del cis-3-hexenal y trans-2-hexenal, así como la de algunos de los compuestos volátiles derivados de la degradación de 
carotenoides (6-metil-5-heptén-2-ona y 6-metil-5-heptén-2-ol), pero no la de la $\beta$-damascenona y $\beta$-ionona. Además, pusieron de manifiesto la compleja relación que parece existir entre el 2-feniletanol, el linalol, el salicilato de metilo, el eugenol, y el etileno.

Las actividades lipoxigenasa (LOX) y alcohol deshidrogenasa (ADH) son esenciales en la biosíntesis de importantes compuestos volátiles en tomate (Yilmaz et al., 2001; Yilmaz et al., 2002b). Se ha descrito que los genes que codifican las LOX del tomate (Tomlox) son regulados diferencialmente por el etileno, ejerciendo cada uno una función específica, entre las que se sugiere la biosíntesis de compuestos volátiles, por lo que el etileno estaría jugando un importante papel en la biosíntesis de algunos de los compuestos volátiles derivados de esta ruta (Griffiths et al., 1999), como confirmaron más tarde Gao et al. (2007). En tomate se han identificado diferentes $A D H s$, siendo $A D H 2$ la isoforma que se acumula durante la maduración del fruto. Aunque su actividad no está regulada por etileno, sino por el estrés de bajo oxígeno (Alexander y Grierson, 2002; Zhu et al., 2005).

La bibliografía sobre la maduración de los frutos y el etileno es extensa. La ruta de biosíntesis del etileno ha sido perfectamente elucidada en diversos frutos, entre ellos el tomate (Prasanna et al., 2007). Sin embargo, todavía no se ha podido establecer un cuadro completo del efecto del etileno en la biosíntesis de compuestos volátiles en los frutos. Ha sido el gran desarrollo conseguido durante la última década en el área de la biología molecular el que ha permitido avanzar en la comprensión de los mecanismos de percepción y transducción de la señal del etileno por parte de las plantas, y en el conocimiento de los genes implicados en la biosíntesis de esta fitohormona (Theologis, 1992; Bleecker y Schaller, 1996; White, 2002; Soares-Chaves y de Mello-Farias, 2006). 
4. Precursores de compuestos volátiles en productos vegetales: los glicósidos

La existencia de precursores de compuestos volátiles glicosilados en productos vegetales ha sido ampliamente descrita, encontrándose a niveles significativos, incluso superiores a los de sus correspondientes formas libres (Krammer et al., 1991; Williams, 1993; Baek y Cadwallader, 1999). La cantidad de precursores de compuestos volátiles glicosilados en frutos y plantas puede diferir en función de la variedad, del clima, del tipo de suelo, del estado de maduración, o del tipo de tejido considerado (Aubert et al., 2003; Lalel et al., 2003; Cabaroglu et al., 2003; Osorio et al., 2003; Pogorzelski y Wilkowska, 2007). No existen datos disponibles en la bibliografía sobre la localización subcelular de los precursores glicosilados en las plantas, si bien, se ha sugerido que podrían acumularse principalmente en vacuolas (Sarry y Günata, 2004). Su función biológica en las plantas es todavía objeto de debate (Raguso y Pichersky, 1999), existen evidencias de que algunos glicósidos precursores de compuestos volátiles podrían intervenir en la defensa contra herbívoros (Mattiacci et al., 1995), o en el transporte de moléculas hidrófobas, como los monoterpenoles, a través de las membranas celulares (Vasserot et al., 1995).

\subsection{Composición química de los glicósidos}

La mayoría de los precursores de compuestos volátiles identificados hasta el momento son glicósidos, principalmente del tipo O- $\beta$-D-glucósidos y O-diglicósidos (Figura 1). La estructura general de un $O-\beta$-D-glucósido es una unidad glucopiranosil unida a través de un enlace $\beta-1,4$-glicosídico a un aglicón, el cual puede ser un monoterpeno (geraniol, nerol, linalol, etc), un norisoprenoide $\mathrm{C} 11 / \mathrm{C} 13$ ( $\beta$-damascenona, $\beta$-ionona, etc), un derivado de benceno (bencil alcohol, 2-feniletil alcohol, etc) $\mathrm{o}$ un alcohol lineal 
(hexanol, etc.). En el caso de un O-diglicósido, otro monosacárido ( $\alpha-L-$ arabinofuranosa, $\alpha$-L-arabinopiranosa, $\quad \alpha$-L-ramnopiranosa, $\quad \beta$-Dglucopiranosa, $\beta$-D-apiofuranosa, $\beta$-D-xilopiranosa) se une a la unidad de glucosa (Williams, 1993; Sarry y Günata, 2004).

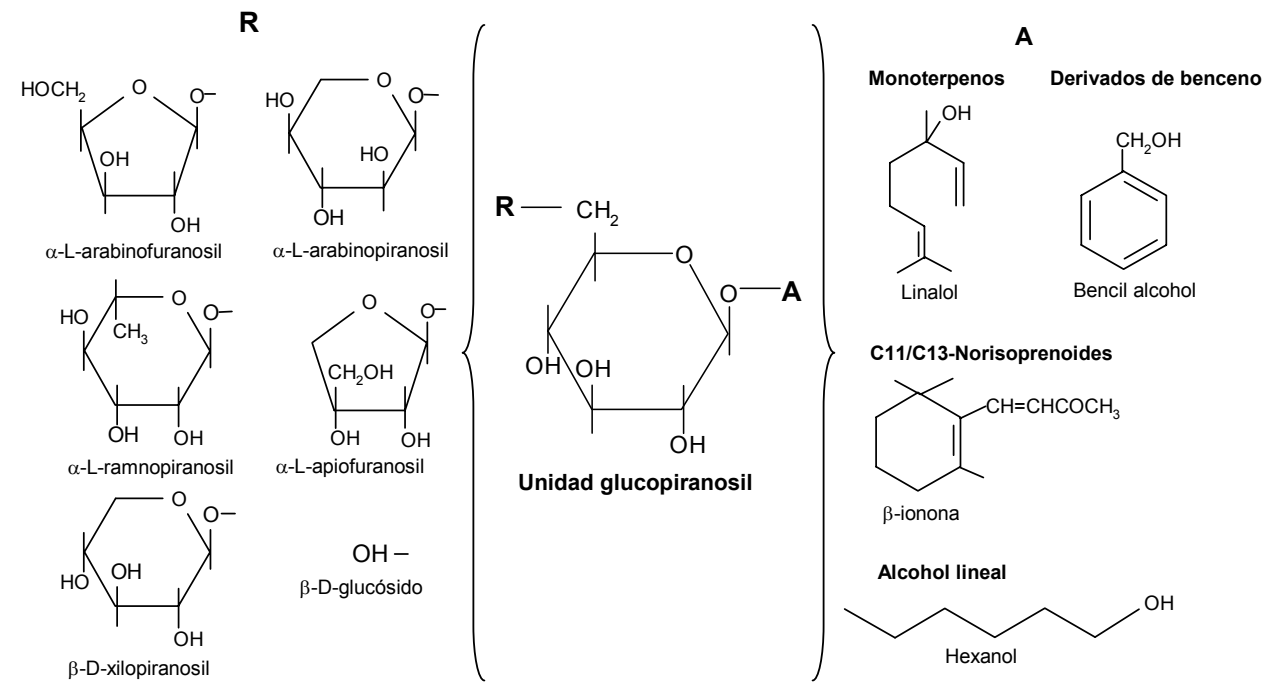

Figura 3. Estructura de los precursores de compuestos volátiles glicosilados.

\subsection{Hidrólisis enzimática de los glicósidos}

Durante las dos últimas décadas, un creciente número de estudios ha demostrado que los glicósidos representan una reserva natural de aroma aún por explotar en tomate (Buttery et al., 1990a; Marlatt et al., 1992; Buttery, 1993; Krammer et al., 1994), y en gran variedad de frutas, frescas o procesadas (Sakho et al., 1997; Parada et al., 2000; Boulanger y Crouzet, 2001; Aubert et al., 2003; Lalel et al., 2003; Osorio et al., 2003), así como en uva y vino (Williams, 1993; Baek y Cadwallader, 1999; Genovés et al., 2003; Sarry y Günata, 2004), en flores y plantas, y en sus derivados (Loughrin et al., 1992; Straubinger et al., 1998; Watanabe et al., 2001; Wang et al., 2001; Nonier et al., 2005). La hidrólisis de los precursores glicosilados, ya sea ácida o enzimática, libera los aglicones 
volátiles modificando el flavor (Williams, 1993). La hidrólisis enzimática está catalizada por glicosidasas. Se trata de un amplio grupo de enzimas de gran importancia biológica, biomédica e industrial, entre las que destacan las $\beta$-glucosidasas. Las $\beta$-glucosidasas se encuentran tanto en las propias plantas como producidas por microorganismos, principalmente levaduras y hongos filamentosos (Pogorzelski y Wilkowska, 2007). Aunque las actividades glicosídicas endógenas aumentan en los frutos durante el proceso de maduración, por el momento no existen evidencias de su relación con la hidrólisis de los precursores de compuestos volátiles glicosilados (Sarry y Günata, 2004). En efecto, para que esta hidrólisis se produzca debe superarse primero la compartimentación que existe en las células entre los enzimas glicosídicos y los sustratos o glicósidos. Como ocurre, por ejemplo, con la aparición del aroma "floral" del té durante el proceso de manufactura (Wang et al., 2001).

Las $\beta$-glucosidasas, hidrolizan los $O-\beta-D$-glucósidos actuando sobre el enlace $\beta$-glicosídico que se establece entre la unidad glucopiranosil y el aglicón (Figura 4).

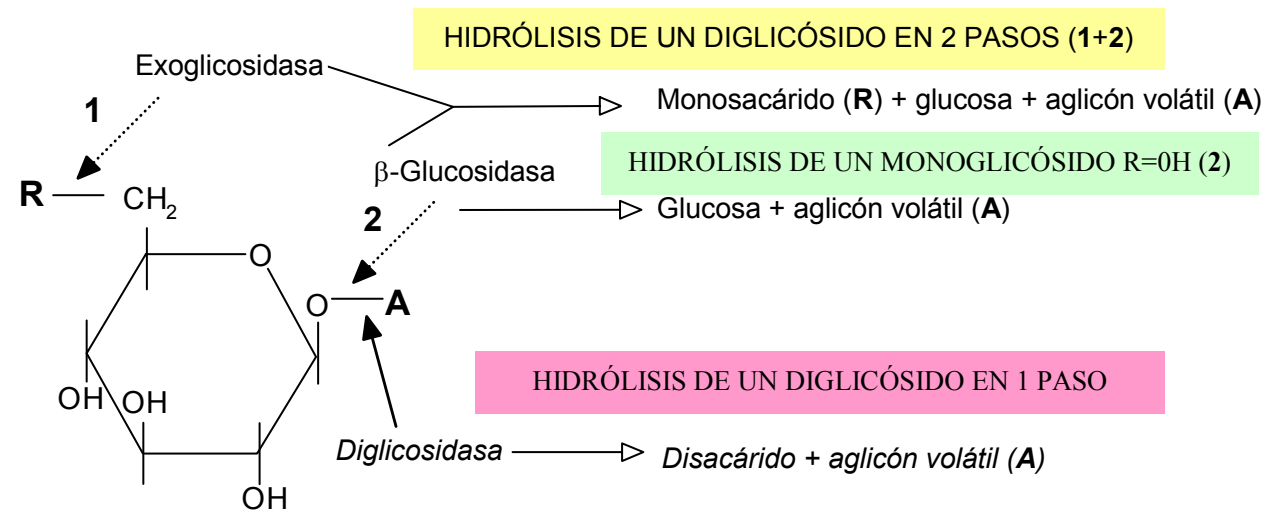

Figura 4. Esquema de la hidrólisis enzimática de los precursores de compuestos volátiles glicosilados. 
La hidrólisis enzimática de los diglicósidos puede realizarse en un solo paso gracias a la acción de una diglicosidasa, liberando el aglicón y el disacárido (Ogawa et al., 1997), o en dos (Figura 4). En este último caso, en un primer paso una exoglicosidasa, específica para la unión entre los azúcares ( $\alpha$-arabinosidasa, $\alpha$-ramnosidasa, $\beta$-apiosidasa, $\beta$-glucosidasa, $\beta$ xilosidasa), libera el monosacárido unido a la unidad de glucosa quedando el $\beta$-D-glucósido. En un segundo paso es una $\beta$-glucosidasa la que libera finalmente el aglicón y la unidad de glucosa correspondiente (Günata et al., 1988; Sarry y Günata, 2004).

\subsection{Los enzimas glicosídicos}

La posibilidad de manipular la producción de compuestos volátiles en productos vegetales ofrece sugerentes aplicaciones para la industria agroalimentaria y de perfumes. Este hecho ha impulsado la caracterización de las enzimas glicosídicas y la investigación sobre su posible aplicación exógena a fin de mejorar el flavor de ciertos productos de origen vegetal (Lecas et al., 1991; Williams, 1993; Kumar y Ramón, 1996; Manzanares et al., 2001; Mizutani et al., 2002; Wei et al., 2004; Tsuruhami et al., 2006). Diferentes trabajos han constatado que la procedencia de la enzima utilizada condiciona el patrón de aglicones liberados, y por tanto las propiedades sensoriales del producto tras la hidrólisis. Por ejemplo, las glicosidasas de la familia Vitaceae, a la que pertenece la uva, son incapaces de liberar el aglicón cuando se trata de un alcohol terciario (linalol, óxidos de linalol, $\alpha$-terpineol), mientras que las glicosidasas de especies fúngicas, especialmente las de la especie Aspergillus niger, sí son capaces de liberarlo (Sarry y Günata, 2004). Por otro lado, la estructura del aglicón ejerce un gran efecto sobre la actividad de las $\beta$ glucosidasas (Lecas et al., 1991), aunque no sobre las exoglicosidasas (Sarry y Günata, 2004). Por ejemplo, las $\beta$-glucosidasas extraídas de las 
almendras sólo son activas en presencia de monoterpenil- $\beta$-D-glucósidos (Vasserot et al., 1995). Otro de los factores que condiciona el éxito de la aplicación exógena de $\beta$-glucosidasas, ya sean de origen vegetal o fúngico, es su estabilidad a pHs ácidos, como el de los zumos de frutas o del mosto en fermentación. Las exoglicosidasas y $\beta$-glucosidasa de $A$. niger y la $\beta$-glucosidasa de Candida molischiana han mostrado una buena estabilidad en el zumo de frutas, contrariamente a las enzimas obtenidas de la uva y de Saccharomyces cerevisiae (Pogorzelski y Wilkowska, 2007). Por otro lado, las $\beta$-glucosidasas fúngicas, pero no las exoglicosidasas, son inhibidas por glucosa, en menor o mayor grado dependiendo de su origen (Sarry y Günata, 2004). En general se han realizado pocos trabajos centrados en la adición de enzimas fúngicas para incrementar el aroma en el zumo de frutas, con la excepción de la uva. A pesar de ello existen evidencias del aumento significativo de los niveles de linalol, bencil alcohol, y 2-feniletanol en el zumo de ciertas frutas (melocotón, cereza, fresas, fruta de la pasión, naranja, manzana, y papaya) por la acción de la $\beta$ glucosidasa de C. molischiana (Gueguen et al., 1996). La mayoría de las aplicaciones de enzimas exógenas para mejorar el aroma se han desarrollado, y conseguido con éxito, en vino (Abbott et al., 1991; Francis et al., 1992; Francis et al., 1998; Cabaroglu et al., 2003; Genovés et al., 2003; Sánchez-Palomo et al., 2005; Gil et al., 2005). Los microorganismos, y especialmente los hongos filamentosos, son productores de muchos aditivos de uso en la industria agroalimentaria, destacando sobre todos ellos los enzimas (Pszczola, 2001; Kirk et al., 2002; van Beilen y Li, 2002). Actualmente existen en el mercado diferentes cócteles enzimáticos ricos en actividades glicosídicas o preparados de $\beta$-glucosidasas procedentes de levaduras $u$ hongos filamentosos que han sido $y$ siguen siendo utilizados para mejorar el aroma en la industria vinícola (Sarry y Günata, 2004). 


\subsection{Métodos de análisis de los glicósidos}

Las principales técnicas para concentrar y aislar la fracción glicosilada (FG) desde el extracto acuoso en el que se encuentra (zumo de frutas, vino desalcoholizado, extracto de plantas) consisten en la retención selectiva de los glicósidos en adsorbentes hidrofóbicos, no polares, como son las resinas cromatográficas C18 en fase inversa (C18- RP) (Wang et al., 1998) o la Amberlita XAD-2 (Günata et al., 1988).

El análisis del concentrado de glicósidos así obtenido se puede abordar desde dos perspectivas. Una, analizando los compuestos volátiles (aglicones) y los azúcares liberados tras la hidrólisis (ácida o enzimática) de los glicósidos. Y otra, más compleja, que consiste en analizar los glicósidos individuales intactos. La mayoría de los trabajos cuantitativos sobre los precursores de compuestos volátiles glicosilados realizados hasta la fecha se han basado en el análisis de los aglicones pues los patrones de referencia de los glicósidos no se encuentran comerciales (Sarry y Günata, 2004). El análisis de los aglicones y de los azúcares a través de técnicas cromatográficas (cromatografía en capa fina -TLC-, cromatografía líquida de alta resolución -HPLC-, y cromatografía gaseosa -GC) permite estimar el número y el tipo de glicósidos precursores de compuestos volátiles presentes en el concentrado (Williams, 1993). Por otro lado, el análisis sensorial descriptivo puede sugerir la contribución que los aglicones liberados aportarían al producto original (Abbott et al., 1991).

El análisis de los glicósidos intactos requiere una separación previa debido a la gran heterogeneidad de aglicones y azúcares que los constituyen (Straubinger et al., 1998; Parada et al., 2000; Morales et al., 2000; Watanabe et al., 2001; Jiang et al., 2001). Algunas de las técnicas utilizadas con este propósito son la cromatografía en contra corriente (CCC), la MLCCC (multilayer coil countercurrent chromatography), la cromatografía líquida de alta resolución preparativa (HPLC-preparativa), o 
la cromatografía de gota en contra corriente (DCCC). Para la identificación de los glicósidos se recurre a técnicas cromatográficas acopladas a técnicas espectrales, entre las que se encuentran la cromatografía de gases, la cromatografía líquida de alta resolución, y el bombardeo por átomo rápido, acopladas a espectrometría de masas (GC-MS, HPLC-MS, FAB-MS, respectivamente), la cromatografía de gases acoplada a espectroscopia de infrarrojos por transformada de Fourier (GC-FTIR), o la resonancia magnética nuclear (NMR).

\subsection{Precursores glicosilados en tomate}

Las primeras evidencias sobre la presencia de precursores de compuestos volátiles glicosilados en tomate surgieron al observar el aumento en la concentración de ciertos compuestos volátiles en la pasta de tomate procesado (Buttery, 1993). Desde entonces, la mayoría de los trabajos sobre los glicósidos en tomate se han basado, principalmente, en el análisis de los aglicones volátiles liberados tras su hidrólisis, ya fuera ácida (Buttery et al., 1990a) o enzimática (Buttery et al., 1990a; Marlatt et al., 1992). Sólo algunos trabajos han profundizado en el análisis de los glicósidos intactos. Por ejemplo, Krammer et al. (1994) aislaron e identificaron el glucósido del furaneol, 2,5-dimetil-4-hidroxi-3(2H)-furanona, en tomate. Aislar y elucidar las estructuras de los glicósidos en tomate constituye todavía uno de los actuales retos en el área de la mejora de la calidad organoléptica de estos frutos.

Buttery et al. (1990a) llevaron a cabo la hidrólisis de la fracción glicosilada del tomate, tanto ácida (a distintos $\mathrm{pHs} 2,3,4.1$, y 5) como enzimática (con una $\beta$-glucosidasa y con una pectinasa comerciales). La hidrólisis enzimática generó un número inferior de aglicones, y en menor concentración, que la ácida. A partir de la hidrólisis enzimática se identificaron benzaldehído, fenilacetaldehído, 2-feniletanol, 3-metilbutanol, 
y trans-2-hexenal. Los compuestos volátiles mayoritarios identificados tras la hidrólisis ácida, a los diferentes pHs ensayados, fueron el ácido 3metilbutírico y la $\beta$-damascenona. En menor cantidad se identificaron fenilacetaldehído, 2-feniletanol, linalol, hotrienol, $\alpha$-terpineol, óxidos de linalol, 4-vinilguaiacol, 4-vinilfenol, benzaldehído, y "dihydroactinidiolide", así como otros 15 posibles norisoprenoides $\mathrm{C} 13$ que no se pudieron identificar. Poco después, Marlatt et al. (1992) hidrolizaron enzimáticamente la FG del tomate con una $\beta$-glucosidasa de almendra y con una pectinasa, ambas comerciales. Los compuestos volátiles mayoritarios identificados en ese trabajo fueron 2-feniletanol, bencilalcohol, ácido benzoico, y varios derivados del ácido shikímico (4hidroxibenzaldehído, eugenol, vanilina, etc.). Otros compuestos, aromáticamente interesantes y reconocidos glicósidos en otras plantas y frutos, fueron detectados a menor concentración. Se trata de ciertos monoterpenoles (linalol, $\alpha$-terpineol, citronelol, nerol, o geraniol), de los C13 norisoprenoides precursores de la $\beta$-damascenona (3-hidroxi- $\beta$ damascenona, megastigma-5-en-7-ine-3,9-diol), y de otros ácidos alifáticos, aromáticos, y fenólicos (ácido 3-metilbutírico, ácido 2metilbutírico, ácido hexanoico, ácido p-cumárico, ácido telúrico, ácido cafeico, ácido sinápico). Los aglicones identificados tras la hidrólisis enzimática en ambos trabajos fueron similares a los compuestos volátiles glicosilados detectados en otras solanáceas (Suárez et al., 1991; Morales et al., 2000). Por otro lado, una parte importante de los aglicones identificados en ambos trabajos (Buttery et al., 1990a; Marlatt et al., 1992) habían sido descritos previamente como compuestos que contribuyen significativamente en el flavor del tomate, confirmando el potencial de los glicósidos como una reserva natural de aroma aún por explotar en estos frutos (Williams, 1993; Sarry y Günata, 2004). Ensayos sensoriales se revelan imprescindibles para determinar el efecto de la liberación de estos 
aglicones sobre el aroma global del tomate (Marlatt et al., 1992; Williams, 1993; Baldwin et al., 2000; Sarry y Günata, 2004).

\section{Biotecnología y mejora del flavor en el área de la Tecnología de los}

\section{Alimentos}

Los intentos de la genética clásica para mejorar el flavor de los productos agrícolas se han visto frustrados o limitados por el gran número de genes que intervienen en la formación del aroma, por la fuerte influencia de las condiciones ambientales y de desarrollo que rodean al cultivo y al manejo postcosecha, y por la falta de una metodología coherente, simple, y barata que permita asociar las preferencias del consumidor y las propiedades químicas de los alimentos (Lewinsohn et al., 2001). A pesar de la complejidad del estudio del flavor, son muchos los esfuerzos encaminados a incrementar y mejorar el perfil sensorial de los alimentos. También es abundante el abanico de posibilidades y estrategias que la biotecnología actual nos permite abordar.

De particular relevancia, por el contenido de este trabajo, son las estrategias encaminadas a la construcción de cepas fúngicas (PérezGonzález et al., 1998), cepas recombinantes de levadura (Sánchez-Torres et al., 1996; Sánchez-Torres et al., 1998; Manzanares et al., 2003; Genovés et al., 2003; Gil et al., 2005), o plantas transgénicas (Wang et al., 1996; Davidovich-Rikanati et al., 2007), que sobre-expresen enzimas específicos, y en concreto glicosidasas. Los enzimas vienen siendo usados de forma empírica en el área de la Tecnología de los Alimentos desde hace siglos, si bien su uso racional se viene produciendo desde hace sólo tres décadas. La aplicación de las técnicas de ingeniería genética en microorganismos ha permitido, mediante técnicas de ingeniería metabólica, sobreproducir y/o producir específicamente muchos enzimas (BrunoBárcena et al., 2002; MacCabe et al., 2002). Por lo que se refiere a las 
glicosidasas, en la bibliografía se ha descrito como la expresión del gen abfB que codifica la $\alpha$-L-arabinofuranosidasa de $A$. niger (Sánchez-Torres et al., 1996), la del gen bgln que codifica la $\beta$-glucosidasa de $C$. molischiana (Sánchez-Torres et al., 1998), la del gen rhaA que codifica una $\alpha$-L-ramnosidasa de A. aculeatus (Manzanares et al., 2003), o la del gen exg1 que codifica una exoglucanasa de S. cerevisiae (Gil et al., 2005), enriquece la fracción aromática de los vinos al liberar varios alcoholes y terpenos aromáticos presentes en el mosto en forma de precursores glicosilados.

Investigaciones recientes en el campo de la biología molecular han aportado nueva información sobre las rutas de biosíntesis de compuestos volátiles en tomate gracias al aislamiento y caracterización de genes que codifican algunas de las enzimas implicadas en su biosíntesis, por ejemplo de la alcohol deshidrogenada ADH (Speirs et al., 1998), de la lipoxigenasa LOX (Ferrie et al., 1994), o de varias dioxigenasas (Simkin et al., 2004). En tomate también se ha identificado un locus directamente implicado en la biosíntesis del 2-fenilacetaldehído y del 2-feniletanol (Tadmor et al., 2002). Por otro lado, distintos trabajos han identificado ciertos marcadores moleculares a través de los métodos para la detección y mapeo de QTLs (loci de rasgos cuantitativos o cuantificables) relacionados con la calidad, y en particular con el flavor del tomate (Fulton et al., 2002; Causse et al., 2002; Tieman et al., 2006), que podrán ser de gran utilidad en los programas de obtención de variedades organolépticamente superiores (Foolad, 2007). Los avances de la última década en biología molecular han permitido igualmente desarrollar frutos de tomate transgénicos con el fin de investigar distintos procesos de su metabolismo (Foolad, 2007). Por ejemplo, el papel de las hidrolasas en la degradación de la pared celular de los frutos durante la maduración (Kramer et al., 1992), el papel del etileno en la maduración y en la síntesis de compuestos volátiles (Oeller et al., 
1991; Sozzi et al., 2002), la síntesis de pigmentos (Bird et al., 1991), o la degradación del almidón (Prasanna et al., 2007). Otras aproximaciones a la manipulación de la calidad y del flavor del tomate a través de la ingeniería genética han sido, por un lado, el aumento del contenido de carotenoides, $\beta$-caroteno (precursor de la vitamina A) y licopeno (Bramley, 2002), y por otro, el aumento del contenido de flavonoides antioxidantes, quercetina y flavonol-glicósidos (Verhoeyen et al., 2002).

A pesar de que el tomate está siendo utilizada como planta modelo en biotecnología por sus múltiples características favorables (Foolad, 2007), y de los grandes avances tecnológicos conseguidos en los últimos tiempos, todavía no tienen respuesta grandes preguntas como el número y efecto de los genes implicados en el control del flavor, la localización de estos genes, o su función fisiológica. 



\section{OBJETIVOS}





\section{OBJETIVOS}

El objetivo global de este trabajo es profundizar en el conocimiento de la composición de la fracción volátil del tomate, incidiendo en aspectos como la variedad y el estado de maduración, para poder conocer el alcance de ciertos enzimas glicosídicos como herramientas útiles para el incremento del aroma de este fruto o de sus derivados. Para la consecución de este objetivo general se abordaron los siguientes objetivos particulares:

1. Caracterizar la fracción volátil de 5 variedades de tomate en cuanto a los componentes libres y glicosilados.

2. Determinar la evolución de los componentes de la fracción volátil a lo largo del proceso de maduración del fruto.

3. Evaluar la utilidad de adicionar individualmente enzimas con actividad $\beta$-glucosidasa para lograr el incremento de compuestos volátiles libres en el tomate.

4. Evaluar la utilidad de adicionar combinaciones de actividades glicosídicas capaces de hidrolizar diglicósidos para lograr el incremento de compuestos volátiles libres en el tomate.

5. Conseguir información sobre la composición global de los glicósidos a través del empleo de actividades glicosídicas específicas y el análisis de los productos de la hidrólisis. 




\section{MATERIALES Y MÉTODOS}

\section{Material biológico y tratamientos previos.}

\subsection{Material vegetal}

Las variedades de tomate (Solanum lycopersicum L.) p73, Jorge, y Durinta fueron cultivadas en invernadero en el sureste de la costa española (Murcia), en el Centro de Edafología y Biología aplicada del Segura (CEBAS-CSIC). Las variedades Moneymaker (MM) y Raf también se cultivaron en invernadero, en el este de la costa española (Valencia), en el Instituto de Biología Molecular y Celular de Plantas (IBMCP). La recolección de los frutos se hizo manualmente y al azar, cosechando entre 10 y 12 frutos por planta. Las variedades p73, Jorge, y Durinta se recolectaron en el momento del cambio de color o estado pintón $(P)$. $Y$ las variedades MM y Raf se recolectaron en 3 estados de maduración, en el estado inmaduro o verde $(\mathrm{V})$, en el momento del cambio de color o estado pintón $(\mathrm{P})$, y en el estado maduro $(\mathrm{M})$, es decir, cuando la coloración era rojiza (Raf) o roja intensa (MM). Todos los frutos fueron transportados al laboratorio en menos de $24 \mathrm{~h}$.

Una vez en el laboratorio los frutos se seleccionaron por uniformidad de tamaño y color, descartándose aquellos con defectos. Los frutos de las variedades $\mathrm{p} 73$, Jorge, y Durinta fueron triturados manualmente con un mortero, filtrados, y centrifugados $15 \mathrm{~min}$ a $3500 \mathrm{rpm}$. Los frutos de las variedades MM y Raf fueron triturados con una licuadora doméstica (SOLAC, modelo 850), filtrados y centrifugados $15 \mathrm{~min}$ a $3500 \mathrm{rpm}$. Finalmente, se recuperó el sobrenadante del zumo de las 5 variedades (zumo limpio) y se conservó a $-20^{\circ} \mathrm{C}$ hasta ser utilizado.

Jorge, Durinta, MM, y Raf son variedades comerciales destinadas al consumo en fresco, siendo las variedades MM y Raf las de mayor 
importancia económica. La variedad Raf, es una de las variedades de tomate más apreciada por sus propiedades organolépticas. La variedad p73 es una variedad utilizada en programas de transformación genética.

\subsection{Cepas de levadura y su crecimiento en condiciones de laboratorio}

En este trabajo se han empleado las cepas de la levadura Saccharomyces cerevisiae de origen vínico transformadas genéticamente en el IATA para sobreexpresar los genes que codifican la actividad $\beta$ glucosidasa de Candida molischiana -BgIN (Sánchez-Torres et al., 1998), la exoglucanasa de S. cerevisiae -Exg1 (Gil et al., 2005), la $\alpha$-Lramnosidasa de Aspergillus aculeatus -RhaA (Manzanares et al., 2003) y la $\alpha$-L-arabinofuranosidasa de Aspergillus niger -AbfB (Sánchez-Torres et al., 1996). En la Tabla 2 se detalla el nombre de la cepa, su genotipo, y su procedencia.

Tabla 2. Cepas de microorganismos utilizadas en este trabajo.

\begin{tabular}{lllll}
\hline \multicolumn{1}{c}{ CEPA } & & \multicolumn{1}{c}{ GENOTIPO } & & \multicolumn{1}{c}{ PROCEDENCIA } \\
\cline { 1 - 1 } S. cerevisiae $\mathrm{T}_{73} / \mathrm{YCB}_{5}$ & & Cepa $\mathrm{T}_{73}$ transformada con el plásmido YCBgln & & Sánchez-Torres et al., 1998 \\
S. cerevisiae $\mathrm{T}_{73} / \mathrm{YCEXG1a}$ & & Cepa $\mathrm{T}_{73}$ transformada con el plásmido YCEXG1 & & Gil et al., 2005 \\
S. cerevisiae $\mathrm{T}_{73} / \mathrm{YR}$ & & Cepa $\mathrm{T}_{73}$ transformada con el plásmido pR38 & & Manzanares et al., 2003 \\
S. cerevisiae $\mathrm{T}_{73} / \mathrm{YCA}_{1}$ & Cepa $\mathrm{T}_{73}$ transformada con el plásmido YCAbfB & & Sánchez-Torres et al., 1996 \\
\hline
\end{tabular}

El crecimiento de las cepas de $S$. cerevisiae transformadas genéticamente $\left(T_{73} / Y C B 3_{5}, T_{73} / Y C E X G 1 a, T_{73} / Y R 8, y T_{73} / Y C A_{1}\right)$ se llevó a cabo en medio de cultivo rico (YPD), el cual se describe más abajo. El medio de cultivo (4.75 L de YPD, $1 \mu \mathrm{g} / \mathrm{mL}$ de cicloheximida; SigmaAldrich, St. Louis, MO) se inoculó a una densidad celular de $2.5 \times 10^{6}$ células $/ \mathrm{mL}$ a partir de un preinóculo también en medio YPD con cicloheximida. Posteriormente, el medio se incubó durante $48 \mathrm{~h}$ a $30^{\circ} \mathrm{C}$ en un agitador orbital a $250 \mathrm{rpm}$.

En todos los casos, el crecimiento de los cultivos en medio líquido se calculó mediante recuento con cámara cuentaglóbulos.

Medio rico líquido (YPD): Se compone de extracto de levadura $1 \%$ $(\mathrm{p} / \mathrm{v})$ (Panreac, Barcelona, Spain), peptona $0.5 \%(\mathrm{p} / \mathrm{v})$ (Panreac, 
Barcelona, Spain), y como fuente de carbono, glucosa al $2 \%(p / v)$ (Panreac, Barcelona, Spain). El medio rico se suplementó con cicloheximida $1 \mu \mathrm{g} / \mathrm{mL}$.

\section{Producción de extractos enriquecidos con los enzimas glicosídicos BgIN, Exg1, RhaA, y AbfB}

Para obtener extractos enriquecidos con las actividades glicosídicas BgIN, Exg1, RhaA, y AbfB se partió de los cultivos en medio líquido YPD de las cepas recombinantes de Saccharomyces cerevisiae de origen vínico transformadas genéticamente en el IATA, $\mathrm{T}_{73} / \mathrm{YCB}_{5}, \mathrm{~T}_{73} / \mathrm{YCEXG1a}$, $\mathrm{T}_{73} / \mathrm{YR} 8$, y $\mathrm{T}_{73} / \mathrm{YCA}_{1}$. El enzima BgIN se localiza principalmente en la pared celular de la cepa $\mathrm{T}_{73} / \mathrm{YCB}_{5}$ (Sánchez-Torres et al., 1998). Para obtener extractos enriquecidos con la actividad BgIN se centrifugó el medio de cultivo, se recuperaron las células de la cepa $T_{73} / Y_{C B} 3_{5} y$, tras medir su actividad $\beta$-glucosidasa, se descartó el sobrenadante del medio de cultivo. Los enzimas Exg1, RhaA, y AbfB son principalmente secretados al medio de cultivo por las respectivas cepas productoras $T_{73} /$ YCEXG1a, $T_{73} / Y R 8, y$ $\mathrm{T}_{73} / \mathrm{YCA}_{1}$ (Sánchez-Torres et al., 1996; Manzanares et al., 2003; Gil et al., 2005). Para obtener extractos enriquecidos con las actividades Exg1, RhaA, y AbfB se centrifugó el medio de cultivo, recuperando por un lado las células, y por otro el sobrenadante del medio de cultivo. Aunque los extractos enriquecidos con las actividades Exg1, RhaA, y AbfB en cantidad suficiente para posteriores experimentos se obtuvieron a partir del sobrenadante del medio de cultivo, como se describe más abajo, en todos los casos se ensayó también la producción a partir de las células de las respectivas cepas productoras, según el protocolo descrito a continuación para BgIN.

Todos los pasos para producir los extractos enriquecidos con los enzimas se realizaron a $4{ }^{\circ} \mathrm{C}$, excepto cuando se indique otra temperatura. 
Las fracciones obtenidas por cromatografía en columna se clasificaron según su actividad, y se conservaron a $-20^{\circ} \mathrm{C}$ (BgIN, Exg1, y AbfB) y a 4 ${ }^{\circ} \mathrm{C}(\mathrm{RhaA})$ hasta su posterior utilización.

\subsection{Producción de extractos enriquecidos con el enzima BgIN}

Las células de la cepa $\mathrm{T}_{73} / \mathrm{YCB}_{5}$ se sometieron a sucesivos lavados con tampón TRIS-HCl $10 \mathrm{mM} \mathrm{pH} \mathrm{7,5}$ con $\mathrm{NaCl} 1 \mathrm{M}$, durante toda la noche y en agitación. Tras cada lavado se centrifugó y se recuperó el sobrenadante del lavado. Al sobrenadante del lavado se le adicionaron 3 volúmenes de agua destilada y la resina DEAE Sephadex A50 (Amersham Biosciences Europe $\mathrm{GMBH}$, Freiburg, Germany; $1 \mathrm{~g}$ rehidratado con tampón TRIS-HCI $10 \mathrm{mM} \mathrm{pH} \mathrm{7,5)} \mathrm{en} \mathrm{batch,} \mathrm{dejándolo} \mathrm{toda} \mathrm{la} \mathrm{noche} \mathrm{en} \mathrm{un} \mathrm{agitador}$ magnético. La resina se recuperó por filtración y se empacó. El enzima se recuperó tras elución en columna cromatográfica con tampón TRIS-HCI 10 $\mathrm{mM} \mathrm{pH} \mathrm{7,5} \mathrm{con} \mathrm{NaCl} 1 \mathrm{M}$, recogiendo fracciones consecutivas de $5 \mathrm{~mL}$.

\subsection{Producción de extractos enriquecidos con los enzimas Exg1 y AbfB}

Para la producción de extractos enriquecidos con los enzimas Exg1 y AbfB se siguió el mismo protocolo, partiendo en cada caso del sobrenadante del medio de cultivo YPD donde crecieron las respectivas cepas productoras ( $\mathrm{T}_{73} / \mathrm{YCEXG1a}$ y $\mathrm{T}_{73} / \mathrm{YCA}_{1}$ ). El sobrenadante del medio de cultivo se dejó en contacto con la resina DEAE Sephadex A50 (Amersham Biosciences Europe GMBH, Freiburg, Germany; 1g rehidratado con tampón TRIS- $\mathrm{HCl} 10 \mathrm{mM} \mathrm{pH} \mathrm{7,5),} \mathrm{durante} \mathrm{toda} \mathrm{la} \mathrm{noche} \mathrm{y}$ en agitación. Seguidamente se recuperó la resina por filtración y los enzimas en ella adsorbidos se recuperaron tras elución en columna cromatográfica con TRIS-HCl $10 \mathrm{mM} \mathrm{pH} \mathrm{7,5} \mathrm{con} \mathrm{NaCl} 1 \mathrm{M}$, recogiendo una primera fracción de $10 \mathrm{~mL}$ y fracciones sucesivas de $5 \mathrm{~mL}$. 


\subsection{Producción de extractos enriquecidos con el enzima RhaA}

La producción de extractos enriquecidos con el enzima RhaA se llevó a cabo según el protocolo descrito para Exg1 y AbfB con modificaciones, debido al diferente punto isoeléctrico de este enzima (Manzanares et al., 2001). El sobrenadante del medio de cultivo en el que creció la cepa $\mathrm{T}_{73} / \mathrm{YR} 8$ se llevó a $\mathrm{pH} 3,8$ con $0,1 \mathrm{M} \mathrm{HCl}$ y acto seguido se puso en contacto con la resina CM Sephadex C-50 (Amersham Biosciences Europe GMBH, Freiburg, Germany; $1 \mathrm{~g}$ rehidratado con tampón citrato de sodio 20

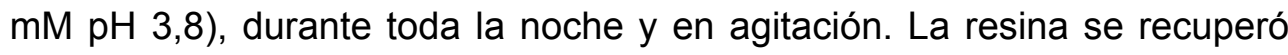
por filtración y el enzima se recuperó por elución en columna cromatográfica con tampón citrato de sodio $10 \mathrm{mM} \mathrm{pH} \mathrm{3,8} \mathrm{con} \mathrm{NaCl} 1 \mathrm{M}$, recogiendo una primera fracción de $10 \mathrm{~mL}$ y sucesivas fracciones de $5 \mathrm{~mL}$.

\subsection{Producción de los enzimas BgIN y Exg1 adicionados al zumo extraído de las variedades p73, Jorge y Durinta}

La producción de los enzimas BgIN y Exg1, adicionados en este trabajo al zumo extraído de las variedades p73, Jorge, y Durinta, se llevó a cabo previamente en este laboratorio siguiendo los protocolos anteriormente expuestos con modificaciones. El crecimiento de las cepas de levadura $\mathrm{T}_{73} / \mathrm{YCB}_{5}$ y $\mathrm{T}_{73} / \mathrm{YCEXG1a}$ se llevó a cabo en medio líquido YPD con cicloheximida usando un fermentador Bioflo III (New Brunswick Scientific, Edison, NJ). El sobrenadante se concentró mediante filtración tangencial con un equipo Pellicon Ultrafiltration System (Millipore Corp., Bedford, MA) empleando membranas de 10000 Daltons de tamaño de poro. Seguidamente, ambos enzimas se precipitaron a $0{ }^{\circ} \mathrm{C}$ con sulfato de amonio al 80\% (p/v) (Sigma-Aldrich, St. Louis, MO), previa adición de seroalbúmina bovina -BSA (Sigma-Aldrich, St. Louis, MO), hasta obtener una concentración de proteína total de $1 \mathrm{mg} / \mathrm{mL}$. Finalmente, el extracto 
enriquecido con los enzimas BgIN y Exg1 se dejó precipitar toda la noche a $4{ }^{\circ} \mathrm{C}$ y se recogió el precipitado.

\section{Medida de la actividad enzimática}

Para medir las actividades $\beta$-glucosidasa, $\alpha$-ramnosidasa, $\alpha$ arabinosidasa, y $\beta$-xilosidasa se utilizaron los sustratos $p$-nitrofenil- $\beta$-Dglucopiranósido (pNPG; Sigma, St. Louis, MO), $p$-nitrofenil- $\alpha$-Lramnopiranósido (pNPR; Sigma), $p$-nitrofenil- $\alpha$-L-arabinofuranósido (pNPA; Sigma), y $p$-nitrofenil- $\beta$-D-xilopiranósido (pNPX; Sigma), respectivamente. Las reacciones tuvieron lugar en tampón Mcllvaine $75 \mathrm{mM}, \mathrm{pH} 5$ conteniendo $5 \mathrm{mM}$ del sustrato correspondiente a cada actividad y una cantidad adecuada de la muestra a ensayar en un volumen final de $250 \mu \mathrm{L}$. Tras incubar a $30^{\circ} \mathrm{C}$ durante $20 \mathrm{~min}$, la reacción se paró adicionando 0.5 $\mathrm{mL}$ de $\mathrm{Na}_{2} \mathrm{CO}_{3} 0.2 \mathrm{M}, \mathrm{pH}$ 10.2. La liberación de p-nitrofenol se midió espectrofotométricamente a $405 \mathrm{~nm}$. Una unidad de actividad enzimática $\left(U_{\text {enz }}\right)$ fue definida como la cantidad de enzima que libera $1 \mu \mathrm{mol}$ de pNP por minuto a $30^{\circ} \mathrm{C}$ en tampón Mcllvaine $75 \mathrm{mM} \mathrm{pH}$ 5. Todas las mediciones enzimáticas se realizaron por duplicado.

\section{Extracción de la fracción glicosilada del tomate}

Para extraer la fracción glicosilada $(F G)$ del tomate se siguió el protocolo descrito por Genovés et al. (2003) con modificaciones. El zumo limpio de tomate se fraccionó en cartuchos C18 de fase inversa (C18-RP) Sep-Pack de 500 mg (Waters Corp., Milford, Mass., U.S.A.). Se pasaron 40 $\mathrm{mL}$ de zumo limpio de tomate a través de un cartucho C18-RP, previamente activado con $10 \mathrm{~mL}$ de metanol y $20 \mathrm{~mL}$ de agua destilada. Después se lavó con $10 \mathrm{~mL}$ de agua, que se desechó. A continuación se lavó con $10 \mathrm{~mL}$ de pentano, y se desechó. Finalmente, los compuestos glicosilados se eluyeron con $10 \mathrm{~mL}$ de metanol, que se llevaron a sequedad a baja presión y $45^{\circ} \mathrm{C}$ con un rotavapor. El extracto seco de 
glicósidos se resuspendió en $3 \mathrm{~mL}$ de tampón Mcllvaine $75 \mathrm{mM}$ pH 5. La extracción se realizó por triplicado para las 5 variedades de tomate en cada uno de los estados de maduración considerados.

\section{Hidrólisis enzimática de la fracción glicosilada de tomate}

\subsection{Caracterización de la fracción glicosilada}

Para caracterizar la FG del tomate se llevó a cabo la hidrólisis enzimática exhaustiva del extracto de glicósidos con un preparado enzimático comercial rico en actividades glicosídicas, Pectinase AR2000 (Gist Brocades, Seclin, France). $1 \mathrm{~mL}$ de extracto se incubó con $100 \mu \mathrm{l}$ de una solución de AR2000 (25 mg $/ \mathrm{mL})$ durante 48 h a $40{ }^{\circ} \mathrm{C}$ en agitación. El hidrolizado se almacenó a $-20{ }^{\circ} \mathrm{C}$ hasta su análisis cromatográfico. Las hidrólisis se realizaron por triplicado.

\subsection{Análisis de la composición de los glicósidos}

Para analizar la composición de los glicósidos de tomate se llevó a cabo la hidrólisis enzimática de los extractos de glicósidos utilizando las actividades específicas BgIN, RhaA, y AbfB. $1 \mathrm{~mL}$ de extracto se incubó durante $48 \mathrm{~h}$ a $40{ }^{\circ} \mathrm{C}$ en agitación, con $20 \mathrm{mU}_{\text {enz }}$ de cada uno de los enzimas, BgIN y RhaA individualmente y las combinaciones $B g I N+R h a A$ y BgIN+RhaA+AbfB. La Tabla 3 recoge los volúmenes adicionados de cada extracto enzimático y tampón Mcllvaine $75 \mathrm{mM} \mathrm{pH} 5$ hasta un volumen total de $41.51 \mu \mathrm{L}$. Tras la incubación cada muestra se dividió en 2 volúmenes iguales, uno para el posterior análisis de los volátiles por cromatografía gaseosa (GC) y otro para analizar los azúcares por cromatografía líquida de alta resolución (HPLC). Ambos se conservaron a $-20{ }^{\circ} \mathrm{C}$ hasta su análisis. El experimento se realizó por triplicado y como control se utilizaron extractos de $1 \mathrm{~mL}$ de $\mathrm{FG}$ de tomate sin adición de enzima (BLC). 
Previamente a su análisis por cromatografía gaseosa las muestras se descongelaron y se adicionó agua destilada hasta un volumen de $3 \mathrm{~mL}$.

Tabla 3. Volumen de solución enzimática y tampón Mcllvain $75 \mathrm{mM} \mathrm{pH5}(\mu \mathrm{L})$ adicionado a $1 \mathrm{~mL}$ de extracto de glicósidos.

\begin{tabular}{|c|c|c|c|c|c|c|}
\hline \multirow{2}{*}{\multicolumn{2}{|c|}{ Tratamiento }} & \multicolumn{4}{|c|}{ Solución enzimática } & \multirow{3}{*}{$\begin{array}{c}\begin{array}{c}\text { Tampón } \\
\text { Mcllvaine }\end{array} \\
41.51\end{array}$} \\
\hline & & \multirow[t]{2}{*}{ BgIN } & \multirow[t]{2}{*}{ RhaA } & \multirow[t]{2}{*}{ AbfB } & \multirow{2}{*}{$\frac{\text { TOTAL }}{0.000}$} & \\
\hline 0 & BLC & & & & & \\
\hline 1 & BgIN & 7.840 & & & 7.840 & 33.67 \\
\hline 2 & RhaA & & 26.84 & & 26.84 & 14.67 \\
\hline 3 & BgIN/RhaA & 7.840 & 26.84 & & 34.68 & 6.830 \\
\hline 4 & BglN/RhaA/AbfB & 7.840 & 26.84 & 6.830 & 41.51 & 0.000 \\
\hline
\end{tabular}

\section{Adición de glicosidasas al zumo de tomate}

El zumo de tomate limpio ( $3 \mathrm{~mL}$ ) se incubó en presencia de $50 \mathrm{mU}_{\mathrm{enz}}$ de cada uno de los enzima BgIN, Exg1, RhaA, y AbfB (Tabla 4), y de 6 mg de benzoato de sodio (Fluka, Buchs, Switzerland), utilizado como conservante del zumo. Junto con el volumen correspondiente de solución enzimática se adicionó agua destilada hasta un volumen total de $0.5 \mathrm{~mL}$ por cada $3 \mathrm{~mL}$ de zumo limpio. El zumo extraído de las variedades p73, Jorge, y Durinta se incubó a $15^{\circ} \mathrm{C}$ durante 6 días en presencia de los enzimas BgIN y Exg1, individualmente. El de las variedades MM y Raf, en los estados de maduración $\mathrm{V}, \mathrm{P}$, y $\mathrm{M}$, se incubó a $20^{\circ} \mathrm{C}$ durante 6 días en presencia de los enzimas BgIN, Exg1, RhaA y AbfB, individualmente y en combinaciones de BgIN y Exg1 con RhaA y AbfB (BgIN+RhaA, BgIN+AbfB, $B g I N+R h a A+A b f B, E x g 1+R h a A, E x g 1+A b f B, y$ Exg1+RhaA+AbfB). Tras la incubación se añadió $0.7 \mathrm{~g}$ de $\mathrm{NaCl}$ a cada muestra y se conservaron a 4 ${ }^{\circ} \mathrm{C}$ hasta su posterior análisis cromatográfico. Para su análisis cromatográfico, las muestras se atemperaron en un baño a $30^{\circ} \mathrm{C}$ durante 5 min. El experimento se realizó por triplicado y como control se utilizaron muestras de $3 \mathrm{~mL}$ de zumo limpio de tomate sin adición de enzima (BLC). 
Tabla 4. Volumen de enzima y agua $(\mu \mathrm{L})$ adicionado a cada muestra de $3 \mathrm{~mL}$ de zumo.

\begin{tabular}{|c|c|c|c|c|c|c|}
\hline \multirow{2}{*}{ Tratamiento } & \multicolumn{5}{|c|}{ Solución enzimática } & \multirow{3}{*}{$\frac{\mathrm{H}_{2} \mathrm{O}}{0.500}$} \\
\hline & $\mathrm{BgIN}$ & Exg1 & RhaA & AbfB & TOTAL & \\
\hline 0 BLC & & & & & 0.000 & \\
\hline $1 \mathrm{BgIN}$ & 0.243 & & & & 0.243 & 0.257 \\
\hline 2 Exg1 & & 0.090 & & & 0.090 & 0.410 \\
\hline 3 RhaA & & & 0.069 & & 0.069 & 0.431 \\
\hline $4 \mathrm{AbfB}$ & & & & 0.059 & 0.059 & 0.441 \\
\hline $5 \mathrm{BgIN} / \mathrm{RhaA}$ & 0.243 & & 0.069 & & 0.312 & 0.188 \\
\hline $6 \mathrm{BgIN} / \mathrm{AbfB}$ & 0.243 & & & 0.059 & 0.302 & 0.198 \\
\hline $7 \mathrm{BgIN} / \mathrm{RhaA} / \mathrm{AbfB}$ & 0.243 & & 0.069 & 0.059 & 0.371 & 0.129 \\
\hline 8 Exg1/RhaA & & 0.090 & 0.069 & & 0.159 & 0.341 \\
\hline 9 Exg1/AbfB & & 0.090 & & 0.059 & 0.149 & 0.351 \\
\hline 10 Exg1/RhaA/AbfB & & 0.090 & 0.069 & 0.059 & 0.218 & 0.282 \\
\hline
\end{tabular}

\section{Análisis de compuestos volátiles en tomate}

\subsection{Detección: microextracción en fase sólida en espacio de cabeza y cromatografía de gases (HS-SPME-GC)}

La metodología utilizada para la detección de compuestos volátiles consta de 2 fases denominadas fase de adsorción y fase de desorción. La fase de adsorción consiste en la exposición del soluto volátil de interés a una fibra polimérica. La fase siguiente o fase de desorción, se realiza acoplada a un cromatógrafo de gases que analizará los solutos volátiles atrapados en la fibra polimérica. La adsorción de los compuestos volátiles se realizó en el espacio de cabeza mediante la técnica de microextracción en fase sólida (HS-SPME). Se utilizó una fibra de sílice fundido de $10 \mathrm{~mm}$ recubierta con $100 \mu \mathrm{m}$ de poli-dimetilsiloxano (PDMS) como material adsorbente (Supelco, Bellefonte, PA, USA). Se colocaron $3 \mathrm{~mL}$ de muestra en un tubo de ensayo con tapón de rosca y septum incorporado. Se adicionaron $0.7 \mathrm{~g}$ de $\mathrm{NaCl}$, a fin de desplazar el equilibrio de la presión de vapor hacia la fase vapor, y se dejó $30 \mathrm{~min}$ en un agitador magnético a temperatura ambiente. Posteriormente, la fibra se introdujo en el tubo de 
ensayo a través del septum y el material adsorbente se expuso durante 30 min al espacio de cabeza de la muestra en agitación. Para la desorción de los analitos, la fibra se inyectó y se mantuvo durante 4 min a $240{ }^{\circ} \mathrm{C}$ en el puerto de inyección del cromatógrafo de gases. Para la separación y detección de los analitos se utilizó un cromatógrafo de gases HP5890 (Hewlett-Packard, Waldbronn, Germany) equipado con un detector de ionización de llama FID provisto de una columna capilar HP-INNOWax (Hewlett Packard) de $30 \mathrm{~m}$ longitud, 0,25 mm diámetro interno, y 0,25 $\mu \mathrm{m}$ de espesor fase estacionaria. Como gas portador se utilizó Helio a un flujo de $1 \mathrm{~mL} / \mathrm{min}$.

Las condiciones de funcionamiento fueron:

- Temperatura del detector (FID) $300^{\circ} \mathrm{C}$

- Temperatura del inyector $240^{\circ} \mathrm{C}$

- La temperatura del horno se mantuvo a $40^{\circ} \mathrm{C}$ durante 5 min y se incrementó a razón de $5{ }^{\circ} \mathrm{C} / \mathrm{min}$ hasta $150{ }^{\circ} \mathrm{C}$, y a 20 ${ }^{\circ} \mathrm{C} /$ min hasta $250{ }^{\circ} \mathrm{C}$. El horno se mantuvo a $250^{\circ} \mathrm{C}$ durante $10 \mathrm{~min}$.

Cada una de los experimentos resueltos por cromatografía de gases en este trabajo se ensayó por triplicado.

Inicialmente se realizó un experimento preliminar para evaluar la dinámica general de los compuestos volátiles dentro del sistema utilizado, determinar el tiempo mínimo de equilibrio de los compuestos volátiles entre la muestra y el espacio de cabeza, y el tiempo apropiado para la extracción de compuestos volátiles con la fibra.

\subsection{Identificación: cromatografía de gases acoplada a espectrometría de masas (GC-MS)}

Para la identificación de los compuestos volátiles se utilizó un cromatógrafo de gases Thermo TRACE GC ULTRA acoplado a un espectrómetro de masas Thermo DSQ (Thermo Electron Corporation, CA, 
USA), equipado con la misma columna y programado con las mismas condiciones cromatográficas descritas en el apartado anterior. La temperatura de la fuente de ionización fue de $200{ }^{\circ} \mathrm{C}$. Se empleó ionozación por impacto electrónico a $70 \mathrm{eV}$. La identificación se realizó mediante comparación de los espectros de masas obtenidos en las muestras de tomate con los de la biblioteca Willey. Paralelamente, se compararon los tiempos de retención de los compuestos volátiles detectados en las muestras de tomate con los de sus correspondientes estándares comerciales (Tabla 5).

\subsection{Cuantificación}

La cuantificación de los compuestos volátiles acumulados en el espacio de cabeza se llevó a cabo mediante curvas de calibrado que respondían a la ecuación:

Área cromatográfica $=$ Factor de respuesta FID x Concentración

Para obtenerlas se aplicó la misma metodología utilizada para la detección de compuestos volátiles por HS-SPME-GC a muestras con concentraciones definidas de los respectivos estándares comerciales. En la Tabla 5 se indican los estándares comerciales empleados en las curvas de calibrado, los factores de respuesta FID de las ecuaciones de las rectas obtenidas, y la bondad de ajuste del modelo lineal $\left(r^{2}\right)$ utilizado. El área mínima integrable osciló entre 20-40 unidades arbitrarias de señal cromatográfica. 
Tabla 5. Estándares comerciales, factores de respuesta FR $(L / \mu g)$, y $r^{2}$ de las curvas de calibrado obtenidas para la cuantificación de los compuestos volátiles en el espacio de cabeza.

\begin{tabular}{|c|c|c|c|}
\hline PRODUCTOS & CASA COMERCIAL & FR & $r^{2}$ \\
\hline Hexanal & Fluka (Buchs, Switzerland) & 44.952 & 0.9999 \\
\hline 3-Metil-1-butanol & Fluka & 34.902 & 0.9999 \\
\hline trans-2-hexenal & Fluka & 17.974 & 1.0000 \\
\hline 3-Octanona & Fluka & 1053.5 & 0.9999 \\
\hline Octanal & Fluka & 448.87 & 0.9999 \\
\hline 6-Metil-5-heptén-2-ona & Sigma-Aldrich (St. Louis, MO) & 13.208 & 0.9990 \\
\hline 4-Metil-1-pentanol & Fluka & 62.805 & 0.9880 \\
\hline 3-Metil-1-pentanol & Fluka & 31.439 & 0.9996 \\
\hline 1-Hexanol & Fluka & 18.262 & 0.9999 \\
\hline cis-3-hexenol & Fluka & 60.468 & 1.0000 \\
\hline Nonanal & Fluka & 1659.6 & 1.0000 \\
\hline 2-Isobutiltiazol & Sigma-Aldrich & 1352.3 & 0.9999 \\
\hline cis-óxido de linalol & Fluka & 89.974 & 0.9997 \\
\hline 1-Heptanol & Fluka & 63.358 & 0.9987 \\
\hline 6-Metil-5-heptén-2-ol & Sigma-Aldrich & 181.58 & 0.9999 \\
\hline trans -óxido de linalol & Fluka & 65.882 & 0.9995 \\
\hline 2-Etil-1-hexanol & Fluka & 13.902 & 0.9930 \\
\hline Decanal & Fluka & 3479.2 & 1.0000 \\
\hline cis-4-decenal & Sigma-Aldrich & 3109.9 & 1.0000 \\
\hline Benzaldehído & Fluka & 26.794 & 0.9988 \\
\hline Linalol & Fluka & 30.938 & 0.9994 \\
\hline 1-Octanol & Fluka & 201.96 & 0.9999 \\
\hline$\alpha$-Terpineol & Fluka & 34.439 & 0.9967 \\
\hline$\beta$-citronellol & Fluka & 235.86 & 0.9986 \\
\hline Salicilato de metilo & Sigma-Aldrich & 152.78 & 1.0000 \\
\hline Nerol & Fluka & 145.87 & 0.9992 \\
\hline Geraniol & Fluka & 103.11 & 0.9991 \\
\hline 3,5-Dimetil benzaldehído & Sigma-Aldrich & 591.51 & 0.9999 \\
\hline Guaiacol & Sigma-Aldrich & 3,9604 & 1.0000 \\
\hline Bencil alcohol & Fluka & 1,2083 & 1.0000 \\
\hline 2-Feniletanol & Fluka & 2,4477 & 0.9999 \\
\hline$\beta$-Ionona & Fluka & 487.96 & 0.9979 \\
\hline Eugenol & Fluka & 23.345 & 0.9999 \\
\hline 2-Metoxi-4-vinilfenol & Sigma-Aldrich & 17.807 & 0.9999 \\
\hline
\end{tabular}




\section{Análisis de azúcares: cromatografía líquida de alta resolución (HPLC)}

Los azúcares liberados a partir de la hidrólisis enzimática de la FG se analizaron mediante cromatografía líquida de alta resolución (HPLC). Se inyectaron $100 \mu \mathrm{l}$ de muestra en un equipo DIONEX consistente en una bomba P680A (Sunnyvale, CA, USA) conectado a un detector evaporativo de dispersión de luz modelo 200s ELSD (SofTA Corporation, USA). Para la separación se utilizó una columna Aminex HPX-87P (300 x 7.8 mm d.i.) manteniendo el horno a una temperatura constante de $60^{\circ} \mathrm{C}$. Como eluyente se utilizó agua miliQ con un flujo de $0.6 \mathrm{~mL} / \mathrm{min}$ en condiciones de elución isocráticas durante $25 \mathrm{~min}$.

La identificación de los monosacáridos detectados se realizó comparando sus tiempos de retención con los de sus estándares comerciales (Tabla 6).

Tabla 6. Estándares comerciales, curvas de calibrado, y $\mathrm{r}^{2}$ de las curvas de calibrado obtenidas para la cuantificación de los monosacáridos.

\begin{tabular}{lccccc}
\hline PRODUCTOS & & CASA COMERCIAL & & Ecuación de la curva de calibrado & $\mathrm{r}^{2}$ \\
\cline { 1 - 3 } \cline { 5 - 6 } D-Glucosa & & Panreac (Barcelona, Spain) & & $\log (\mathrm{y})=\log (1.4293) \mathrm{X}-0.6342$ & 0.9974 \\
D-Xilosa & & Sigma-Aldrich (St. Louis, MO) & & $\log (\mathrm{y})=\log (1.5453) \mathrm{X}-0.6669$ & 0.9995 \\
L-Ramnosa & & Sigma-Aldrich & & $\log (\mathrm{y})=\log (1.2806) \mathrm{X}-0.4334$ & 0.9932 \\
L-Arabinosa & & Sigma-Aldrich & & $\log (\mathrm{y})=\log (1.5798) \mathrm{X}-0.7303$ & 0.9998 \\
\hline
\end{tabular}

La cuantificación de los monosacáridos se llevó a cabo mediante curvas de calibrado que respondían a la ecuación:

$$
\log (y)=a+X \log (m)
$$

Donde "y" es el área cromatográfica, "X" es la concentración, y "a" y "m" son constantes.

Para obtener las curvas de calibrado se utilizó la misma metodología utilizada para el análisis de los azúcares liberados a partir de la hidrólisis enzimática de la FG, aplicada a muestras con concentraciones definidas de los respectivos estándares comerciales. En la Tabla 6 se indican los estándares comerciales empleados en las curvas de calibrado, las 
ecuaciones de las rectas obtenidas, y la bondad de ajuste del modelo utilizado $\left(r^{2}\right)$.

\section{Análisis estadístico}

Los efectos de las variables sobre los distintos datos analizados se evaluaron mediante análisis de la varianza (ANOVA) y la significación estadística se evaluó mediante el test $F$ de Snedecor. La significación estadística para la comparación viene dada por el valor de $p$. Las influencias de las variables se consideraron significativas a partir de $p<$ 0.05. Para comparar las medias de los distintos niveles se usó el Test de la Diferencia Honestamente Significativa (HSD) de Tukey. Todos los análisis estadísticos fueron realizados mediante el programa Statgraphics Plus $v$ 5.1 . 
RESULTADOS Y DISCUSIÓN 



\section{CAPÍTULO 1. CARACTERIZACIÓN DEL PERFIL AROMÁTICO DEL TOMATE}

El aroma es uno de los principales criterios a la hora de evaluar la calidad organoléptica del tomate (para revisión ver Baldwin et al., 2000). Aunque en la fracción volátil libre (FVL) del tomate se han identificado más de 400 compuestos volátiles (Pétro-Turza, 1987), se considera que sólo unos 16 ejercen una contribución relevante sobre el aroma final (Buttery, 1993). Al igual que en otros frutos, en las últimas décadas se ha confirmado la existencia de compuestos volátiles glicosilados, o aglicones, en tomate (Buttery et al., 1990a; Marlatt et al., 1992; Buttery, 1993). Estos precursores de compuestos volátiles se engloban en la fracción glicosilada (FG) y se revelan especialmente interesantes por constituir una potencial fuente para incrementar el aroma final del fruto o de sus derivados.

El primer objetivo de este trabajo se ha centrado en caracterizar los principales componentes de la FVL y de la FG de distintas variedades de tomate, prestando especial atención a los compuestos más relevantes, cuantitativa y cualitativamente, de acuerdo con la literatura, hallados en ambas fracciones, así como a su evolución a lo largo de la maduración del fruto.

\section{Caracterización de la fracción volátil del tomate}

La calidad organoléptica de las distintas variedades de tomate para consumo en fresco existentes en el mercado está sujeta a una gran variabilidad, ya sea a nivel del aroma, del sabor, de la textura, o del aspecto externo. La diversidad de componentes de la FVL entre diferentes variedades de tomate ha sido documentada en numerosos trabajos, pero existe muy poca información acerca de los aglicones que constituyen la FG. Seguidamente se presentan los resultados de analizar la composición de la fracción volátil, tanto libre como glicosilada, de 5 variedades eligiendo 
el estado de maduración denominado pintón $(P)$. Las variedades de tomate estudiadas fueron p73, Jorge, Durinta (cuyos resultados se describen en Ortiz-Serrano y Gil, 2007), Moneymaker (MM), y Raf (Figura 5).

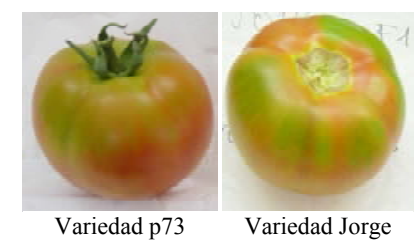

Variedad p73

Variedad Jorge

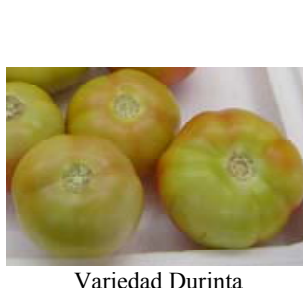

Variedad Durinta

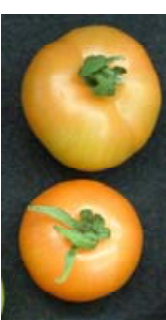

Variedad Moneymake

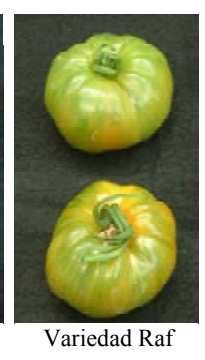

Variedad Raf

Figura 5. Frutos de las variedades de tomate estudiadas, p73, Jorge, Durinta, Moneymaker, y Raf, en el estado de maduración pintón.

\subsection{Fracción volátil libre}

La Figura 6 muestra un cromatograma tipo de la FVL del tomate obtenido por microextracción en fase sólida en espacio de cabeza acoplada a cromatografía de gases (HS-SPME-GC).

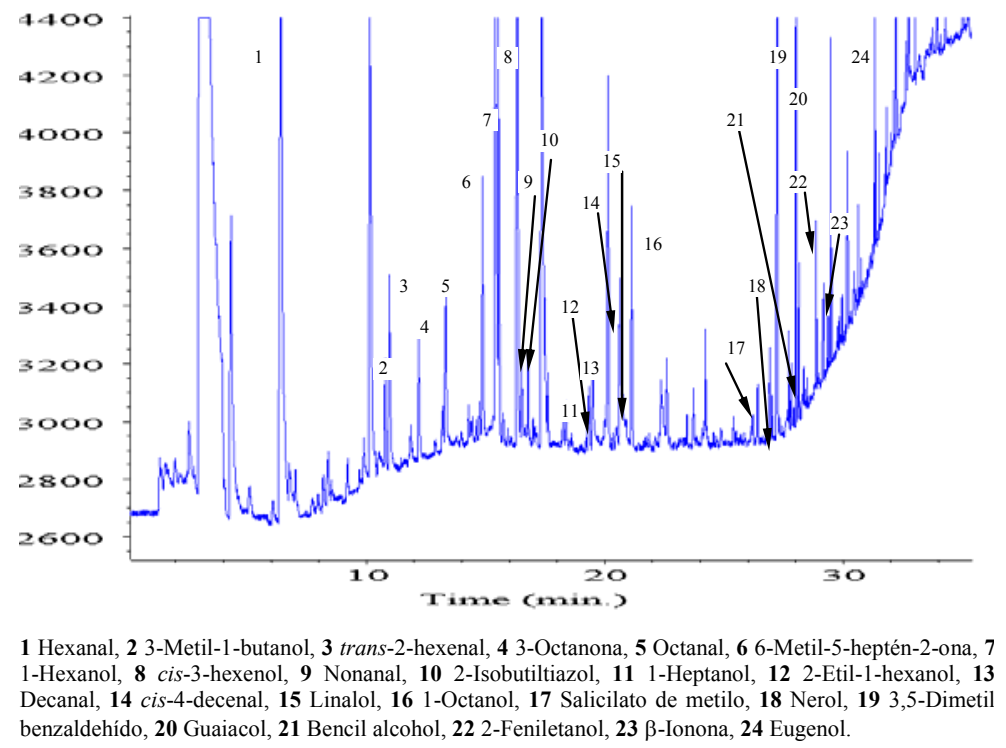

Figura 6. Cromatograma de gases (HS-SPME-GC) representativo de la fracción volátil libre del tomate obtenido a partir del zumo de la variedad $\mathrm{p} 73$. 
La Tabla 7 recoge las concentraciones de los 24 compuestos volátiles, por orden de elución cromatográfica, detectados en la FVL de las 5 variedades consideradas ( $\mathrm{p} 73$, Jorge, Durinta, MM, y Raf) así como las diferencias estadísticamente significativas entre ellas.

Tabla 7. Concentración $(\mu \mathrm{g} / \mathrm{L})$ de los compuestos volátiles identificados en la FVL de las variedades de tomate, p73, Jorge, Durinta, Moneymaker (MM), y Raf.

\begin{tabular}{lccccc}
\hline Compuestos FVL & p73 & Jorge & Durinta & MM & Raf \\
\hline Hexanal & $599.6 \mathrm{c}$ & $177.7 \mathrm{a}$ & $455.8 \mathrm{~b}$ & $826.6 \mathrm{~d}$ & $117.8 \mathrm{a}$ \\
3-Metil-1-butanol & $370.8 \mathrm{a}$ & $227.4 \mathrm{~b}$ & $437.4 \mathrm{a}$ & $1536 \mathrm{c}$ & $401.4 \mathrm{a}$ \\
trans-2-hexenal & $133.9 \mathrm{~b}$ & $59.16 \mathrm{a}$ & $75.70 \mathrm{ab}$ & $261.8 \mathrm{c}$ & $49.39 \mathrm{a}$ \\
3-Octanona & $1.561 \mathrm{~d}$ & $0.735 \mathrm{bc}$ & $0.847 \mathrm{c}$ & $0.398 \mathrm{a}$ & $0.542 \mathrm{ab}$ \\
Octanal & $5.435 \mathrm{c}$ & $1.245 \mathrm{a}$ & $2.155 \mathrm{ab}$ & $4.009 \mathrm{abc}$ & $4.575 \mathrm{bc}$ \\
6-Metil-5-heptén-2-ona & $20.65 \mathrm{~b}$ & $8.189 \mathrm{a}$ & $6.456 \mathrm{a}$ & $18.62 \mathrm{~b}$ & $9.439 \mathrm{a}$ \\
1-Hexanol & $966.4 \mathrm{c}$ & $789.7 \mathrm{bc}$ & $605.8 \mathrm{~b}$ & $245.1 \mathrm{a}$ & $184.3 \mathrm{a}$ \\
cis-3-hexenol & $3056 \mathrm{c}$ & $1931 \mathrm{~b}$ & $1603 \mathrm{~b}$ & $695.6 \mathrm{a}$ & $983.5 \mathrm{a}$ \\
Nonanal & $0.877 \mathrm{c}$ & $0.609 \mathrm{bc}$ & $0.413 \mathrm{ab}$ & $0.258 \mathrm{a}$ & $0.229 \mathrm{a}$ \\
2-Isobutiltiazol & $0.795 \mathrm{~d}$ & $0.572 \mathrm{c}$ & $0.433 \mathrm{~b}$ & $2.837 \mathrm{e}$ & $0.208 \mathrm{a}$ \\
1-Heptanol & $6.934 \mathrm{bc}$ & $3.562 \mathrm{a}$ & $\operatorname{tr}$ & $4.698 \mathrm{ab}$ & $8.655 \mathrm{c}$ \\
2-Etil-1-hexanol & $4.824 \mathrm{a}$ & $2.307 \mathrm{a}$ & $2.817 \mathrm{a}$ & $3.580 \mathrm{a}$ & $4.361 \mathrm{a}$ \\
Decanal & $0.425 \mathrm{~b}$ & $0.365 \mathrm{~b}$ & $0.278 \mathrm{ab}$ & $0.122 \mathrm{a}$ & $0.128 \mathrm{a}$ \\
cis-4-decenal & $0.986 \mathrm{c}$ & $0.128 \mathrm{a}$ & $0.362 \mathrm{~b}$ & $0.135 \mathrm{a}$ & $\operatorname{tr}$ \\
Linalol & $0.488 \mathrm{a}$ & $0.206 \mathrm{a}$ & $0.238 \mathrm{a}$ & $1.418 \mathrm{~b}$ & $2.055 \mathrm{~b}$ \\
1-Octanol & $11.41 \mathrm{c}$ & $4.427 \mathrm{~b}$ & $1.584 \mathrm{a}$ & $1.771 \mathrm{a}$ & $2.094 \mathrm{a}$ \\
Salicilato de metilo & $4.226 \mathrm{~b}$ & $3.449 \mathrm{ab}$ & $5.636 \mathrm{~b}$ & $1.662 \mathrm{a}$ & $1.883 \mathrm{a}$ \\
Nerol & $2.836 \mathrm{~b}$ & $1.229 \mathrm{a}$ & $0.857 \mathrm{a}$ & $1.650 \mathrm{a}$ & $1.586 \mathrm{a}$ \\
3,5-Dimetil benzaldehído & $8.011 \mathrm{c}$ & $3.723 \mathrm{~b}$ & $1.813 \mathrm{a}$ & $1.782 \mathrm{a}$ & $2.845 \mathrm{~b}$ \\
Guaiacol & $944.9 \mathrm{~b}$ & $521.9 \mathrm{ab}$ & $503.9 \mathrm{ab}$ & $550.9 \mathrm{ab}$ & $150.5 \mathrm{a}$ \\
Bencil alcohol & $537.9 \mathrm{a}$ & $153.4 \mathrm{a}$ & $128.8 \mathrm{a}$ & $416.6 \mathrm{a}$ & $296.8 \mathrm{a}$ \\
2-Feniletanol & $502.8 \mathrm{c}$ & $332.4 \mathrm{~b}$ & $263.8 \mathrm{~b}$ & $77.76 \mathrm{a}$ & $136.0 \mathrm{a}$ \\
3-Ionona & $1.346 \mathrm{~b}$ & $0.544 \mathrm{a}$ & $0.739 \mathrm{a}$ & $\operatorname{tr}$ & $\operatorname{tr}$ \\
Eugenol & $99.75 \mathrm{c}$ & $89.21 \mathrm{c}$ & $39.09 \mathrm{~b}$ & $175.5 \mathrm{~d}$ & $10.29 \mathrm{a}$ \\
\hline & & & & &
\end{tabular}

nd: compuesto no detectado; tr: concentración $<0.1 \mu \mathrm{g} / \mathrm{L}$.

Diferentes letras para cada compuesto indican diferencias significativas entre las variedades según el Test de Tukey's HSD aplicado con un intervalo de confianza del $95 \%$ a 3 repeticiones. La letra "a" se asigna a la menor concentración de un compuesto. 
Todos los compuestos detectados se encuentran entre los citados en la bibliografía como componentes del aroma del tomate (Buttery et al., 1990a; Marlatt et al., 1992; Buttery, 1993; Langlois et al., 1996; Krumbein y Auerswald, 1998; Baldwin et al., 2000). Se trata de aldehídos, cetonas, alcoholes, y terpenos. De los más de 400 compuestos volátiles identificados en el tomate y sus derivados (para revisión ver Servili et al., 2000), sólo unos 30 fueron destacados por Buttery (1993) por encontrarse a una concentración superior a $1 \mu \mathrm{g} / \mathrm{L}$ en el zumo de tomates con un cierto grado de madurez (Introducción, Tabla 1). La caracterización de la fracción volátil llevada a cabo en el presente estudio se centró en los componentes susceptibles de encontrarse en forma glicosilada y que, de acuerdo con la bibliografía, pudieran tener más influencia en la percepción del aroma del tomate. Únicamente 9 de los 24 compuestos identificados en la FVL fueron detectados a una concentración inferior a $1 \mu \mathrm{g} / \mathrm{L}$ en alguna de las 5 variedades analizadas. Estos compuestos fueron la 3-octanona, nonanal, 2-isobutiltiazol, 1-heptanol, decanal, cis-4-decenal, linalol, nerol, y $\beta$ ionona. Sólo la concentración de nonanal, decanal, y cis-4-decenal, fue inferior a $1 \mu \mathrm{g} / \mathrm{L}$ en todas las variedades analizadas. En la variedad Durinta, el 1-heptanol fue detectado a nivel de traza (concentración inferior a $0.1 \mu \mathrm{g} / \mathrm{L}$ ) y el nerol se encontró a una concentración inferior a $1 \mu \mathrm{g} / \mathrm{L}$. La concentración de linalol fue superior a $1 \mu \mathrm{g} / \mathrm{L}$ sólo en los variedades MM y Raf, la de 2-isobutiltiazol en MM y la de 3-octanona y $\beta$-ionona sólo en la variedad $p 73$. Además, en las variedades MM y Raf la $\beta$-ionona se detectó a nivel de traza. Entre los compuestos detectados a muy baja concentración cabe destacar que se encuentran linalol, nerol, 2isobutiltiazol, y $\beta$-ionona, compuestos que han sido descritos como especialmente interesantes en el aroma del tomate (para revisión ver Baldwin et al., 2000). Por otro lado, hexanal, 3-metil-1-butanol, 1-hexanol, cis-3-hexenol, guaiacol y bencil alcohol fueron los compuestos más abundantes en la FVL, detectados en las 5 variedades, a una 
concentración siempre superior a $100 \mu \mathrm{g} / \mathrm{L}$. Los 3 compuestos volátiles más abundantes en las variedades p73, Jorge, y Durinta fueron, de mayor a menor concentración, cis-3-hexenol, 1-hexanol, y guaiacol. En la variedad MM los compuestos más abundantes son, por orden de magnitud, 3-metil-1-butanol, hexanal, y cis-3-hexenol; y en la variedad Raf, cis-3hexenol, 3-metil-1-butanol y bencil alcohol. Además, las concentraciones de eugenol y trans-2-hexenal fueron prácticamente del orden de $100 \mu \mathrm{g} / \mathrm{L} \mathrm{o}$ superiores sólo en las variedades p73 y MM. Y la concentración de 2feniletanol fue inferior a $100 \mu \mathrm{g} / \mathrm{L}$ sólo en la variedad MM.

Los resultados del estudio comparativo entre las FVLs de las 5 variedades de tomate consideradas (Tabla 7), indican que sólo las concentraciones de 2-etil-1-hexanol y bencil alcohol no presentaron diferencias significativas entre ninguno de los 5 variedades analizadas. La mayor parte de las diferencias se centraron entre la variedad p73 y el resto de variedades. De los 24 compuestos identificados, 14 no mostraron diferencias significativas entre las variedades Jorge y Durinta, y 13 no lo hicieron entre las variedades MM y Raf. Sólo el 2-isobutiltiazol resultó significativamente diferente entre las 5 variedades.

El logaritmo de las unidades de olor (LogU) de un compuesto, es decir, el logaritmo de la relación entre su concentración en el fruto y su umbral de percepción en agua, se ha postulado como una herramienta útil para medir la contribución teórica individual de cada compuesto sobre el flavor final de un alimento (Buttery et al., 1971; Buttery, 1993; Buttery et al., 1995; Baldwin et al., 2000; Tandon et al., 2003; Bezman et al., 2003; Plotto et al., 2004; Ruíz et al., 2005; Pino y Mesa, 2006). En la Tabla 8 se muestran los LogU de todos los compuestos detectados en la FVL, exceptuando el cis-4-decenal y 3,5-dimetilbenzaldehído, calculados utilizando los umbrales de percepción en agua citados en la bibliografía (Buttery et al., 1971; Fazzalari, 1978; Buttery et al., 1988b; Buttery, 1993; Ohloff, 1994; Pino y Mesa, 2006). 
Tabla 8. LogU de los compuestos volátiles identificados en la FVL de las variedades de tomate p73, Jorge, Durinta, Moneymaker (MM), y Raf.

\begin{tabular}{|c|c|c|c|c|c|c|}
\hline \multirow{2}{*}{ Compuestos FVL } & \multirow{2}{*}{$U P^{(*)}$} & \multicolumn{5}{|c|}{ Variedades } \\
\hline & & p73 & Jorge & Durinta & MM & Raf \\
\hline Hexanal & $4.5^{(1)}$ & 2.125 & 1.597 & 2.006 & 2.264 & 1.418 \\
\hline 3-Metil-1-butanol & $250^{(1)}$ & 0.171 & -0.041 & 0.243 & 0.788 & 0.206 \\
\hline trans-2-hexenal & $17^{(2)}$ & 0.896 & 0.542 & 0.649 & 1.188 & 0.463 \\
\hline 3-Octanona & $28^{(3)}$ & -1.254 & -1.581 & -1.519 & -1.848 & -1.713 \\
\hline Octanal & $0.7^{(4)}$ & 0.890 & 0.250 & 0.488 & 0.758 & 0.815 \\
\hline 6-Metil-5-heptén-2-ona & $50^{(1)}$ & -0.384 & -0.786 & -0.889 & -0.429 & -0.724 \\
\hline 1-Hexanol & $500^{(1)}$ & 0.286 & 0.199 & 0.083 & -0.310 & -0.433 \\
\hline cis-3-hexenol & $70^{(2)}$ & 1.640 & 1.441 & 1.360 & 0.997 & 1.148 \\
\hline Nonanal & $1^{(3)}$ & -0.057 & -0.216 & -0.384 & -0.588 & -0.640 \\
\hline 2-Isobutiltiazol & $3.5^{(1)}$ & -0.644 & -0.786 & -0.907 & -0.091 & -1.226 \\
\hline 1-Heptanol & $425^{(4)}$ & -1.787 & -2.077 & 0.000 & -1.956 & -1.691 \\
\hline 2-Etil-1-hexanol & $270000^{(5)}$ & -4.748 & -5.068 & -4.982 & -4.877 & -4.792 \\
\hline Decanal & $0.1^{(3)}$ & 0.628 & 0.563 & 0.445 & 0.085 & 0.085 \\
\hline cis-4-decenal & - & & & & & \\
\hline Linalol & $6^{(1)}$ & -1.090 & -1.465 & -1.401 & -0.626 & -0.465 \\
\hline 1-Octanol & $110^{(1)}$ & -0.984 & -1.395 & -1.842 & -1.793 & -1.720 \\
\hline Salicilato de metilo & $40^{(1)}$ & -0.976 & -1.064 & -0.851 & -1.381 & -1.327 \\
\hline Nerol & $300^{(6)}$ & -2.024 & -2.387 & -2.544 & -2.260 & -2.277 \\
\hline 3,5-Dimetil benzaldehído & - & & & & & \\
\hline Guaiacol & $3^{(2)}$ & 2.498 & 2.240 & 2.225 & 2.264 & 1.700 \\
\hline Bencil alcohol & $10000^{(3)}$ & -1.269 & -1.814 & -1.890 & -1.380 & -1.527 \\
\hline 2-Fenil etanol & $1000^{(1)}$ & -0.299 & -0.478 & -0.579 & -1.109 & -0.866 \\
\hline$\beta$-Ionona & $4^{(1)}$ & -0.473 & -0.866 & -0.733 & nd & nd \\
\hline Eugenol & $6^{(2)}$ & 1.221 & 1.172 & 0.814 & 1.466 & 0.234 \\
\hline
\end{tabular}

UP: Umbral de percepción en agua ( $\left.\mu \mathrm{g} / \mathrm{L}) .{ }^{*}{ }^{*}\right)$ Referencia bibliográfica: Buttery, $1993^{(1)}$; Buttery et al., $1971^{(2)}$; Buttery et al., $1988^{(3)}$; Pino y Mesa, $2006^{(4)}$; Fazzalari, $1978^{(5)}$; Ohloff, $1994^{(6)}$. nd: compuesto no detectado

Se considera que valores de LogU positivos corresponden a compuestos que contribuyen de forma fundamental sobre el flavor final de un alimento mientras que aquellos con valores de LogU negativos serían muy poco influyentes en el aroma final (Buttery et al., 1988b). En la FVL de las 5 variedades analizadas, hexanal, trans-2-hexenal, octanal, cis-3hexenol, decanal, guaiacol, y eugenol mostraron LogU positivos. Los valores de LogU positivos más altos fueron alcanzados en las variedades MM y p73. EI LogU de 3-metil-1-butanol sólo fue negativo en la variedad 
Jorge y el de 1-hexanol en las variedades Raf y MM. Estos 9 compuestos serían los que, teóricamente, podrían influir de una forma más intensa en el aroma del tomate.

\subsection{Fracción volátil glicosilada}

Los componentes volátiles, o aglicones, de la FG, previamente obtenida por extracción en fase sólida del zumo limpio de las 5 variedades de tomate p73, Jorge, Durinta, MM, y Raf, se determinaron tras la hidrólisis enzimática de la misma con AR2000. En la Figura 7 se muestra un cromatograma tipo de la fracción glicosilada del tomate obtenido por microextracción en fase sólida en espacio de cabeza acoplada a cromatografía de gases (HS-SPME-GC).

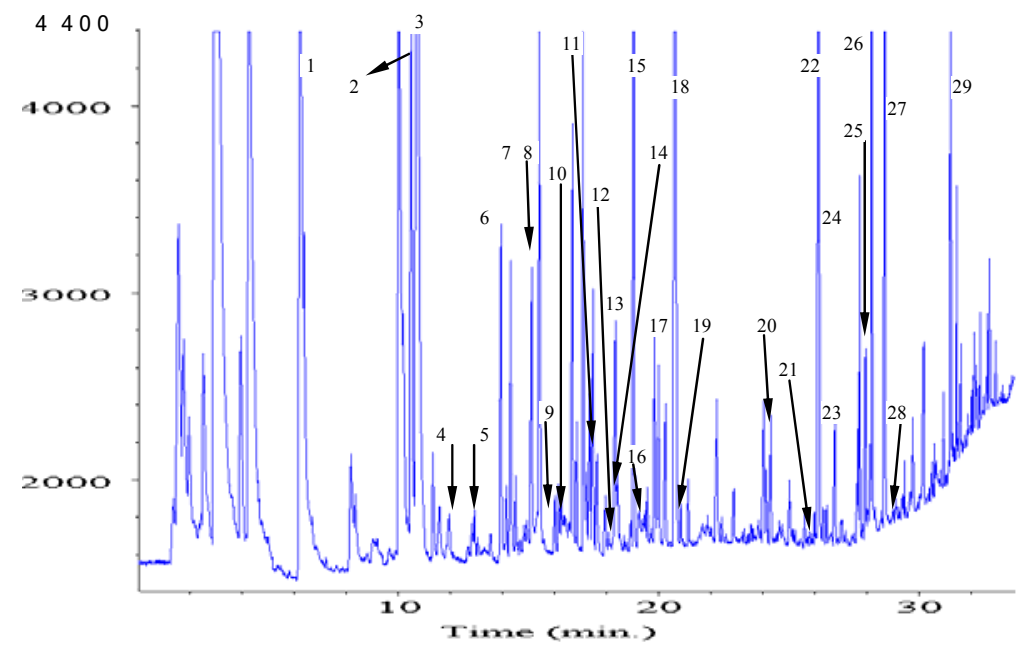

1 Hexanal, 2 3-Metil-1-butanol, 3 trans-2-hexenal, 4 3-Octanona, 5 Octanal, 6 4-Metil-1-pentanol, 73 Metil-1-pentanol, 8 1-Hexanol, 9 cis-3-hexenol, 10 Nonanal, 11 cis-óxido de linalol, 12 1-Heptanol, 13 6Metil-5-heptén-2-ol, 14 trans-óxido de linalol, 15 2-Etil-1-hexanol, 16 Decanal, 17 Benzaldehído, 18 Linalol, 19 1-Octanol, $20 \alpha$-Terpineol, $21 \beta$-Citronelol, 22 Salicilato de metilo, 23 Nerol, 24 Geraniol, 25

Guaiacol, 26 Bencil alcohol, 27 2-Feniletanol, 28 -Ionona, 29 Eugenol.

Figura 7. Cromatograma de gases (HS-SPME-GC) representativo de la fracción glicosilada del tomate, en este caso, previamente extraída de la variedad Raf, obtenido tras hidrólisis enzimática de la misma con AR2000.

Se detectaron y cuantificaron 32 aglicones volátiles entre las 5 variedades analizadas. Sus concentraciones, referidas al volumen de zumo de tomate, y las diferencias estadísticamente significativas de la 
comparación entre variedades se muestran en la Tabla 9, siguiendo su orden de elución cromatográfica.

Tabla 9. Concentración $(\mu \mathrm{g} / \mathrm{L})$ de los aglicones detectados tras la hidrólisis enzimática del extracto de glicósidos de las variedades de tomate p73, Jorge, Durinta, Moneymaker (MM), y Raf.

\begin{tabular}{|c|c|c|c|c|c|}
\hline \multirow{2}{*}{ Aglicones } & \multicolumn{5}{|c|}{ Variedades } \\
\hline & p73 & Jorge & Durinta & MM & Raf \\
\hline $\begin{array}{l}\text { Hexanal } \\
\text { 3-Metil-1-butanol }\end{array}$ & $\begin{array}{l}48.24 \mathrm{a} \\
324.3 \mathrm{ab}\end{array}$ & $\begin{array}{l}75.30 \mathrm{a} \\
335.5 \mathrm{bc}\end{array}$ & $\begin{array}{l}101.8 \mathrm{a} \\
483.2 \mathrm{~d}\end{array}$ & $\begin{array}{l}95.04 a \\
261.3 a\end{array}$ & $\begin{array}{l}70.11 \mathrm{a} \\
390.6 \mathrm{c}\end{array}$ \\
\hline $\begin{array}{l}\text { trans-2-hexenal } \\
\text { 3-Octanona }\end{array}$ & $\begin{array}{l}154.8 \mathrm{a} \\
\mathrm{nd}\end{array}$ & $\begin{array}{l}145.5 \mathrm{a} \\
\text { nd }\end{array}$ & $\begin{array}{l}168.8 \text { a } \\
\text { nd }\end{array}$ & $\begin{array}{l}1071 \mathrm{~b} \\
\mathrm{tr}\end{array}$ & $\begin{array}{l}741.5 \mathrm{~b} \\
\operatorname{tr}\end{array}$ \\
\hline Octanal & nd & nd & nd & $\operatorname{tr}$ & $\operatorname{tr}$ \\
\hline 4-Metil-1-pentanol & $0.169 \mathrm{a}$ & $0.257 \mathrm{a}$ & $0.219 \mathrm{a}$ & $0.269 \mathrm{~b}$ & $0.746 \mathrm{~b}$ \\
\hline 3-Metil-1-pentanol & $0.451 \mathrm{a}$ & $0.786 \mathrm{~b}$ & $0.502 \mathrm{a}$ & $1.939 \mathrm{~d}$ & $1.241 \mathrm{c}$ \\
\hline 1-Hexanol & $15.22 \mathrm{a}$ & $26.07 \mathrm{a}$ & $22.14 \mathrm{a}$ & $7.270 \mathrm{a}$ & $54.83 \mathrm{a}$ \\
\hline cis-3-hexenol & nd & nd & nd & $7.772 \mathrm{a}$ & $13.58 \mathrm{~b}$ \\
\hline Nonanal & nd & nd & nd & $\operatorname{tr}$ & $\operatorname{tr}$ \\
\hline 2-Isobutiltiazol & $\operatorname{tr}$ & $\operatorname{tr}$ & $\operatorname{tr}$ & $\operatorname{tr}$ & nd \\
\hline cis-óxido de linalol & $1.578 \mathrm{a}$ & $1.264 \mathrm{a}$ & $0.828 a$ & $16.36 \mathrm{~b}$ & $18.36 \mathrm{c}$ \\
\hline 1-Heptanol & $0.337 \mathrm{a}$ & $0.787 \mathrm{~b}$ & $0.863 b$ & $0.298 \mathrm{a}$ & $0.424 \mathrm{a}$ \\
\hline 6-Metil-5-heptén-2-ol & $\operatorname{tr}$ & $0.265 \mathrm{~b}$ & $0.119 \mathrm{a}$ & $0.132 \mathrm{a}$ & $0.163 \mathrm{a}$ \\
\hline trans-óxido de linalol & $5.165 b$ & nd & $0.573 a$ & $17.82 \mathrm{c}$ & $20.42 \mathrm{c}$ \\
\hline 2-Etil-1-hexanol & $4.084 \mathrm{a}$ & $5.764 a b$ & $6.800 a b$ & $8.222 b$ & $5.398 a b$ \\
\hline Decanal & nd & nd & nd & $\operatorname{tr}$ & $\operatorname{tr}$ \\
\hline cis-4-decenal & $\operatorname{tr}$ & $\operatorname{tr}$ & $\operatorname{tr}$ & nd & nd \\
\hline Benzaldehído & $33.54 b$ & $47.69 \mathrm{c}$ & $43.62 \mathrm{c}$ & $14.20 \mathrm{a}$ & $10.71 \mathrm{a}$ \\
\hline Linalol & 6.968 a & $5.869 \mathrm{a}$ & $3.712 \mathrm{a}$ & $39.48 b$ & $48.58 c$ \\
\hline 1-Octanol & $0.299 a b$ & $0.600 \mathrm{c}$ & $0.473 \mathrm{ac}$ & $0.232 b$ & $0.368 \mathrm{ab}$ \\
\hline$\alpha$-Terpineol & $1.943 \mathrm{~b}$ & $1.992 b$ & $1.061 \mathrm{a}$ & $3.064 \mathrm{c}$ & $5.383 d$ \\
\hline$\beta$-citronelol & $0.172 \mathrm{a}$ & $0.619 \mathrm{c}$ & $0.340 \mathrm{~b}$ & $0.154 \mathrm{a}$ & $0.171 \mathrm{a}$ \\
\hline Salicilato de metilo & $3.088 \mathrm{a}$ & $6.677 \mathrm{a}$ & $15.73 b$ & $4.363 a$ & $22.52 \mathrm{c}$ \\
\hline Nerol & $1.773 \mathrm{bc}$ & $2.045 \mathrm{c}$ & $1.499 a b$ & $1.560 \mathrm{ab}$ & $1.244 \mathrm{a}$ \\
\hline Geraniol & $2.216 \mathrm{~b}$ & $2.016 \mathrm{~b}$ & $1.223 \mathrm{a}$ & $3.331 \mathrm{c}$ & $3.944 \mathrm{~d}$ \\
\hline Guaiacol & $70.55 b$ & $102.8 \mathrm{c}$ & $113.5 \mathrm{c}$ & $25.31 \mathrm{a}$ & $47.16 \mathrm{a}$ \\
\hline Bencil alcohol & $533.8 \mathrm{a}$ & $810.1 \mathrm{bc}$ & $930.1 \mathrm{~cd}$ & $683.1 \mathrm{ab}$ & $1087 \mathrm{~d}$ \\
\hline 2-Feniletanol & $582.7 \mathrm{c}$ & $714.5 \mathrm{~d}$ & $694.3 \mathrm{~d}$ & $260.9 a$ & $403.7 b$ \\
\hline $\begin{array}{l}\beta \text {-lonona } \\
\text { Eugenol }\end{array}$ & $\begin{array}{l}\text { nd } \\
58.31 \mathrm{a}\end{array}$ & $\begin{array}{l}\text { nd } \\
188.6 \mathrm{~b}\end{array}$ & $\begin{array}{l}\text { nd } \\
81.02 \mathrm{a}\end{array}$ & $\begin{array}{l}\operatorname{tr} \\
75.49 a\end{array}$ & $\begin{array}{l}\operatorname{tr} \\
189.6 \mathrm{~b}\end{array}$ \\
\hline 2-Metoxi-4-vinilfenol & $1.023 b$ & $0.465 a$ & $1.317 \mathrm{~b}$ & nd & nd \\
\hline
\end{tabular}

nd: compuesto no detectado; tr: concentración $<0.1 \mu \mathrm{g} / \mathrm{L}$.

Diferentes letras para cada compuesto indican diferencias significativas entre las variedades según el Test de Tukey's HSD aplicado con un intervalo de confianza del $95 \%$ a 3 repeticiones. La letra "a" se asigna a la menor concentración de un compuesto. 
Todos los componente de la FVL se detectaron en forma glicosilada, excepto la 6-metil-5-heptén-2-ona y el 3,5-dimetil benzaldehído. Además, en la FG se detectaron 10 compuestos que no habían sido detectados en forma libre. Estos 10 compuestos volátiles se han descrito previamente como componentes de la FG del tomate (Buttery et al., 1990a; Marlatt et al., 1992). Se trata del 4-metil-1-pentanol, 3-metil-1-pentanol, cis-óxido de linalol, 6-metil-5-heptén-2-ol, trans-óxido de linalol, benzaldehído, $\alpha$ terpineol, $\beta$-citronelol, geraniol, y 2-metoxi-4-vinilfenol. El hecho de que estos 10 compuestos hayan sido detectados sólo en forma glicosilada los hace especialmente interesantes, ya que su potencial liberación podría implicar un cambio cualitativo de la FVL del tomate. Entre ellos destacan el benzaldehído y los terpenoles cis-óxido de linalol, trans-óxido de linalol, $\alpha$ terpineol, $\beta$-citronelol, y geraniol, por estar asociados a notas florales y frutales (Marais, 1983; Knudsen et al., 1993; Krumbein y Auerswald, 1998; Burdock, 2002; Baldwin et al., 2004; Lewinsohn et al., 2005b). Únicamente el $\beta$-citronelol se encontró a una concentración inferior a $1 \mu \mathrm{g} / \mathrm{L}$ en todas las variedades analizadas. Otros aglicones presentes a una concentración inferior a $1 \mu \mathrm{g} / \mathrm{L}$ en las 5 variedades fueron 4-metil-1-pentanol, 1-heptanol, 6-metil-5-heptén-2-ol, y 1-octanol, además de los cis- y trans-óxidos de linalol en la variedad Durinta, el 3-metil-1-pentanol en las variedades p73, Jorge, y Durinta, y el 2-metoxi-4-vinilfenol en las variedades Jorge, MM y Raf. Los compuestos 2-isobutiltiazol, 3-octanona, octanal, nonanal, decanal, $\beta$-lonona, y cis-4-decenal o no fueron detectados o tan sólo a nivel de trazas (concentración inferior a $0.1 \mu \mathrm{g} / \mathrm{L}$ ).

Los aglicones más abundantes en la FG en las 5 variedades analizadas, fueron 3-metil-1-butanol, trans-2-hexenal, bencil alcohol, y 2feniletanol, cuyas concentraciones superaron los $100 \mu \mathrm{g} / \mathrm{L}$. La concentración de hexanal fue superior a $100 \mu \mathrm{g} / \mathrm{L}$ sólo en la variedad Durinta, la de guaiacol en las variedades Jorge y Durinta, y la de eugenol en las variedades Jorge y Raf. 
Por otro lado, de los 32 aglicones identificados en la FG sólo las concentraciones de hexanal y 1-hexanol no mostraron diferencias significativas entre las 5 variedades analizadas (Tabla 9). Estos resultados ponen de manifiesto la gran variabilidad que existe entre las concentraciones de los compuestos glicosilados de las 5 variedades consideradas. Los compuestos 1-heptanol, 2-etil-1-hexanol, 1-octanol, salicilato de metilo, guaiacol, y 2-metoxi-4-vinilfenol se han descrito como parte de la FG del tomate por primera vez en el presente trabajo.

\subsection{Potencial aromático de la fracción glicosilada}

Los compuestos volátiles glicosilados suponen una fuente potencial para incrementar el aroma en la medida en que los enlaces glicosídicos sean hidrolizados y los correspondientes aglicones liberados. Cuanto mayor sea la proporción de un determinado aglicón con respecto a su concentración en forma libre mayor podrá ser el impacto que sobre el aroma final tenga su liberación. En la Figura 8 se muestran los 9 compuestos cuyas concentraciones fueron mayores en la FG que en la FVL en al menos una de las 5 variedades y la razón entre ambas concentraciones. La concentración en forma libre de estos compuestos puede incrementarse entre un $20 \%$ y $2800 \%$, en función del compuesto y de la variedad considerados. El linalol, especialmente interesante por su repercusión organoléptica (Buttery et al., 1971; Buttery et al., 1990b), fue el compuesto con mayor potencial para aumentar su concentración en forma libre, entre un $1400 \%$ y un $2800 \%$ en función de la variedad. La concentración en forma libre de trans-2-hexenal, salicilato de metilo, y eugenol en la variedad Raf puede aumentar un $1500 \%, 1200 \%$, y 1840 $\%$, respectivamente, mientras que para el resto de variedades este aumento osciló entre un $40 \%$ y un $410 \%$. Así pues, es la variedad Raf la que presenta un mayor potencial teórico para incrementar estos compuestos en la FVL, y es también la variedad con mayor contenido en 
linalol tanto en forma libre como glicosilada. El 3-metil-1-butanol y el nerol pueden aumentar su concentración en la FVL entre un $20 \%$ y un $170 \%$ dependiendo de la variedad, el 2-etil-1-hexanol podría hacerlo entre un 80 $\%$ y un $250 \%$, el bencil alcohol entre un $100 \%$ en la variedad p73 hasta un $720 \%$ en la variedad Durinta, y el 2-feniletanol entre $120 \%$ en la variedad p73 y un $330 \%$ en la variedad MM.
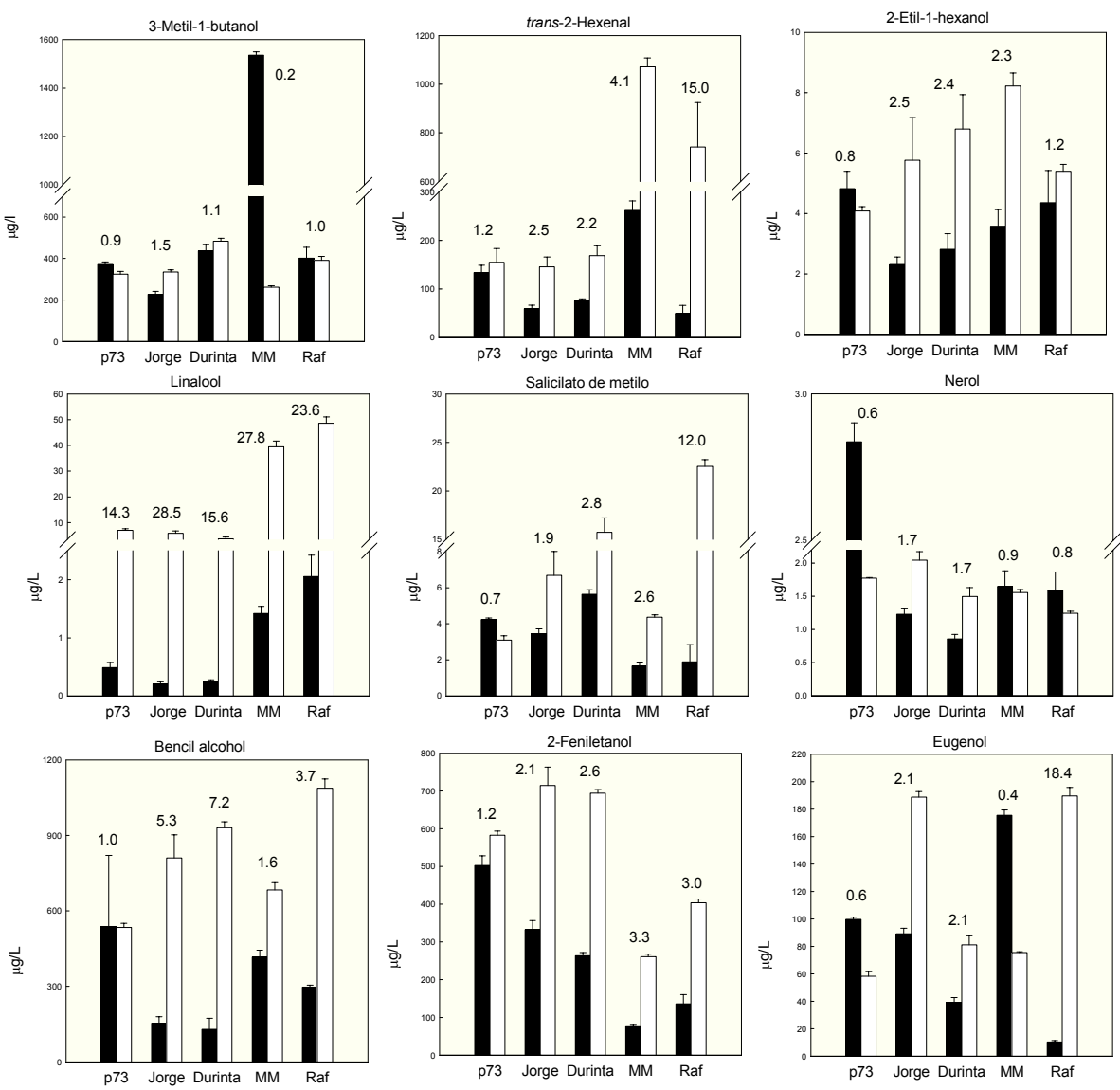

Figura 8. Concentración en forma libre (barras en negro) y en forma glicosilada (barras en blanco), expresada como la media \pm error estándar de 3 repeticiones, en las variedades p73, Jorge, Durinta, Moneymaker (MM) y Raf. Los valores numéricos señalados corresponden a la razón entre la concentración en forma glicosilada y libre, para cada compuesto y variedad.

El potencial del resto de compuestos de la FG no mostrados en la Figura 8 es inferior puesto que su concentración en forma libre (Tabla 7) es 
superior a su concentración en forma glicosilada (Tabla 9). Por ejemplo, la cantidad de 1-hexanol glicosilado representa el $2 \%$ del libre en la variedad p73 y llega al $30 \%$ en la variedad Raf.

En función de la variedad considerada, el abanico de aumentos potenciales de los 9 compuestos volátiles representados en la Figura 8 en forma libre es amplio, siendo en la variedad p73 en la que los posibles aumentos podrían ser menores.

\section{Influencia del estado de maduración en el perfil aromático}

La maduración de los frutos es un fenómeno que se caracteriza por cambios en la textura, el color, y el flavor (para revisión ver White, 2002). El estado de maduración del fruto en el momento de la recolección condiciona enormemente la calidad final del tomate (Kader et al., 1977; Watada y Aulenbach, 1979; Stern et al., 1994; Maul et al., 1998). Tras la caracterización de la fracción volátil de 5 variedades de tomate, se escogieron las 2 variedades con mayor importancia económica en el mercado, Moneymaker (MM) y Raf, para profundizar en el estudio de la evolución de los compuestos volátiles libres y glicosilados durante la maduración del fruto (Figura 9).

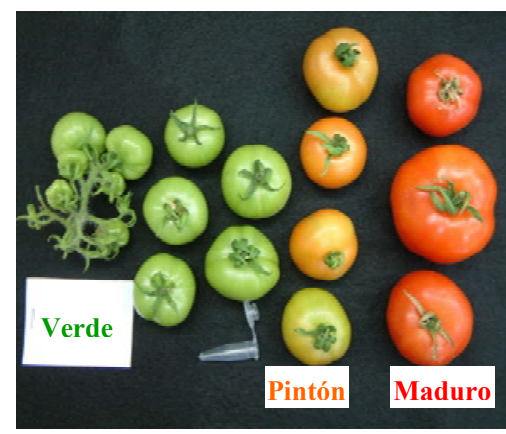

Variedad Moneymaker

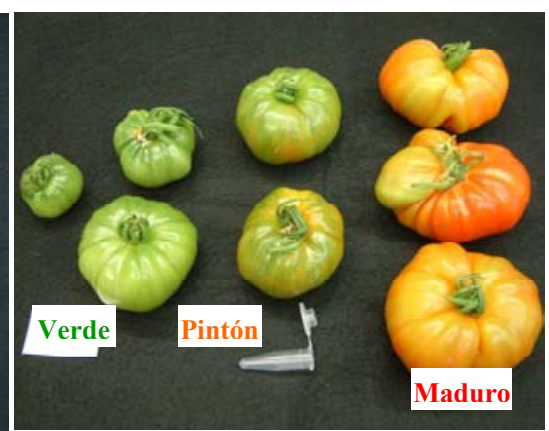

Variedad Raf

Figura 9. Frutos de las variedades Moneymaker y Raf en los 3 estados de maduración considerados, V, P, y M.

Se consideraron 3 estados de maduración, en base a la pigmentación externa del fruto, representativos de un momento temprano 
del proceso, verde $(\mathrm{V})$, del momento de cambio de color o pintón $(\mathrm{P})$, y de un estado final maduro (M), caracterizado por haberse alcanzado plenamente la pigmentación rojiza (Raf) o roja intensa (MM) de la piel.

\subsection{Fracción volátil libre}

La Tabla 10 muestra las concentraciones de los 24 compuestos volátiles, por orden de elución cromatográfica, detectados en la FVL de las variedades MM y Raf en los estados de maduración V, P, y M. En ella se recogen también las diferencias estadísticamente significativas encontradas a lo largo de la maduración en cada una de las variedades. Sólo nonanal, decanal, y cis-4-decenal fueron detectados, en la FVL de ambas variedades, a una concentración inferior a $1 \mu \mathrm{g} / \mathrm{L}$ en los 3 estados de maduración considerados. Además, la concentración de la 3-octanona y de la $\beta$-ionona fue superior a $1 \mu \mathrm{g} / \mathrm{L}$ únicamente en el estado $\mathrm{M}$ de la variedad Raf y de la las variedades Raf y MM, respectivamente. La concentración del 2-isobutiltiazol fue superior a $1 \mu \mathrm{g} / \mathrm{L}$ únicamente en los estados $\mathrm{P}$ y $\mathrm{M}$ de la variedad $\mathrm{MM}$, y sólo en el estado $\mathrm{M}$ de la variedad Raf. Por otro lado, el 3-metil-1-butanol no se detectó en el estado de maduración $\mathrm{V}$ de ambas variedades.

De acuerdo con el análisis estadístico (Tabla 10) se desprende que sólo la concentración de nerol y decanal permaneció sin cambio significativo durante la maduración en ambas variedades Tampoco se registró variación significativa para nonanal, salicilato de metilo, y 2feniletanol en la variedad MM, y para 1-octanal, 2-etil-1-hexanol, y 3,5dimetil benzaldehído en la variedad Raf. El resto de los 24 compuestos identificados en la FVL sí experimentó cambios significativos en sus concentraciones durante el proceso de maduración del fruto.

La tendencia general de los compuestos volátiles durante la maduración de los frutos fue a aumentar su concentración en ambas variedades, alcanzando su máximo nivel en el estado $M$, lo que está de 
acuerdo con otros trabajos previos realizados con otras variedades (Baldwin et al., 1991b; Buttery, 1993; Tieman et al., 2006).

Tabla 10. Concentración ( $\mu \mathrm{g} / \mathrm{L})$ de los compuestos volátiles identificados en la FVL de las variedades $\mathrm{MM}$ y Raf en los estados $\mathrm{V}, \mathrm{P}$ y $\mathrm{M}$.

\begin{tabular}{|c|c|c|c|c|c|c|}
\hline \multirow{2}{*}{ Compuestos FVL } & \multicolumn{3}{|c|}{ MM } & \multicolumn{3}{|c|}{ Raf } \\
\hline & Verde & Pintón & Maduro & Verde & Pintón & Maduro \\
\hline Hexanal & $194.6 \mathrm{a}$ & $826.6 \mathrm{~b}$ & $1827 \mathrm{c}$ & $255.9 \mathrm{~b}$ & $117.8 \mathrm{a}$ & $2679 \mathrm{c}$ \\
\hline 3-Metil-1-butanol & nd & $1536 \mathrm{~b}$ & $623.6 \mathrm{a}$ & nd & $401.4 \mathrm{a}$ & 596.8 a \\
\hline trans-2-hexenal & $252.4 \mathrm{~b}$ & $261.8 b$ & $122.4 \mathrm{a}$ & $253.6 \mathrm{c}$ & 49.39 a & $152.0 \mathrm{~b}$ \\
\hline 3-Octanona & $0.208 a$ & $0.398 \mathrm{a}$ & $0.841 \mathrm{~b}$ & $0.351 \mathrm{a}$ & $0.542 \mathrm{a}$ & $1.140 \mathrm{~b}$ \\
\hline Octanal & $3.365 b$ & $4.009 \mathrm{c}$ & $2.733 \mathrm{a}$ & $3.632 \mathrm{a}$ & $4.575 \mathrm{a}$ & $2.732 \mathrm{a}$ \\
\hline 6-Metil-5-heptén-2-ona & $1.570 \mathrm{a}$ & $18.62 b$ & $121.2 \mathrm{c}$ & $1.648 \mathrm{a}$ & $9.439 \mathrm{~b}$ & $160.7 \mathrm{c}$ \\
\hline 1-Hexanol & $35.79 \mathrm{a}$ & $245.1 \mathrm{~b}$ & $3735 \mathrm{c}$ & $55.80 \mathrm{a}$ & $184.3 \mathrm{~b}$ & $2359 \mathrm{c}$ \\
\hline cis-3-hexenol & $88.86 \mathrm{a}$ & $695.6 \mathrm{~b}$ & $3121 \mathrm{c}$ & $192.7 \mathrm{a}$ & $983.5 \mathrm{~b}$ & $2817 \mathrm{c}$ \\
\hline Nona & $0.295 \mathrm{a}$ & $0.258 \mathrm{a}$ & $0.532 \mathrm{a}$ & $0.198 \mathrm{a}$ & $0.229 \mathrm{a}$ & $0.686 \mathrm{~b}$ \\
\hline 2-Isobutiltiazol & $0.186 \mathrm{a}$ & $2.837 \mathrm{~b}$ & $11.99 \mathrm{c}$ & $0.202 \mathrm{a}$ & $0.208 \mathrm{a}$ & $2.114 b$ \\
\hline 1-Heptanol & $7.571 \mathrm{ab}$ & $4.698 \mathrm{a}$ & $9.254 \mathrm{~b}$ & $24.20 \mathrm{~b}$ & $8.655 \mathrm{a}$ & $26.12 b$ \\
\hline 2-Etil-1-hexanol & $15.57 \mathrm{~b}$ & $3.580 \mathrm{a}$ & $7.517 \mathrm{ab}$ & $3.889 a$ & $4.361 \mathrm{a}$ & $4.343 \mathrm{a}$ \\
\hline Decanal & $\operatorname{tr}$ & $0.122 \mathrm{a}$ & $0.272 \mathrm{a}$ & $0.161 \mathrm{a}$ & $0.128 a$ & $0.278 a$ \\
\hline cis-4-decenal & $\operatorname{tr}$ & $0.135 \mathrm{a}$ & $0.353 \mathrm{~b}$ & $0.117 \mathrm{a}$ & $0.093 a$ & $0.228 \mathrm{~b}$ \\
\hline Linalol & $1.088 \mathrm{a}$ & $1.418 a b$ & $1.595 \mathrm{~b}$ & $1.200 \mathrm{a}$ & $2.055 \mathrm{ab}$ & $2.603 \mathrm{~b}$ \\
\hline 1-Octanol & $2.411 \mathrm{a}$ & $1.771 \mathrm{a}$ & $5.840 \mathrm{~b}$ & $1.362 \mathrm{a}$ & $2.094 \mathrm{a}$ & $6.911 b$ \\
\hline Salicilato de metilo & $1.756 \mathrm{a}$ & $1.662 \mathrm{a}$ & $1.252 \mathrm{a}$ & $181.9 \mathrm{~b}$ & $1.883 \mathrm{a}$ & nd \\
\hline Nerol & $1.753 \mathrm{a}$ & $1.650 \mathrm{a}$ & $2.025 \mathrm{a}$ & $1.616 \mathrm{a}$ & $1.586 \mathrm{a}$ & $1.803 \mathrm{a}$ \\
\hline 3,5-Dimetil benzaldehído & $1.422 \mathrm{a}$ & $1.782 \mathrm{~b}$ & $3.418 \mathrm{c}$ & $3.878 \mathrm{a}$ & $2.845 \mathrm{a}$ & $2.536 \mathrm{a}$ \\
\hline Guaiacol & $125.2 \mathrm{a}$ & $550.9 \mathrm{~b}$ & $3240 \mathrm{c}$ & 250.7 a & $150.5 \mathrm{a}$ & $4712 \mathrm{~b}$ \\
\hline Bencil alcohol & $263.2 \mathrm{a}$ & $416.6 \mathrm{~b}$ & 291.9 a & $323.6 \mathrm{ab}$ & $296.8 \mathrm{a}$ & $505.1 \mathrm{~b}$ \\
\hline 2-Feniletanol & $71.22 \mathrm{a}$ & $77.76 \mathrm{a}$ & $67.00 \mathrm{a}$ & $116.0 \mathrm{a}$ & $136.0 \mathrm{a}$ & $280.0 \mathrm{~b}$ \\
\hline$\beta$-Ionona & $\operatorname{tr}$ & $\operatorname{tr}$ & 2.003 & $\operatorname{tr}$ & $\operatorname{tr}$ & 2.190 \\
\hline Eugenol & $12.35 \mathrm{a}$ & $175.5 \mathrm{~b}$ & $305.4 \mathrm{c}$ & $6.811 \mathrm{a}$ & $10.29 a$ & $25.50 \mathrm{~b}$ \\
\hline
\end{tabular}

nd: compuesto no detectado.

Diferentes letras para cada compuesto indican diferencias significativas entre los 3 estados de maduración considerados para cada variedad según el Test de Tukey's HSD aplicado con un intervalo de confianza del $95 \%$ a 3 repeticiones. La letra "a" se asigna a la menor concentración de un compuesto. En negrita se resaltan los compuestos que forman parte de la combinación que reproduce el aroma de tomate maduro troceado propuesta por Buttery (1993).

Las concentraciones de 16 compuestos experimentaron aumentos a lo largo de la maduración de acuerdo con el siguiente patrón. Hexanal, 6- 
metil-5-heptén-2-ona, 1-hexanol, cis-3-hexenol, 2-isobutiltiazol, guaiacol, y eugenol experimentaron grandes aumentos durante la maduración, entre un $1000 \%$ y un $10000 \%$, en ambas variedades. Las concentraciones de 3-octanona, 1-heptanol, cis-4-decenal, linalol, y 1-octanol también aumentaron con la maduración en ambas variedades, si bien la magnitud de estos aumentos fue menor. Otros compuestos volátiles, nonanal, bencil alcohol, y 2-feniletanol, aumentaron conforme avanzaba el proceso de maduración sólo en la variedad Raf, y el 3,5-dimetil benzaldehído lo hizo sólo en la variedad MM. Las tendencias al aumento en las concentraciones de estos 16 compuestos no sólo variaron en su magnitud sino también en su forma. Algunos compuestos volátiles experimentaron aumentos estadísticamente significativos al cambiar del estado $\mathrm{V}$ al $\mathrm{P}$, o al cambiar del $\mathrm{P}$ al $\mathrm{M}$. Otros como el hexanal en la variedad Raf y el 1-heptanol en ambas variedades disminuyeron al pasar del $\mathrm{V}$ al $\mathrm{P}$. Aunque todos alcanzaron su máxima concentración en el estado M. Los compuestos 3metil-1-butanol, octanal, y bencil alcohol en la variedad MM alcanzaron su máxima concentración en el estado $\mathrm{P}$. Estos 3 compuestos aumentaron significativamente entre el estado $\mathrm{V}$ y el $\mathrm{P}$, pero su concentración disminuyó significativamente en el estado $\mathrm{M}$.

Otros compuestos volátiles tendieron a disminuir conforme avanzaba la maduración, mostrando su máxima concentración en el estado de maduración V. Estos compuestos fueron el trans-2-hexenal y salicilato de metilo en ambas variedades, y 2-etil-1-hexanol en la variedad MM. Por otro lado, la concentración de salicilato de metilo sólo disminuyó significativamente en la variedad Raf, y lo hizo hasta llegar a no ser detectado en el estado $\mathrm{M}$.

Buttery (1993) propuso una combinación de 10 compuestos que, a las concentraciones adecuadas (Introducción, Tabla 1), reproduce de forma aproximada el aroma del tomate maduro troceado. La Figura 10 
representa la suma de las concentraciones ponderadas, respecto al estado de maduración $\mathrm{V}$, de 7 de estos 10 compuestos identificados en las variedades MM y Raf, y las diferencias estadísticamente significativas entre los 3 estados de maduración considerados para cada variedad.

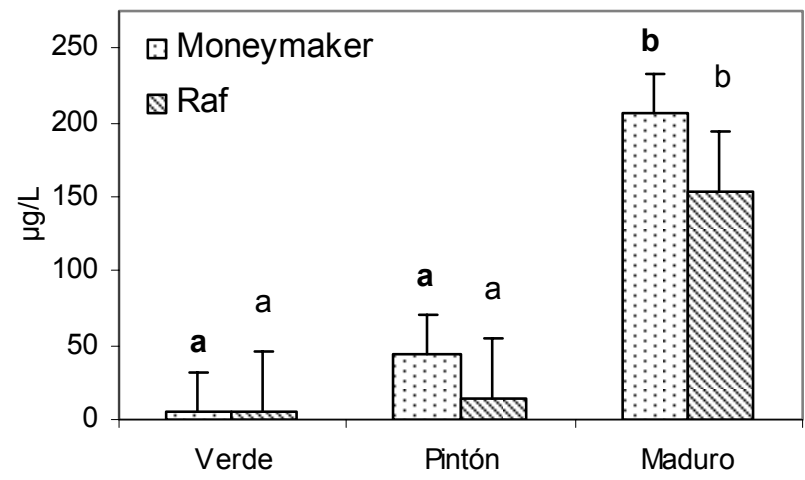

Figura 10. Suma ponderada de las concentraciones de 7 de los 10 compuestos cuya mezcla reproduce el aroma del tomate fresco maduro. Diferentes letras indican diferencias significativas entre los 3 estados de maduración considerados para cada variedad según el Test de Tukey's HSD aplicado con un intervalo de confianza del 95\% a 3 repeticiones.

Esos 7 compuestos fueron el hexanal, trans-2-hexenal, 6-metil-5heptén-2-ona, cis-3-hexenol, 2-isobutiltiazol, salicilato de metilo, y $\beta$ ionona. El aumento relativo de estos 7 compuestos volátiles en el estado de maduración $\mathrm{M}$ fue significativamente superior al obtenido en los otros 2 estados de maduración, $\mathrm{V}$ y $\mathrm{P}$, entre los cuales, además, no aparecieron diferencias significativas. Estos resultados apoyan la aproximación al aroma típico del tomate maduro troceado propuesta por Buttery (1993).

En la Tabla 11 se presentan los LogU de todos los componentes detectados en la FVL de las variedades MM y Raf calculados utilizando los umbrales de percepción en agua citados en la bibliografía. Como ya se comentó anteriormente, se considera que valores de LogU positivos corresponden a compuestos que contribuyen de forma fundamental al flavor final de un alimento mientras que aquellos con valores de LogU negativos lo harían de manera más sutil. Los compuestos hexanal, trans-2- 
hexenal, octanal, cis-3-hexenol, guaiacol, y eugenol obtuvieron valores de LogU positivos en los 3 estados de maduración y para las 2 variedades analizadas, al igual que 3-metil-1-butanol, si exceptuamos el estado de maduración $\mathrm{V}$, en el que no fue detectado. El decanal también mostró valores de LogU positivos en la variedad Raf en los 3 estados de maduración considerados.

Tabla 11. LogU de los compuestos volátiles identificados en la FVL de las variedades MM y Raf, en los estados de maduración $\mathrm{V}, \mathrm{P}, \mathrm{y} \mathrm{M}$.

\begin{tabular}{|c|c|c|c|c|c|c|c|}
\hline \multirow{2}{*}{ Compuestos FVL } & \multirow{2}{*}{$\mathrm{UP}^{(*)}$} & \multicolumn{3}{|c|}{ MM } & \multicolumn{3}{|c|}{ Raf } \\
\hline & & Verde & Pintón & Maduro & Verde & Pintón & Maduro \\
\hline Hexanal & $4.5^{(1)}$ & 1.636 & 2.264 & 2.609 & 1.755 & 1.418 & 2.775 \\
\hline 3-Metil-1-butanol & $250^{(1)}$ & nd & 0.788 & 0.397 & nd & 0.206 & 0.378 \\
\hline trans-2-hexenal & $17^{(2)}$ & 1.172 & 1.188 & 0.857 & 1.174 & 0.463 & 0.951 \\
\hline 3-Octanona & $28^{(3)}$ & -2.129 & -1.848 & -1.522 & -1.902 & -1.713 & -1.390 \\
\hline Octanal & $0.7^{(4)}$ & 0.682 & 0.758 & 0.592 & 0.715 & 0.815 & 0.591 \\
\hline 6-Metil-5-heptén-2-ona & $50^{(1)}$ & -1.503 & -0.429 & 0.385 & -1.482 & -0.724 & 0.507 \\
\hline 1-Hexanol & $500^{(1)}$ & -1.145 & -0.310 & 0.873 & -0.952 & -0.433 & 0.674 \\
\hline cis-3-hexenol & $70^{(2)}$ & 0.104 & 0.997 & 1.649 & 0.440 & 1.148 & 1.605 \\
\hline Nonanal & $1^{(3)}$ & -0.530 & -0.588 & -0.274 & -0.703 & -0.640 & -0.163 \\
\hline 2-Isobutiltiazol & $3.5^{(1)}$ & -1.275 & -0.091 & 0.535 & -1.238 & -1.226 & -0.219 \\
\hline 1-Heptanol & $425^{(4)}$ & -1.749 & -1.956 & -1.662 & -1.245 & -1.691 & -1.211 \\
\hline 2-Etil-1-hexanol & $270000^{(5)}$ & -4.239 & -4.878 & -4.555 & -4.842 & -4.792 & -4.794 \\
\hline Decanal & $0.1^{(3)}$ & -0.283 & 0.086 & 0.434 & 0.208 & 0.085 & 0.444 \\
\hline cis-4-decenal & - & & & & & & \\
\hline Linalol & $6^{(1)}$ & -0.741 & -0.627 & -0.576 & -0.699 & -0.465 & -0.363 \\
\hline 1-Octanol & $110^{(1)}$ & -1.659 & -1.793 & -1.275 & -1.907 & -1.720 & -1.202 \\
\hline Salicilato de metilo & $40^{(1)}$ & -1.357 & -1.381 & -1.504 & 0.658 & -1.327 & $\operatorname{tr}$ \\
\hline Nerol & $300^{(6)}$ & -2.233 & -2.260 & -2.171 & -2.269 & -2.277 & -2.221 \\
\hline 3,5-Dimetil benzaldehído & - & & & & & & \\
\hline Guaiacol & $3^{(2)}$ & 1.620 & 2.264 & 3.033 & 1.922 & 1.700 & 3.196 \\
\hline Bencil alcohol & $10000^{(3)}$ & -1.580 & -1.380 & -1.535 & -1.490 & -1.527 & -1.297 \\
\hline 2-Feniletanol & $1000^{(1)}$ & -1.147 & -1.109 & -1.174 & -0.935 & -0.866 & -0.553 \\
\hline$\beta$-Ionona & $4^{(1)}$ & $\operatorname{tr}$ & $\operatorname{tr}$ & -0.300 & $\operatorname{tr}$ & $\operatorname{tr}$ & -0.262 \\
\hline Eugenol & $6^{(2)}$ & 0.314 & 1.466 & 1.707 & 0.055 & 0.234 & 0.628 \\
\hline
\end{tabular}

UP: Umbral de percepción de cada compuesto en agua $\left.(\mu \mathrm{g} / \mathrm{L}) .{ }^{*}\right)$ Referencia bibliográfica:

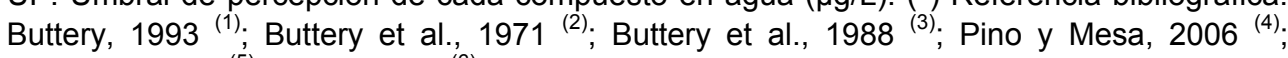
Fazzalari, $1978^{(5)}$; Ohloff, $1994^{\left({ }^{(6)}\right.}$. nd: compuesto no detectado

Especialmente significativo fue el cambio de signo del LogU de 6metil-5-heptén-2-ona y 1-hexanol en ambas variedades, y de 2isobutiltiazol y decanal en la variedad MM, pues evolucionaron hacia 
valores cada vez menos negativos a medida que avanzó el estado de maduración de los frutos, hasta alcanzar valores de LogU positivos en el estado M. Una evolución opuesta siguió el salicilato de metilo, que en la variedad Raf cambió el valor de su LogU de positivo en el estado $\mathrm{V}$ a negativo al avanzar la maduración.

Entre los 7 compuestos volátiles detectados en la FVL de las variedades MM y Raf y que forman parte de la combinación que reproduce de forma aproximada el aroma del tomate maduro troceado (Buttery, 1993), hexanal, trans-2-hexenal, y cis-3-hexenol obtuvieron los mayores valores positivos de LogU, y además se encuentran entre los compuestos adicionados a mayor concentración en la combinación propuesta por Buttery (1993) (Introducción, Tabla 1). El resto, 6-metil-5-heptén-2-ona, 2isobutiltiazol, salicilato de metilo, y $\beta$-ionona, con valores de LogU inferiores, incluso negativos en nuestras condiciones experimentales, coinciden con los que se adicionan a menor concentración en esta combinación de compuestos.

\subsubsection{Comparación entre las variedades MM y Raf en el estado de maduración verde}

La Figura 11 muestra las diferencias significativas entre la FVL de las variedades MM y Raf en el estado de maduración V. En ella se observan los 6 compuestos que mostraron concentraciones significativamente diferentes entre las variedades MM y Raf en el estado de maduración V. Estos compuestos fueron el hexanal, cis-3-hexenol, 1-heptanol, 2-etil-1hexanol, salicilato de metilo, y guaiacol. La concentración de 2-etil-1hexanol fue significativamente más abundante en la variedad MM, y la de hexanal, cis-3-hexenol, 1-heptanol, salicilato de metilo, y guaiacol lo fue en la variedad Raf. 


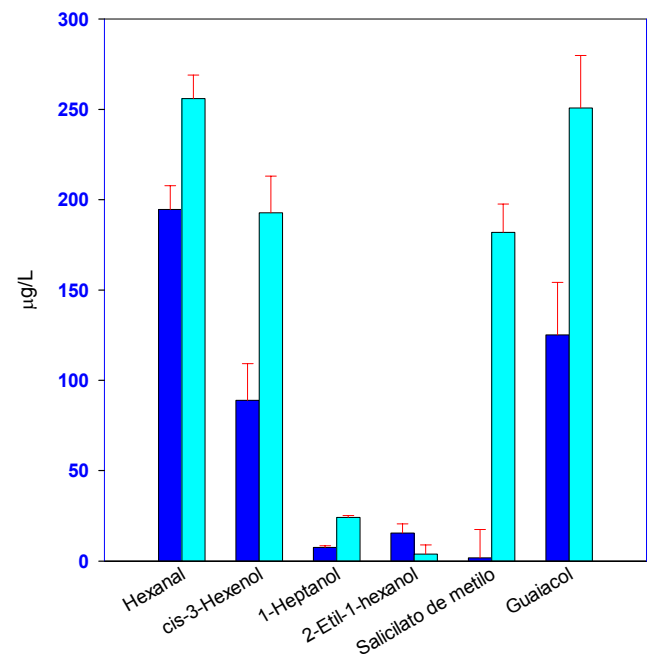

Figura 11. Concentración de los compuestos volátiles identificados en la FVL que mostraron diferencias significativas entre las variedades MM (barras en azul oscuro) y Raf (barras en azul claro) en el estado de maduración V, según el Test de Tukey's HSD aplicado con un intervalo de confianza del $95 \%$ a 3 repeticiones.

\subsubsection{Comparación entre las variedades MM y Raf en el estado de maduración pintón}

La Figura 12 muestra las diferencias significativas entre la FVL de las variedades MM y Raf en el estado de maduración P. En ella se recogen las concentraciones de los 10 compuestos, hexanal, 3-metil-1-butanol, trans-2hexenal, guaiacol, bencil alcohol, 6-metil-5-heptén-2-ona, 2-isobutiltiazol, 1heptanol, 3,5-dimetil benzaldehído, y eugenol, que mostraron diferencias significativas entre las variedades MM y Raf en el estado de maduración P. La concentración de hexanal, 3-metil-1-butanol, trans-2-hexenal, guaiacol, bencil alcohol, 6-metil-5-heptén-2-ona, 2-isobutiltiazol, y eugenol fue significativamente más abundante en la variedad $\mathrm{MM}$, y la de 1-heptanol y 3,5-dimetil benzaldehído lo fue en la variedad Raf. 


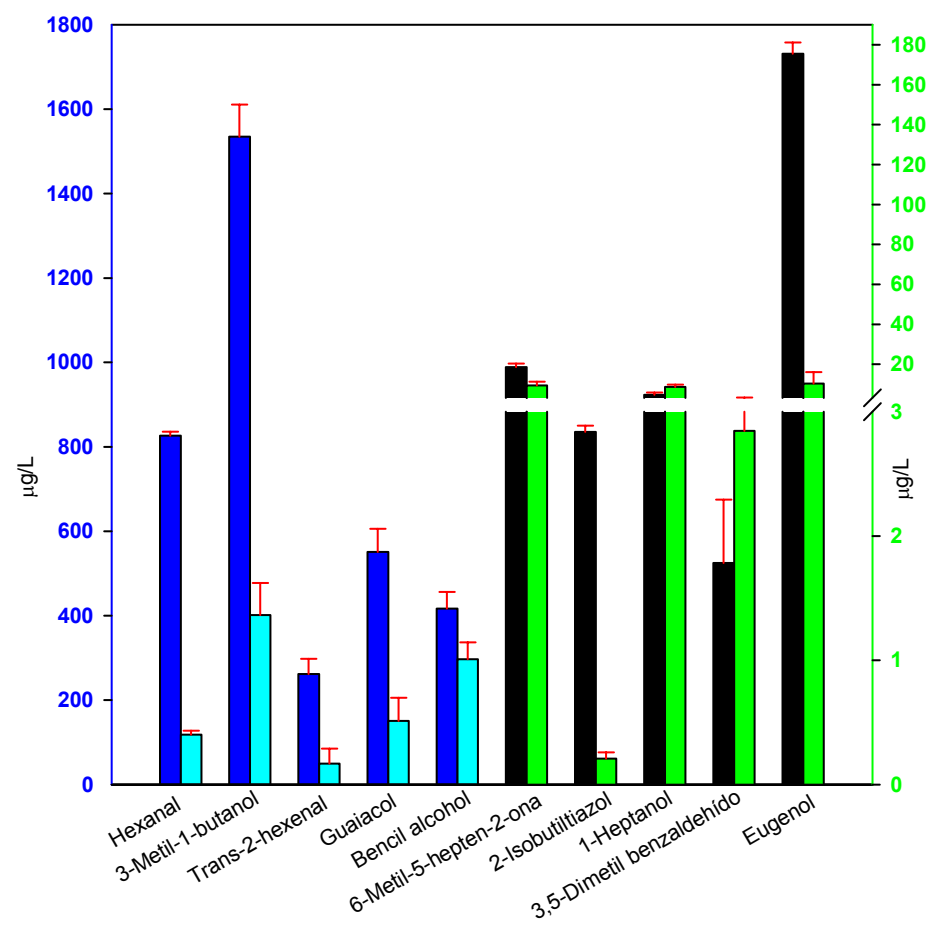

Figura 12. Concentración de los compuestos volátiles identificados en la FVL que mostraron diferencias significativas entre las variedades MM (azul y verde oscuros) y Raf (azul y verde claros) en el estado de maduración $\mathrm{P}$, según el Test de Tukey's HSD aplicado con un intervalo de confianza del $95 \%$ a 3 repeticiones. Barras en azul para concentraciones entre 100-1800 $\mu \mathrm{g} / \mathrm{L}$, y en verde para concentraciones entre 0.2-180 $\mu \mathrm{g} / \mathrm{L}$.

\subsubsection{Comparación entre las variedades MM y Raf en el estado de maduración maduro}

La Figura 13 muestra la comparación entre la FVL de las variedades MM y Raf en el estado de maduración M. En ella se observan los 14 compuestos que presentaron diferencias significativas entre ambas variedades en este estado de maduración. Estos compuestos fueron el hexanal, 1-hexanol, cis-3-hexenol, guaiacol, bencil alcohol, 3-octanona, 6metil-5-heptén-2-ona, 2-isobutiltiazol, 1-heptanol, linalol, 1-octanol, 3,5dimetil benzaldehído, 2-feniletanol, y eugenol. La concentración de 1hexanol, cis-3-hexenol, 2-isobutiltiazol, 3,5-dimetil benzaldehído, y eugenol 
fue significativamente más abundante en la variedad MM. Los 9 compuestos restantes lo fueron en la variedad Raf, entre ellos destacan linalol y 2-feniletanol, ambos compuestos están asociados a notas frutales y florales (Baldwin et al., 2004; Berna et al., 2005a).

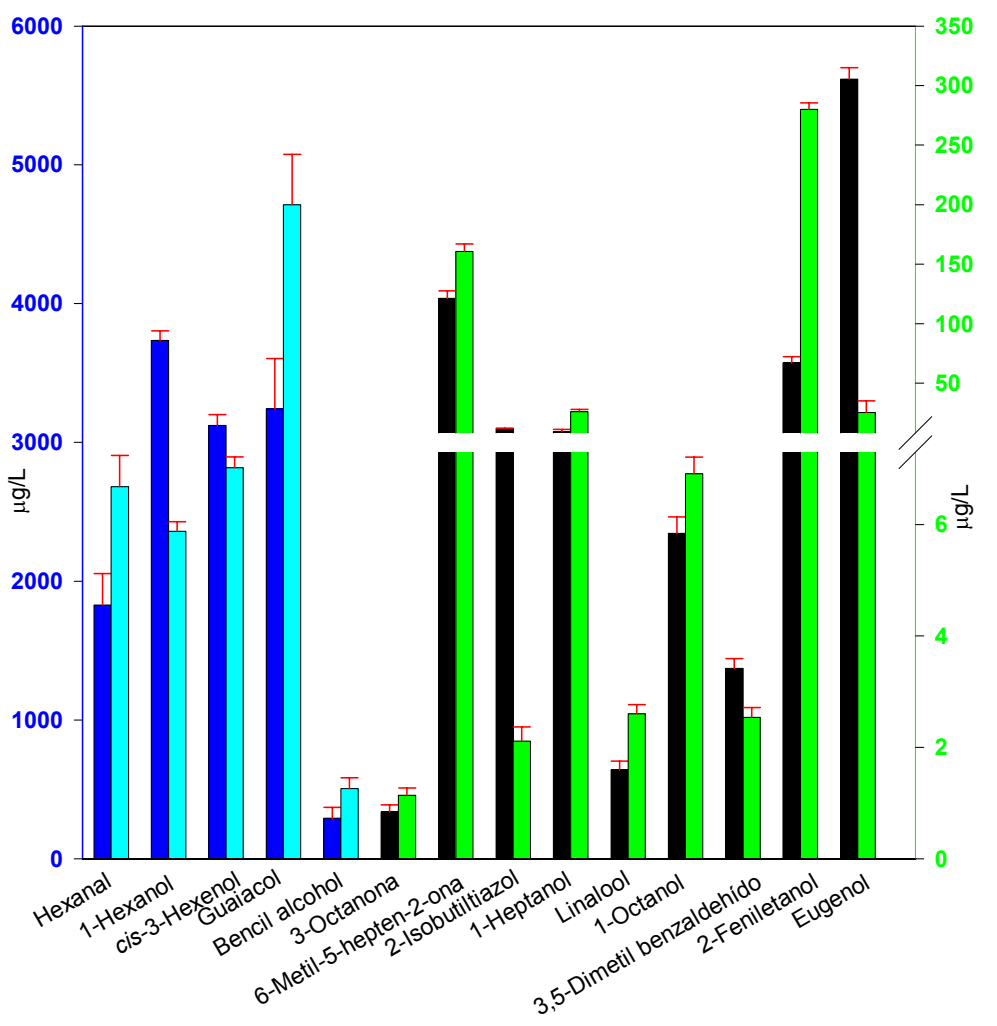

Figura 13. Concentración de los compuestos volátiles identificados en la FVL que mostraron diferencias significativas entre las variedades MM (azul y verde oscuros) y Raf (azul y verde claros) en el estado de maduración M, según el Test de Tukey's HSD aplicado con un intervalo de confianza del $95 \%$ a 3 repeticiones. Barras en azul para concentraciones entre $290-6000 \mu \mathrm{g} / \mathrm{L}$, y en verde para concentraciones entre 0.8-350 $\mu \mathrm{g} / \mathrm{L}$.

Finalmente, de los 24 compuestos identificados en la FVL de las variedades MM y Raf, sólo 1-octanal, nonanal, decanal, y nerol no presentaron concentraciones significativamente diferentes entre ambas variedades en ninguno de los 3 estados de maduración considerados (Figura 11, Figura 12, y Figura 13). La cantidad de compuestos volátiles 
presentes en la FVL cuya concentración fue significativamente distinta entre las 2 variedades fue aumentando con la maduración del tomate.

\subsection{Fracción glicosilada}

\subsubsection{Perfil de compuestos volátiles}

La Tabla 12 muestra las concentraciones de los 30 aglicones identificados tras la hidrólisis enzimática de la $F G$ de las variedades Moneymaker (MM) y Raf a lo largo de la maduración, así como las diferencias estadísticamente significativas encontradas entre los estados de maduración $\mathrm{V}, \mathrm{P}$, y $\mathrm{M}$ en cada una de las variedades. Los compuestos 3-octanona, nonanal, decanal, y $\beta$-ionona fueron detectados a una concentración inferior a $0.1 \mu \mathrm{g} / \mathrm{L}$ (nivel de traza) en las 2 variedades y en los 3 estados de maduración considerados. El 2-isobutiltiazol no fue detectado en el estado $V$ de ambas variedades, ni en el $P$ de la variedad Raf, y en el resto de estados de maduración su concentración fue del inferior a $0.1 \mu \mathrm{g} / \mathrm{L}$

De la misma forma que ocurrió en la FVL, la tendencia general de los compuestos volátiles glicosilados fue a aumentar sus concentraciones durante la maduración, alcanzando la máxima concentración en el estado de maduración M. Sólo las concentraciones de guaiacol en la variedad MM, y de trans-2-hexenal, 4-metil-1-pentanol, 1-hexanol, 1-heptanol, transóxido de linalol, y benzaldehído en la variedad Raf, no cambiaron significativamente entre los 3 estados de maduración considerados.

Las concentraciones de 16 aglicones aumentaron significativamente a lo largo de la maduración según el siguiente patrón. Hexanal, 3-metil-1butanol, 6-metil-5-heptén-2-ol, $\beta$-citronelol, bencil alcohol, y eugenol experimentaron grandes aumentos durante la maduración, que oscilaron entre un $1000 \%$ y un $8000 \%$, en ambas variedades. Las concentraciones de 3-metil-1-pentanol, 1-octanol, $\alpha$-terpineol, nerol, geraniol, y 2-feniletanol 
también aumentaron con la maduración en ambas variedades, si bien la magnitud de estos aumentos fue menor.

Tabla 12. Concentración $(\mu \mathrm{g} / \mathrm{L})$ de los aglicones detectados tras la hidrólisis enzimática del extracto de glicósidos de las variedades MM y Raf en los estados de maduración $\mathrm{V}, \mathrm{P}$, y M.

\begin{tabular}{|c|c|c|c|c|c|c|}
\hline \multirow{2}{*}{ Aglicones } & \multicolumn{3}{|c|}{ MM } & \multicolumn{3}{|c|}{ Raf } \\
\hline & Verde & Pintón & Maduro & Verde & Pintón & Maduro \\
\hline Hexanal & $22.76 \mathrm{a}$ & $95.04 \mathrm{~b}$ & $402.9 \mathrm{c}$ & $19.11 \mathrm{a}$ & $70.11 a$ & $311.3 b$ \\
\hline 3-Metil-1-butanol & $28.41 \mathrm{a}$ & $261.3 b$ & $7240 \mathrm{c}$ & $18.36 \mathrm{a}$ & $390.6 \mathrm{~b}$ & $1762 \mathrm{c}$ \\
\hline trans-2-hexenal & $371.6 \mathrm{~b}$ & $1071 \mathrm{c}$ & $192.8 \mathrm{a}$ & $389.2 \mathrm{a}$ & $741.5 \mathrm{a}$ & $356.9 \mathrm{a}$ \\
\hline 3-Octanona & $\operatorname{tr}$ & $\operatorname{tr}$ & $\operatorname{tr}$ & $\operatorname{tr}$ & $\operatorname{tr}$ & $\operatorname{tr}$ \\
\hline Octanal & 0.472 & $\operatorname{tr}$ & $\operatorname{tr}$ & 0.467 & $\operatorname{tr}$ & $\operatorname{tr}$ \\
\hline 4-Metil-1-pentanol & nd & $0.269 \mathrm{a}$ & $1.196 \mathrm{~b}$ & $\operatorname{tr}$ & $0.746 \mathrm{a}$ & $0.763 a$ \\
\hline 3-Metil-1-pentanol & nd & $1.939 \mathrm{a}$ & $13.64 \mathrm{~b}$ & nd & $1.241 \mathrm{a}$ & $4.422 \mathrm{~b}$ \\
\hline 1-Hexanol & $8.484 \mathrm{a}$ & $7.270 \mathrm{a}$ & $109.6 b$ & $11.06 \mathrm{a}$ & $54.83 \mathrm{a}$ & $25.73 \mathrm{a}$ \\
\hline cis-3-hexenol & $16.47 \mathrm{~b}$ & $7.772 \mathrm{a}$ & $23.43 \mathrm{c}$ & $16.06 \mathrm{~b}$ & $13.58 \mathrm{ab}$ & $9.463 \mathrm{a}$ \\
\hline Nonanal & $\operatorname{tr}$ & $\operatorname{tr}$ & $\operatorname{tr}$ & $\operatorname{tr}$ & $\operatorname{tr}$ & $\operatorname{tr}$ \\
\hline 2-Isobutiltiazol & nd & $\operatorname{tr}$ & $\operatorname{tr}$ & nd & nd & $\operatorname{tr}$ \\
\hline cis-óxido de linalol & $28.15 b$ & $16.36 \mathrm{a}$ & $10.55 \mathrm{a}$ & $22.34 \mathrm{c}$ & $18.36 \mathrm{~b}$ & $6.959 \mathrm{a}$ \\
\hline 1-Heptanol & $0.484 \mathrm{~b}$ & $0.298 \mathrm{a}$ & $2.815 \mathrm{c}$ & $1.070 \mathrm{a}$ & $0.424 a$ & $0.951 \mathrm{a}$ \\
\hline 6-Metil-5-heptén-2-ol & $0.127 a$ & $0.132 \mathrm{a}$ & $7.946 \mathrm{~b}$ & $\operatorname{tr}$ & $0.163 \mathrm{a}$ & $3.557 \mathrm{~b}$ \\
\hline trans-óxido de linalol & $35.46 \mathrm{~b}$ & $17.82 \mathrm{a}$ & nd & $22.48 \mathrm{a}$ & $20.42 \mathrm{a}$ & nd \\
\hline 2-Etil-1-hexanol & $5.740 a b$ & $8.222 \mathrm{~b}$ & $3.504 \mathrm{a}$ & $10.13 \mathrm{c}$ & $5.398 b$ & $3.826 \mathrm{a}$ \\
\hline Decanal & $\operatorname{tr}$ & $\operatorname{tr}$ & $\operatorname{tr}$ & $\operatorname{tr}$ & $\operatorname{tr}$ & $\operatorname{tr}$ \\
\hline Benzaldehído & $33.06 \mathrm{c}$ & $14.20 \mathrm{a}$ & $24.84 b$ & $29.74 \mathrm{a}$ & $10.71 \mathrm{a}$ & $15.87 \mathrm{a}$ \\
\hline Linalol & $63.86 \mathrm{~b}$ & 39.48 a & $28.79 \mathrm{a}$ & $77.32 \mathrm{c}$ & $48.58 \mathrm{~b}$ & $35.59 \mathrm{a}$ \\
\hline 1-Octanol & $0.334 \mathrm{~b}$ & $0.232 a$ & $0.436 \mathrm{c}$ & $0.330 \mathrm{a}$ & $0.368 a$ & $0.809 \mathrm{~b}$ \\
\hline$\alpha$-Terpineol & $3.088 \mathrm{a}$ & $3.064 \mathrm{a}$ & $5.299 \mathrm{~b}$ & $4.811 \mathrm{a}$ & $5.383 a b$ & $6.136 \mathrm{~b}$ \\
\hline$\beta$-Citronelol & $0.260 \mathrm{a}$ & $0.154 \mathrm{a}$ & $4.888 \mathrm{~b}$ & $0.140 \mathrm{a}$ & $0.171 \mathrm{a}$ & $2.577 \mathrm{~b}$ \\
\hline Salicilato de metilo & $3.903 \mathrm{~b}$ & $4.363 \mathrm{~b}$ & $2.464 \mathrm{a}$ & $9.820 \mathrm{a}$ & $22.52 b$ & $33.00 \mathrm{c}$ \\
\hline Nerol & $1.844 \mathrm{a}$ & $1.560 \mathrm{a}$ & $9.345 \mathrm{~b}$ & $1.198 \mathrm{a}$ & $1.244 \mathrm{a}$ & $4.999 \mathrm{~b}$ \\
\hline Geraniol & $4.443 b$ & $3.331 \mathrm{a}$ & $9.771 \mathrm{c}$ & $3.087 \mathrm{a}$ & $3.944 \mathrm{a}$ & $7.254 \mathrm{~b}$ \\
\hline Guaiacol & $36.60 \mathrm{a}$ & $25.31 \mathrm{a}$ & $18.57 \mathrm{a}$ & $61.10 \mathrm{~b}$ & $47.16 \mathrm{a}$ & $43.60 \mathrm{a}$ \\
\hline Bencil alcohol & $252.1 \mathrm{a}$ & $683.1 \mathrm{~b}$ & $2030 c$ & $436.5 a$ & $1087 \mathrm{~b}$ & $2168 c$ \\
\hline 2-Feniletanol & $291.4 \mathrm{~b}$ & 260.9 a & $539.8 \mathrm{c}$ & $311.2 \mathrm{a}$ & $403.7 \mathrm{~b}$ & $894.2 \mathrm{C}$ \\
\hline$\beta$-Ionona & $\operatorname{tr}$ & $\operatorname{tr}$ & $\operatorname{tr}$ & $\operatorname{tr}$ & $\operatorname{tr}$ & $\operatorname{tr}$ \\
\hline Eugenol & $6.024 \mathrm{a}$ & $75.49 \mathrm{~b}$ & $212.1 \mathrm{c}$ & $6.835 \mathrm{a}$ & $189.6 \mathrm{~b}$ & $492.8 \mathrm{c}$ \\
\hline
\end{tabular}

nd: compuesto no detectado; tr: concentración $<0.1 \mu \mathrm{g} / \mathrm{L}$.

Diferentes letras para cada compuesto indican diferencias significativas entre los 3 estados de maduración considerados en cada variedad según el Test de Tukey's HSD aplicado con un intervalo de confianza del $95 \%$ a 3 repeticiones. La letra "a" se asigna a la menor concentración de un compuesto.

El salicilato de metilo aumentó conforme avanzaba el proceso de maduración sólo en la variedad Raf, y otros, como 4-metil-1-pentanol, 1hexanol (cuya concentración experimentó un gran aumento durante la 
maduración), y cis-3-hexenol, lo hicieron, de forma significativamente estadística, sólo en la variedad MM. Las tendencias al aumento en las concentraciones de estos 16 aglicones no sólo variaron en su magnitud sino también en su forma. Algunos experimentaron aumentos estadísticamente significativos desde el estado $V$ (por ejemplo, 3-metil-1butanol) y otros desde el P (por ejemplo, $\beta$-citronelol). Otros, como cis-3hexenol, 1-heptanol, 1-octanol, geraniol, y 2-feniletanol en la variedad MM disminuyeron significativamente su concentración entre los estados $V$ y $P$. Todos alcanzaron su máxima concentración en el estado $\mathrm{M}$.

Los cambios en la concentración del trans-2-hexenal sólo fueron estadísticamente significativos en la variedad MM, aunque este compuesto experimentó un fuerte aumento entre los estados de maduración $\mathrm{V}$ y $\mathrm{P}$ en ambas variedades, a partir del cual disminuyó en gran medida, alcanzando su máxima concentración en el estado $P$.

Las concentraciones de los aglicones octanal, cis-óxido de linalol, trans-óxido de linalol, 2-etil-1-hexanol, benzaldehído, linalol, y guaiacol tendieron a disminuir en ambas variedades conforme avanzaba la maduración. El cis-3-hexenol lo hizo en la variedad Raf, y el salicilato de metilo en la variedad MM. Las tendencias a la disminución en las concentraciones de estos 8 compuestos no sólo variaron en su magnitud sino también en su forma. Algunos experimentaron disminuciones estadísticamente significativas desde el estado $\mathrm{V}$ (cis-óxido de linalol, 2etil-1-hexanol, linalol, y guaiacol en la variedad Raf), otros desde el P (cis3-hexenol en la variedad Raf, y salicilato de metilo en la variedad MM), y otros tendieron a la disminución aunque ésta no fue estadísticamente significativa (guaiacol en la variedad MM, y trans-óxido de linalol y benzaldehído en la variedad Raf). Aunque los 8 alcanzaron su máxima concentración en el estado $V$, excepto en el caso de 2-etil-1-hexanol y salicilato de metilo en la variedad MM, cuya concentración máxima correspondió, numéricamente, al estado P. 


\subsubsection{Perfil de azúcares}

La Figura 14 muestra la concentración de los 4 azúcares identificados y cuantificados tras hidrólisis de la FG de las variedades MM y Raf en cada uno de los 3 estados de maduración considerados, así como las diferencias estadísticamente significativas encontradas entre los azúcares en cada estado de maduración.

Variedad Moneymaker

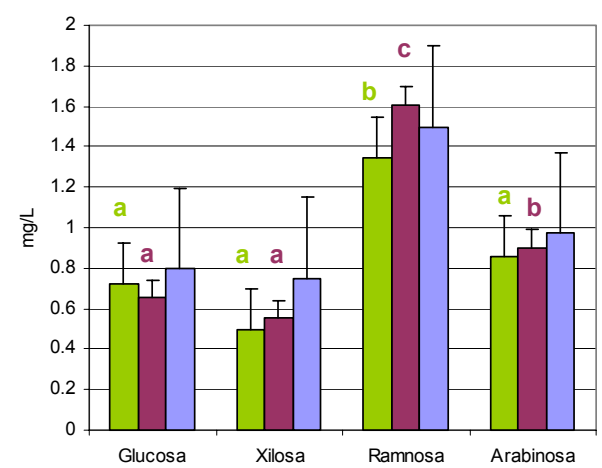

Variedad Raf

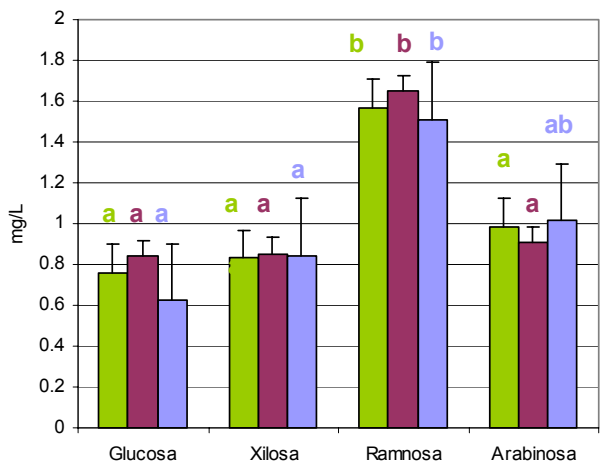

Figura 14. Concentración de glucosa, xilosa, arabinosa, y ramnosa detectada tras la hidrólisis enzimática del extracto de glicósidos de las variedades MM y Raf en los estados de maduración V (verde), P (burdeos), y M (azulado). Diferentes letras para cada estado de maduración representan la existencia de diferencias significativas entre los azúcares según el el Test de Tukey's HSD aplicado con un intervalo de confianza del $95 \%$ a 3 repeticiones.

Los azúcares identificados se encuentran entre los citados en la bibliografía como constituyentes de precursores de compuestos volátiles glicosilados en uva (Williams, 1993), y en otros vegetales (Sarry y Günata, 2004). Se trata de glucosa, xilosa, ramnosa, y arabinosa. De acuerdo con el análisis estadístico (Figura 14) se desprende que en los estados de maduración $\mathrm{V}$ y $\mathrm{P}$ la concentración de ramnosa fue significativamente mayor que la del resto de azúcares en ambas variedades. En la variedad Raf la concentración de ramnosa fue también significativamente mayor que la de glucosa y xilosa en el estado $\mathrm{M}$. La ramnosa fue el azúcar mayoritario en los 3 estados de maduración y para las 2 variedades, seguido de la arabinosa, de la glucosa en la variedad MM, o de la xilosa en la variedad 
Raf. No se hallaron diferencias significativas en el nivel de azúcares entre los 3 estados de maduración.

\subsubsection{Comparación entre las variedades Moneymaker y Raf}

\section{a) Comparación entre las variedades MM y Raf en el estado verde}

La Figura 15 muestra la comparación entre la FG de las variedades MM y Raf en el estado de maduración V. En ella se observan los 13 aglicones que presentaron concentraciones significativamente diferentes entre ambas variedades en el estado de maduración V.

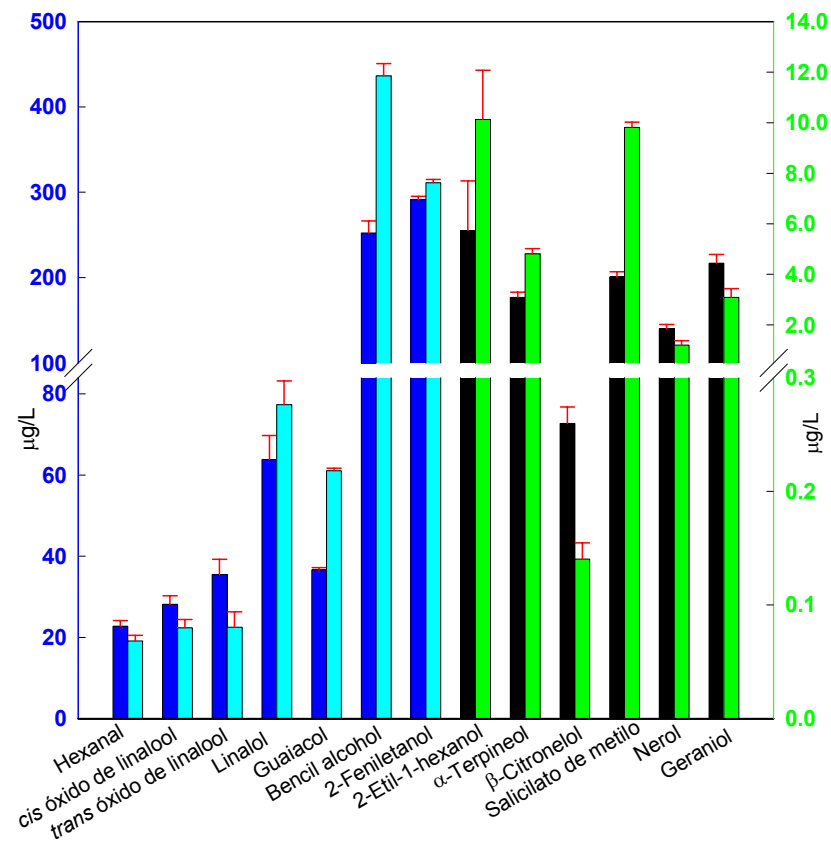

Figura 15. Concentración de los aglicones que mostraron diferencias significativas, tras hidrólisis enzimática de la FG, entre las variedades MM (barras en azul y verde oscuros) y Raf (barras en azul y verde claros) en el estado de maduración $\mathrm{V}$, según el Test de Tukey's HSD aplicado con un intervalo de confianza del $95 \%$ a 3 repeticiones. Barras en azul para concentraciones entre $19-500 \mu \mathrm{g} / \mathrm{L}$, y en verde para concentraciones entre 0.1-14 $\mu \mathrm{g} / \mathrm{L}$.

Estos compuestos fueron el hexanal, cis y trans-óxido de linalol, linalol, guaiacol, bencil alcohol, 2-feniletanol, 2-etil-1-hexanol, $\alpha$-terpineol, $\beta$-citronelol, salicilato de metilo, nerol, y geraniol. La variedad MM fue 
significativamente más abundante en 6 de estos 13 aglicones, entre los que destacaron los terpenoles cis y trans-óxido de linalol, $\beta$-citronelol, nerol, y geraniol. Entre los 7 compuestos significativamente más abundantes en la variedad Raf, destacaron el linalol, 2-feniletanol, y $\alpha$ terpineol, todos ellos asociados a notas florales y frutales.

\section{b) Comparación entre las variedades MM y Raf en el estado pintón}

La Figura 16 muestra la comparación entre la FG de las variedades MM y Raf en el estado de maduración $P$.

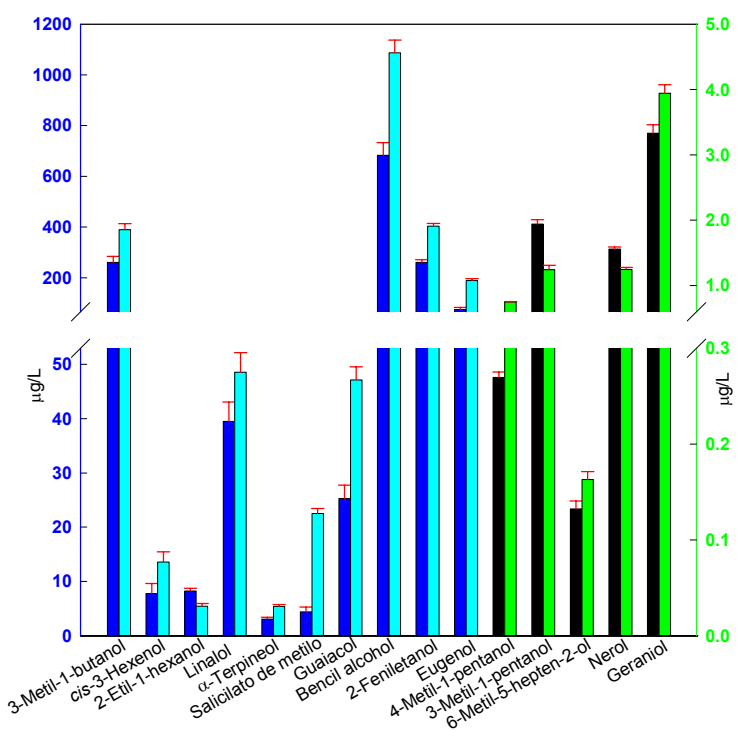

Figura 16. Concentración de los aglicones que mostraron diferencias significativas, tras la hidrólisis enzimática de la FG, entre las variedades MM (barras en azul y verde oscuros) y Raf (barras en azul y verde claros) en el estado de maduración P, según el Test de Tukey's HSD aplicado con un intervalo de confianza del $95 \%$ a 3 repeticiones. Barras en azul para concentraciones entre 3-1200 $\mu \mathrm{g} / \mathrm{L}$, y en verde para concentraciones entre $0.1-5 \mu \mathrm{g} / \mathrm{L}$.

En ella se recogen los 15 aglicones que fueron significativamente diferentes entre las variedades MM y Raf en el estado de maduración P. Estos compuestos fueron el 3-metil-1-butanol, cis-3-hexenol, 2-etil-1hexanol, linalol, $\alpha$-terpineol, salicilato de metilo, guaiacol, bencil alcohol, 2feniletanol, eugenol, 4-metil-1-pentanol, 3-metil-1-pentanol, 6-metil-5heptén-2-ol, nerol, y geraniol. Los compuestos 3-metil-1-pentanol, 2-etil-1- 
hexanol, y nerol fueron significativamente más abundantes en la variedad MM. Los 12 aglicones restantes lo fueron en la variedad Raf. Entre ellos destacan linalol, $\alpha$-terpineol, 2-feniletanol, eugenol, y geraniol, pues se trata de compuestos asociados a notas frutales y florales.

\section{c) Comparación entre las variedades MM y Raf en el estado maduro}

La Figura 17 muestra la comparación entre la FG de las variedades MM y Raf en el estado de maduración M.

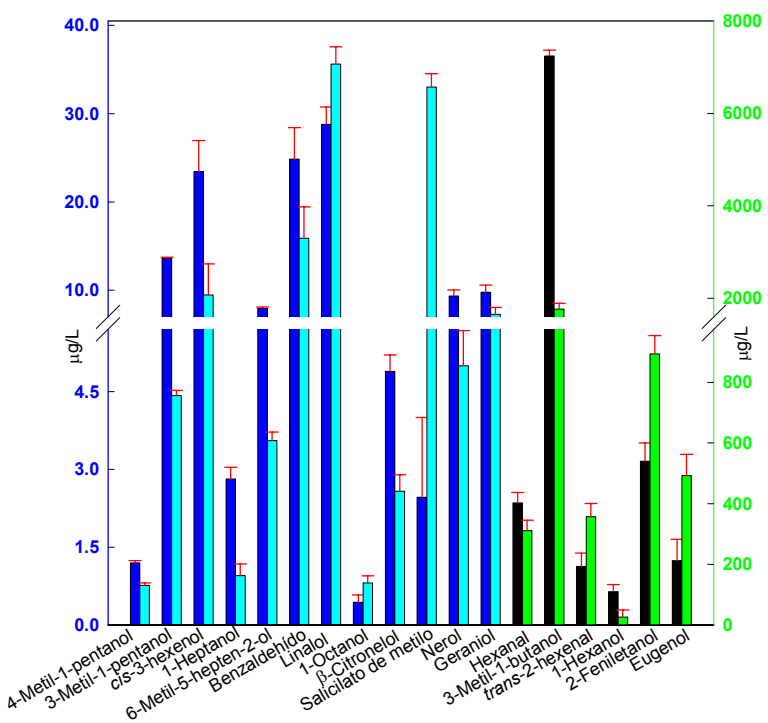

Figura 17. Concentración de los aglicones que mostraron diferencias significativas, tras la hidrólisis enzimática de la FG, entre las variedades $M M$ (barras en azul y verde oscuros) y Raf (barras en azul y verde claros) en el estado de maduración M, según el Test de Tukey's HSD aplicado con un intervalo de confianza del $95 \%$ a 3 repeticiones. Barras en azul para concentraciones entre $0.4-40 \mu \mathrm{g} / \mathrm{L}$, y en verde para concentraciones entre $25-8000 \mu \mathrm{g} / \mathrm{L}$.

En ella se muestran los 18 aglicones que presentaron concentraciones significativamente diferentes entre las variedades MM y Raf en el estado de maduración M. Estos compuestos fueron el 4-metil-1pentanol, 3-metil-1-pentanol, cis-3-hexenol, 1-heptanol, 6-metil-5-heptén-2ol, benzaldehído, linalol, 1-octanol, $\beta$-citronelol, salicilato de metilo, nerol, geraniol, hexanal, 3-metil-1-butanol, trans-2-hexenal, 1-hexanol, 2feniletanol, y eugenol. Los compuestos trans-2-hexenal, linalol, 1-octanol, 
salicilato de metilo, 2-feniletanol, y eugenol fueron significativamente más abundantes en la variedad Raf. Los restantes 12 aglicones lo fueron en la variedad MM. Entre ellos destacan $\beta$-citronelol, nerol, y geraniol, pues se trata de compuestos asociados a notas frutales y florales.

Todos los aglicones detectados por encima del nivel de traza (concentración superior a $0.1 \mu \mathrm{g} / \mathrm{L}$ ) mostraron concentraciones significativamente diferentes entre las variedades MM y Raf en alguno de los 3 estados de maduración considerados (Figura 15, Figura 16, y Figura 17). Los compuestos linalol, salicilato de metilo, nerol, geraniol, y 2feniletanol fueron significativamente diferentes entre las 2 variedades en los 3 estados de maduración considerados. La cantidad de componentes de la FG cuya concentración fue significativamente distinta entre las 2 variedades fue aumentando con la maduración del tomate.

\subsection{Potencial aromático de la fracción glicosilada}

En la medida en que los enlaces glicosídicos son hidrolizados y los aglicones liberados, la FG supone una fuente potencial para incrementar el aroma del tomate. Durante el proceso de maduración de las variedades Moneymaker (MM) y Raf, todos los componentes de la FVL se detectaron en forma glicosilada, excepto 6-metil-5-heptén-2-ona, cis-4-decenal, y 3,5dimetil benzaldehído (Tabla 12). Además, en la $\mathrm{FG}$ se detectaron 9 compuestos volátiles que no habían sido detectados en forma libre. Estos compuestos fueron el 4-metil-1-pentanol, 3-metil-1-pentanol, cis-óxido de linalol, 6-metil-5-heptén-2-ol, trans-óxido de linalol, benzaldehído, $\alpha$ terpineol, $\beta$-citronelol, y geraniol. La abundancia de estos 9 aglicones dependió del estado de maduración considerado, de forma que sólo cisóxido de linalol, benzaldehído, $\alpha$-terpineol, $\beta$-citronelol, y geraniol fueron detectados en los 3 estados de maduración considerados y en las 2 variedades a una concentración superior a $0.1 \mu \mathrm{g} / \mathrm{L}$ (Tabla 12). El hecho de que estos 9 compuestos hayan sido detectados sólo en forma glicosilada 
los hace especialmente interesantes, ya que su potencial liberación podría implicar un cambio cualitativo de la FVL del tomate. Entre ellos destacan los terpenoles cis- y trans- óxidos de linalol, $\alpha$-terpineol, $\beta$-citronelol, y geraniol, por estar asociados a notas florales y frutales.

En la Figura 18 se muestran los 9 compuestos cuyas concentraciones fueron mayores en la FG que en la FVL en al menos uno de los 3 estados de maduración considerados ( $V, P, y, M)$ en las variedades MM y Raf, y la razón entre ambas concentraciones. Cuanto mayor sea la proporción de un compuesto glicosilado con respecto a su concentración en forma libre mayor podrá ser el impacto que sobre el aroma final tenga su liberación. La concentración en forma libre de estos 9 compuestos puede incrementarse entre un $10 \%$ y un $6400 \%$, en función del compuesto, del estado de maduración, y de la variedad considerados. El linalol, interesante por su repercusión organoléptica, fue el compuesto con mayor potencial para aumentar su concentración en forma libre, entre un $1400 \%$ y un $6400 \%$ según la variedad y el estado de maduración considerados. El potencial del 3-metil-1-butanol, nerol, y bencil alcohol en ambas variedades, del 2-feniletanol en la variedad MM, y del salicilato de metilo y del eugenol en la variedad Raf, para incrementar su concentración en forma libre aumentó a medida que avanzó la maduración del fruto. En el estado $M$, la concentración de 3-metil-1-butanol en forma libre puede incrementarse hasta un $1160 \%$, la de nerol hasta un $460 \%$, la de bencil alcohol hasta un $700 \%$, la de 2-feniletanol hasta un $810 \%$, y la de eugenol hasta un $1930 \%$. En el caso del salicilato de metilo, su concentración en la FVL fue disminuyendo con la maduración hasta no ser detectado en el estado $M$, pero en su forma glicosilada aumentó con la maduración alcanzando su nivel máximo en el estado $\mathrm{M}$.

La concentración en forma libre del trans-2-hexenal en ambas variedades, y del 2-etil-1-hexanol en la variedad MM, puede aumentar 
considerablemente del estado $\mathrm{V}$ al $\mathrm{P}$ pero en el estado $\mathrm{M}$ el potencial para incrementar su concentración volvió a ser como en el $\mathrm{V}$.
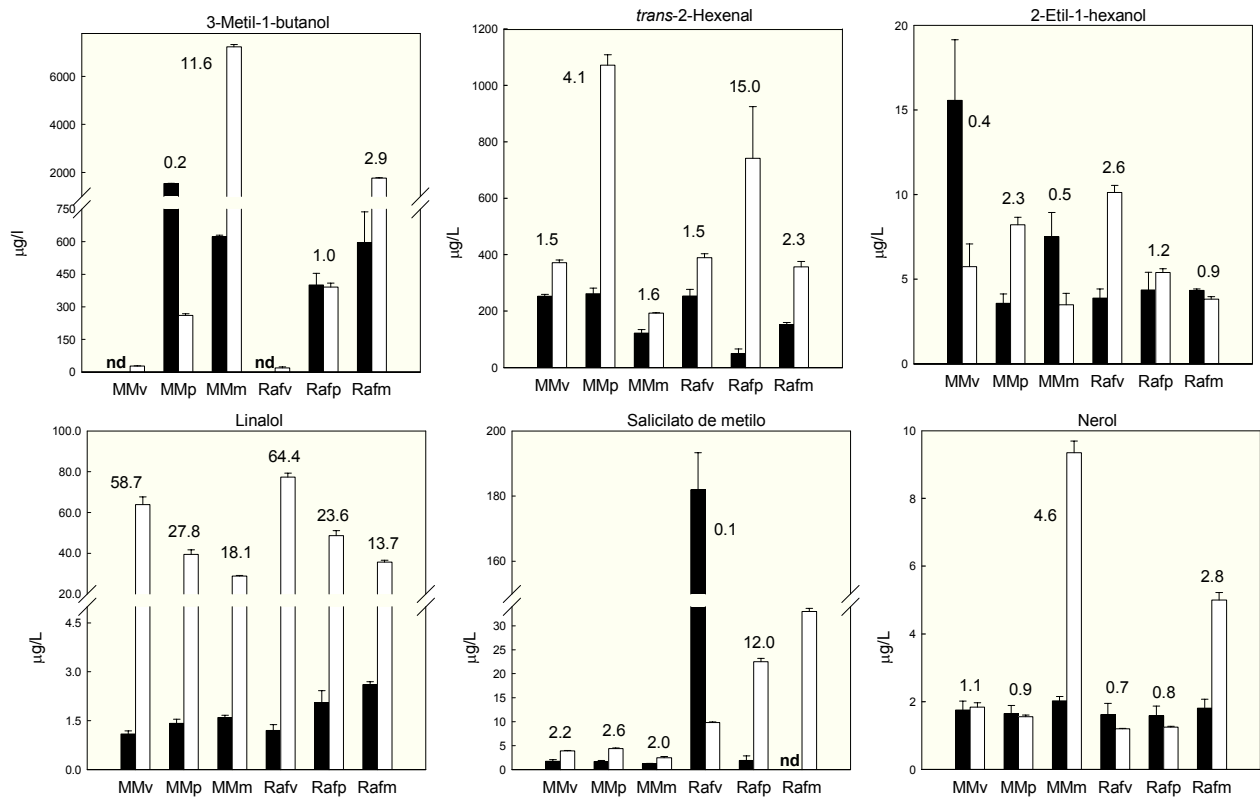

Bencil alcoh
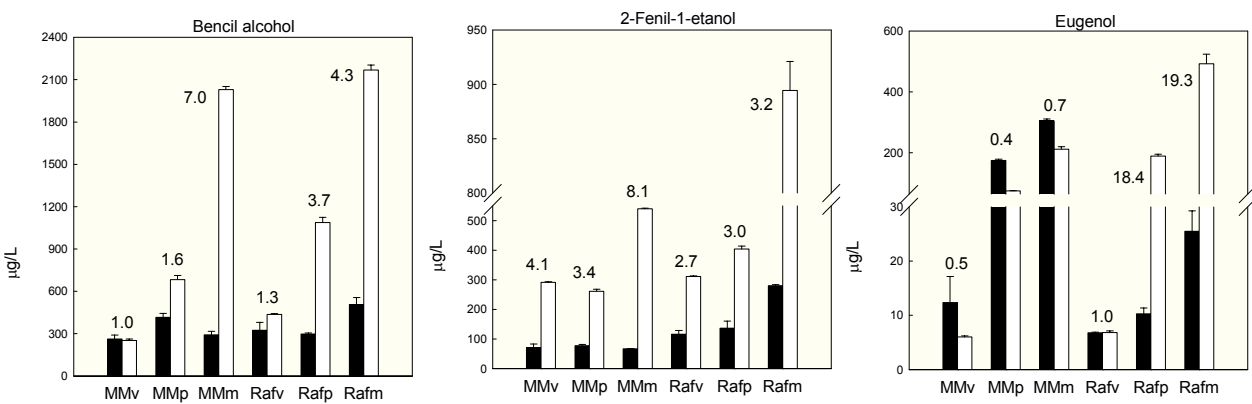

Figura 18. Concentración en la FVL (barras en negro) y en la FG (barras en blanco) en los estados de maduración verde $(\mathrm{v})$, pintón $(\mathrm{p})$, y maduro $(\mathrm{m})$ de las variedades MM y Raf, expresada como la media \pm error estándar de 3 repeticiones. Los valores numéricos señalados corresponden a la razón entre la concentración en forma glicosilada y libre, para cada compuesto y variedad. nd: compuesto no detectado.

La concentración en forma libre de trans-2-hexenal puede incrementarse hasta un $410 \%$ en la variedad MM y hasta un $1500 \%$ en la variedad Raf, y la de 2-etil-1-hexanol en la variedad MM hasta un $230 \%$.

La posibilidad de aumentar en forma libre la concentración del salicilato de metilo y del eugenol en la variedad MM, y del 2-feniletanol en 
la variedad Raf, no cambia significativamente durante la maduración, pudiendo aumentar hasta un $260 \%$, un $70 \%$, y un $320 \%$, respectivamente.

Por último, el potencial para aumentar la concentración de linalol en forma libre en ambas variedades, y la de 2-etil-1-hexanol en la variedad Raf, disminuyó progresivamente conforme avanzó la maduración. La posibilidad de aumentar la concentración de ambos compuestos en la FVL fue máxima en el estado de maduración $V$ del fruto, hasta un $5870 \%$ en la variedad MM y un $6440 \%$ en la variedad Raf de linalol, y hasta un $260 \%$ de 2-etil-1-hexanol en la variedad Raf. Al contrario que el salicilato de metilo, la concentración de linalol aumentó en la FVL durante la maduración, pero en su forma glicosilada disminuyó a medida que avanzó la maduración del fruto.

\section{Discusión}

\subsection{Caracterización de la fracción volátil del tomate}

El sabor y el aroma del tomate son el resultado de las interacciones que se establecen, principalmente, entre sus azúcares, ácidos orgánicos, aminoácidos libres, minerales y compuestos volátiles, jugando estos últimos un papel muy relevante en la apreciación sensorial final. Una parte de estos compuestos se encuentran en forma libre, constituyendo la FVL pero otra parte se encuentra en forma glicosilada y los aglicones que la forman no pueden ser percibidos por los receptores olfativos, constituyendo la denominada FG. El estudio comparativo, entre 5 variedades y 3 estados de maduración, de la fracción volátil del tomate ha permitido profundizar en la caracterización del perfil aromático de este popular y versátil fruto. Como se discute a continuación, existen diferencias en la composición de la FVL y de la FG entre las variedades de tomate estudiadas, que puede ser utilizada como una herramienta para la identificación de las variedades de tomate. Se ha estudiado la influencia de 
la maduración en el perfil aromático del tomate, observándose que los compuestos volátiles de la FVL y de la FG tienden, en general, a aumentar sus concentraciones a medida que avanza la maduración del fruto, aunque con relevantes excepciones. El conjunto de resultados obtenidos en este trabajo constata el potencial que posee la FG para incrementar los compuestos volátiles libres en frutos de tomate.

\subsubsection{Caracterización de la fracción volátil libre}

La FVL del tomate está formada por un complejo grupo de compuestos volátiles (aldehídos, alcoholes, cetonas, ésteres, lactonas, terpenos, hidrocarburos, ácidos carboxílicos, sulfuros, compuestos nitrogenados), que se forman tanto en el fruto intacto durante la maduración como al proceder a la ruptura de los tejidos celulares. La influencia que sobre la FVL ejercen las prácticas de pre- y post-cosecha, la climatología durante el cultivo, el estado de maduración del fruto o el potencial genético del material vegetal, ha sido objeto de múltiples estudios (para revisión ver Baldwin et al., 2000). Los resultados obtenidos en este trabajo confirman la existencia de una gran variabilidad en la composición de la FVL del tomate entre variedades. Los 24 compuestos detectados en la FVL del tomate se encontraron en las 5 variedades estudiadas, p73, Jorge, Durinta, Moneymaker (MM), y Raf (Tabla 7). De acuerdo con estos resultados, las diferencias encontradas en la composición de la FVL entre las 5 variedades analizadas fueron principalmente cuantitativas. Las variedades $\mathrm{p} 73$, Jorge, y Durinta comparten sus 3 compuestos más abundantes en la FVL, que por orden decreciente de magnitud, son cis-3hexenol, 1-hexanol, y guaiacol. En la variedad MM son, por orden decreciente de magnitud, 3-metil-1-butanol, hexanal, y cis-3-hexenol. $Y$ en la variedad Raf, cis-3-hexenol, 3-metil-1-butanol, y bencil alcohol (Tabla 7). Linalol, nerol, 2-isobutiltiazol, y $\beta$-ionona, se encuentran entre los compuestos menos abundantes detectados en la FVL de estas 5 
variedades. Sin embargo, según propuso Buttery (1993), un compuesto volátil no tiene que ser necesariamente abundante para tener un impacto significativo sobre el flavor del tomate. Este es el caso de la $\beta$-ionona y del 2-isobutiltiazol (Buttery, 1993), y debe ser también el caso del linalol y del nerol, terpenos característicos de los aceites esenciales de especias, flores y frutas, y partes activas del aroma de muchas bebidas y alimentos (Marais, 1983; Knudsen et al., 1993; Krumbein y Auerswald, 1998; Burdock, 2002; Baldwin et al., 2004; Lewinsohn et al., 2005b).

De acuerdo con el análisis estadístico, la concentración de la mayoría de compuestos detectados en la FVL fue significativamente diferente entre las variedades p73, Jorge, Durinta, MM, y Raf. Sólo la concentración de 2-etil-1-hexanol y de bencil alcohol no fue significativamente diferente entre variedades. Por otro lado, sólo la concentración de 2-isobutiltiazol fue significativamente diferente entre las 5 variedades (Tabla 7). Este resultado coincide con la gran variación de la concentración de 2-isobutiltiazol entre variedades de tomate descrita en la bibliografía, donde también se señala que esta variación contribuye a las diferencias de flavor percibidas entre variedades (Kazeniac y Hall, 1970; Stevens, 1972). La mayor parte de las diferencias entre las FVLs de las distintas variedades se encontraran entre la variedad p73, que es la única variedad no comercial utilizada en programas de transformación genética, y el resto de variedades, todas comerciales (Tabla 7).

Estos resultados muestran que la variedad es uno de los factores que influye sobre la composición de la FVL del tomate, y en particular sobre la concentración de los compuestos volátiles en ella presentes, lo que coincide con lo expuesto previamente por otros autores (Stevens, 1972; Stevens et al., 1977; Stevens et al., 1979; Baldwin et al., 1991a; Baldwin et al., 1991b; Langlois et al., 1996; Brauss et al., 1998; Berna et al., 2004; Ruíz et al., 2005; Carbonell-Barrachina et al., 2006). Los resultados obtenidos avalan la posibilidad de utilizar el perfil aromático del 
tomate como una herramienta para la identificación de las variedades, de gran utilidad por ejemplo para la selección de genotipos de mayor calidad organoléptica en los programas de mejora genética (Baldwin et al., 1991a; Baldwin et al., 1991b; Langlois et al., 1996; Brauss et al., 1998; Tandon et al., 2003; Krumbein et al., 2004; Berna et al., 2004; Ruíz et al., 2005; Carbonell-Barrachina et al., 2006; Serrano-Megías y López-Nicolás, 2006).

\section{a) Influencia del estado de maduración}

El estado de maduración del fruto influye sobre la composición aromática del mismo. En la bibliografía se ha descrito que la síntesis de muchos de los compuestos volátiles derivados de la degradación de los lípidos, como son aldehídos y alcoholes, es dependiente del proceso de maduración en tomate (Yilmaz et al., 2002b). De hecho, una de las principales causas de la baja calidad que se percibe en la mayoría de los tomates comerciales es su recolección en un estado de maduración excesivamente temprano, principalmente por razones de transporte y comercialización (Kader et al., 1977; Watada y Aulenbach, 1979; Stern et al., 1994; Maul et al., 1998). Para estudiar la influencia de la maduración en el perfil aromático del tomate, se llevó a cabo la caracterización de la FVL de 2 variedades de tomate, especialmente relevantes económica y organolépticamente, Moneymaker (MM) y Raf, en 3 momentos del proceso de maduración, $\mathrm{V}, \mathrm{P}, \mathrm{y} \mathrm{M}$.

En general, la concentración de los compuestos detectados en la FVL aumentó a medida que avanzó la maduración del fruto, alcanzando su máximo nivel en el estado M (Tabla 10), lo que está de acuerdo con otros trabajos previos (Baldwin et al., 1991b; Buttery, 1993; Tieman et al., 2006). Sin embargo, no todos los compuestos volátiles siguieron esta tendencia. Algunos alcanzaron su máxima concentración en el estado $\mathrm{P}$, como 3metil-1-butanol, octanal, y bencil alcohol en la variedad MM. Otros, tendieron a disminuir conforme avanzó la maduración, alcanzando su 
máxima concentración en el estado de maduración $\mathrm{V}$. Estos compuestos fueron el trans-2-hexenal en ambas variedades, 2-etil-1-hexanol en la variedad MM, y salicilato de metilo en la variedad Raf. Otros no experimentaron cambios significativos en sus concentraciones durante el proceso de maduración del fruto, estos compuestos fueron el nerol y decanal en ambas variedades, nonanal, salicilato de metilo, y 2-feniletanol en la variedad MM, y 1-octanal, 2-etil-1-hexanol, y 3,5-dimetil benzaldehído en la variedad Raf.

En la bibliografía se ha descrito la disminución de eugenol (Baldwin et al., 1991b), la ausencia de cambios significativos en la concentración de linalol (Gao et al., 2007), y el aumento de trans-2-hexenal (Kazeniac y Hall, 1970; Baldwin et al., 1991b; Tieman et al., 2006; Gao et al., 2007) durante el proceso de maduración de distintas variedades de tomate destinadas al consumo en fresco. En nuestras condiciones experimentales, la concentración de eugenol y linalol tendió a aumentar, y la de trans-2hexenal a disminuir significativamente en algún momento del proceso de maduración en las 2 variedades analizadas (Tabla 10). A pesar de que el proceso de maduración de los frutos, y en particular del tomate, ha sido un fenómeno ampliamente estudiado, los datos cuantitativos que se encuentran en la bibliografía en ocasiones son confusos o incluso contradictorios. Por ejemplo, en la bibliografía se ha descrito tanto la disminución (Tieman et al., 2006) como el aumento (Baldwin et al., 1991b) de 2-isobutiltiazol durante la maduración, así como la disminución (Baldwin et al., 1991b) y la ausencia de cambios significativos (Gao et al., 2007) en la concentración de eugenol durante la maduración del tomate.

Los resultados de la caracterización de la FVL de las variedades MM y Raf (Tabla 10) sugieren que la contribución al aroma del 3-metil-1butanol en el estado de maduración $\mathrm{V}$ es probablemente despreciable, pues no fue detectado. 
Por otro lado, las diferencias significativas encontradas entre los estados de maduración $\mathrm{V}$ y $\mathrm{P}$ respecto al $\mathrm{M}$, al representar la suma ponderada de 7 de los 10 compuestos definidos por Buttery (1993) como aquellos cuya mezcla a la concentración adecuada reproduce de forma aproximada el aroma del tomate troceado maduro (Figura 10), confirman que estos compuestos (cis-3-hexenal, cis-3-hexenol, hexanal, 1-pentén-3ona, 3-metilbutanal, trans-2-hexenal, 6-metil-5-heptén-2-ona, salicilato de metilo, 2-isobutiltiazol y $\beta$-ionona) son más abundantes en la FVL del tomate maduro, $\mathrm{M}$.

Finalmente, de acuerdo con el análisis estadístico, el número de compuestos cuya concentración en la FVL resultó significativamente diferente entre las variedades MM y Raf aumentó conforme avanzó la maduración (Figura 11, Figura 12, Figura 13). Entre las diferencias encontradas en la composición de la FVL de ambas variedades destaca la concentración significativamente superior de 2-isobutiltiazol y eugenol en la FVL de la variedad MM en los estados de maduración $\mathrm{P}$ y $\mathrm{M}$, y la de linalol y 2-feniletanol en la FVL de la variedad Raf en el estado de maduración M. Estos 4 compuestos son muy interesantes, de acuerdo con la bibliografía, desde el punto de vista de su repercusión organoléptica para el tomate y la variabilidad que se observa en su concentración entre las variedades MM y Raf podría contribuir a las diferencias sensoriales establecidas entre ambas variedades. Los resultados de la comparación de la composición de la FVL entre las variedades MM y Raf confirman la especificidad que existe entre cada variedad de tomate y su FVL, mostrando además que esta especificidad se hace aún más marcada a medida que la maduración de los frutos avanza. 
b) Contribución teórica de cada compuesto volátil al aroma del tomate a través del logaritmo de las unidades de olor (LogU)

El aroma de algunas frutas y verduras puede asociarse a un único compuesto volátil dominante, como es el caso de la banana (Musa acuminata Colla) y el 3-metilbutil acetato (Marriott, 1980). Sin embargo, el aroma final del tomate es el resultado de una mezcla compleja de compuestos, entre los cuales sólo un número limitado juega un papel principal, y el resto aporta al aroma final notas más sutiles (para revisión ver Baldwin et al., 2000), pero que puede ser igualmente importante en la calidad final. El logaritmo del cociente entre la concentración de un compuesto en el fruto y su umbral de percepción en agua (LogU) se ha postulado como una excelente herramienta para intentar abordar el complejo aroma del tomate. El LogU permite estimar de forma teórica la contribución individual de un compuesto volátil sobre el flavor final de un alimento (ver apartado 2.2 de la Introducción).

Los valores positivos de LogU obtenidos para hexanal, trans-2hexenal, octanal, cis-3-hexenol, decanal, guaiacol, y eugenol en la FVL de las variedades $\mathrm{p} 73$, Jorge, Durinta, MM, y Raf (Tabla 8 ) sugieren que estos compuestos pueden juegar un papel destacado en el aroma final de estas variedades. Por otro lado, el LogU de 3-metil-1-butanol fue negativo en la variedad Jorge, y el de 1-hexanol en las variedades Raf y MM, mientras que en el resto de variedades ambos compuestos presentaron valores de LogU positivos. Estas diferencias en el signo de LogU podrían ser relevantes para explicar las diferencias sensoriales existentes entre las variedades Raf y MM, y p73, Jorge, y Durinta.

En los 3 estados de maduración considerados de las variedades MM y Raf, se obtuvieron valores positivos de LogU (Tabla 11) para hexanal, trans-2-hexenal, octanal, cis-3-hexenol, guaiacol, y eugenol en ambas variedades, y para el decanal en la variedad Raf. Estos resultados apoyan la hipótesis, sugerida por otros autores (para revisión ver Baldwin et al., 
2000), de que estos compuestos contribuyen de manera fundamental al aroma final del tomate, y que además lo hacen en los 3 estados de maduración considerados. Por otro lado, los LogU de 6-metil-5-heptén-2ona y 1-hexanol en ambas variedades, y de 2-isobutiltiazol y decanal en la variedad MM, evolucionaron desde valores negativos a positivos durante la maduración de los frutos. En la variedad Raf los valores de LogU de 2isobutiltiazol evolucionaron a cada vez menos negativos y los de decanal a cada vez más positivos, con la maduración. Probablemente, 6-metil-5heptén-2-ona, 1-hexanol, 2-isobutiltiazol, y decanal juegan un importante papel en el aroma final de estas variedades en el estado maduro, M. En efecto, el 6-metil-5-heptén-2-ona y el 2-isobutiltiazol se encuentran en el grupo de compuestos que reproducen el aroma del tomate troceado maduro propuesto por Buttery (1993). Por otro lado, el 1-hexanol y el decanal podrían ser compuestos particulares del estado de maduración $\mathrm{M}$ de las variedades MM y Raf. Contrariamente a la evolución de estos compuestos, el LogU del salicilato de metilo en la variedad Raf cambió su signo de positivo a negativo, y en la variedad MM se hizo cada vez más negativo, a medida que avanzó la maduración. Posiblemente, el salicilato de metilo juega un importante papel en la percepción del aroma a tomate verde, y su pérdida puede ser importante en la conversión al aroma de tomate maduro, especialmente de la variedad Raf, resultado que coincide con otros trabajos previos (Gao et al., 2007). Aunque el salicilato de metilo es uno de los 10 compuestos cuya mezcla reproduce el aroma del tomate troceado maduro (Buttery, 1993), su concentración en dicha mezcla es de las más bajas.

Los cambios observados en el signo de LogU durante la maduración, ya sean ascendentes o descendentes, contribuyen a comprender las enormes diferencias aromáticas percibidas entre tomates maduros y verdes. Por otro lado, las diferencias en el valor de LogU de distintos compuestos volátiles entre las variedades MM y Raf sugieren la existencia 
de diferencias sensoriales entre ambas variedades. Finalmente, los resultados de LogU obtenidos indicarían que tan sólo unos pocos compuestos contribuyen de forma principal al aroma del tomate, en concordancia con lo que ya ha sido descrito en la bibliografía (para revisión ver Baldwin et al., 2000). El resto de componentes, muchos de ellos con valor de LogU negativo, podría aportar notas de fondo, ciertas características varietales o, sencillamente, no tendrían ninguna influencia significativa.

Al interpretar los resultados del cálculo del LogU hay que tener en cuenta las limitaciones de este parámetro. Como simplificación de un sistema complejo, el LogU no considera las consecuencias sensoriales de las múltiples interacciones que pueden surgir entre los distintos componentes de mezclas complejas (Lawless, 1986), incluyendo la propia matriz del tomate (Tandon et al., 2000; Bezman et al., 2003; Plotto et al., 2004; Ruíz et al., 2005), y en especial los componentes del flavor, azúcares, ácidos, compuestos volátiles, y textura (Pétro-Turza, 1987; Buttery, 1993; Malundo et al., 1995; Baldwin et al., 2000; Baldwin et al., 2004).

Finalmente, a la hora de extraer conclusiones sobre la composición de la FVL del tomate, es importante tener en cuenta que la homogeneización del tomate en zumo puede favorecer la formación de productos derivados de la oxidación enzimática. Además, esta capacidad de oxidación parece que aumenta con el estado de maduración de los frutos (Baldwin et al., 1991b). De manera que, aunque las muestras utilizadas en este trabajo fueron procesadas con rapidez, la concentración de algunos compuestos pudo aumentar o disminuir como resultado de esta manipulación. Por ejemplo, el cis-3-hexenal es un componente clave en el flavor del tomate, pero al mismo tiempo se trata también de un compuesto altamente inestable (Buttery et al., 1987; Buttery et al., 1988a). 
Aparentemente isomeriza rápidamente a trans-2-hexenal durante los procesos de preparación y análisis de las muestras (Kazeniac y Hall, 1970; Gray et al., 1999), de manera que el pico de trans-2-hexenal detectado por GC-MS en este trabajo podría representar el contenido de cis-3-hexenal en la muestra ya que la cantidad de trans-2-hexenal en el fruto intacto es prácticamente inapreciable (Riley y Thompson, 1998). Por otro lado, el cis3-hexenal se degrada con rapidez si los frutos se someten a bajas temperaturas o a procesos de congelación (Buttery et al., 1987; Buttery, 1993; Maul et al., 2000). Probablemente, en nuestras condiciones experimentales, no se detectó cis-3-hexenal debido, por un lado, a la isomerización cis-trans y, por otro, al uso de muestras de zumo de tomate congeladas en los experimentos planteados. En consecuencia, quizá los niveles de trans-2-hexenal detectados en este trabajo fueron también más elevados de lo que cabría esperar.

\subsubsection{Caracterización de la fracción glicosilada}

Los estudios realizados durante las 2 últimas décadas han constatado la presencia de precursores de compuestos volátiles glicosilados en el tomate, tanto fresco como procesado (Buttery et al., 1990b; Marlatt et al., 1992; Buttery, 1993; Baldwin et al., 2000). Estos aglicones no pueden ser percibidos por los receptores olfativos, y forman parte de la denominada FG. En el presente estudio se ha caracterización la FG de las variedades de tomate p73, Jorge, Durinta, Moneymaker (MM), y Raf, tras hidrólisis enzimática mediante el preparado comercial AR2000, en el estado de maduración $\mathrm{P}$, y posterior detección y cuantificación de los aglicones volátiles resultantes.

Los compuestos 1-heptanol, 2-etil-1-hexanol, 1-octanol, salicilato de metilo, guaiacol, y 2-metoxi-4-vinilfenol se han descrito por primera vez como parte de la FG del tomate (Tabla 9) en el presente trabajo. 
Entre los 32 aglicones detectados en la FG de las variedades p73, Jorge, Durinta, Moneymaker (MM), y Raf tras la hidrólisis enzimática de los glicósidos (Tabla 9), se encuentran aldehídos, alcoholes, y terpenos. Los aglicones más abundantes, comunes a las 5 variedades analizadas, fueron 3-metil-1-butanol, trans-2-hexenal, bencil alcohol, y 2-feniletanol. El 2feniletanol ha sido descrito previamente en la bibliografía como uno de los componentes mayoritarios en la FG del tomate (Marlatt et al., 1992).

Los resultados del análisis estadístico confirman la existencia de diferencias, tanto cuantitativas como cualitativas, en la composición de la FG entre las diferentes variedades de tomate (Tabla 9). Desde un punto de vista cuantitativo, sólo la concentración de hexanal y de 1-hexanol no fue significativamente diferente entre ninguna de las 5 variedades analizadas. El aglicón más abundante detectado en las variedades Jorge, Durinta, y Raf fue el bencil alcohol. En la variedad p73 fue el 2-feniletanol. Y en la variedad MM fue el trans-2-hexenal. En cuanto a las diferencias cualitativas, los compuestos cis-3-hexenol, 3-octanona, octanal, nonanal, decanal, y $\beta$-Ionona sólo fueron detectados en las variedades MM y Raf. Mientras que cis-4-decenal y 2-metoxi-4-vinilfenol lo fueron sólo en las variedades $\mathrm{p73}$, Jorge, y Durinta. La ausencia de 2-isobutiltiazol glicosilado en la variedad Raf puede estar asociada a leves fluctuaciones del grado de maduración de los frutos en el momento del análisis, pues sí fue detectado en el estado de maduración $\mathrm{M}$ de la misma variedad (Tabla 12).

El conjunto de resultados obtenidos a partir de la caracterización de la FG, muestra, al igual que la caracterización de la fracción volátil libre, que la variedad de tomate tiene una importante influencia en la composición y abundancia de los glicósidos de compuestos volátiles del tomate.

\section{a) Influencia del estado de maduración}

La influencia del estado de maduración sobre la composición de la FG de otros frutos, como el mango (Lalel et al., 2003) y la nectarina 
(Aubert et al., 2003), ha sido previamente descrita en la bibliografía. En estos frutos se ha constatado que, en general, la concentración de los compuestos volátiles detectados en la FG tras hidrólisis enzimática, y en particular la de los monoterpenoles y norisoprenoides C13, aumenta con el estado de maduración del fruto. Para analizar la influencia del estado de maduración del fruto sobre la composición de la FG del tomate se llevó a cabo la incubación de extractos de la FG, extraída de las variedades MM y Raf por ser variedades especialmente interesantes económica y organolépticamente, en presencia del preparado enzimático comercial AR2000, en 3 momentos del proceso de maduración del fruto, $V, P, y ~ M$.

En general, la concentración de los aglicones aumentó conforme avanzó la maduración, alcanzando su máximo en el estado M (Tabla 12). Del análisis estadístico se desprende que algunos aglicones no experimentaron cambios significativos en su concentración durante la maduración, como el guaiacol en la variedad MM, y el trans-2-hexenal, 4metil-1-pentanol, 1-hexanol, 1-heptanol, trans-óxido de linalol, y benzaldehído en la variedad Raf. Aunque también se detectaron compuestos cuya concentración disminuyó, siendo más abundantes en la FG en el estado de maduración V. Estos fueron el octanal, cis- y transóxido de linalol, benzaldehído, linalol, y guaiacol en ambas variedades, y de cis-3-hexenol y 2-etil-1-hexanol en la variedad Raf. Resulta especialmente relevante la posibilidad de liberar en el estado $\mathrm{V}$ los compuestos volátiles cis- y trans-óxido de linalool, benzaldehído, y linalol, asociados a notas florales y frutales que, según la biliografía, influyen además sobre la sensación de dulzor del fruto (Baldwin et al., 2004), ya que, en general, tomates más dulces son mejor aceptados (Malundo et al., 1995). La posibilidad de liberar estos aglicones a la FVL del tomate en estados de maduración tempranos del fruto podría ser una forma de mejorar la percepción de un tomate de calidad por parte del consumidor sin tener por ello que prolongar el tiempo de maduración del fruto en la planta, 
con las consiguientes ventajas para su posterior distribución y comercialización.

Por otro lado, de acuerdo con el análisis estadístico, la variabilidad que se observa en la composición de la FG entre las variedades MM y Raf durante el proceso de maduración del fruto (Figura 15, Figura 16, Figura 17), confirma la especificidad que existe entre cada variedad de tomate y su $F G$, especificidad que se hace aún más marcada a medida que la maduración de los frutos avanza. Los aglicones linalol, salicilato de metilo, nerol, geraniol, y 2-feniletanol fueron significativamente diferentes entre las 2 variedades en los 3 estados de maduración considerados. Este resultado sugiere que estos 5 compuestos podrían ser de ayuda a la hora de distinguir entre las variedades MM y Raf, independientemente del estado de maduración en el que se encontraran los frutos.

\subsubsection{Potencial aromático de la fracción glicosilada}

La caracterización de la FG ha mostrado la existencia de compuestos interesantes por su posible papel organoléptico positivo y que, por tanto, puede ser una fuente natural de aroma con la que enriquecer la FVL, lo que está de acuerdo con otros trabajos previos (Buttery et al., 1990b; Marlatt et al., 1992; Buttery, 1993; Baldwin et al., 2000). Sin embargo, el alcance sensorial que puede tener la liberación de los aglicones volátiles no sólo es dependiente de la cantidad del compuesto glicosilado que potencialmente pueda ser hidrolizado sino también de la cantidad de ese mismo compuesto que ya se encuentre de forma natural en forma libre.

Resultan de especial interés los compuestos volátiles detectados sólo en forma glicosilada (4-metil-1-pentanol, 3-metil-1-pentanol, cis-óxido de linalol, 6-metil-5-heptén-2-ol, trans-óxido de linalol, benzaldehído, $\alpha$ terpineol, $\beta$-citronelol, geraniol, y 2-metoxi-4-vinilfenol), ya que su potencial liberación podría implicar un cambio cualitativo en la composición de la FVL del tomate. En particular, la liberación del benzaldehído y de los 
terpenoles cis- y trans-óxidos de linalol, $\alpha$-terpineol, $\beta$-citronelol, y geraniol, podría suponer una mejora del flavor del tomate, puesto que, según la bibliografía, por un lado son compuestos que aportan notas florales y frutales al aroma (Marais, 1983; Knudsen et al., 1993; Krumbein y Auerswald, 1998; Burdock, 2002; Lewinsohn et al., 2005b), y por otro, intensifican la sensación de dulzor del fruto (Baldwin et al., 2004).

Por otro lado, la potencial liberación de compuestos como 3octanona, octanal, 1-hexanol, cis-3-hexenol, nonanal, 2-isobutiltiazol, 1heptanol, decanal, cis-4-decenal, 1-octanol, guaiacol, o $\beta$-ionona, minoritarios en forma glicosilada (Tabla 9) y más abundantes en su forma libre (Tabla 7), no es esperable que produjera un impacto significativo sobre la FVL del tomate.

Los 9 compuestos cuyas concentraciones en el zumo de tomate, fueron mayores en la FG que en la FVL (Figura 8) son especialmente interesantes por su posible impacto cuantitativo sobre la FVL. Entre ellos destacan por su trascendencia organoléptica, según la bibliografía, el trans-2-hexenal, linalol, nerol, bencil alcohol, 2-feniletanol, y eugenol. La concentración de linalol podría aumentar en forma libre entre entre un 1400 $\%$ y un $2800 \%$, en función de la variedad, considerando la hidrólisis total de su precursor glicosilado. Este resultado está de acuerdo con la mayor abundancia de ciertos terpenoles, y particularmente de linalol (Baek y Cadwallader, 1999), en la FG respecto a la FVL en uva descrita en la bibliografía (Günata et al., 1988). El salicilato de metilo es otro de los compuestos que destaca porque podría aumentar su concentración en forma libre entre un $40 \%$ y $1200 \%$, en función de la variedad. Sin embargo, su aumento quizá no sería tan interesante para el flavor del tomate como en los casos anteriores pues, según la bibliografía, se trata de un compuesto volátil característico de estados inmaduros o verdes, menos apreciados organolépticamente en tomate. 
a) Influencia del estado de maduración

Los compuestos 4-metil-1-pentanol y 3-metil-1-pentanol en los estados $\mathrm{P}$ y $\mathrm{M}$, el trans-óxido de linalol en los estados $\mathrm{V}$ y $\mathrm{P}$, y el cis-óxido de linalol, 6-metil-5-heptén-2-ol, benzaldehído, $\alpha$-terpineol, $\beta$-citronelol, y geraniol en los estados $\mathrm{V}, \mathrm{P}, \mathrm{y} \mathrm{M}$, fueron detectados únicamente en forma glicosilada en las variedades MM y Raf (Tabla 10 y Tabla 12). La liberación de estos compuestos implicaría un cambio cualitativo en la composición de la FVL. Entre ellos destacan el benzaldehído, y los terpenoles cis- y transóxidos de linalol, geraniol, $\alpha$-terpineol, y $\beta$-citronelol que han sido descritos en trabajos anteriores por su contribución con notas florales y frutales al aroma y por potenciar la sensación de dulzor del tomate, como ya se comentó anteriormente.

Durante el proceso de maduración, en la FG de las variedades MM y Raf (Figura 18), resultan especialmente interesantes los mismos compuestos cuyas concentraciones fueron mayores en forma glicosilada que en forma libre en el estado de maduración $P$ de las variedades $p 73$, Jorge, Durinta, MM, y Raf (Figura 8). Destacan por su trascendencia organoléptica el trans-2-hexenal, linalol, nerol, bencil alcohol, 2-feniletanol, y eugenol. Los máximos aumentos en la concentración en forma libre de nerol, bencil alcohol, 2-feniletanol, y eugenol se alcanzarían en el estado M. Su concentración podría incrementarse hasta un $460 \%$, un $700 \%$, un $810 \%$, y un $1930 \%$, respectivamente. El máximo aumento que podría alcanzar el trans-2-hexenal se conseguiría en el estado $P$, hasta un 1500 $\%$. Si se liberara todo el linalol glicosilado el máximo aumento de su concentración en la FVL se conseguiría en el estado V, hasta un $6400 \%$. Estos resultados muestran que el estado de maduración en el que se encuentran los frutos puede resultar muy relevante a la hora de establecer el momento idóneo en el que realizar los tratamientos enzimáticos. Como se ha demostrado, se puede conseguir la liberación de compuestos en el estado de maduración $\mathrm{V}$ del fruto que pueden contribuir a incrementar la 
percepción a tomate maduro. Por otro lado, puesto que todos los estados de maduración se alcanzaron en planta, sería interesante estudiar además, la influencia de la maduración en planta o post-cosecha de los frutos, y las posibles implicaciones en la composición de las fracciones volátiles. 


\section{CAPÍTULO 2. EMPLEO DE GLICOSIDASAS PARA LA LIBERACIÓN DE COMPUESTOS VOLÁTILES GLICOSILADOS DEL TOMATE}

La caracterización de la fracción volátil del tomate, abordada en el Capítulo 1, ha mostrado el potencial de la fracción glicosilada (FG) como una fuente natural para incrementar el aroma de este fruto. Para estudiar la viabilidad de conseguir esta posible mejora organoléptica, así como información sobre los glicósidos, se planteó analizar la utilidad de ciertas glicosidasas fúngicas que ya se habían mostrado útiles en la hidrólisis de glicósidos en uva. Para ello se realizaron 2 tipos de experimentos. En primer lugar ensayos de adición de estas actividades enzimáticas directamente al zumo de tomate e incubación a temperatura controlada para medir el posible incremento en los componentes de la fracción volátil en el zumo. En segundo lugar se llevaron a cabo ensayos de adición de estos enzimas sobre extractos de los glicósidos de tomate en condiciones tamponadas y a mayor temperatura para poder conocer los efectos que estos enzimas pueden tener sobre los glicósidos del tomate en condiciones de incubación cercanas a las óptimas para las actividades analizadas, y poder valorar los azúcares resultantes tras la hidrólisis con cada uno delos enzimas o sus combinaciones. El conocimiento de los azúcares ofrece información sobre la composición de los glicósidos y, por tanto, de las actividades específicas que pueden ser de mayor utilidad en su hidrólisis. Sin embargo, es importante tener en cuenta que los compuestos volátiles glicosilados que pueden resultar interesantes para el aroma final son sólo una fracción del total de compuestos glicosilados del tomate, como por ejemplo norisoprenoides o muchos derivados fenólicos, por lo que no se puede extraer una correlación directa entre los azúcares y los volátiles liberados. Las actividades glicosídicas utilizadas en esta segunda parte se encuentran entre las que posee el preparado enzimático comercial AR2000, ampliamente utilizado en investigaciones similares en otros 
frutos, particularmente en vino (Baek y Cadwallader, 1999; Aubert et al., 2003), y del que nos servimos en el capítulo anterior para caracterizar la FG del tomate. Los enzimas utilizados forman parte de la colección recopilada por el grupo de investigación en Enzimas y levaduras vínicas del Departamento de Biotecnología del Instituto de Agroquímica y Tecnología de los Alimentos (IATA-CSIC). Además, se dispone de su caracterización bioquímica y de los genes clonados, por lo que su utilidad como herramienta biotecnológica es particularmente relevante, tanto para su posible producción industrial como para abordar, en el futuro, la creación de transgénicos de tomate.

\section{Producción de extractos enriquecidos con las actividades BgIN, Exg1, RhaA, y AbfB}

Las actividades glicosídicas de origen fúngico, como la $\beta$ glucosidasa, la $\alpha$-L-arabinofuranosidasa, o la $\alpha$-L-ramnosidasa, han sido objeto de múltiples estudios por su potencial aplicación en la mejora del aroma del vino (Sarry y Günata, 2004). Las cepas de Saccharomyces cerevisiae de origen vínico transformadas genéticamente en el IATA para sobreexpresar los genes que codifican la actividad $\beta$-glucosidasa de Candida molischiana -BgIN (Sánchez-Torres et al., 1998), la exoglucanasa de S. cerevisiae -Exg1 (Gil et al., 2005), la $\alpha$-L-ramnosidasa de Aspergillus aculeatus -RhaA (Manzanares et al., 2003) y la $\alpha$-L-arabinofuranosidasa de Aspergillus niger -AbfB (Sánchez-Torres et al., 1996), han sido utilizadas con éxito en el proceso de vinificación en laboratorio para hidrolizar los glicósidos presentes en el mosto y en el vino.

Para los primeros ensayos de incubación de los enzimas BgIN y Exg1 en zumo de tomate se utilizaron los enzimas producidos previamente en este laboratorio a partir de las cepas de levadura $\mathrm{T}_{73} / \mathrm{YCB}_{5}$ y $\mathrm{T}_{73} /$ YCEXG1a, respectivamente, según la metodología descrita en 
Materiales y Métodos consistente en concentrar hasta obtener los extractos enriquecidos con esas actividades y precipitar los enzimas.

Para producir los enzimas glicosídicos BgIN, Exg1, RhaA, y AbfB en cantidad suficiente para llevar a cabo el resto de experimentos se utilizaron las cepas de $S$. cerevisiae $\mathrm{T}_{73} / \mathrm{YCB}_{5}, \mathrm{~T}_{73} / \mathrm{YCEXG1a}, \mathrm{T}_{73} / \mathrm{YR} 8$, y $\mathrm{T}_{73} / \mathrm{YCA}_{1}$, respectivamente. La metodología utilizada se basó en la diferente localización de las actividades enzimáticas producidas por las distintas cepas así como en las propiedades bioquímicas de los enzimas (Apartado 2 de Materiales y Métodos). Tras el crecimiento de las respectivas cepas de levadura en medio YPD, se midió la actividad de cada uno de los enzimas a partir del sobrenadante del lavado de las células con $\mathrm{NaCl} 1 \mathrm{M}, \mathrm{y}$ directamente del sobrenadante del medio de cultivo. En el sobrenadante de los medios de cultivo de las distintas cepas se obtuvo más del $90 \%$ de la actividad total de los enzimas Exg1, AbfB, y RhaA, pero menos del 20 $\%$ de la actividad BgIN, que se localizó preferentemente en las células. Estos resultados confirman la localización de BgIN principalmente en la pared celular de la levadura (Sánchez-Torres et al., 1998), y que los enzimas Exg1, AbfB, y RhaA son principalmente secretados al medio de cultivo por las cepas productoras (Sánchez-Torres et al., 1996; Manzanares et al., 2003; Gil et al., 2005).

La Figura 19 muestra los valores de actividad del enzima BgIN obtenido tras elución en columna cromatográfica a partir del sobrenadante de lavados de las células con $\mathrm{NaCl} 1 \mathrm{M}$. Se define 1 unidad de actividad $\left(U_{\text {enz }}\right)$ como la cantidad de enzima que libera $1 \mu \mathrm{mol}$ de pNP por minuto a $30{ }^{\circ} \mathrm{C}$ en tampón Mcllvaine $75 \mathrm{mM}$ pH 5. En la Figura 19 se observa como las mismas células de la cepa productora de BgIN se lavaron hasta 9 veces consecutivas obteniendo siempre niveles apreciables de actividad $\beta$ glucosidasa, en el sobrenadante de dichos lavados. 


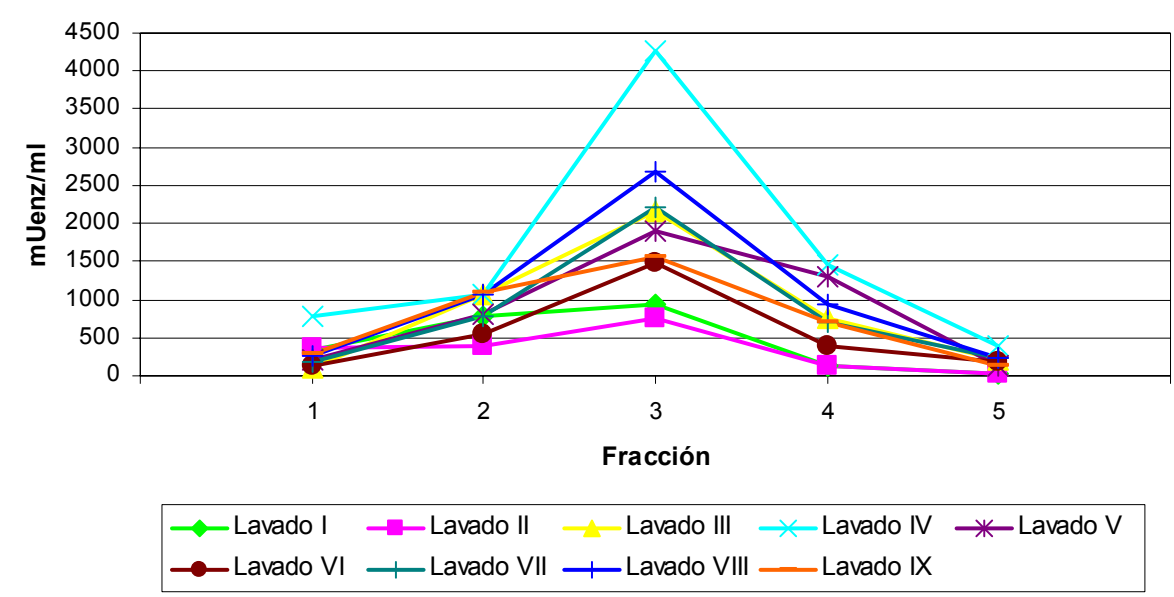

Figura 19. Actividad $\beta$-glucosidasa del enzima BgIN medida en las 5 fracciones cromatográficas.

La Figura 20 muestra los valores de actividad de los enzimas Exg1, RhaA, y AbfB, obtenidos tras la concentración del sobrenadante del medio de cultivo.

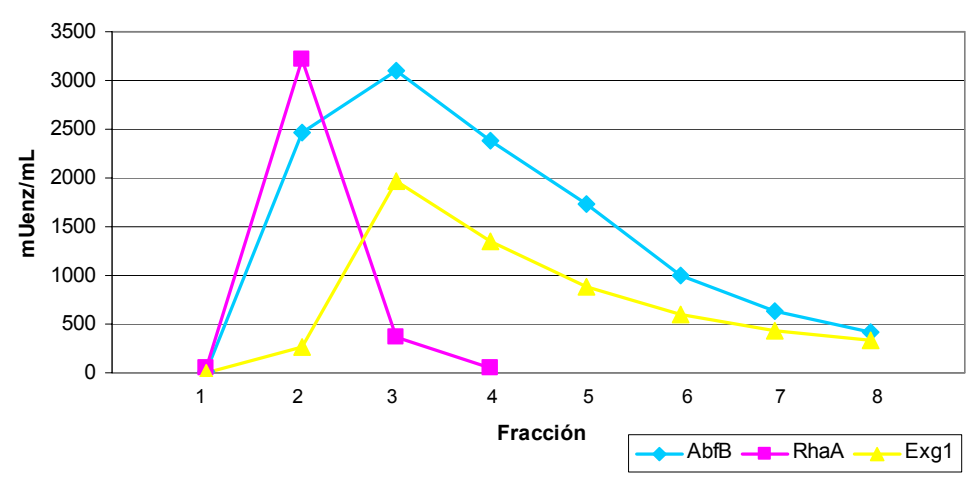

Figura 20. Actividad de los enzimas Exg1, AbfB, y RhaA medida en las sucesivas fracciones cromatográficas. La fracción 1 resultó de eluir con $10 \mathrm{~mL}$, y el resto con $5 \mathrm{~mL}$.

Para definir las condiciones de almacenamiento que garantizaran la mayor estabilidad de los enzimas durante el transcurso de los experimentos se midió la actividad de todos los extractos, con y $\sin$ filtración $(0.45 \mu \mathrm{m})$, tras una semana de conservación a $4^{\circ} \mathrm{C}$ y $-20^{\circ} \mathrm{C}$. A partir de los resultados obtenidos se decidió filtrar todos los extractos y 
conservar a $-20^{\circ} \mathrm{C}$ los enzimas BgIN, Exg1, y AfbB, y a $4{ }^{\circ} \mathrm{C}$ RhaA. A los extractos de los enzimas AbfB y RhaA también se les midió la actividad $\beta$ glucosidasa, obteniendo respectivamente un $0.39 \%$ y un $0.24 \%$ respecto a su actividad principal.

En la Tabla 13 se recoge la actividad enzimática de las fracciones utilizadas en los experimentos de adición de glicosidasas al zumo de tomate (Exp1), y al extracto de los glicósidos de tomate (Exp2).

Tabla 13. Actividad enzimática $\left(\mathrm{mU}_{\mathrm{enz}} / \mathrm{mL}\right)$ de las fracciones utilizadas en los posteriores experimentos.

\begin{tabular}{|c|c|c|c|}
\hline Enzima & Actividad & Exp1 & Exp2 \\
\hline $\mathrm{BgIN}$ & $\overline{\beta \text {-glucosidasa }}$ & 205.7 & 2550 \\
\hline Exg1 & $\beta$-glucosidasa & 556.8 & 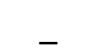 \\
\hline RhaA & $\alpha$-ramnosidasa & 724.9 & 745.3 \\
\hline AbfB & $\alpha$-arabinosidasa & 868.7 & 2928 \\
\hline
\end{tabular}

Exp1: experimento de adición de glicosidasas al zumo de tomate. Exp2: experimento de adición de glicosidasas al extracto de glicósidos. Se define 1 unidad de actividad $\left(\mathrm{U}_{\mathrm{enz}}\right)$ como la cantidad de enzima que libera $1 \mu \mathrm{mol}$ de pNP por minuto a $30^{\circ} \mathrm{C}$ en tampón Mcllvaine $75 \mathrm{mM} \mathrm{pH} 5$.

\section{Efecto de la adición de los enzimas BgIN y Exg1 al zumo de las varidades de tomate p73, Jorge, y Durinta (Ortiz-Serrano y Gil, 2007)}

Los enzimas BgIN y Exg1 poseen actividad $\beta$-glucosidasa capaz de hidrolizar el enlace $\beta$-1,4-glicosídico y por tanto de liberar el aglicón unido al residuo de glucosa. La capacidad de estas actividades enzimáticas para liberar compuestos volátiles en el vino ha sido previamente descrita (Genovés et al., 2003; Gil et al., 2005). En primer lugar se evaluó el efecto de estos 2 enzimas en la liberación de compuestos volátiles a partir del zumo de tomate al ser esta una aproximación más simple, tanto tecnológica como metodológicamente, que la adición de mezclas de enzimas, más dirigida a la hidrólisis de diglicósidos. Como sustrato se escogió el zumo extraído de las variedades p73, Jorge, y Durinta, en 
estado de maduración pintón $(P)$. Las muestras de zumo $(3 \mathrm{~mL})$, con y sin enzimas añadidos, se incubaron a $15^{\circ} \mathrm{C}$ durante 6 días.

La Tabla 14 muestra la concentración de los 24 compuestos, por orden de elución cromatográfica, detectados en la FVL de las variedades p73, Jorge, y Durinta tras la incubación sin adición de enzima (BLC), en presencia de BgIN (BGLN), y en presencia de Exg1 (EXG1), así como las diferencias estadísticamente significativas entre los 3 tratamientos analizados.

Tabla 14. Concentración $(\mu \mathrm{g} / \mathrm{L})$ de los compuestos volátiles detectados tras la incubación de los zumos extraídos de las variedades $\mathrm{p73}$, Jorge, y Durinta sin adición de enzima (BLC), con adición de BgIN (BGLN), y de Exg1(EXG1).

\begin{tabular}{|c|c|c|c|c|c|c|c|c|c|}
\hline \multirow{2}{*}{ Compuestos } & \multicolumn{3}{|c|}{ p73 } & \multicolumn{3}{|c|}{ Jorge } & \multicolumn{3}{|c|}{ Durinta } \\
\hline & BLC & BGLN & EXG1 & BLC & BGLN & EXG1 & BLC & BGLN & EXG1 \\
\hline Hexanal & $610.7 \mathrm{a}$ & $578.4 \mathrm{a}$ & $545.5 \mathrm{a}$ & $169.5 \mathrm{a}$ & 166.9 a & $191.1 \mathrm{~b}$ & $149.1 \mathrm{a}$ & $172.0 \mathrm{a}$ & $185.0 \mathrm{a}$ \\
\hline 3-Metil-1-butanol & 1065 a & $1377 \mathrm{~b}$ & 1057 a & $313.1 \mathrm{a}$ & $445.3 \mathrm{~b}$ & $314.1 \mathrm{a}$ & $510.6 \mathrm{a}$ & $611.3 b$ & $507.1 \mathrm{a}$ \\
\hline trans-2-hexenal & $694.8 \mathrm{a}$ & 745.6 a & $677.4 \mathrm{a}$ & $68.90 \mathrm{a}$ & $63.26 \mathrm{a}$ & $72.85 \mathrm{a}$ & $43.27 \mathrm{a}$ & 39.56 a & $45.05 \mathrm{a}$ \\
\hline 3-Octanona & $0.666 \mathrm{a}$ & $0.630 \mathrm{a}$ & $0.582 \mathrm{a}$ & $1283 a$ & $1.303 \mathrm{a}$ & $1.301 \mathrm{a}$ & $1.522 \mathrm{~b}$ & $1.400 \mathrm{a}$ & $1.467 a b$ \\
\hline Octanal & $0.997 \mathrm{a}$ & $0.942 \mathrm{a}$ & $0.895 \mathrm{a}$ & $0.866 \mathrm{a}$ & $0.843 a$ & 0.877 a & $2.125 \mathrm{a}$ & $2.058 \mathrm{a}$ & $2.463 \mathrm{a}$ \\
\hline 6-Metil-5-hepten-2-ona & $354.7 \mathrm{a}$ & $354.8 \mathrm{a}$ & $338.4 \mathrm{a}$ & $17.11 \mathrm{a}$ & 16.87 a & $19.01 \mathrm{a}$ & $12.99 \mathrm{a}$ & $11.92 \mathrm{a}$ & $13.18 \mathrm{a}$ \\
\hline 1-Hexanol & $154.7 \mathrm{a}$ & $33.75 \mathrm{a}$ & $41.07 \mathrm{a}$ & $910.5 \mathrm{a}$ & 849.4 a & $943.1 \mathrm{a}$ & $665.5 \mathrm{a}$ & $611.3 \mathrm{a}$ & $721.4 \mathrm{a}$ \\
\hline cis-3-hexenol & $151.9 \mathrm{a}$ & $178.7 \mathrm{a}$ & $158.8 \mathrm{a}$ & $2350 a b$ & 2158 a & $2387 b$ & 1797 a & 1694 a & 1765 a \\
\hline Nonanal & $0.264 \mathrm{a}$ & $0.290 \mathrm{a}$ & $0.266 \mathrm{a}$ & $0.198 \mathrm{a}$ & $0.179 a$ & $0.272 \mathrm{a}$ & $0.380 \mathrm{a}$ & $0.236 a$ & $0.362 \mathrm{a}$ \\
\hline 2-Isobutiltiazol & $5.587 \mathrm{a}$ & $5.934 \mathrm{a}$ & $5.669 \mathrm{a}$ & $0.949 a$ & $1.110 a b$ & $1.466 \mathrm{~b}$ & $0.498 \mathrm{a}$ & $0.459 \mathrm{a}$ & $0.593 a$ \\
\hline 1-Heptanol & $3.930 \mathrm{a}$ & $5.451 \mathrm{a}$ & $5.019 \mathrm{a}$ & $6.487 \mathrm{a}$ & $7.008 \mathrm{a}$ & $6.734 \mathrm{a}$ & $7.392 \mathrm{a}$ & $8.207 \mathrm{a}$ & $7.697 \mathrm{a}$ \\
\hline 2-Etil-1-hexanol & $5.742 \mathrm{a}$ & $10.92 \mathrm{~b}$ & 6.939 a & $14.94 \mathrm{a}$ & $21.93 \mathrm{a}$ & $22.87 \mathrm{a}$ & $6.081 \mathrm{a}$ & $8.370 \mathrm{a}$ & $6.872 \mathrm{a}$ \\
\hline Decanal & $0.175 \mathrm{a}$ & $0.132 \mathrm{a}$ & $\operatorname{tr}$ & $0.162 \mathrm{a}$ & $0.106 \mathrm{a}$ & $\operatorname{tr}$ & $0.214 \mathrm{~b}$ & $0.123 a$ & $0.149 \mathrm{a}$ \\
\hline cis-4-decenal & $\operatorname{tr}$ & $\operatorname{tr}$ & $\operatorname{tr}$ & $0.257 a$ & $0.220 a$ & $0.259 a$ & $0.569 \mathrm{a}$ & $0.383 a$ & $0.469 a$ \\
\hline Linalool & $4.122 \mathrm{a}$ & $5.855 b$ & $4.504 \mathrm{a}$ & $0.702 \mathrm{a}$ & $0.802 \mathrm{a}$ & $0.863 \mathrm{a}$ & $0.734 \mathrm{a}$ & $0.868 \mathrm{a}$ & $0.767 \mathrm{a}$ \\
\hline 1-Octanol & $1.058 \mathrm{a}$ & $1.177 \mathrm{a}$ & $1.091 \mathrm{a}$ & $5.717 \mathrm{ab}$ & $5.156 \mathrm{a}$ & $5.962 \mathrm{~b}$ & $7.832 \mathrm{~b}$ & $6.303 \mathrm{a}$ & $6.978 \mathrm{a}$ \\
\hline Salicilato de metilo & $341.3 \mathrm{a}$ & $322.1 \mathrm{a}$ & 315.8 a & 3.386 a & $3.340 \mathrm{a}$ & $4.508 \mathrm{~b}$ & $1.327 \mathrm{a}$ & $1.538 \mathrm{a}$ & $1.523 \mathrm{a}$ \\
\hline Nerol & $1.851 \mathrm{a}$ & $1.993 \mathrm{a}$ & $1.712 \mathrm{a}$ & $1.924 \mathrm{a}$ & $1.463 \mathrm{a}$ & $1.561 \mathrm{a}$ & $0.962 \mathrm{a}$ & $1.115 \mathrm{a}$ & $1.485 \mathrm{~b}$ \\
\hline 3,5-Dimetil benzaldehído & $3.807 \mathrm{a}$ & $3.525 \mathrm{a}$ & $3.498 \mathrm{a}$ & $3.115 \mathrm{a}$ & $3.389 a$ & $3.616 \mathrm{a}$ & $2.922 \mathrm{a}$ & $3.055 \mathrm{a}$ & $3.074 \mathrm{a}$ \\
\hline Guaiacol & 2622 a & 2918 a & 2671 a & $530.5 \mathrm{~b}$ & $242.7 \mathrm{a}$ & 344.8 a & $387.7 \mathrm{~b}$ & $212.8 \mathrm{a}$ & $288.5 \mathrm{ab}$ \\
\hline Bencil alcohol & $457.1 \mathrm{a}$ & $348.4 \mathrm{a}$ & $420.4 \mathrm{a}$ & $358.1 \mathrm{a}$ & $266.5 \mathrm{a}$ & $293.2 \mathrm{a}$ & $592.3 \mathrm{~b}$ & $374.1 \mathrm{a}$ & 395.9 a \\
\hline 2-Feniletanol & $150.5 \mathrm{a}$ & $2189 \mathrm{c}$ & $1031 \mathrm{~b}$ & 351.6 a & $2335 \mathrm{~b}$ & $2195 b$ & $154.8 \mathrm{a}$ & $1803 \mathrm{c}$ & $1415 \mathrm{~b}$ \\
\hline$\beta$-Ionona & $1.856 \mathrm{~b}$ & $1.275 \mathrm{a}$ & $1.474 \mathrm{a}$ & $0.504 \mathrm{a}$ & $0.285 a$ & 0.497 a & $0.821 \mathrm{a}$ & $0.432 \mathrm{a}$ & $0.695 a$ \\
\hline Eugenol & $166.8 \mathrm{a}$ & $214.2 \mathrm{~b}$ & $162.2 \mathrm{a}$ & $121.4 \mathrm{a}$ & $178.9 \mathrm{~b}$ & $275.6 \mathrm{c}$ & $10.00 \mathrm{a}$ & $6.026 \mathrm{a}$ & $9.524 \mathrm{a}$ \\
\hline
\end{tabular}

tr: concentración $<0.1 \mu \mathrm{g} / \mathrm{L}$.

Diferentes letras para cada compuesto indican diferencias significativas entre los 3 tratamientos dentro de cada variedad según el Test de Tukey's HSD aplicado con un intervalo de confianza del $95 \%$ a 3 repeticiones.

Los compuestos volátiles detectados se encuentran entre los citados en la bibliografía como componentes de la FVL del tomate (Buttery et al., 1990a; Marlatt et al., 1992; Buttery, 1993; Langlois et al., 1996; Krumbein y Auerswald, 1998; Baldwin et al., 2000) y coinciden con los identificados 
como componentes de la FVL de las variedades $p 73$, Jorge, y Durinta (Tabla 7).

De acuerdo con el análisis estadístico se desprende que la concentración de 16 compuestos mostraron diferencias significativas entre alguno de los 3 tratamientos analizados. En el caso del cis-3-hexenol y del 1-octanol en la variedad Jorge las diferencias sólo se observaron entre los zumos incubados en presencia de BgIN y de Exg1, pero no respecto al BLC. En el resto de compuestos, las diferencias encontradas se tradujeron en aumentos o disminuciones significativas de sus concentraciones en la FVL, con respecto al BLC.

En la Figura 21, se muestra la concentración de los 10 compuestos volátiles que aumentaron significativamente en la FVL, con respecto al BLC, tras la incubación del zumo extraído de las variedades p73, Jorge, y Durinta en presencia de los enzimas, BgIN y/o Exg1. Estos compuestos fueron el hexanal, 3-metil-1-butanol, 2-isobutiltiazol, 2-etil-1-hexanol, cis-4decenal, linalol, salicilato de metilo, nerol, 2-feniletanol, y eugenol. Los aumentos observados se dieron mayoritariamente en las variedades Jorge y p73, y su cuantía osciló entre un $13 \%$ de incremento del hexanal en la variedad Jorge incubada con Exg1, y un $1354 \%$ de incremento del 2feniletanol en la variedad p73 incubada con BgIN, respecto al BLC.

La concentración de 3-metil-1-butanol en las 3 variedades, y la de 2etil-1-hexanol y linalol en la variedad p73, aumentó significativamente sólo en los zumos incubados en presencia de BgIN. Mientras que la concentración de hexanal, 2-isobutiltiazol y salicilato de metilo en la variedad Jorge, y la de nerol en la variedad Durinta, aumentó sólo en los zumos incubados con adición de Exg1. La concentración de 2-feniletanol y eugenol aumentó significativamente tras incubación del zumo tanto con adición de BgIN como de Exg1, aunque la magnitud de cada aumento varió en función de la variedad considerada. 

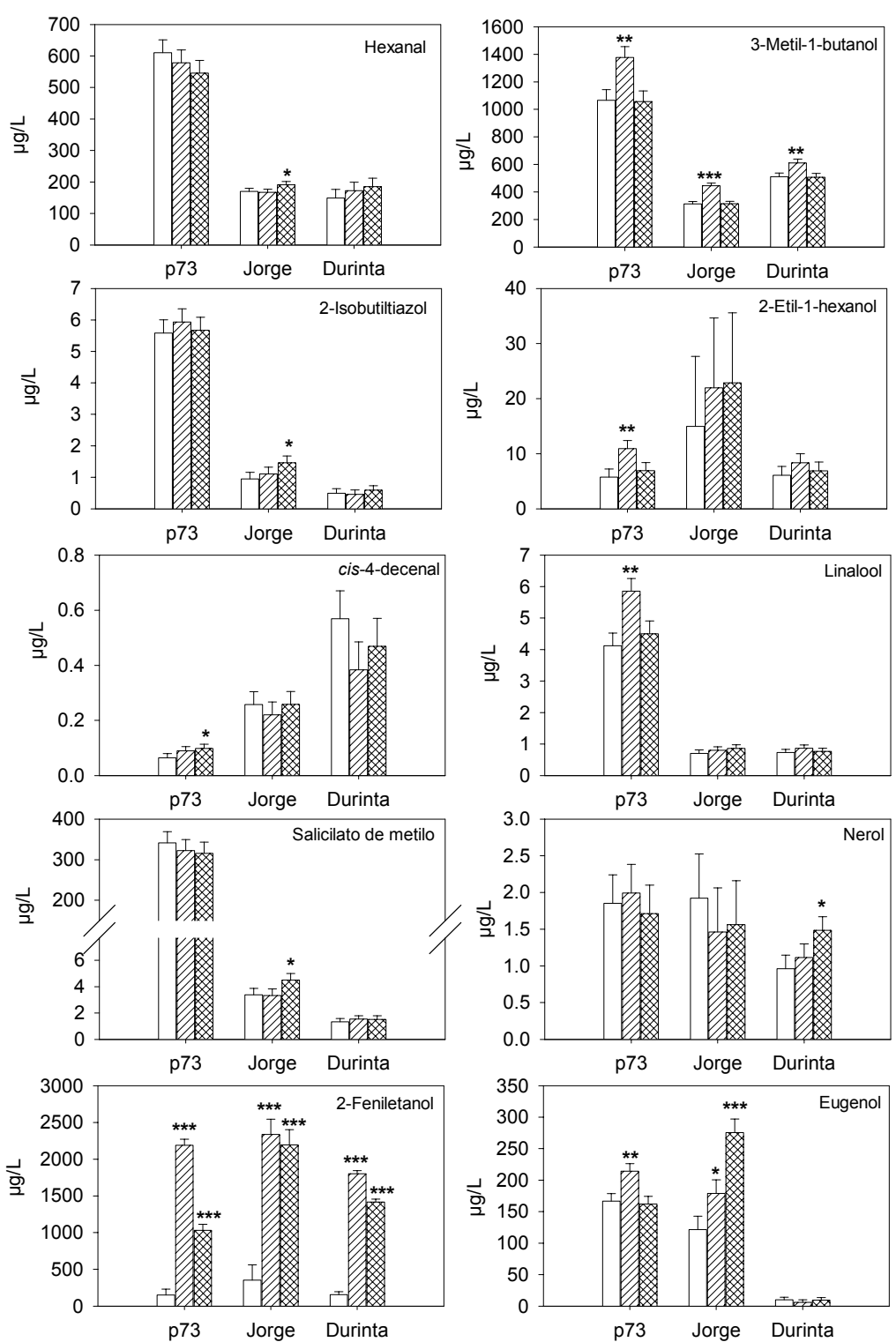

Figura 21. Concentración de los compuestos volátiles que aumentaron significativamente tras la incubación de los zumos de las variedades p73, Jorge, y Durinta en presencia de BgIN y/o Exg1. ${ }^{*} p<0.05,{ }^{* *} p<0.01,{ }^{* * *} p<0.001$, según el Test de Tukey's HSD aplicado con un intervalo de confianza del $95 \%$ a 3 repeticiones. Barras en blanco para el zumo incubado sin enzima (BLC), barras con rayas diagonales para el tratamiento con $\mathrm{Bg} I \mathrm{~N}, \mathrm{y}$ barras con rombos para el tratamiento con Exg1. 
Así, en las variedades p73 y Durinta el aumento de 2-feniletanol fue mayor tras incubación en presencia de BgIN, y en la variedad Jorge no se observaron diferencias significativas entre los aumentos obtenidos tras incubación con ambos enzimas. Su concentración experimentó los mayores aumentos detectados por un componente de la FVL, resultando entre 6.2 y 14.5 veces superior en los zumos incubados con enzimas que en los BLCs. Además, el 2-feniletanol, fue el único compuesto que aumentó su concentración en la $\mathrm{FVL}$ en las 3 variedades independientemente del enzima empleado. El aumento de eugenol en la variedad Jorge fue mayor tras incubación con Exg1, mientras que en la variedad p73 su concentración sólo aumentó tras incubación en presencia de BgIN.

Tras la incubación del zumo extraído de las variedades p73, Jorge, y Durinta en presencia de los enzimas BgIN y Exg1 también se observaron algunas disminuciones que resultaron estadísticamente significativas en las concentraciones de 6 componentes de la FVL (Figura 22). Estos compuestos fueron la 3-octanona, decanal, 1-octanol, guaiacol, bencil alcohol, y $\beta$-ionona. La cuantía de estas disminuciones osciló entre el $8 \%$ de la 3-octanona en el zumo de la variedad Durinta incubada con BgIN, y el $54 \%$ de guaiacol en el zumo de la variedad Jorge incubado también con BgIN. En los zumos de la variedad p73 se registró una disminución de $\beta$ ionona debida a la incubación en presencia de Exg1 ó BgIN. En la variedad Jorge sólo se detectó la disminución significativa de la concentración de guaiacol, igualmente registrada tras la incubación con Exg1 ó BgIN. En el zumo de la variedad Durinta se registró la disminución significativa de 5 compuestos, 3-octanona, decanal, 1-octanol, guaiacol, y bencil alcohol. 

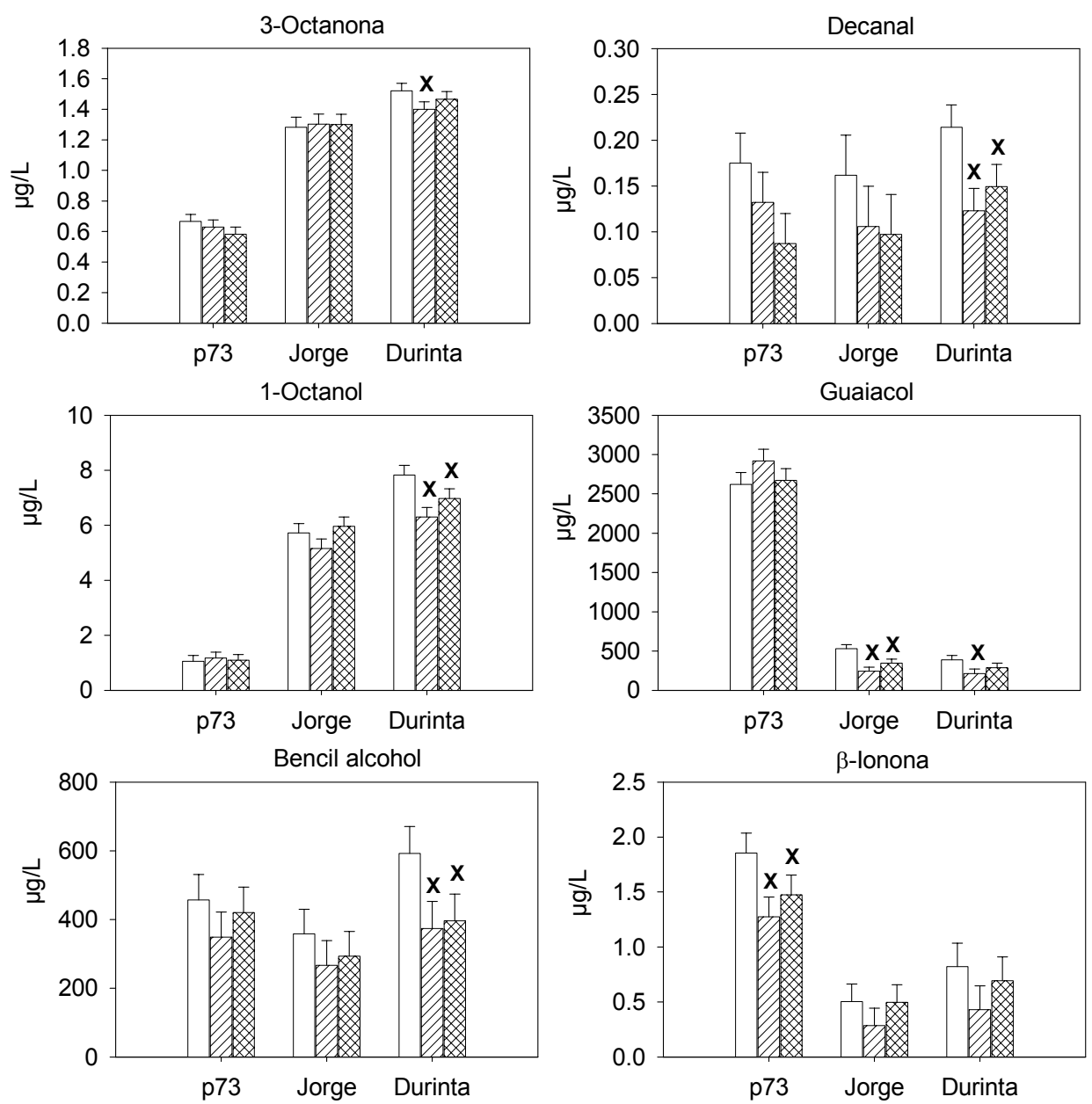

Figura 22. Concentración de los compuestos volátiles que disminuyeron significativamente tras la incubación de los zumos de las variedades p73, Jorge, y Durinta en presencia de BgIN y/o Exg1. X p < 0.05 según el Test de Tukey's HSD aplicado con un intervalo de confianza del $95 \%$ a 3 repeticiones. Barras en blanco para el zumo incubado sin enzima (BLC), barras con rayas diagonales para el tratamiento con BgIN, y barras con rombos para el tratamiento con Exg1.

Como ya se comentó en el Capítulo 1, el logaritmo del cociente entre la concentración de un compuesto volátil en el fruto y su umbral de percepción en agua ( $\mathrm{Log} U$ ) resulta una excelente herramienta para estimar la contribución individual teórica de un compuesto sobre el flavor final de un alimento. La Tabla 15 muestra los LogU de los compuestos detectados 
tras 6 días de incubación a $15^{\circ} \mathrm{C}$ en presencia de BgIN y Exg1. Los LogU se calcularon utilizando los umbrales de percepción en agua citados en la bibliografía.

Tabla 15. LogU de los compuestos volátiles detectados tras la incubación del zumo extraído de las variedades p73, Jorge, y Durinta sin adición de enzima (BLC), con adición de BgIN (BGLN), y de Exg1 (EXG1).

\begin{tabular}{|c|c|c|c|c|c|c|c|c|c|c|}
\hline \multirow{2}{*}{ Compuestos } & \multirow{2}{*}{$\begin{array}{l}\text { Umbral de } \\
\text { Percepción }\left(^{*}\right)\end{array}$} & \multicolumn{3}{|c|}{ p73 } & \multicolumn{3}{|c|}{ Jorge } & \multicolumn{3}{|c|}{ Durinta } \\
\hline & & BLC & BGLN & EXG1 & BLC & BGLN & EXG1 & BLC & BGLN & EXG1 \\
\hline Hexanal & $4.5^{(1)}$ & 2.133 & 2.109 & 2.084 & 1.576 & 1.569 & 1.628 & 1.520 & 1.582 & 1.614 \\
\hline 3-Metil-1-butanol & $250^{(1)}$ & 0.629 & 0.741 & 0.626 & 0.098 & 0.251 & 0.099 & 0.310 & 0.388 & 0.307 \\
\hline trans-2-hexenal & $17^{(2)}$ & 1.611 & 1.642 & 1.600 & 0.608 & 0.571 & 0.632 & 0.406 & 0.367 & 0.423 \\
\hline 3-Octanona & $28^{(3)}$ & -1.624 & -1.648 & -1.682 & -1.339 & -1.332 & -1.333 & -1.265 & -1.301 & -1.281 \\
\hline Octanal & $0.7^{(4)}$ & 0.154 & 0.129 & 0.107 & 0.092 & 0.081 & 0.098 & 0.482 & 0.468 & 0.546 \\
\hline 6-Metil-5-hepten-2-ona & $50^{(1)}$ & 0.851 & 0.851 & 0.830 & -0.466 & -0.472 & -0.420 & -0.585 & -0.623 & -0.579 \\
\hline 1-Hexanol & $500^{(1)}$ & -0.510 & -1.171 & -1.085 & 0.260 & 0.230 & 0.276 & 0.124 & 0.087 & 0.159 \\
\hline cis-3-hexenol & $70^{(2)}$ & 0.336 & 0.407 & 0.356 & 1.526 & 1.489 & 1.533 & 1.410 & 1.384 & 1.402 \\
\hline Nonanal & $1^{(3)}$ & -0.578 & -0.537 & -0.575 & -0.703 & -0.747 & -0.566 & -0.420 & -0.628 & -0.442 \\
\hline 2-Isobutilitiazol & $3.5^{(1)}$ & 0.203 & 0.229 & 0.209 & -0.567 & -0.499 & -0.378 & -0.847 & -0.882 & -0.771 \\
\hline 1-Heptanol & $425^{(4)}$ & -2.034 & -1.892 & -1.928 & -1.816 & -1.783 & -1.800 & -1.760 & -1.714 & -1.742 \\
\hline 2-Etil-1-hexanol & $270000^{(5)}$ & -4.672 & -4.393 & -4.590 & -4.257 & -4.090 & -4.072 & -4.647 & -4.509 & -4.594 \\
\hline $\begin{array}{l}\text { Decanal } \\
\text { cis-4-decenal }\end{array}$ & $\begin{array}{c}0.1^{(3)} \\
-\end{array}$ & 0.243 & 0.121 & $\operatorname{tr}$ & 0.209 & 0.026 & $\operatorname{tr}$ & 0.331 & 0.091 & 0.174 \\
\hline Linalool & $6^{(1)}$ & -0.163 & -0.011 & -0.125 & -0.932 & -0.874 & -0.842 & -0.913 & -0.839 & -0.893 \\
\hline 1-Octanol & $110^{(1)}$ & -2.017 & -1.971 & -2.004 & -1.284 & -1.329 & -1.266 & -1.148 & -1.242 & -1.198 \\
\hline Salicilato de metilo & $40^{(1)}$ & 0.931 & 0.906 & 0.897 & -1.072 & -1.078 & -0.948 & -1.479 & -1.415 & -1.419 \\
\hline Nerol & $300^{(6)}$ & -2.210 & -2.178 & -2.244 & -2.193 & -2.312 & -2.284 & -2.494 & -2.430 & -2.305 \\
\hline 3,5-Dimetil benzaldehído & - & & & & & & & & & \\
\hline Guaiacol & $3^{(2)}$ & 2.942 & 2.988 & 2.950 & 2.248 & 1.908 & 2.060 & 2.111 & 1.851 & 1.983 \\
\hline Bencil alcohol & $10000^{(3)}$ & -1.340 & -1.458 & -1.376 & -1.446 & -1.574 & -1.533 & -1.227 & -1.427 & -1.402 \\
\hline 2-Feniletanol & $1000^{(1)}$ & -0.823 & 0.340 & 0.013 & -0.454 & 0.368 & 0.341 & -0.810 & 0.256 & 0.151 \\
\hline$\beta$-Ionona & $4^{(1)}$ & -0.333 & -0.496 & -0.434 & -0.900 & -1.147 & -0.905 & -0.688 & -0.967 & -0.760 \\
\hline Eugenol & $6^{(2)}$ & 1.444 & 1.553 & 1.432 & 1.306 & 1.475 & 1.662 & 0.222 & 0.002 & 0.201 \\
\hline
\end{tabular}

UP: Umbral de percepción de cada compuesto en agua ( $\mu \mathrm{g} / \mathrm{L}) .\left(^{*}\right)$ Referencia bibliográfica: $\left(^{\star}\right)$ Referencia bibliográfica: Buttery, $1993^{(1)}$; Buttery et al., $1971^{(2)}$; Buttery et al., $1988^{(3)}$; Pino y Mesa, $2006^{(4)}$; Fazzalari, $1978^{(5)}$; Ohloff, $1994^{(6)}$. tr: concentración $<0.1 \mu \mathrm{g} / \mathrm{L}$.

Como consecuencia de los aumentos experimentados por la concentración de 2-feniletanol en la FVL tras la incubación del zumo en presencia de BgIN y Exg1, en cualquiera de las 3 variedades analizadas, el signo de su LogU cambió desde valores negativos en el BLC a positivos tras la incubación en presencia de los enzimas. No ocurrió lo mismo con los 6 compuestos cuyas concentraciones disminuyeron tras la incubación en presencia de BgIN y/o Exg1. A pesar de ser estadísticamente significativas, estas disminuciones no se tradujeron en cambios en el signo del LogU entre el BLC y los zumos incubados con los enzimas. Por su posible repercusión favorable en el aroma resulta interesante señalar que 
el linalol obtuvo un valor de LogU muy próximo a cero tras incubar el zumo de la variedad p73 con BgIN.

\section{Experimentos de adición de actividades glucosidasa, ramnosidasa,} y arabinosidasa al zumo de tomate en distintos estados de maduración

Los experimentos de adición de distintas actividades glicosídicas al zumo de tomate se definieron en base a que, en primer lugar, la incubación del zumo de tomate con las actividades enzimáticas BgIN y Exg1 dio lugar a incrementos significativos de algunos componentes de la FVL. Estos incrementos tienen la importancia de ser obtenidos con la intervención de una única actividad enzimática, lo que supone, de cara a una posible aplicación biotecnológica, una aproximación más simple y asequible que el empleo de 2 ó más enzimas. En segundo lugar, dado que el perfil de azúcares detectados tras la caracterización del extracto de glicósidos del tomate mostró cantidades significativas de ramnosa, arabinosa, y xilosa (Capítulo 1, Figura 14), se realizaron experimentos de incubación en presencia de las actividades arabinosidasa y ramnosidasa junto con actividades glucosidasa para conocer si la utilización de estos enzimas, solos o en combinación, podían incrementar la concentración de los componentes de la FVL. Para llevar a cabo estos experimentos, se utilizó el zumo extraído de las variedades Moneymaker (MM) y Raf, en los estados de maduración $\mathrm{V}, \mathrm{P}$, y $\mathrm{M}$. Y se incubó durante 6 días a $20^{\circ} \mathrm{C}$ con los enzimas glicosídicos BgIN ( $\beta$-glucosidasa de Candida molischiana), Exg1 (exoglucanasa de Saccharomyces cerevisiae), RhaA ( $\alpha$-Lramnosidasa de Aspergillus aculeatus) y AbfB ( $\alpha$-L-arabinofuranosidasa de Aspergillus niger), individualmente y en combinaciones, $\mathrm{BgIN}+\mathrm{RhaA}$, BglN+AbfB, BglN+RhaA+AbfB, Exg1+RhaA, Exg1+AbfB, y Exg1+RhaA+AbfB. 
La Tabla 16 y la Tabla 17 muestran las concentraciones de todos los compuestos detectados en los 3 estados de maduración en las variedades MM y Raf, respectivamente. Los compuestos volátiles identificados se encuentran entre los citados en la bibliografía como componentes de la FVL del tomate, y coinciden con los compuestos identificados como componentes de la FVL de las variedades MM y Raf (Capítulo 1, Tabla 10), excepto por la ausencia de decanal y $\beta$-ionona, y por la presencia de cisóxido de linalol y geraniol, sí que fueron detectados, estos 2 últimos, en la FG (Capítulo 1, Tabla 12). Del análisis estadístico se desprende que 10 compuestos volátiles de la FVL de la variedad MM y otros 10 compuestos de la variedad Raf, incrementaron significativamente su concentración tras incubación con alguno de los extractos enzimáticos analizados o con mezclas de los mismos. Por otro lado, también se detectó la disminución significativa de hexanal y salicilato de metilo en la variedad MM, y de hexanal, octanal, nonanal, y salicilato de metilo en la variedad Raf. 
Tabla 16. Concentración $(\mu \mathrm{g} / \mathrm{L})$ de los compuestos volátiles detectados tras la incubación del zumo extraído de la variedad Moneymaker sin adición de enzimas (BLC), y en presencia de los enzimas BgIN, Exg1, RhaA, y AbfB, individualmente y combinados.

\begin{tabular}{|c|c|c|c|c|c|c|c|c|c|c|c|c|c|}
\hline \multirow{2}{*}{\multicolumn{2}{|c|}{ Compuesto / Maduración }} & \multirow{3}{*}{$\frac{\text { BLC }}{87.26}$} & \multicolumn{10}{|c|}{ Tratamiento Enzimático } & \multirow{3}{*}{$\begin{array}{l}\text { Tukey } \\
95 \% \\
8.815\end{array}$} \\
\hline & & & \multirow{2}{*}{$\frac{1}{87.55}$} & \multirow{2}{*}{$\frac{2}{77.84}$} & \multirow{2}{*}{$\frac{3}{58.93}$} & \multirow{2}{*}{$\begin{array}{c}4 \\
80.40\end{array}$} & \multirow{2}{*}{$\frac{5}{58.64}$} & \multirow{2}{*}{$\begin{array}{c}6 \\
68.06\end{array}$} & \multirow{2}{*}{$\frac{7}{59.69}$} & \multirow{2}{*}{$\frac{8}{61.29}$} & \multirow{2}{*}{$\frac{9}{69.18}$} & \multirow{2}{*}{$\frac{10}{61.21}$} & \\
\hline & $\mathrm{V}$ & & & & & & & & & & & & \\
\hline \multirow[t]{3}{*}{ 1-Hexanal } & $P$ & 1331 & 1337 & 1318 & 1295 & 1326 & 1317 & 1300 & 1279 & 1298 & 1206 & 1217 & 73.34 \\
\hline & M & 4381 & 4382 & 4468 & 4838 & 4241 & 4550 & 4477 & 4632 & 4361 & 4257 & 4611 & 388.1 \\
\hline & V & 107.1 & 86.15 & 58.16 & 639.1 & 86.15 & 798.5 & 60.65 & 834.4 & 669.7 & 64.56 & 657.4 & 63.40 \\
\hline \multirow[t]{3}{*}{ 3-Metil-1-butanol } & $P$ & 394.9 & 490.8 & 432.7 & 618.9 & 417.6 & 749.3 & 481.8 & 767.6 & 717.0 & 480.0 & 726.0 & 75.28 \\
\hline & M & 975.8 & 1125 & 1172 & 1493 & 1002 & 1733 & 1102 & 1770 & 1735 & 1107 & 1690 & 103.7 \\
\hline & V & 170.4 & 173.2 & 182.6 & 202.0 & 171.7 & 201.3 & 185.9 & 206.2 & 197.3 & 177.4 & 196.3 & 17.44 \\
\hline \multirow[t]{3}{*}{ trans-2-hexenal } & $P$ & 1649 & 1694 & 1628 & 1653 & 1680 & 1728 & 1697 & 1692 & 1701 & 1639 & 1632 & 51.96 \\
\hline & M & 1517 & 1658 & 1560 & 1582 & 1443 & 1606 & 1659 & 1661 & 1552 & 1527 & 1569 & 114.5 \\
\hline & $\mathrm{V}$ & 0.619 & 0.565 & 0.445 & 1.016 & 0.454 & 0.684 & 0.389 & 0.993 & 1.161 & 0.487 & 0.911 & 0.175 \\
\hline 3-Octanona & $\mathrm{P}$ & 1.083 & 1.333 & 1.588 & 1.711 & 1.290 & 1.663 & 1.037 & 2.002 & 2.020 & 1.336 & 2.074 & 0.583 \\
\hline & M & 1.053 & 0.935 & 1.252 & 1.375 & 1.073 & 1.414 & 1.086 & 1.565 & 1.497 & 1.155 & 1.824 & 0.339 \\
\hline & $\mathrm{V}$ & 4.505 & 4.413 & 3.829 & 3.181 & 4.161 & 4.353 & 3.698 & 3.815 & 2.938 & 3.667 & 3.760 & 0.978 \\
\hline Octanal & $P$ & 3.119 & 3.314 & 2.869 & 2.842 & 3.258 & 3.155 & 3.144 & 3.076 & 2.937 & 3.172 & 3.141 & 0.360 \\
\hline & M & 2.803 & 2.253 & 2.410 & 2.656 & 1.793 & 3.683 & 2.015 & 4.306 & 4.603 & 2.288 & 3.264 & 1.257 \\
\hline & V & nd & nd & nd & nd & nd & nd & nd & nd & nd & nd & nd & nd \\
\hline 6-Metil-5-hepten-2-ona & $P$ & 10.78 & 10.65 & 12.92 & 12.58 & 10.93 & 11.58 & 11.93 & 10.97 & 11.25 & 10.83 & 10.42 & 2.083 \\
\hline & M & 120.8 & 96.84 & 94.48 & 123.9 & 102.4 & 112.2 & 115.4 & 120.7 & 119.8 & 104.7 & 113.7 & 22.29 \\
\hline & $\mathrm{V}$ & 24.31 & 24.42 & 24.82 & 33.69 & 23.73 & 36.67 & 26.19 & 38.53 & 36.38 & 26.92 & 37.11 & 2.981 \\
\hline 1-Hexanol & $\mathrm{P}$ & 100.4 & 102.0 & 103.4 & 102.0 & 103.2 & 106.2 & 103.6 & 106.3 & 106.0 & 102.4 & 102.8 & 7.054 \\
\hline & M & 750.6 & 824.6 & 775.2 & 814.5 & 838.3 & 830.1 & 815.2 & 854.5 & 819.1 & 743.2 & 814.2 & 68.47 \\
\hline & V & 147.9 & 143.2 & 156.6 & 151.4 & 150.9 & 139.4 & 147.3 & 159.0 & 161.7 & 145.7 & 165.4 & 12.61 \\
\hline cis-3-hexenol & $P$ & 497.6 & 481.4 & 488.6 & 490.7 & 452.0 & 470.7 & 440.8 & 466.4 & 454.5 & 450.9 & 448.1 & 86.14 \\
\hline & M & 839.1 & 885.1 & 867.1 & 851.0 & 853.2 & 857.4 & 860.5 & 893.3 & 856.6 & 840.1 & 865.0 & 40.33 \\
\hline & $\mathrm{V}$ & 1.428 & 1.369 & 1.327 & 1.341 & 1.292 & 0.983 & 0.988 & 1.352 & 1.485 & 1.190 & 1.520 & 0.380 \\
\hline Nonanal & $P$ & 2.630 & 2.129 & 2.699 & 2.520 & 2.326 & 2.482 & 2.269 & 2.149 & 2.209 & 1.864 & 2.126 & 0.475 \\
\hline & M & 2.558 & 2.292 & 2.235 & 2.635 & 2.259 & 2.421 & 2.072 & 2.431 & 2.423 & 2.186 & 2.571 & 2.287 \\
\hline & V & nd & nd & nd & nd & nd & nd & nd & nd & nd & nd & nd & nd \\
\hline 2-Isobutiltiazol & $P$ & 1.183 & 1.001 & 1.223 & 1.304 & 1.180 & 1.339 & 1.050 & 1.051 & 1.088 & 1.019 & 1.100 & 0.322 \\
\hline & M & 12.63 & 12.87 & 12.67 & 12.36 & 12.19 & 12.69 & 12.65 & 12.92 & 12.58 & 12.21 & 12.40 & 0.641 \\
\hline & $\mathrm{V}$ & 42.90 & 41.57 & 36.64 & 34.64 & 48.46 & 32.79 & 37.42 & 35.86 & 31.86 & 42.42 & 28.12 & 9.299 \\
\hline cis-óxido de linalool & $P$ & 72.13 & 34.53 & 40.42 & 34.20 & 33.27 & 27.93 & 24.90 & 32.12 & 29.12 & 27.75 & 34.49 & 23.89 \\
\hline & M & 42.86 & 57.02 & 46.42 & 52.57 & 55.28 & 69.76 & 46.83 & 68.02 & 67.24 & 42.68 & 54.46 & 26.74 \\
\hline & V & 12.35 & 13.16 & 10.79 & 11.93 & 11.43 & 8.365 & 9.459 & 16.59 & 15.17 & 10.12 & 15.75 & 2.903 \\
\hline 1-Heptanol & P & 15.82 & 18.04 & 20.74 & 17.65 & 24.84 & 18.63 & 15.23 & 22.34 & 19.56 & 16.74 & 18.10 & 9.267 \\
\hline & M & 17.11 & 17.51 & 16.13 & 23.29 & 16.11 & 14.96 & 42.76 & 21.12 & 19.63 & 10.85 & 20.90 & 15.83 \\
\hline & V & 16.86 & 19.87 & 17.52 & 16.52 & 17.88 & 19.21 & 22.29 & 21.07 & 20.50 & 19.07 & 18.70 & 2.435 \\
\hline 2-Etil-1-hexanol & $\mathrm{P}$ & 10.64 & 14.13 & 12.57 & 12.39 & 11.49 & 15.18 & 13.84 & 15.31 & 13.55 & 12.77 & 13.23 & 1.338 \\
\hline & M & 18.15 & 20.34 & 18.14 & 20.02 & 18.07 & 23.15 & 21.35 & 24.73 & 24.81 & 18.42 & 23.44 & 4.005 \\
\hline & v & tr & $\operatorname{tr}$ & $\operatorname{tr}$ & $\operatorname{tr}$ & $\operatorname{tr}$ & $\operatorname{tr}$ & $\operatorname{tr}$ & $\operatorname{tr}$ & $\operatorname{tr}$ & $\operatorname{tr}$ & $\operatorname{tr}$ & $\operatorname{tr}$ \\
\hline cis -4-decenal & $P$ & tr & tr & $\operatorname{tr}$ & $\operatorname{tr}$ & $\operatorname{tr}$ & $\operatorname{tr}$ & $\operatorname{tr}$ & $\operatorname{tr}$ & $\operatorname{tr}$ & $\operatorname{tr}$ & $\operatorname{tr}$ & $\operatorname{tr}$ \\
\hline & M & 0.137 & 0.141 & 0.113 & 0.127 & 0.152 & 0.149 & 0.152 & 0.129 & 0.096 & 0.132 & 0.113 & 0.027 \\
\hline & V & 4.003 & 10.12 & 4.790 & 5.035 & 4.321 & 11.64 & 11.21 & 10.77 & 5.920 & 4.916 & 6.010 & 2.041 \\
\hline Linalool & $P$ & 3.683 & 5.976 & 3.951 & 4.543 & 4.514 & 7.570 & 6.951 & 7.862 & 5.308 & 4.679 & 5.097 & 1.723 \\
\hline & M & 4.986 & 9.426 & 6.302 & 5.680 & 5.816 & 9.440 & 9.329 & 9.947 & 6.818 & 6.416 & 6.304 & 2.654 \\
\hline & V & 4.521 & 4.740 & 4.623 & 4.098 & 4.585 & 4.909 & 4.463 & 4.859 & 4.580 & 4.973 & 4.456 & 0.372 \\
\hline 1-Octanol & $P$ & 4.468 & 4.699 & 5.395 & 4.755 & 4.664 & 4.856 & 5.229 & 4.654 & 4.965 & 4.763 & 4.739 & 0.492 \\
\hline & M & 5.737 & 6.072 & 5.932 & 6.168 & 5.899 & 7.238 & 5.940 & 7.175 & 6.726 & 5.995 & 6.523 & 0.752 \\
\hline
\end{tabular}




\begin{tabular}{|c|c|c|c|c|c|c|c|c|c|c|c|c|c|}
\hline \multirow{2}{*}{\multicolumn{2}{|c|}{ Compuesto / Maduración }} & \multirow{3}{*}{$\frac{\text { BLC }}{7.464}$} & \multicolumn{10}{|c|}{ Tratamiento Enzimático } & \multirow{3}{*}{$\begin{array}{l}\text { Tukey } \\
\frac{95 \%}{0.520}\end{array}$} \\
\hline & & & \multirow{2}{*}{$\frac{1}{8.524}$} & \multirow{2}{*}{$\frac{2}{7.442}$} & \multirow{2}{*}{$\frac{3}{4.628}$} & \multirow{2}{*}{$\frac{4}{7.495}$} & \multirow{2}{*}{$\frac{5}{6.052}$} & \multirow{2}{*}{$\frac{6}{8.112}$} & \multirow{2}{*}{$\frac{7}{5.662}$} & \multirow{2}{*}{$\frac{8}{5.609}$} & \multirow{2}{*}{$\frac{9}{7.366}$} & \multirow{2}{*}{$\frac{10}{5.304}$} & \\
\hline & V & & & & & & & & & & & & \\
\hline \multirow[t]{2}{*}{ Salicilato de metilo } & $P$ & 160.5 & 161.4 & 163.2 & 170.3 & 166.3 & 171.7 & 163.2 & 167.3 & 167.7 & 154.0 & 157.7 & 11.15 \\
\hline & M & 4.669 & 5.937 & 5.243 & 3.781 & 4.730 & 5.256 & 6.148 & 5.627 & 4.248 & 4.911 & 4.377 & 0.550 \\
\hline \multirow{3}{*}{ Nerol } & V & 9.248 & 9.790 & 9.461 & 9.888 & 9.367 & 10.21 & 9.463 & 10.17 & 10.13 & 9.829 & 9.740 & 0.689 \\
\hline & $P$ & 18.56 & 18.94 & 18.37 & 19.11 & 18.88 & 19.39 & 18.50 & 19.02 & 19.35 & 18.26 & 18.65 & 0.592 \\
\hline & M & 13.45 & 15.83 & 14.57 & 13.37 & 13.47 & 14.79 & 16.36 & 15.24 & 14.36 & 14.19 & 13.87 & 1.052 \\
\hline \multirow{3}{*}{ 3,5-Dimetil benzaldehído } & V & 2.265 & 2.452 & 2.433 & 5.295 & 2.490 & 5.963 & 2.791 & 5.209 & 4.760 & 2.500 & 5.050 & 0.570 \\
\hline & $P$ & 8.722 & 9.119 & 8.557 & 9.108 & 9.194 & 10.12 & 9.565 & 9.835 & 9.094 & 9.124 & 9.056 & 1.067 \\
\hline & M & 8.955 & 10.75 & 9.952 & 12.48 & 9.368 & 11.32 & 10.48 & 11.72 & 7.838 & 10.31 & 11.99 & 3.128 \\
\hline \multirow{3}{*}{ Geraniol } & V & 22.39 & 22.11 & 23.95 & 20.69 & 22.81 & 21.13 & 23.58 & 20.88 & 21.55 & 23.33 & 21.68 & 2.210 \\
\hline & $P$ & 34.50 & 36.33 & 36.34 & 37.03 & 37.07 & 38.58 & 36.27 & 37.98 & 40.83 & 36.04 & 38.92 & 4.691 \\
\hline & M & 23.92 & 31.07 & 27.04 & 19.45 & 26.02 & 25.14 & 28.42 & 25.46 & 24.16 & 25.72 & 21.11 & 6.342 \\
\hline \multirow{3}{*}{ Guaiacol } & V & 214.9 & 227.9 & 212.9 & 245.3 & 218.4 & 233.8 & 217.1 & 242.8 & 197.0 & 228.9 & 196.5 & 40.48 \\
\hline & $P$ & 254.8 & 307.4 & 245.9 & 347.1 & 318.4 & 335.2 & 308.5 & 295.1 & 369.2 & 276.2 & 320.4 & 81.78 \\
\hline & M & 234.2 & 232.6 & 200.6 & 184.7 & 223.0 & 201.2 & 272.3 & 214.3 & 188.4 & 215.4 & 184.1 & 55.37 \\
\hline \multirow{3}{*}{ Bencil alcohol } & $\mathrm{V}$ & 1549 & 1667 & 1691 & 1931 & 1543 & 1766 & 1478 & 1719 & 1700 & 1676 & 1713 & 236.6 \\
\hline & $P$ & 2579 & 2652 & 2747 & 2983 & 2701 & 2737 & 2810 & 2583 & 2733 & 2340 & 2566 & 524.4 \\
\hline & M & 1841 & 2073 & 2052 & 1638 & 1810 & 1931 & 2166 & 2001 & 1808 & 1892 & 1580 & 229.8 \\
\hline \multirow{3}{*}{ 2-Feniletanol } & V & 210.1 & 225.4 & 224.8 & 277.4 & 195.1 & 322.2 & 192.7 & 342.1 & 295.0 & 236.8 & 292.5 & 42.90 \\
\hline & $\mathrm{P}$ & 488.2 & 627.1 & 586.7 & 535.1 & 556.0 & 664.8 & 499.2 & 491.8 & 530.3 & 507.4 & 525.1 & 131.2 \\
\hline & M & 232.5 & 432.8 & 290.6 & 315.4 & 265.1 & 497.7 & 468.2 & 576.3 & 367.3 & 266.1 & 366.2 & 56.92 \\
\hline \multirow{3}{*}{ Eugenol } & V & 83.62 & 79.97 & 89.20 & 89.16 & 88.73 & 94.45 & 93.64 & 88.31 & 93.90 & 96.67 & 87.71 & 20.67 \\
\hline & $\mathrm{P}$ & 94.78 & 98.39 & 124.6 & 94.40 & 165.1 & 153.4 & 129.3 & 120.9 & 129.1 & 122.1 & 117.9 & 50.38 \\
\hline & M & 94.28 & 110.0 & 101.9 & 92.05 & 99.28 & 103.6 & 94.68 & 102.1 & 104.7 & 98.86 & 98.41 & 17.22 \\
\hline
\end{tabular}

BLC (Zumo incubado sin enzimas añadidos). Tratamientos enzimáticos: 1 (Zumo+BglN), 2 (Zumo+Exg1), 3 (Zumo+RhaA), 4 (Zumo+AbfB), 5 (Zumo+BgIN+RhaA), 6 (Zumo+AbfB), 7

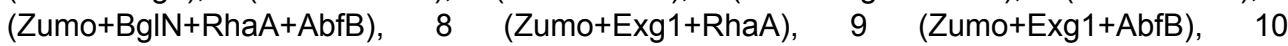
(Zumo+Exg1+RhaA+AbfB).

En rojo concentraciones que aumentaron significativamente, y en azul concentraciones que disminuyeron significativamente, tras incubación con algún tratamiento enzimático respecto al BLC, según el Test de Tukey's HSD aplicado con un intervalo de confianza del $95 \%$ a 3 repeticiones, para cada uno de los estados de maduración considerados, $\mathrm{V}, \mathrm{P}, \mathrm{y} \mathrm{M}$.

nd: compuesto no detectado; tr: concentración $<0.1 \mu \mathrm{g} / \mathrm{L}$. 
Tabla 17. Concentración $(\mu \mathrm{g} / \mathrm{L})$ de los compuestos volátiles detectados tras la incubación del zumo extraído de la variedad Raf sin adición de enzimas (BLC), y en presencia de los enzimas BgIN, Exg1, RhaA, y AbfB, individualmente y combinados.

\begin{tabular}{|c|c|c|c|c|c|c|c|c|c|c|c|c|c|}
\hline \multirow{2}{*}{\multicolumn{2}{|c|}{ Compuesto / Maduración }} & \multirow{3}{*}{$\frac{\text { BLC }}{188.9}$} & \multicolumn{10}{|c|}{ Tratamiento Enzimático } & \multirow{3}{*}{$\begin{array}{c}\text { Tukey } \\
95 \%\end{array}$} \\
\hline & & & \multirow{2}{*}{$\frac{1}{80.20}$} & \multirow{2}{*}{$\frac{2}{93.80}$} & \multirow{2}{*}{$\frac{3}{143.6}$} & \multirow{2}{*}{$\frac{4}{132.8}$} & \multirow{2}{*}{$\begin{array}{c}5 \\
149.2\end{array}$} & \multirow{2}{*}{$\frac{6}{73.70}$} & \multirow{2}{*}{$\frac{7}{151.2}$} & \multirow{2}{*}{$\frac{8}{146.1}$} & \multirow{2}{*}{$\frac{9}{127.1}$} & \multirow{2}{*}{$\frac{10}{101.2}$} & \\
\hline & $\mathrm{V}$ & & & & & & & & & & & & \\
\hline \multirow[t]{3}{*}{ 1-Hexanal } & $P$ & 2037 & 1922 & 2056 & 1967 & 2016 & 2008 & 2007 & 2022 & 1922 & 1860 & 1963 & 394.1 \\
\hline & M & 3875 & 3820 & 3784 & 4144 & 3637 & 3846 & 3439 & 4200 & 4122 & 3524 & 4086 & 378.1 \\
\hline & V & 75.74 & 73.83 & 51.38 & 630.4 & 87.10 & 791.5 & 82.09 & 828.8 & 766.3 & 58.16 & 731.7 & 72.77 \\
\hline \multirow[t]{3}{*}{ 3-Metil-1-butanol } & $P$ & 174.5 & 284.1 & 230.1 & 392.1 & 226.4 & 457.9 & 302.6 & 504.9 & 455.0 & 247.1 & 507.1 & 108.0 \\
\hline & M & 322.2 & 370.8 & 359.7 & 902.3 & 322.1 & 977.9 & 345.4 & 1059 & 991.0 & 334.6 & 979.4 & 86.25 \\
\hline & V & 275.2 & 284.7 & 184.1 & 340.3 & 194.9 & 342.9 & 303.4 & 333.8 & 318.3 & 256.7 & 200.4 & 95.17 \\
\hline \multirow[t]{3}{*}{ trans-2-hexenal } & $P$ & 2981 & 2863 & 2960 & 2904 & 2965 & 2986 & 2996 & 3011 & 2900 & 2885 & 2946 & 586.9 \\
\hline & M & 2435 & 2532 & 2383 & 2558 & 2319 & 2633 & 2385 & 2697 & 2576 & 2366 & 2605 & 127.0 \\
\hline & V & 0.747 & 0.636 & 0.913 & 0.849 & 0.524 & 0.845 & 0.462 & 0.737 & 0.814 & 0.593 & 1.207 & 0.317 \\
\hline 3-Octanona & $\mathrm{P}$ & 0.912 & 0.831 & 0.743 & 1.101 & 0.816 & 1.366 & 0.804 & 1.341 & 1.410 & 0.931 & 1.396 & 0.564 \\
\hline & $M$ & 0.848 & 0.865 & 1.050 & 1.266 & 0.836 & 1.226 & 0.898 & 1.234 & 1.683 & 0.863 & 1.386 & 0.446 \\
\hline & V & 4.563 & 3.688 & 1.472 & 3.137 & 3.213 & 3.129 & 3.404 & 3.197 & 3.867 & 1.911 & 2.259 & 1.278 \\
\hline Octanal & $P$ & 2.447 & 2.932 & 2.519 & 2.993 & 3.031 & 3.527 & 2.971 & 3.739 & 3.034 & 3.385 & 4.046 & 1.555 \\
\hline & M & 2.834 & 2.883 & 3.005 & 3.717 & 3.034 & 4.761 & 3.195 & 4.815 & 3.298 & 2.575 & 3.748 & 0.791 \\
\hline & V & nd & nd & nd & nd & nd & nd & nd & nd & nd & nd & nd & nd \\
\hline 6-Metil-5-hepten-2-ona & $P$ & 9.585 & 8.733 & 9.214 & 8.159 & 8.222 & 8.316 & 6.865 & 8.813 & 8.089 & 8.666 & 9.726 & 3.906 \\
\hline & M & 73.74 & 74.51 & 78.62 & 82.86 & 76.06 & 76.56 & 76.67 & 80.72 & 85.68 & 75.55 & 84.02 & 12.43 \\
\hline & V & 65.62 & 99.00 & 74.62 & 75.20 & 72.41 & 74.51 & 133.1 & 78.43 & 77.28 & 78.34 & 92.20 & 18.00 \\
\hline 1-Hexanol & $\mathrm{P}$ & 130.7 & 121.0 & 131.2 & 129.1 & 131.8 & 132.8 & 131.3 & 134.8 & 128.0 & 125.9 & 132.5 & 35.44 \\
\hline & M & 503.3 & 524.8 & 495.7 & 507.0 & 482.7 & 509.6 & 507.8 & 519.5 & 516.0 & 491.5 & 504.2 & 20.92 \\
\hline & V & 382.5 & 382.0 & 381.0 & 430.6 & 333.1 & 403.1 & 354.6 & 467.4 & 427.3 & 391.6 & 411.5 & 56.17 \\
\hline cis-3-hexenol & $P$ & 606.4 & 609.2 & 642.8 & 608.3 & 661.8 & 659.7 & 647.1 & 682.5 & 648.0 & 602.2 & 650.2 & 174.0 \\
\hline & M & 1088 & 1111 & 1079 & 1146 & 1052 & 1125 & 1065 & 1141 & 1133 & 1054 & 1102 & 69.78 \\
\hline & V & 0.796 & 0.656 & 0.585 & 0.575 & 0.772 & 0.877 & 0.721 & 0.991 & 0.714 & 0.663 & 0.709 & 0.252 \\
\hline Nonanal & $P$ & 1.078 & 1.471 & 1.149 & 1.254 & 1.636 & 1.441 & 1.294 & 1.849 & 1.647 & 1.255 & 1.300 & 0.789 \\
\hline & M & 2.421 & 2.285 & 2.946 & 1.131 & 2.441 & 1.868 & 2.148 & 2.925 & 2.751 & 2.221 & 2.680 & 0.474 \\
\hline & V & nd & nd & nd & nd & nd & nd & nd & nd & nd & nd & nd & nd \\
\hline 2-Isobutiltiazol & $P$ & 0.219 & 0.246 & 0.212 & 0.151 & 0.258 & 0.215 & 0.214 & 0.460 & 0.214 & 0.169 & 0.168 & 0.216 \\
\hline & M & 3148 & 3332 & 3683 & 3245 & 3250 & 3305 & 3215 & 3690 & 3591 & 2809 & 3403 & 0.385 \\
\hline & V & 44.35 & 35.05 & 39.64 & 44.83 & 40.16 & 32.68 & 38.07 & 30.42 & 28.97 & 35.79 & 31.08 & 19.69 \\
\hline cis-óxido de linalool & $P$ & 58.57 & 33.79 & 25.67 & 43.90 & 62.35 & 42.49 & 36.27 & 44.61 & 47.98 & 29.86 & 38.05 & 29.83 \\
\hline & M & 43.09 & 51.27 & 43.72 & 47.57 & 46.05 & 57.05 & 50.42 & 68.35 & 56.39 & 34.34 & 53.79 & 19.55 \\
\hline & V & 14.11 & 14.65 & 12.83 & 23.87 & 14.46 & 11.56 & 14.88 & 12.24 & 16.35 & 12.87 & 17.67 & 6.152 \\
\hline 1-Heptanol & $P$ & 27.01 & 13.02 & 30.65 & 12.56 & 12.90 & 19.46 & 16.70 & 16.75 & 17.58 & 17.62 & 13.91 & 14.62 \\
\hline & M & 15.83 & 17.72 & 16.53 & 20.43 & 17.58 & 12.56 & 16.88 & 21.27 & 20.84 & 15.57 & 21.85 & 4.284 \\
\hline & V & 27.28 & 42.12 & 24.44 & 20.71 & 31.02 & 22.41 & 24.02 & 24.91 & 25.32 & 26.12 & 27.84 & 12.71 \\
\hline 2-Etil-1-hexanol & $\mathrm{P}$ & 13.44 & 20.62 & 17.64 & 31.52 & 15.64 & 23.12 & 16.41 & 22.42 & 25.87 & 14.31 & 17.37 & 16.47 \\
\hline & M & 23.53 & 18.63 & 28.99 & 20.44 & 18.78 & 23.51 & 45.59 & 26.62 & 22.72 & 16.91 & 22.84 & 23.49 \\
\hline & V & 0.065 & $\operatorname{tr}$ & $\operatorname{tr}$ & 0.173 & 0.109 & 0.285 & 0.110 & 0.275 & 0.212 & $\operatorname{tr}$ & 0.251 & 0.062 \\
\hline cis-4-decenal & $P$ & 0.235 & 0.192 & 0.249 & 0.178 & 0.252 & 0.224 & 0.220 & 0.208 & 0.236 & 0.220 & 0.176 & 0.113 \\
\hline & M & 0.063 & $\operatorname{tr}$ & $\operatorname{tr}$ & 0.143 & $\operatorname{tr}$ & 0.201 & $\operatorname{tr}$ & 0.177 & 0.137 & $\operatorname{tr}$ & 0.168 & 0.024 \\
\hline & V & 3.269 & 15.03 & 3.819 & 4.088 & 4.216 & 13.01 & 16.15 & 14.06 & 5.053 & 4.082 & 5.432 & 1.810 \\
\hline Linalool & $P$ & 4.067 & 6.568 & 4.365 & 4.284 & 4.548 & 8.244 & 7.603 & 8.408 & 5.675 & 4.933 & 5.989 & 2.098 \\
\hline & M & 6.225 & 8.782 & 5.754 & 5.926 & 5.725 & 9.391 & 8.801 & 10.41 & 6.704 & 6.213 & 6.925 & 2.265 \\
\hline & V & 4.189 & 4.083 & 4.154 & 4.684 & 4.196 & 5.036 & 3.716 & 4.925 & 4.760 & 4.420 & 4.116 & 4.189 \\
\hline 1-Octanol & $P$ & 3.704 & 3.892 & 4.258 & 4.341 & 4.055 & 4.367 & 3.803 & 4.458 & 3.923 & 3.816 & 4.255 & 1.332 \\
\hline & M & 5.151 & 4.919 & 4.917 & 5.608 & 5.197 & 5.604 & 4.636 & 6.638 & 5.915 & 5.209 & 5.749 & 0.512 \\
\hline
\end{tabular}




\begin{tabular}{|c|c|c|c|c|c|c|c|c|c|c|c|c|c|}
\hline \multirow{2}{*}{\multicolumn{2}{|c|}{ Compuesto / Maduración }} & \multirow{3}{*}{$\frac{\text { BLC }}{9.868}$} & \multicolumn{10}{|c|}{ Tratamiento Enzimático } & \multirow{3}{*}{$\begin{array}{l}\text { Tukey } \\
\frac{95 \%}{0.898}\end{array}$} \\
\hline & & & \multirow{2}{*}{$\frac{1}{12.69}$} & \multirow{2}{*}{$\frac{2}{11.78}$} & \multirow{2}{*}{$\frac{3}{5.241}$} & \multirow{2}{*}{$\frac{4}{9.857}$} & \multirow{2}{*}{$\frac{5}{7.868}$} & \multirow{2}{*}{$\frac{6}{12.41}$} & \multirow{2}{*}{$\frac{7}{7.673}$} & \multirow{2}{*}{$\frac{8}{8.980}$} & \multirow{2}{*}{$\frac{9}{12.98}$} & \multirow{2}{*}{$\frac{10}{8.972}$} & \\
\hline & V & & & & & & & & & & & & \\
\hline \multirow[t]{2}{*}{ Salicilato de metilo } & $P$ & 10.03 & 16.29 & 10.92 & 11.87 & 10.40 & 21.14 & 17.23 & 21.48 & 13.08 & 10.56 & 13.75 & 4.328 \\
\hline & M & 18.80 & 24.17 & 18.39 & 13.37 & 17.78 & 17.60 & 23.72 & 18.18 & 13.47 & 18.30 & 13.03 & 0.970 \\
\hline \multirow{3}{*}{ Nerol } & V & 34.44 & 35.26 & 36.22 & 35.24 & 35.28 & 35.83 & 37.70 & 35.52 & 35.69 & 36.61 & 35.92 & 2.402 \\
\hline & $P$ & 17.03 & 16.10 & 17.17 & 17.11 & 17.64 & 18.34 & 17.26 & 18.65 & 17.34 & 16.81 & 17.61 & 5.275 \\
\hline & M & 11.76 & 14.28 & 13.17 & 11.67 & 12.88 & 12.45 & 14.04 & 13.11 & 12.56 & 11.35 & 12.19 & 2.348 \\
\hline \multirow{3}{*}{ 3,5-Dimetil benzaldehído } & V & 0.862 & 0.912 & 0.797 & 2.760 & 0.897 & 2.865 & 0.732 & 2.766 & 2.184 & 1.373 & 1.928 & 0.510 \\
\hline & $P$ & 6.274 & 6.286 & 6.446 & 6.446 & 7.111 & 7.215 & 7.012 & 7.551 & 6.929 & 7.282 & 7.229 & 2.533 \\
\hline & M & 10.16 & 10.19 & 9.254 & 11.28 & 9.387 & 9.769 & 9.466 & 11.16 & 10.93 & 9.090 & 11.12 & 1.403 \\
\hline \multirow{3}{*}{ Geraniol } & V & 34.92 & 36.40 & 35.23 & 32.86 & 38.02 & 36.06 & 34.87 & 35.66 & 34.25 & 40.47 & 36.52 & 4.194 \\
\hline & $P$ & 18.67 & 17.49 & 19.30 & 19.91 & 21.51 & 23.19 & 20.58 & 22.95 & 21.95 & 19.14 & 20.89 & 6.531 \\
\hline & M & 27.20 & 31.70 & 25.52 & 25.54 & 28.52 & 23.58 & 33.72 & 26.11 & 25.41 & 26.12 & 25.50 & 3.440 \\
\hline \multirow{3}{*}{ Guaiacol } & V & 230.7 & 230.9 & 226.4 & 188.4 & 248.3 & 257.3 & 266.5 & 250.7 & 234.3 & 294.8 & 248.7 & 42.78 \\
\hline & $P$ & 306.7 & 204.9 & 265.5 & 353.7 & 397.4 & 380.2 & 325.2 & 315.5 & 305.2 & 237.5 & 344.7 & 199.3 \\
\hline & M & 243.5 & 242.8 & 224.4 & 244.5 & 224.6 & 247.7 & 235.9 & 261.4 & 276.2 & 230.1 & 268.8 & 35.94 \\
\hline \multirow{3}{*}{ Bencil alcohol } & $\mathrm{V}$ & 1535 & 1386 & 1465 & 1639 & 1472 & 1906 & 1396 & 1729 & 1733 & 1457 & 1728 & 286.3 \\
\hline & $P$ & 2966 & 2066 & 2462 & 3138 & 3429 & 3212 & 2440 & 3121 & 2622 & 2198 & 2728 & 1225 \\
\hline & M & 1683 & 1724 & 1581 & 1976 & 1609 & 1867 & 1772 & 1924 & 1926 & 1532 & 2021 & 221.1 \\
\hline \multirow{3}{*}{ 2-Feniletanol } & V & 188.2 & 189.7 & 161.8 & 272.1 & 161.2 & 357.1 & 196.7 & 362.9 & 272.6 & 215.7 & 319.5 & 57.75 \\
\hline & $\mathrm{P}$ & 482.6 & 529.1 & 552.5 & 618.9 & 741.0 & 791.9 & 683.4 & 900.0 & 684.9 & 515.0 & 647.5 & 306.5 \\
\hline & M & 485.2 & 586.4 & 504.3 & 624.0 & 447.2 & 628.6 & 581.4 & 697.4 & 719.3 & 513.0 & 544.2 & 102.2 \\
\hline \multirow{3}{*}{ Eugenol } & V & 66.62 & 75.82 & 73.35 & 79.53 & 84.49 & 80.87 & 86.59 & 88.86 & 97.99 & 78.30 & 86.73 & 20.67 \\
\hline & $P$ & 148.6 & 128.3 & 163.1 & 175.0 & 177.0 & 187.4 & 171.7 & 180.8 & 184.4 & 140.4 & 153.7 & 79.33 \\
\hline & M & 91.15 & 93.30 & 81.15 & 107.3 & 83.22 & 103.9 & 86.13 & 113.3 & 93.25 & 81.56 & 107.8 & 22.76 \\
\hline
\end{tabular}

BLC (Zumo incubado sin enzimas añadidos). Tratamientos enzimáticos: 1 (Zumo+BgIN), 2 (Zumo+Exg1), 3 (Zumo+RhaA), 4 (Zumo+AbfB), 5 (Zumo+BgIN+RhaA), 6 (Zumo+AbfB), 7

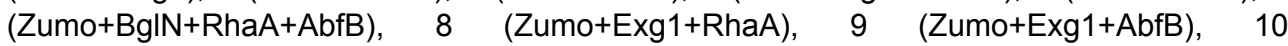
(Zumo+Exg1+RhaA+AbfB).

En rojo concentraciones que aumentaron significativamente, y en azul concentraciones que disminuyeron significativamente, tras incubación con algún tratamiento enzimático respecto al BLC, según el Test de Tukey's HSD aplicado con un intervalo de confianza del $95 \%$ a 3 repeticiones, para cada uno de los estados de maduración considerados, $\mathrm{V}, \mathrm{P}, \mathrm{y} \mathrm{M}$.

nd: compuesto no detectado; tr: concentración $<0.1 \mu \mathrm{g} / \mathrm{L}$.

A continuación se describen los efectos de las incubaciones con las actividades enzimáticas arabinosidasa, ramnosidasa, y glucosidasa, solas o en combinación, sobre la FVL de las variedades de tomate MM y Raf en función del estado de maduración.

\subsection{Tratamientos enzimáticos en la variedad Moneymaker}

La concentración de 10 compuestos volátiles aumentó significativamente en la FVL de la variedad Moneymaker (MM), con 
respecto al zumo incubado sin enzimas (BLC), tras incubación con alguno de los 10 tratamientos enzimáticos analizados (BgIN, Exg1, RhaA, AbfB, BglN+RhaA, BglN+AbfB, BglN+RhaA+AbfB, Exg1+RhaA, Exg1+AbfB, y Exg1+RhaA+AbfB), y en alguno de los 3 estados de maduración considerados (Figura 23 y Figura 24). Estos compuestos fueron el 3-metil1-butanol, trans-2-hexenal, 3-octanona, 1-hexanol, 2-etill-1-hexanol, linalol, nerol, 3,5-dimetil benzaldehído, salicilato de metilo, y 2-feniletanol. La concentración del salicilato de metilo también disminuyó significativamente en el estado de maduración $\mathrm{V}$, como se verá en detalle más adelante (Figura 24).

La cuantía de estos aumentos osciló entre un $14 \%$ y un $679 \%$ con respecto al BLC, en función del compuesto, del tratamiento enzimático, y del estado de maduración considerados. El 3-metil-1-butanol fue el compuesto que experimentó mayores aumentos en la variedad $\mathrm{MM}$, entre un $53 \%$ en el estado de maduración $M$ tras la incubación con RhaA, y un $679 \%$ en el estado $V$ en presencia de BgIN+RhaA+AbfB. El linalol y el 3,5dimetil benzaldehído también experimentaron grandes aumentos, entre un $106 \%$ en el estado $\mathrm{P}$ y un $191 \%$ en el estado $\mathrm{V}$ en presencia de BgIN+RhaA para el linalol, y entre un $110 \%$ con adición de Exg1+RhaA y un $163 \%$ en presencia de BgIN+RhaA en el estado $V$ para el 3,5-dimetil benzaldehído. La 3-octanona y el 2-feniletanol aumentaron en menor cantidad, entre un $60 \%$ en el estado $\mathrm{V}$ tras la incubación con adición de $\mathrm{BgIN}+\mathrm{RhaA}+\mathrm{AbfB}$ y un $88 \%$ en el estado $\mathrm{V}$ en presencia de Exg1+RhaA para la 3-octanona, y entre un $53 \%$ en el estado $V$ en presencia de $B g l n+R h a A$ y un $148 \%$ en el estado $M$ en presencia de $B g I N+R h a A+A b f B$ para el 2-feniletanol. Los aumentos experimentados por el 1-hexanol, 2etil-1-hexanol, nerol (Figura 23), y salicilato de metilo (Figura 24) fueron los menores, oscilando entre un $14 \%$ en el estado $\mathrm{V}$ tras la incubación con BgIN para el salicilato de metilo y un $44 \%$ en el estado $P$ con BgIN+RhaA+AbfB para el 2-etil-1-hexanol. 

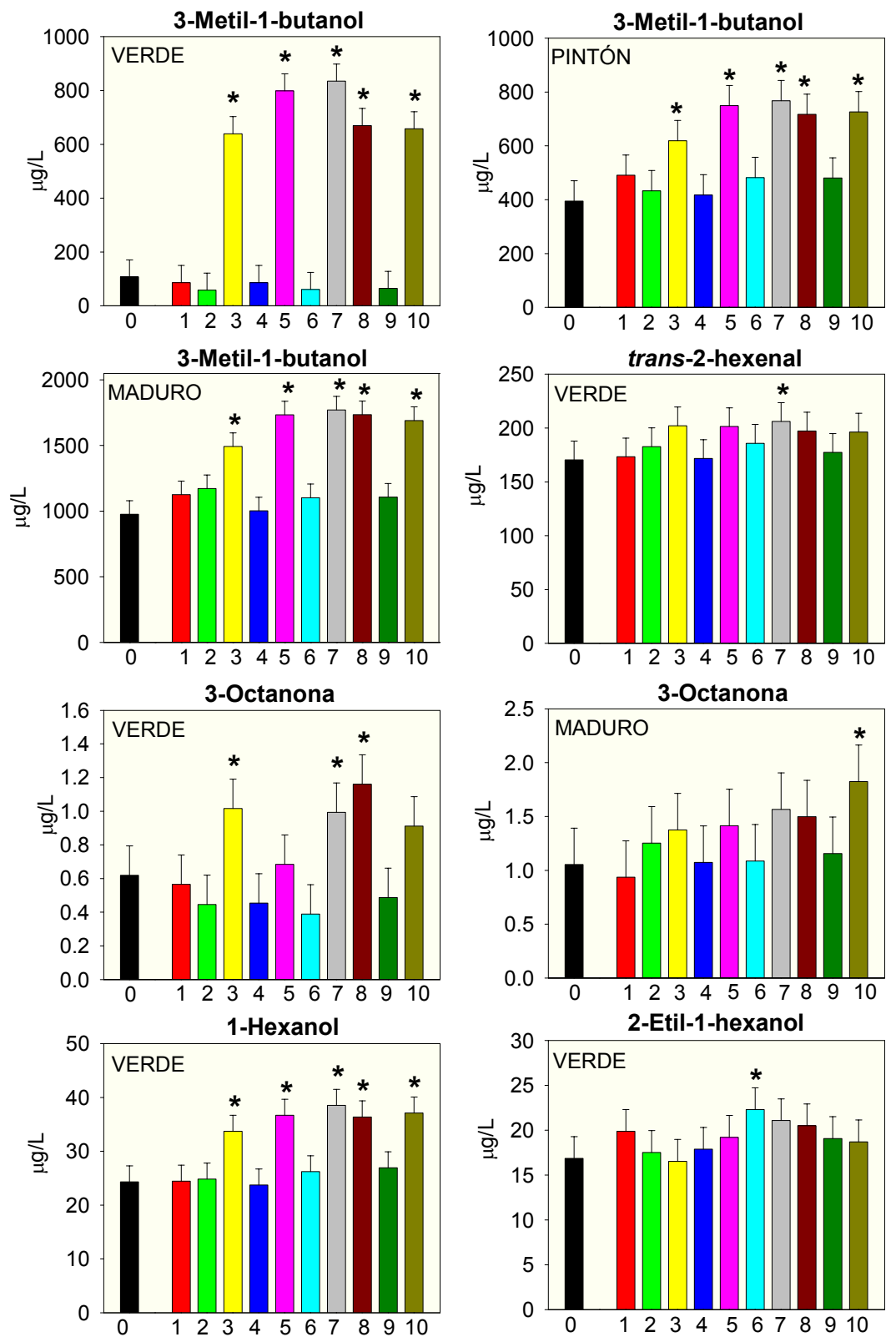

Figura 23. Concentración de los compuestos volátiles que aumentaron significativamente tras la incubación del zumo extraído de la variedad Moneymaker en presencia de los enzimas BgIN, Exg1, RhaA, y AbfB, individualmente y combinados, según el Test de Tukey's HSD aplicado con un intervalo de confianza del $95 \%$ a 3 repeticiones. ${ }^{*} p<0.05$ respecto al zumo incubado sin adición de enzimas o blanco (BLC).

(Continúa) 

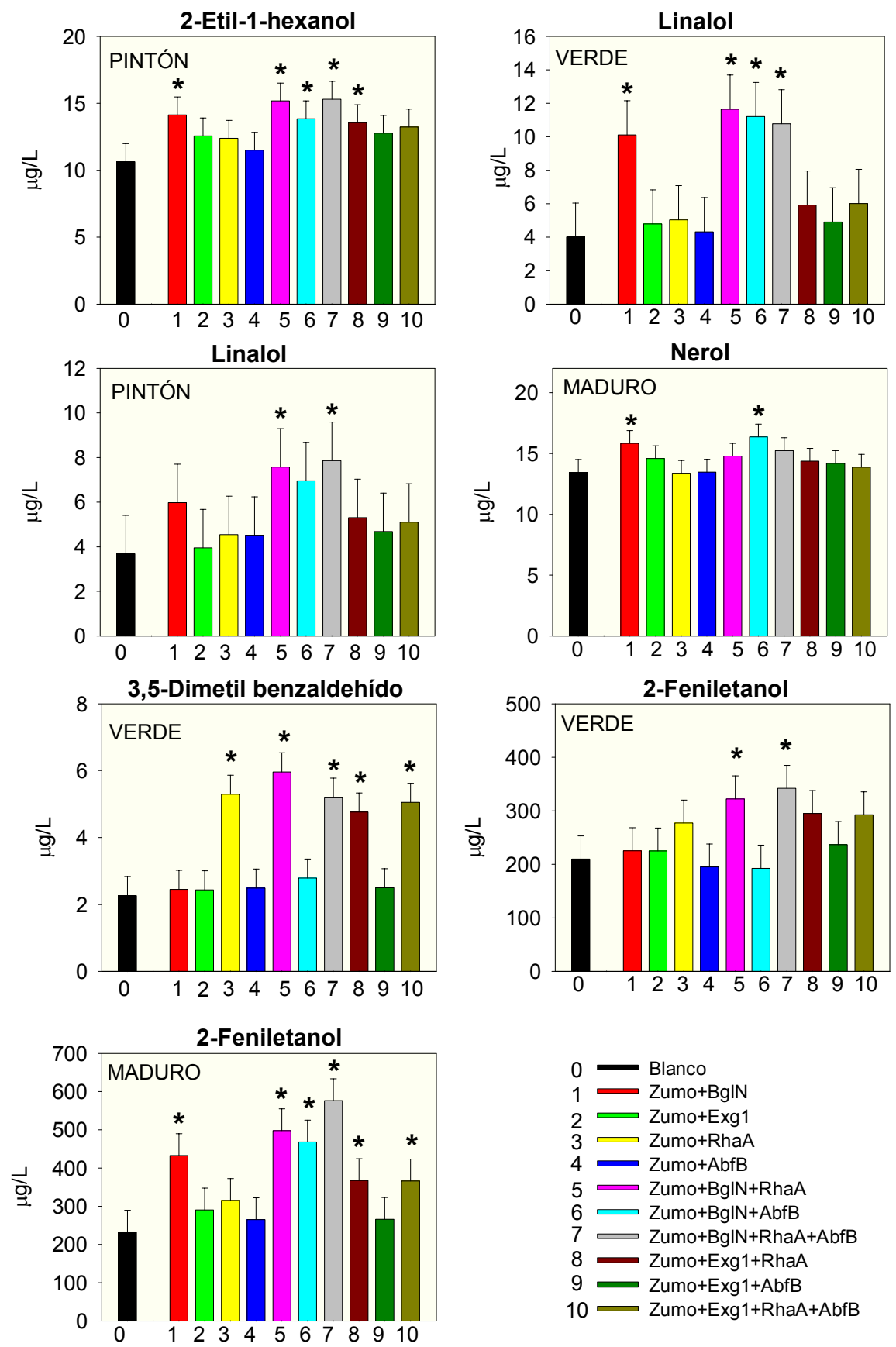

Figura 23. Continuación 
Todos estos compuestos aumentaron su concentración tras la incubación enzimática del zumo extraído de la variedad MM en el estado de maduración $\mathrm{V}$, excepto el nerol que lo hizo sólo en el $\mathrm{M}$. La concentración de los compuestos 2-etil-1-hexanol y linalol aumentó, significativamente con respecto al BLC, además en el estado $\mathrm{P}$, y la de 3octanona, salicilato de metilo, y 2-feniletanol aumentó también en el M. La concentración del 3-metil-1-butanol aumentó, significativamente con respecto al BLC, en los 3 estados de maduración, alcanzando su máximo aumento en el estado V. El aumento experimentado por los compuestos 3octanona, 1-hexanol, linalol, y 3,5-dimetil benzaldehído también fue máximo en el estado V. Mientras que el del salicilato de metilo (Figura 24), nerol, y 2-feniletanol lo fue en el estado $\mathrm{M}$, y el del 2-etil-1-hexanol en el $\mathrm{P}$.
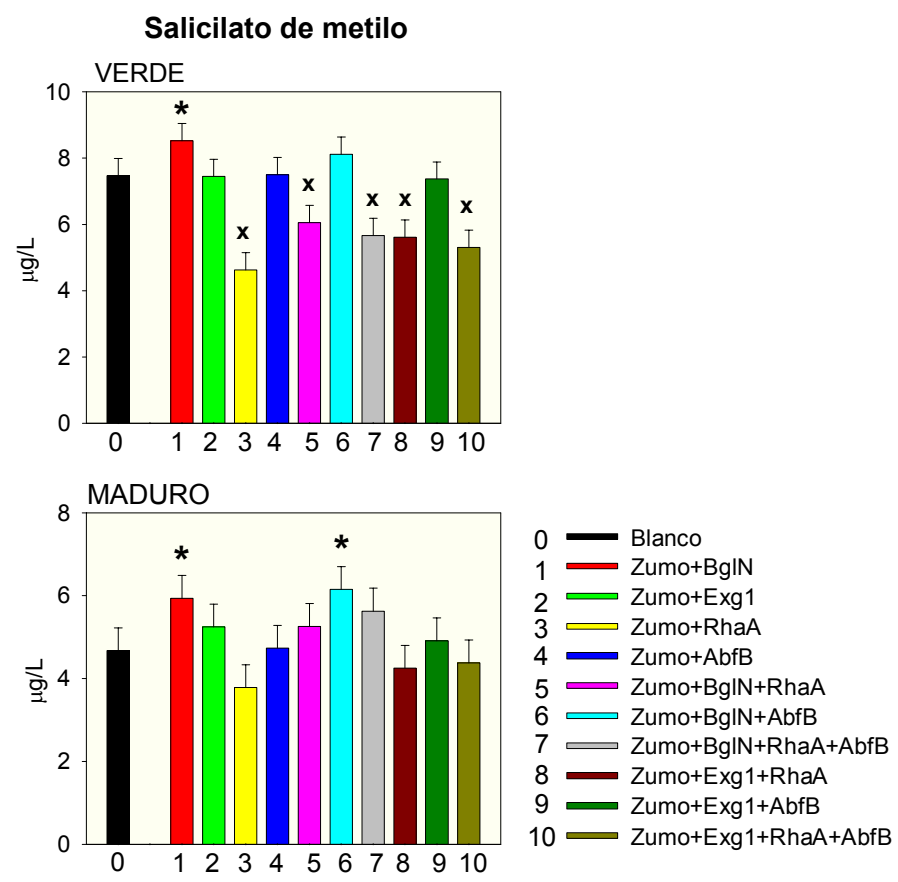

Figura 24. Aumentos $\left(^{*}\right)$ y disminuciones $(X)$ significativas de la concentración del salicilato de metilo tras la incubación del zumo extraído de la variedad Moneymaker en presencia de los enzimas BgIN, Exg1, RhaA, y AbfB, individualmente y combinados, según el Test de Tukey's HSD aplicado con un intervalo de confianza del $95 \%$ a 3 repeticiones. $X,{ }^{*} p<0.05$ respecto al zumo incubado sin adición de enzimas o blanco (BLC). 
El 3-metil-1-butanol aumentó siempre tras incubación en presencia de RhaA, individualmente o combinado. Tras la incubación del zumo con adición de RhaA también se observaron aumentos en la concentración de 3-octanona, 1-hexanol, y 3,5-dimetil benzaldehído en el estado $\mathrm{V}$.

Tras la incubación del zumo con los tratamientos enzimáticos Exg1, AbfB y su combinación, Exg1+AbfB, no se observaron aumentos significativos en la concentración de ninguno de los compuestos. Tras incubación en presencia de las combinaciones Exg1+RhaA y Exg1+RhaA+AbfB la concentración de 3-metil-1-butanol, 3-octanona, 1hexanol, 3,5-dimetil benzaldehído, y 2-feniletanol aumentó significativamente. Además, la incubación con adición de Exg1+RhaA aumentó también la concentración del 2-etil-1-hexanol en el estado P.

La incubación en presencia de los enzimas $\mathrm{BgIN}$ y $\mathrm{BgIN}+\mathrm{AbfB}$ produjo aumentos significativos en la concentración de 2-etil-1-hexanol, linalol, salicilato de metilo, nerol, y 2-feniletanol. Además, mientras que la incubación con BgIN dio lugar a aumentos en la concentración de 2-etil-1hexanol sólo en el estado $\mathrm{P}$, BgIN+AbfB la aumentó también en el estado $\mathrm{V}$, siendo éste el único tratamiento enzimático que lo consiguió. El tratamiento enzimático del zumo con la combinación enzimática BgIN+RhaA dio lugar a aumentos en la concentración de los mismos 6 compuestos que aumentaron tras la incubación en presencia de $\mathrm{BgIN}$ o de RhaA individualmente. Estos compuestos fueron el 3-metil-1-butanol, 1hexanol, 2-etil-1-hexanol, linalol, 3,5-dimetil benzaldehído, y 2-feniletanol. El aumento conseguido en los 6 compuestos recién mencionados tras incubación con BglN+RhaA fue siempre superior al conseguido individualmente con cada enzima, BgIN o RhaA, aunque las diferencias no fueron significativas. En general, los aumentos experimentados por la concentración de linalol se produjeron tras incubación en presencia del enzima BgIN, individualmente o combinado. Por último, fue la adición de la combinación $\mathrm{BgIN}+\mathrm{RhaA}+\mathrm{AbfB}$ la que dio lugar a aumentos significativos 
en la concentración de un mayor número de compuestos en la variedad MM, siendo la cuantía de estos aumentos la mayor para 6 de los 10 compuestos que experimentaron aumentos significativos (Figura 23 y Figura 24).

Tras incubar el zumo extraído de la variedad MM con alguno de los 10 tratamientos enzimáticos analizados también se constataron disminuciones en la concentración de salicilato de metilo (Figura 24) y de hexanal (Figura 25) que llegaron a ser significativas.
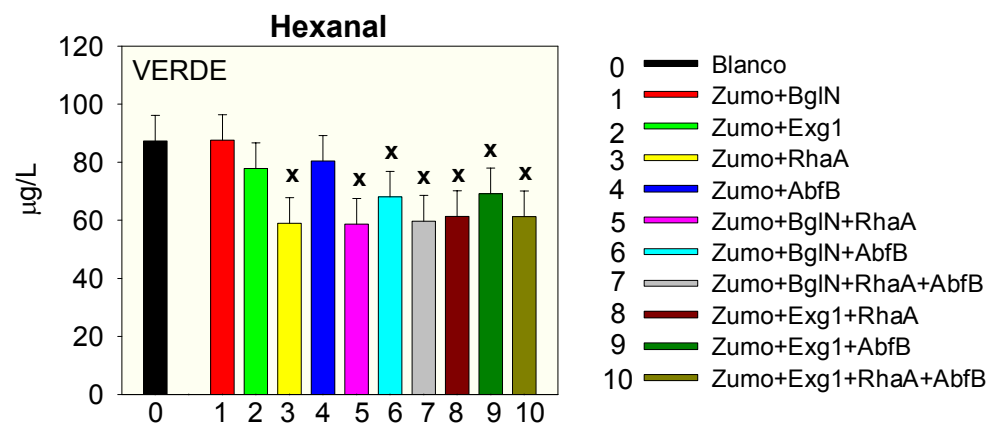

Figura 25. Disminuciones significativas de la concentración del hexanal tras la incubación del zumo extraído de la variedad Moneymaker en presencia de los enzimas BgIN, Exg1, RhaA, y AbfB, individualmente y combinados, según el Test de Tukey's HSD aplicado con un intervalo de confianza del $95 \%$ a 3 repeticiones. $X p<0.05$ respecto al zumo incubado sin adición de enzimas o blanco (BLC).

La concentración de salicilato de metilo disminuyó significativamente en la variedad MM en el estado de maduración $\mathrm{V}$ tras la incubación en presencia del enzima RhaA, ya fuera individualmente o combinado (Figura 24). Su concentración disminuyó entre un $19 \%$ tras incubación en presencia de BgIN+RhaA y un $38 \%$ con RhaA, con respecto al BLC. La concentración de hexanal disminuyó significativamente en el estado de maduración $\mathrm{V}$ tras la incubación en presencia de todas las combinaciones enzimáticas analizadas excepto de BgIN, Exg1, y AbfB (Figura 25). La cuantía de estas disminuciones osciló entre un $20 \%$ de descenso tras la 
incubación con Exg1+AbfB y un $33 \%$ en presencia de $B g I N+R h a A$, con respecto al BLC.

\subsection{Tratamientos enzimáticos en la variedad Raf}

Tras la incubación del zumo de la variedad Raf, en los 3 estados de maduración considerados, con alguno de los 10 tratamientos enzimáticos analizados se registró el incremento significativo de la concentración de 10 compuestos volátiles en la FVL, con respecto al zumo incubado sin enzimas (BLC) (Figura 26 y Figura 27). Estos compuestos fueron el 3metil-1-butanol, trans-2-hexenal, octanal, 1-hexanol, cis-4-decenal, linalol, 1-octanol, 3,5-dimetil benzaldehído, salicilato de metilo, y 2-feniletanol. La concentración de salicilato de metilo, en los estados de maduración $\mathrm{V}$ y $\mathrm{M}$, y de octanal, en el estado $\mathrm{V}$, además disminuyó significativamente, como se tratará en detalle más adelante (Figura 27).

La cuantía de estos aumentos osciló entre un $11 \%$ y un $994 \%$ con respecto al BLC, en función del compuesto, del tratamiento enzimático, y del estado de maduración considerados. Al igual que en la variedad MM, el 3-metil-1-butanol fue también en la variedad Raf el compuesto que experimentó los mayores aumentos, entre un $125 \%$ en el estado de maduración $\mathrm{P}$ en presencia de RhaA, y un $994 \%$ en el estado $\mathrm{V}$ con BgIN+RhaA+AbfB. Los compuestos 1-hexanol, cis-4-decenal, linalol, y 3,5dimetil benzaldehído también experimentaron grandes aumentos, que oscilaron entre un $103 \%$ en el estado $V$ con adición de $B g I N+A b f B$ para el 1-hexanol, y un $394 \%$ en el estado $V$ en presencia de $B g I N+A b f B$ para el linalol. La concentración de trans-2-hexenal, octanal (Figura 27), 1-octanol, y 2-feniletanol aumentó en menor cuantía, entre un $11 \%$ en el estado $\mathrm{M}$ con BglN+RhaA+AbfB para el trans-2-hexenal, y un $93 \%$ en el estado $\mathrm{V}$ con adición de BgIN+RhaA+AbfB para el 2-feniletanol. 

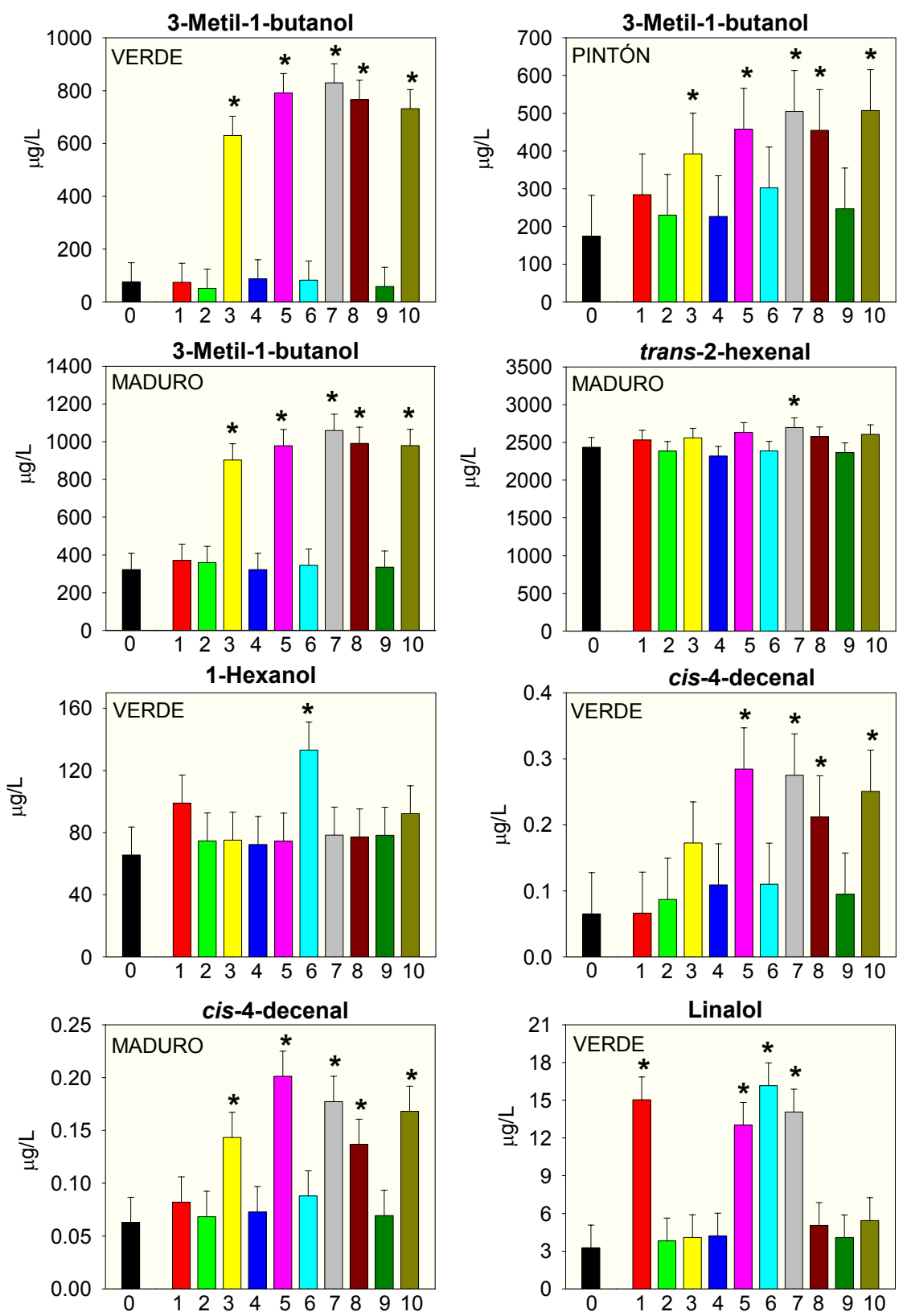

Figura 26. Concentración de los compuestos volátiles que aumentaron significativamente tras la incubación del zumo extraído de la variedad Raf en presencia de los enzimas BgIN, Exg1, RhaA, y AbfB, individualmente y combinados, según el Test de Tukey's HSD aplicado con un intervalo de confianza del $95 \%$ a 3 repeticiones. ${ }^{*} p<0.05$ respecto al zumo incubado sin adición de enzimas o blanco (BLC).

(Continúa) 

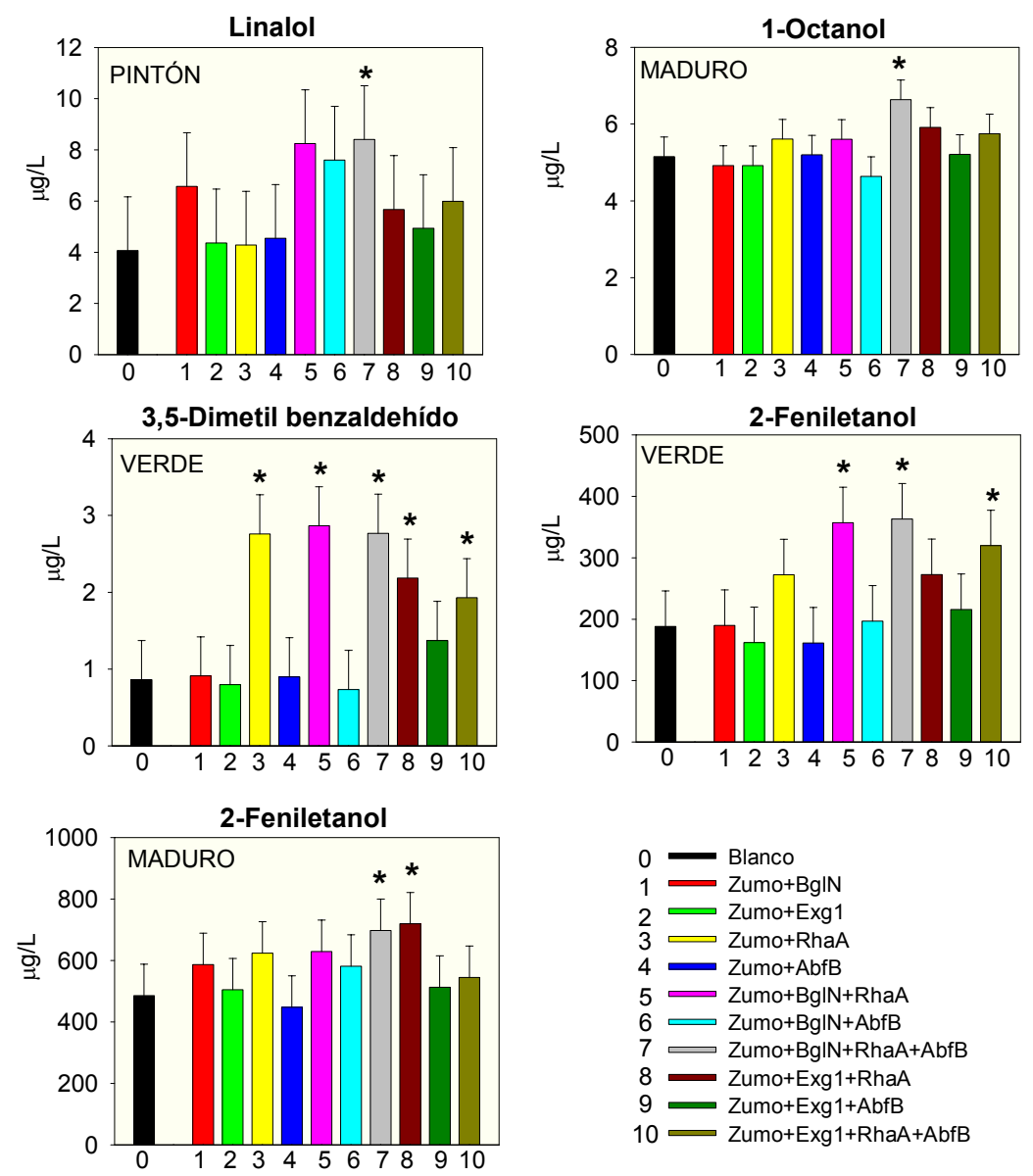

Figura 26. Continuación.

Por otra parte, el salicilato de metilo (Figura 27) aumentó en gran cuantía en el estado $\mathrm{P}$, un $111 \%$ tras incubación con $\mathrm{Bg} I \mathrm{~N}+\mathrm{RhaA}$ y un 114 $\%$ con $\mathrm{BglN}+\mathrm{RhaA}+\mathrm{AbfB}$, y en los estados $\mathrm{V}$ y $\mathrm{M}$ el aumento fue menor, entre un $19 \%$ en el estado $V$ en presencia de Exg1 y un $31 \%$ también en el estado $V$ con adición de Exg1+AbfB.

Todos estos compuestos aumentaron su concentración en el estado $\checkmark$ tras incubación en presencia de alguno de los tratamientos enzimáticos analizados, excepto trans-2-hexenal, octanal (Figura 27), y 1-octanol que lo hicieron sólo en el estado M. 
Salicilato de metilo
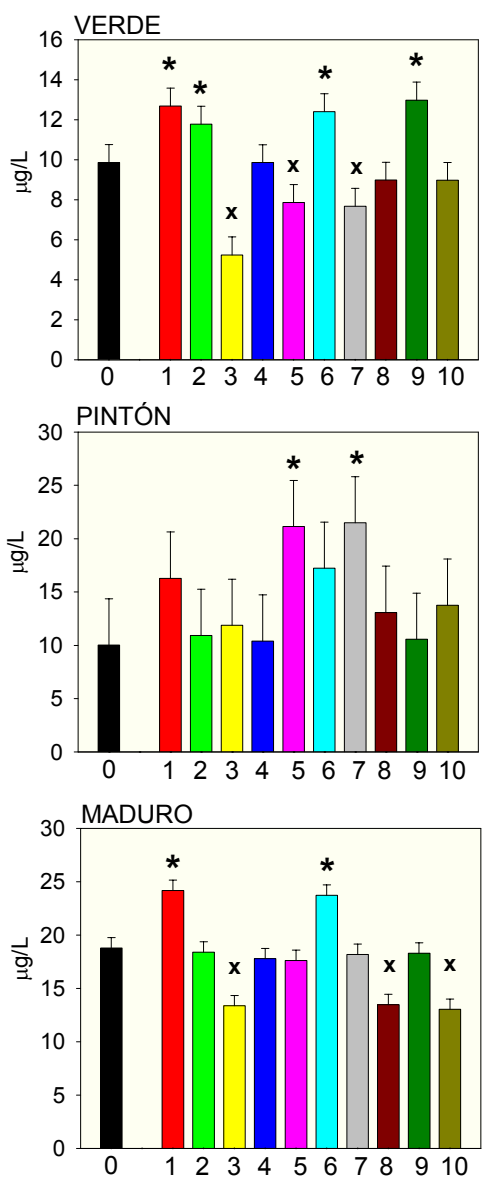

Octanal
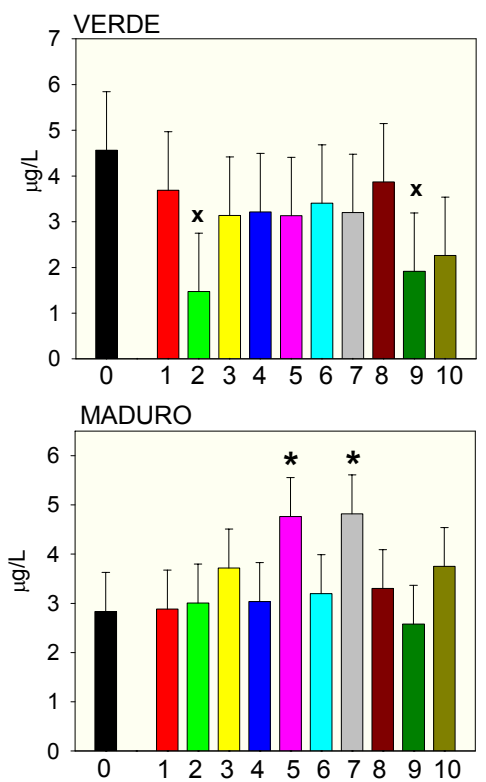

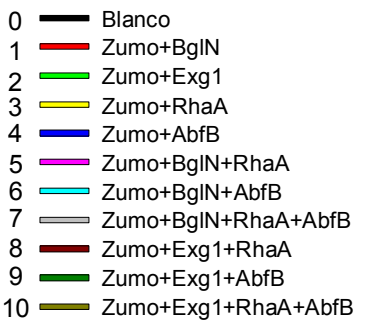

Figura 27. Aumentos $\left(^{*}\right)$ y disminuciones $(X)$ significativas de la concentración del salicilato de metilo y del octanal tras la incubación del zumo extraído de la variedad Raf en presencia de los enzimas BgIN, Exg1, RhaA, y AbfB, individualmente y combinados, según el Test de Tukey's HSD aplicado con un intervalo de confianza del $95 \%$ a 3 repeticiones. $X,{ }^{*} p<0.05$ respecto al zumo incubado sin adición de enzimas o blanco (BLC).

Los compuestos cis-4-decenal y 2-feniletanol aumentaron su concentración además en el estado $\mathrm{M}$, y linalol en el estado $\mathrm{P}$. El 3-metil-1butanol (Figura 26) y el salicilato de metilo (Figura 27) experimentaron aumentos significativos en su concentración en los 3 estados de maduración considerados, alcanzando su máximo en el estado de maduración $\mathrm{V}$ y $\mathrm{P}$, respectivamente. El aumento experimentado por los compuestos 1-hexanol, cis-4-decenal, linalol, 3,5-dimetil benzaldehído, y 2- 
feniletanol también fue máximo en el estado $\mathrm{V}$, mientras que el del trans-2hexenal, octanal, y 1-octanol lo fue en el estado M. La concentración de 3metil-1-butanol aumentó siempre tras incubación en presencia del enzima RhaA, individualmente o combinado. En la variedad Raf, la incubación con RhaA, solo o combinado, también dio lugar a aumentos en las concentraciones de cis-4-decenal, 3,5-dimetil benzaldehído, y 2-feniletanol.

Como en el caso de la variedad MM, en la variedad Raf la incubación en presencia de Exg1, AbfB y de su combinación, Exg1+AbfB, tampoco dio lugar a aumentos significativos, con respecto al BLC, en la concentración de ninguno de los compuestos. Excepto para el salicilato de metilo, cuya concentración en el estado $\mathrm{V}$ aumentó un $19 \%$, con respecto al BLC, tras la incubación con adición de Exg1, y un 31 \% con Exg1+AbfB (Figura 27). Tras incubación en presencia de las combinaciones enzimáticas Exg1+RhaA y Exg1+RhaA+AbfB aumentaron los mismos 4 compuestos volátiles que también aumentaron en presencia de RhaA: 3-metil-1butanol, cis-4-decenal, 3,5-dimetil benzaldehído, y 2-feniletanol.

La incubación en presencia de BgIN y BgIN+AbfB aumentó significativamente, con respecto al BLC, la concentración de linalol en el estado $\mathrm{V}$ (Figura 26), y la de salicilato de metilo en los estados $\mathrm{V}$ y $\mathrm{M}$ (Figura 27). Tras incubación en presencia de BgIN+AbfB también aumentó la concentración de 1-hexanol en estado $\mathrm{V}$, siendo la única combinación enzimática que lo consiguió. La incubación en presencia de BgIN+RhaA dio lugar a aumentos significativos en la concentración de los compuestos 3-metil-1-butanol, octanal, cis-4-decenal, linalol, salicilato de metilo, 3,5dimetil benzaldehído, y 2-feniletanol. El aumento de 3-metil-1-butanol en el estado $\mathrm{V}$ y el de cis-4-decenal en el estado $\mathrm{M}$ tras incubación en presencia de $\mathrm{BgIN}+\mathrm{RhaA}$ fue significativamente superior al conseguido con RhaA. Al igual que en la variedad MM, la concentración de linalol aumentó siempre tras incubación en presencia del enzima $\mathrm{BgIN}$, individualmente o combinado. Por último, en la variedad Raf, también fue la incubación en 
presencia de la combinación de enzimas $B g I N+R h a A+A b f B$ la que dio lugar a aumentos significativos, con respecto al BLC, en la concentración de un mayor número de compuestos, siendo la cuantía de estos aumentos la mayor para 7 de los 10 compuestos que experimentaron aumentos significativos (Figura 26 y Figura 27).

Tras incubar el zumo extraído de la variedad Raf en presencia de los 10 tratamientos enzimáticos analizados también se constataron disminuciones que llegaron a ser significativas en la concentración de salicilato de metilo en los estados de maduración $\mathrm{V}$ y $\mathrm{M}$, de octanal en el estado $V$ (Figura 27), de hexanal en el estado $V$, y de nonanal en el estado M (Figura 28).
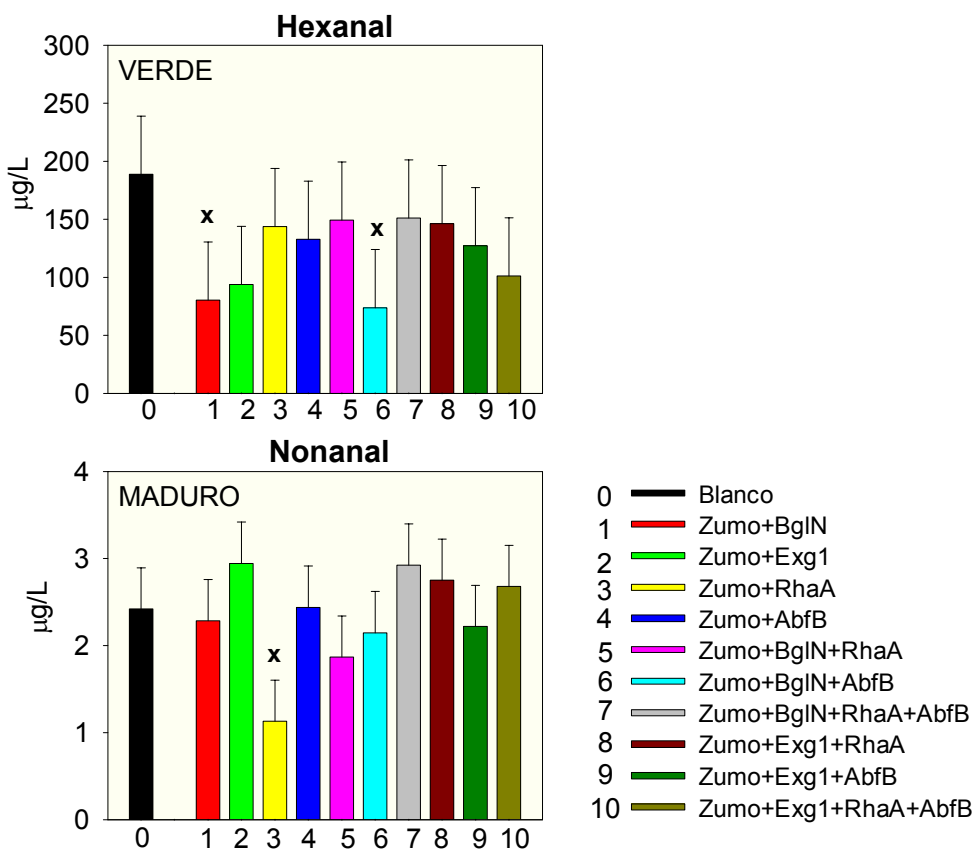

Figura 28. Disminuciones significativas de la concentración del hexanal y del nonanal tras la incubación del zumo extraído de la variedad Raf en presencia de los enzimas BgIN, Exg1, RhaA, y AbfB, individualmente y combinados, según el Test de Tukey's HSD aplicado con un intervalo de confianza del $95 \%$ a 3 repeticiones. $X p<0.05$ respecto al zumo incubado sin adición de enzimas o blanco (BLC). 
La concentración de salicilato de metilo disminuyó significativamente en los estados de maduración $\mathrm{V}$ y $\mathrm{M}$ tras incubación con adición de RhaA, individualmente o combinado con BgIN en el estado $\mathrm{V}$ y con Exg1 en el estado M (Figura 27). En el estado $V$, su concentración disminuyó un $47 \%$, un $20 \%$, y un $22 \%$ tras incubación en presencia de RhaA, BgIN+RhaA, y BglN+RhaA+AbfB, respectivamente. $Y$ en el estado $M$, un $29 \%$, un $28 \%$, y un $31 \%$, con respecto al BLC, tras incubación con RhaA, Exg1+RhaA, y Exg1+RhaA+AbfB, respectivamente.

La concentración de octanal en el estado de maduración $\mathrm{V}$ (Figura 27), disminuyó un 68 \% y un $58 \%$ tras incubación con adición de Exg1 y de Exg1+AbfB, respectivamente, y en el estado de maduración $M$ un $53 \%$ tras incubación con RhaA. El octanal fue el único compuesto volátil que experimentó disminuciones significativas tras incubación en presencia de Exg1. El hexanal en el estado $V$ de la variedad MM (Figura 25) y el octanal en el estado $V$ de la variedad Raf (Figura 27) fueron los únicos compuestos que disminuyeron significativamente con respecto al BLC tras incubación en presencia de Exg1+AbfB.

$\mathrm{Al}$ igual que en la variedad MM, la concentración de hexanal en la variedad Raf disminuyó significativamente en el estado de maduración $\mathrm{V}$ (Figura 28), un 58 \% tras incubación con BgIN y un $61 \%$ con BgIN+AbfB.

\subsection{Efecto global sobre la fracción volátil libre}

Con el objetivo de poder valorar el incremento total de compuestos de la FVL tras las incubaciones con las distintas mezclas enzimáticas se calculó la suma de las concentraciones ponderadas, respecto al zumo incubado sin enzima (BLC), de todos los compuestos volátiles identificados en la FVL de las variedades Moneymaker (MM) y Raf (Figura 29). Esta suma ponderada se obtuvo otorgando el valor de referencia 1 para cada componente en el BLC y calculando el valor proporcional para el resto de mezclas enzimáticas. De esta forma la suma total no está influenciada por 
los órdenes de magnitud de las concentraciones respectivas de cada componente, y refleja mejor los incrementos totales alcanzados en la FVL. Además, al sumar de forma ponderada la contribución de todos los componentes puede llegar a verse con mayor claridad efectos estadísticamente significativos que podrían pasar desapercibidos en el estudio individual de cada componente.

Del análisis estadístico se desprende que la suma total ponderada de los componentes de la FVL (Figura 29) aumentó significativamente tras la incubación en presencia de RhaA, individualmente y combinado en los estados de maduración $\mathrm{V}, \mathrm{P}, \mathrm{y} \mathrm{M}$ de la variedad $\mathrm{MM}$, y en el $\mathrm{V}$ y $\mathrm{M}$ de la variedad Raf. Esta suma total alcanzó sus mayores aumentos tras incubación con adición de $B g I N+R h a A+A b f B$, y particularmente en el estado de maduración $\mathrm{V}$.

La contribución ponderada a la composición de la FVL aumentó entre un $134 \%$ y un $156 \%$ en la variedad MM, y entre un $120 \%$ y un $197 \%$ en la variedad Raf, en función de la mezcla enzimática y del estado de maduración considerado. En el estado $\mathrm{V}$, la suma total ponderada aumentó significativamente un $134 \%$, un $149 \%$, un $156 \%$, un $139 \%$, y un $138 \%$ tras incubación con RhaA, BgIN+RhaA, BgIN+RhaA+AbfB, Exg1+RhaA, y Exg1+RhaA+AbfB, respectivamente, en la variedad MM. El incremento fue de un $160 \%$, un $192 \%$, y un $197 \%$ tras incubación en presencia de RhaA, $B g I N+R h a A$, y BgIN+RhaA+AbfB, respectivamente, en la variedad Raf. En el estado $P$, esta suma total aumentó un $127 \%$ y un $129 \%$ en presencia de $B g I N+R h a A$ y de $B g I N+R h a A+A b f B$, en la variedad $M M$. En el estado $M$, la suma total ponderada aumentó un $123 \%$, un $126 \%$, y un $130 \%$ en la variedad $M M$, tras incubación con adición de $B g I N+R h a A, B g I N+A b f B$ y $\mathrm{BgIN+RhaA+AbfB}$. Tras la incubación en presencia de RhaA, BgIN+RhaA, $\mathrm{BgIN}+\mathrm{RhaA}+\mathrm{AbfB}, \quad$ Exg1+RhaA, y Exg1+RhaA+AbfB, los incrementos fueron de un $120 \%$, un $129 \%$, un $144 \%$, un $130 \%$, y un $125 \%$, respectivamente, en la variedad Raf. 

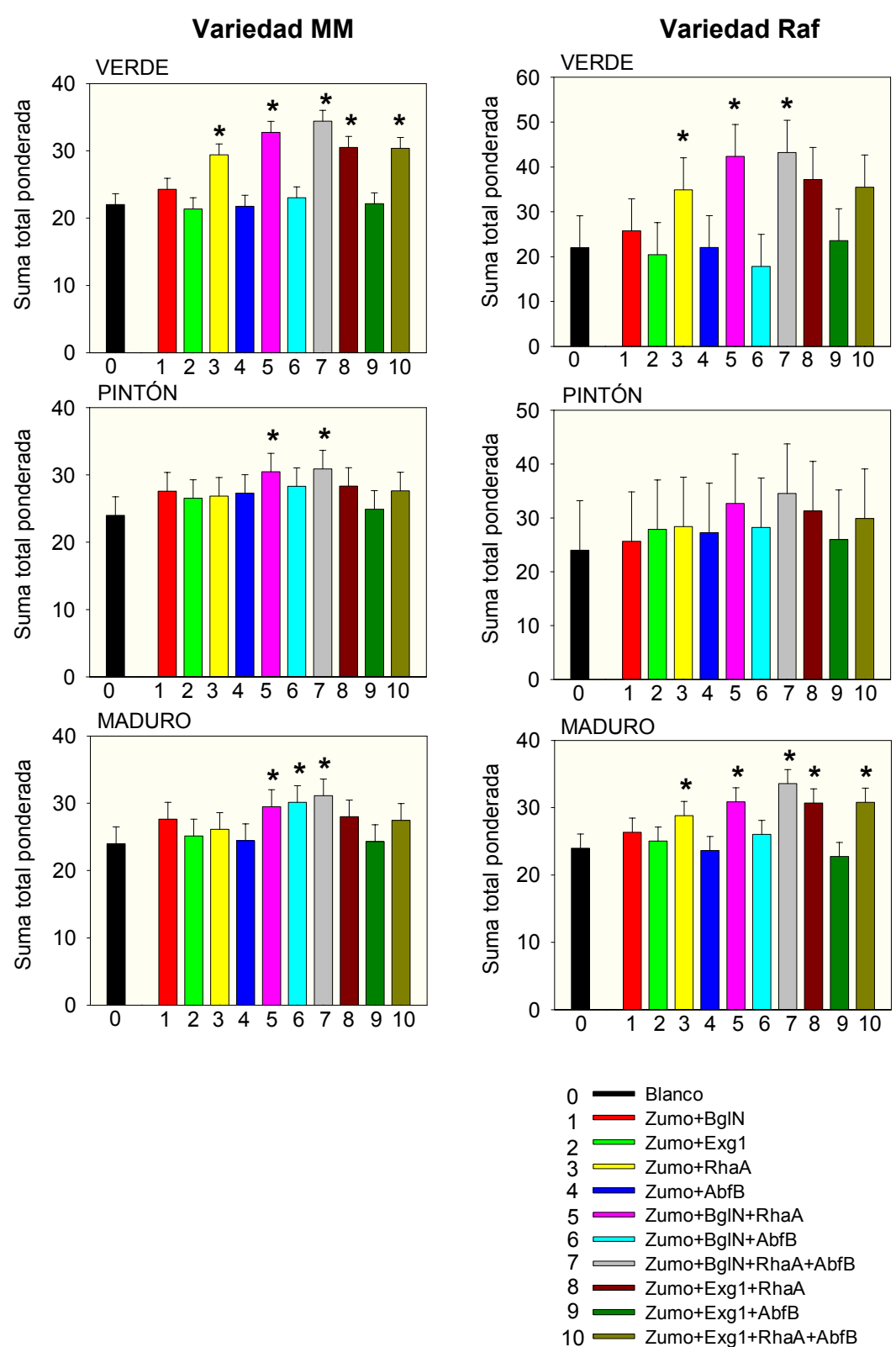

Figura 29. Suma ponderada de todos los compuestos volátiles identificados en los estados de maduración $\mathrm{V}, \mathrm{P}$, y $\mathrm{M}$ tras la incubación del zumo extraído de las variedades Moneymaker y Raf en presencia de los enzimas BgIN, Exg1, RhaA, y AbfB, individualmente y combinados, según el Test de Tukey's HSD aplicado con un intervalo de confianza del 95 $\%$ a 3 repeticiones. ${ }^{*} p<0.05$ respecto al zumo incubado sin adición de enzimas o blanco $(\mathrm{BLC})$. 


\section{Análisis de la composición de los glicósidos}

El análisis de la composición de los glicósidos del tomate se llevó a cabo a través del análisis cromatográfico de los aglicones volátiles y de los azúcares liberados tras la hidrólisis enzimática de los extractos de glicósidos extraídos de las variedades Moneymaker (MM) y Raf en los estados de maduración $\mathrm{V}, \mathrm{P}, \mathrm{y} \mathrm{M}$. Los extractos se incubaron durante $48 \mathrm{~h}$ a $40^{\circ} \mathrm{C}$. Los enzimas utilizados fueron BgIN ( $\beta$-glucosidasa de Candida molischiana), RhaA ( $\alpha$-L-ramnosidasa de Aspergillus aculeatus), y AbfB ( $\alpha$ L-arabinofuranosidasa de Aspergillus niger). Las combinaciones enzimáticas utilizadas para realizar las incubaciones en soluciones tamponadas con el extractos de glicósidos obtenido del zumo de las variedades MM y Raf se seleccionaron en base a los resultados obtenidos en el apartado anterior y fueron BgIN, RhaA, BgIN+RhaA, y BglN+RhaA+AbfB.

\subsection{Perfil de aglicones en el estado de maduración verde}

En la Tabla 18 se muestran, por orden de elución cromatográfica, los 18 aglicones detectados en las variedades Moneymaker (MM) y Raf en el estado de maduración $\mathrm{V}$, así como las diferencias estadísticamente significativas entre las 4 combinaciones enzimáticas analizadas (BglN, RhaA, BgIN+RhaA, y BgIN+RhaA+AbfB) y el extracto de glicósidos incubado sin enzimas (BLC). De acuerdo con el análisis estadístico, 10 aglicones mostraron concentraciones significativamente superiores respecto al BLC en el estado V. Estos compuestos fueron el 3-metil-1butanol, 1-hexanol, benzaldehído, linalol, y guaiacol en las variedades MM y Raf; el bencil alcohol y eugenol en la variedad MM; y el hexanal, nerol, y geraniol en la variedad Raf. La concentración de 1-hexanol en la variedad MM, y la de 3-metil-1-butanol y geraniol en la variedad Raf, fue significativamente superior respecto al BLC únicamente tras la incubación en presencia de BgIN. En las muestras tratadas con las combinaciones de 
enzimas que incluían BgIN también se observaron aumentos de estos compuestos, aunque no fueron estadísticamente significativos. La concentración de 1-hexanol, nerol, y guaiacol en la variedad Raf fue estadísticamente superior únicamente tras incubación en presencia de $B g I N+R h a A+A b f B$. La concentración de eugenol en la variedad MM fue significativamente superior con respecto al BLC tras la incubación con BglN y BglN+RhaA+AbfB, no se observaron diferencias significativas entre ambas incubaciones. $Y$ la de hexanal lo fue en la variedad Raf tras incubación con adición de BgIN y de RhaA, y tampoco se observaron diferencias significativas entre ambas incubaciones.

Tabla 18. Concentración $(\mu \mathrm{g} / \mathrm{L})$ de los aglicones detectados tras la incubación del extracto de glicósidos de las variedades Moneymaker (MM) y Raf en el estado de maduración $V$ en presencia de BgIN (E1), RhaA (E2), BgIN+ RhaA (E3), BgIN+ RhaA+AbfB (E4), y sin adición de enzimas (BLC).

\begin{tabular}{|c|c|c|c|c|c|c|c|c|c|c|}
\hline \multirow{2}{*}{ Aglicones } & \multicolumn{5}{|c|}{ MM } & \multicolumn{5}{|c|}{ Raf } \\
\hline & BLC & E1 & E2 & E3 & E4 & BLC & E1 & E2 & E3 & E4 \\
\hline Hexanal & $4.348 \mathrm{a}$ & $4.828 \mathrm{a}$ & $4.882 \mathrm{a}$ & $4.511 \mathrm{a}$ & $4.501 \mathrm{a}$ & $5.092 \mathrm{a}$ & $7.164 \mathrm{~b}$ & $7.251 \mathrm{~b}$ & $5.543 a$ & $5.906 \mathrm{a}$ \\
\hline 3-Metil-1-butanol & $9.557 \mathrm{a}$ & $113.4 \mathrm{c}$ & $77.75 b$ & $126.4 \mathrm{c}$ & $87.33 \mathrm{~b}$ & 02.6 a & $184.5 \mathrm{~b}$ & $114.1 \mathrm{a}$ & $98.76 \mathrm{a}$ & 106.6 a \\
\hline trans-2-hexenal & $8.682 \mathrm{a}$ & $12.79 \mathrm{a}$ & $11.18 \mathrm{a}$ & $11.22 \mathrm{a}$ & $11.09 \mathrm{a}$ & $13.45 \mathrm{a}$ & $15.01 \mathrm{a}$ & $13.00 \mathrm{a}$ & $13.58 \mathrm{a}$ & $14.07 \mathrm{a}$ \\
\hline 1-Hexanol & $.741 \mathrm{a}$ & $11.03 \mathrm{c}$ & $7.277 \mathrm{ab}$ & $8.854 a b c$ & $7.770 a b$ & $7.507 \mathrm{a}$ & $7.811 \mathrm{a}$ & $8.329 a b$ & $9.232 a b c$ & $11.08 \mathrm{bc}$ \\
\hline Nonanal & $\operatorname{tr}$ & $\operatorname{tr}$ & $\operatorname{tr}$ & $\operatorname{tr}$ & $\operatorname{tr}$ & $\operatorname{tr}$ & $\operatorname{tr}$ & $\operatorname{tr}$ & $\operatorname{tr}$ & $\operatorname{tr}$ \\
\hline 6-Metil-5-heptén-2-ol & $0.122 \mathrm{a}$ & $0.235 a$ & $0.128 a$ & $0.329 \mathrm{a}$ & $0.329 a$ & $0.285 a$ & $0.358 \mathrm{a}$ & $0.312 \mathrm{a}$ & $0.397 \mathrm{a}$ & $0.384 \mathrm{a}$ \\
\hline 2-Etil-1-hexanol & $2.344 \mathrm{a}$ & $3.158 \mathrm{a}$ & $3.106 a$ & $3.214 \mathrm{a}$ & $3.017 \mathrm{a}$ & $1.354 \mathrm{a}$ & $2.701 \mathrm{a}$ & $1.518 \mathrm{a}$ & $2.901 \mathrm{a}$ & $3.250 \mathrm{a}$ \\
\hline Benzaldehído & $1.064 \mathrm{a}$ & $17.75 b$ & $3.521 \mathrm{a}$ & $17.42 \mathrm{~b}$ & $18.09 \mathrm{~b}$ & $3.398 \mathrm{a}$ & $8.800 \mathrm{bc}$ & $3.857 \mathrm{a}$ & $7.422 \mathrm{~b}$ & $11.06 \mathrm{c}$ \\
\hline Linalol & $3.724 \mathrm{a}$ & $16.77 \mathrm{~b}$ & $3.425 \mathrm{a}$ & $17.09 \mathrm{~b}$ & $18.26 \mathrm{~b}$ & $5.238 a$ & $28.80 \mathrm{c}$ & $6.229 a b$ & $21.78 b c$ & $27.39 c$ \\
\hline$\alpha$-Terpineol & $3.728 a$ & $3.950 \mathrm{a}$ & $3.267 \mathrm{a}$ & $4.138 \mathrm{a}$ & $4.090 \mathrm{a}$ & $4.025 \mathrm{a}$ & $5.510 \mathrm{a}$ & $4.769 a$ & $4.430 \mathrm{a}$ & $5.427 \mathrm{a}$ \\
\hline$\beta$-Citronelol & $0.122 \mathrm{a}$ & $0.196 \mathrm{a}$ & $0.124 \mathrm{a}$ & $0.143 a$ & $0.170 \mathrm{a}$ & $0.104 a$ & $0.130 \mathrm{a}$ & $0.137 a$ & $0.123 a$ & $0.163 a$ \\
\hline Salicilato de metilo & $0.777 \mathrm{a}$ & $1.766 \mathrm{a}$ & $1.734 \mathrm{a}$ & $2.005 \mathrm{a}$ & $2.693 \mathrm{a}$ & $1.127 \mathrm{a}$ & $3.580 \mathrm{a}$ & $1.213 \mathrm{a}$ & $1.544 \mathrm{a}$ & $5.545 a$ \\
\hline Nerol & $0.460 \mathrm{a}$ & $0.722 \mathrm{a}$ & $0.596 a$ & $0.603 a$ & $0.644 a$ & $0.606 \mathrm{a}$ & $0.936 a b$ & $0.607 a$ & $0.905 a b$ & $1.371 \mathrm{~b}$ \\
\hline Geranic & $0.800 \mathrm{a}$ & $1.225 \mathrm{a}$ & $0.853 a$ & $1.191 \mathrm{a}$ & $1.497 \mathrm{a}$ & $0.912 a$ & $1.610 \mathrm{~b}$ & $1.095 \mathrm{ab}$ & $1.263 \mathrm{ab}$ & $1.512 \mathrm{ab}$ \\
\hline Guaiacol & $5.075 a$ & $22.35 \mathrm{~b}$ & $6.401 \mathrm{a}$ & $20.57 b$ & $27.88 \mathrm{~b}$ & $8.673 \mathrm{a}$ & $24.32 a b$ & $7.802 \mathrm{a}$ & $19.20 \mathrm{ab}$ & $31.63 \mathrm{~b}$ \\
\hline Bencil & $104.7 \mathrm{a}$ & $653.9 \mathrm{~d}$ & $98.32 \mathrm{a}$ & $238.5 \mathrm{~b}$ & $366.6 \mathrm{c}$ & $142.6 \mathrm{a}$ & $257.3 \mathrm{a}$ & $101.7 \mathrm{a}$ & $198.9 a$ & $174.7 \mathrm{a}$ \\
\hline & $1.43 a$ & $358.6 \mathrm{a}$ & $91.74 \mathrm{a}$ & $117.2 \mathrm{a}$ & $124.2 \mathrm{a}$ & $83.90 \mathrm{a}$ & $107.5 \mathrm{a}$ & $83.28 a$ & $106.1 \mathrm{a}$ & $93.76 \mathrm{a}$ \\
\hline Eugenol & $0.456 \mathrm{a}$ & $2.448 b$ & $0.514 a$ & $1.452 \mathrm{a}$ & $1.908 b$ & $0.520 a$ & $1.131 \mathrm{a}$ & $0.707 a$ & $1.542 \mathrm{a}$ & $1.285 a$ \\
\hline
\end{tabular}

tr: concentración $<0.1 \mu \mathrm{g} / \mathrm{L}$.

Diferentes letras para cada compuesto indican diferencias significativas entre las combinaciones enzimáticas analizadas respecto al BLC para cada variedad según el Test de Tukey's HSD aplicado con un intervalo de confianza del $95 \%$ a 3 repeticiones. La letra "a" se asigna a la menor concentración de un compuesto.

La concentración de benzaldehído y linalol en ambas variedades, y la de guaiacol y bencil alcohol en la variedad MM, fue significativamente superior con respecto al BLC tras incubación en presencia de BgIN, BgIN+RhaA, y BgIN+RhaA+AbfB. La concentración de estos 4 aglicones 
no mostró diferencias significativas entre las 3 incubaciones, excepto el bencil alcohol en la variedad MM, y el benzaldehído en la variedad Raf. La concentración de bencil alcohol en la veriedad MM tras incubación en presencia de BgIN fue significativamente mayor a la obtenida tras la incubación con BglN+RhaA+AbfB, y ésta, a su vez, fue superior a la obtenida con BgIN+RhaA. La concentración de benzaldehído en la variedad Raf tras la incubación en presencia de $B g I N+R h a A+A b f B$ fue significativamente mayor a la obtenida con $\mathrm{BglN}+\mathrm{RhaA}$, mientras que tras la incubación en presencia de BgIN su concentración no mostró diferencias significativas con respecto a BgIN+RhaA y a BgIN+RhaA+AbfB. La concentración de 3-metil-1-butanol en la variedad MM fue significativamente mayor, con respecto al BLC, tras la incubación con las 4 combinaciones enzimáticas analizadas, BgIN, RhaA, BglN+RhaA, y BglN+RhaA+AbfB. La concentración de 3-metil-1-butanol obtenida tras la incubación con adición de BgIN y de BgIN+RhaA fue significativamente superior a la obtenida tras incubación en presencia de RhaA y de BgIN+RhaA+AbfB. Esto confirma el papel destacado de los enzimas BgIN y de su combinación con RhaA para hidrolizar los glicósidos del tomate.

Los aglicones que se detectaron en mayor cantidad tras la hidrólisis enzimática de los extractos de glicósidos en el estado de maduración $\mathrm{V}$ fueron el 3-metil-1-butanol y benzaldehído en la variedad MM, cuyas concentraciones aumentaron significativamente, con respecto al BLC, hasta un $1317 \%$ tras incubación con BgIN+RhaA+AbfB y hasta un 1645 $\%$ con BgIN+RhaA, respectivamente. En menor cantidad se detectaron el bencil alcohol y el geraniol también en la variedad MM, sus concentraciones aumentaron hasta un $625 \%$ y hasta un $537 \%$, respectivamente, tras incubación con adición de BgIN. $\mathrm{Y}$ el linalol y guaiacol en ambas variedades, que aumentaron hasta un $550 \%$ tras incubación en presencia de BgIN, y de $B g I N+R h a A+A b f B$, respectivamente. Finalmente, los aumentos de 1-hexanol en ambas 
variedades, y los de hexanal, 3-metil-1-butanol, benzaldehído, nerol, y geraniol en la variedad Raf, fueron menores y llegaron a ser hasta un 142 \% superiores para el hexanal tras incubación con RhaA y hasta un $325 \%$ superiores para el benzaldehído en presencia de $B g I N+R h a A+A b f B$, con respecto al BLC.

En el estado de maduración $\mathrm{V}$, se obtuvieron concentraciones significativamente superiores, con respecto al BLC, para un mayor número de aglicones tras la incubación de los extractos de glicósidos, en orden descendente, en presencia de BgIN, BgIN+RhaA+AbfB, y BgIN+RhaA.

\subsection{Perfil de aglicones en el estado de maduración pintón}

En la Tabla 19 se muestran los 18 aglicones detectados en las variedades $\mathrm{MM}$ y Raf en el estado de maduración $\mathrm{P}$, así como las diferencias estadísticamente significativas entre las 4 combinaciones enzimáticas analizadas (BgIN, RhaA, BgIN+RhaA, y BgIN+RhaA+AbfB) y los extractos de glicósidos incubados sin enzimas (BLC). Del análisis estadístico se desprende que 13 aglicones mostraron concentraciones estadísticamente superiores, con respecto al BLC, en el estado P. Estos compuestos fueron hexanal, 3-metil-1-butanol, 6-metil-5-heptén-2-ol, salicilato de metilo, y geraniol en la variedad MM; 2-feniletanol en la variedad Raf; y trans-2-hexenal, benzaldehído, linalol, nerol, guaiacol, bencil alcohol, y eugenol en ambas variedades. La concentración de 6metil-5-heptén-2-ol en la variedad MM, y la de nerol en la variedad Raf, fue significativamente superior respecto al BLC únicamente tras la incubación de los extractos de glicósidos en presencia de BglN+RhaA+AbfB. Y la de trans-2-hexenal en la variedad Raf lo fue únicamente tras incubación con $\mathrm{BgIN}$. En las muestras tratadas con las combinaciones de enzimas que incluían BgIN también se observaron aumentos de estos compuestos, aunque no fueron estadísticamente significativos, al igual que ocurrió en el estado de maduración V. La concentración de hexanal y 3-metil-1-butanol 
en la variedad $M M$ fue significativamente superior, con respecto al $B L C$, tras la incubación con $B g I N+R h a A$ y $B g I N+R h a A+A b f B$, aunque no se observaron diferencias significativas entre ambas incubaciones. La de 2feniletanol en la variedad Raf lo fue tras incubación en presencia de BgIN y $\mathrm{BgIN}+\mathrm{RhaA}$, sin observarse tampoco diferencias significativas entre ambas incubaciones.

Tabla 19. Concentración $(\mu \mathrm{g} / \mathrm{L})$ de los aglicones detectados tras la incubación del extracto de glicósidos de las variedades Moneymaker (MM) y Raf en el estado de maduración $P$ en presencia de BgIN (E1), RhaA (E2), BgIN+ RhaA (E3), BgIN+RhaA+AbfB (E4), y sin adición de enzimas (BLC).

\begin{tabular}{|c|c|c|c|c|c|c|c|c|c|c|}
\hline \multirow{2}{*}{ Aglicones } & \multicolumn{5}{|c|}{ MM } & \multicolumn{5}{|c|}{ Raf } \\
\hline & BLC & E1 & E2 & E3 & E4 & BLC & E1 & E2 & E3 & E4 \\
\hline Hexanal & $58.75 \mathrm{a}$ & $61.58 \mathrm{a}$ & $59.18 \mathrm{a}$ & $68.45 \mathrm{~b}$ & $74.73 \mathrm{~b}$ & $34.57 \mathrm{a}$ & $37.68 \mathrm{a}$ & $42.33 \mathrm{a}$ & $37.10 \mathrm{a}$ & $36.32 \mathrm{a}$ \\
\hline 3-Metil-1-butanol & $121.9 \mathrm{a}$ & $130.1 \mathrm{a}$ & $136.2 \mathrm{a}$ & $246.6 \mathrm{~b}$ & $236.1 \mathrm{~b}$ & $92.87 \mathrm{a}$ & $94.94 \mathrm{a}$ & $94.93 \mathrm{a}$ & $98.63 \mathrm{a}$ & $98.44 \mathrm{a}$ \\
\hline trans-2-hexenal & $34.57 \mathrm{a}$ & $106.4 \mathrm{~b}$ & 54.09 & $103.1 \mathrm{~b}$ & $132.1 \mathrm{c}$ & $125.4 \mathrm{a}$ & $154.5 \mathrm{~b}$ & $117.3 \mathrm{a}$ & $133.6 \mathrm{ab}$ & $135.4 a b$ \\
\hline 1-Hexanol & $8.592 \mathrm{a}$ & $10.65 \mathrm{a}$ & $7.195 \mathrm{a}$ & $8.624 \mathrm{a}$ & $9.889 a$ & $7.590 \mathrm{a}$ & $9.766 \mathrm{a}$ & $7.532 \mathrm{a}$ & $7.935 \mathrm{a}$ & $9.906 \mathrm{a}$ \\
\hline Nonanal & $\operatorname{tr}$ & $\operatorname{tr}$ & $\operatorname{tr}$ & $\operatorname{tr}$ & $\operatorname{tr}$ & $\operatorname{tr}$ & $\operatorname{tr}$ & $\operatorname{tr}$ & $\operatorname{tr}$ & $\operatorname{tr}$ \\
\hline 6-Metil-5-heptén-2-ol & $0.291 \mathrm{a}$ & $0.433 \mathrm{a}$ & $0.441 \mathrm{a}$ & $0.481 \mathrm{ab}$ & $0.717 \mathrm{~b}$ & $0.312 \mathrm{a}$ & $0.430 \mathrm{a}$ & $0.415 a$ & $0.405 a$ & $0.403 \mathrm{a}$ \\
\hline 2-Etil-1-hexanol & $3.400 a$ & $3.570 \mathrm{a}$ & $3.863 a$ & $3.593 \mathrm{a}$ & $3.125 \mathrm{a}$ & $2.592 \mathrm{a}$ & $2.293 \mathrm{a}$ & $1.881 \mathrm{a}$ & $2.600 \mathrm{a}$ & $3.006 \mathrm{a}$ \\
\hline Benzaldehído & $2.508 \mathrm{a}$ & $19.57 \mathrm{c}$ & $4.557 \mathrm{a}$ & $12.33 \mathrm{~b}$ & $11.27 \mathrm{~b}$ & $4.988 \mathrm{a}$ & $9.327 \mathrm{~b}$ & $4.372 \mathrm{a}$ & $9.943 \mathrm{~b}$ & $11.22 \mathrm{~b}$ \\
\hline Linalol & $2.599 \mathrm{a}$ & $9.202 b$ & $2.518 \mathrm{a}$ & $10.13 \mathrm{~b}$ & $12.32 \mathrm{~b}$ & $4.025 \mathrm{a}$ & $12.80 \mathrm{~b}$ & $3.757 \mathrm{a}$ & $12.31 \mathrm{~b}$ & $14.43 \mathrm{~b}$ \\
\hline$\alpha$-Terpineol & $2.474 \mathrm{a}$ & $3.219 \mathrm{a}$ & $1.947 \mathrm{a}$ & $2.735 \mathrm{a}$ & $3.889 a$ & $3.097 \mathrm{a}$ & $3.489 a$ & $3.027 \mathrm{a}$ & $3.676 \mathrm{a}$ & $4.475 \mathrm{a}$ \\
\hline$\beta$-Citronelol & $0.107 a$ & $0.216 a$ & $0.097 \mathrm{a}$ & $0.224 \mathrm{a}$ & $0.186 a$ & $0.130 \mathrm{a}$ & $0.170 \mathrm{a}$ & $0.144 \mathrm{a}$ & $0.197 \mathrm{a}$ & $0.207 \mathrm{a}$ \\
\hline Salicilato de metilo & $1.272 \mathrm{a}$ & $2.527 \mathrm{~b}$ & $1.462 \mathrm{a}$ & $2.515 \mathrm{~b}$ & $2.512 b$ & $1.488 \mathrm{a}$ & $2.355 \mathrm{a}$ & $1.472 \mathrm{a}$ & $2.302 \mathrm{a}$ & $3.274 \mathrm{a}$ \\
\hline Nerol & $0.384 a$ & $0.634 \mathrm{a}$ & $0.335 \mathrm{a}$ & $0.601 \mathrm{a}$ & $2.886 \mathrm{~b}$ & $0.430 \mathrm{a}$ & $0.551 a b$ & $0.441 \mathrm{a}$ & $0.501 a b$ & $0.773 \mathrm{~b}$ \\
\hline Geraniol & $0.607 a$ & $1.859 \mathrm{~b}$ & $0.783 a$ & $1.748 \mathrm{~b}$ & $3.006 \mathrm{c}$ & $0.644 a$ & $1.084 \mathrm{a}$ & $0.730 a$ & $1.170 \mathrm{a}$ & $1.242 \mathrm{a}$ \\
\hline Guaiacol & $5.416 a$ & $18.56 \mathrm{~b}$ & $7.916 \mathrm{a}$ & $19.43 \mathrm{~b}$ & $23.07 \mathrm{~b}$ & $7.120 \mathrm{a}$ & $14.35 \mathrm{~b}$ & $6.363 \mathrm{a}$ & $13.98 \mathrm{~b}$ & $16.42 b$ \\
\hline Bencil alcohol & $61.82 \mathrm{a}$ & $1029 \mathrm{~b}$ & $76.10 \mathrm{a}$ & $1048 \mathrm{~b}$ & $1703 \mathrm{c}$ & $98.13 \mathrm{a}$ & $609.3 \mathrm{c}$ & $121.5 \mathrm{a}$ & $272.1 \mathrm{~b}$ & $417.9 \mathrm{bc}$ \\
\hline 2-Fen & $106.1 \mathrm{a}$ & $112.2 \mathrm{a}$ & $82.55 a$ & $117.2 \mathrm{a}$ & $108.8 \mathrm{a}$ & $85.12 \mathrm{a}$ & $110.3 \mathrm{~b}$ & $81.32 \mathrm{a}$ & $122.9 \mathrm{~b}$ & $104.5 \mathrm{ab}$ \\
\hline Eugenol & $1.221 \mathrm{a}$ & $32.00 \mathrm{~b}$ & $1.279 a$ & $33.16 \mathrm{~b}$ & $68.87 \mathrm{c}$ & $0.990 \mathrm{a}$ & $9.015 b$ & $1.291 \mathrm{a}$ & $7.421 a b$ & $10.28 b$ \\
\hline
\end{tabular}

tr: concentración $<0.1 \mu \mathrm{g} / \mathrm{L}$.

Diferentes letras para cada compuesto indican diferencias significativas entre los tratamientos enzimáticos ensayados respecto al BLC para cada variedad según el Test de Tukey's HSD aplicado con un intervalo de confianza del 95\% a 3 repeticiones. La letra "a" se asigna a la menor concentración de un compuesto.

La concentración de eugenol en la variedad Raf fue significativamente superior tras incubación con adición de BglN y $\mathrm{BgIN}+\mathrm{RhaA}+\mathrm{AbfB}$, entre las cuales tampoco se observaron diferencias significativas. La concentración de trans-2-hexenal, salicilato de metilo, geraniol, y eugenol en la variedad MM, y la de benzaldehído, linalol, guaiacol, y bencil alcohol en ambas variedades, fue significativamente superior tras incubación en presencia de BgIN, BgIN+RhaA, y $\mathrm{BgIN}+\mathrm{RhaA}+\mathrm{AbfB}$. Entre estos aglicones, la concentración obtenida tras 
incubación con BgIN+RhaA+AbfB para el bencil alcohol, trans-2-hexenal, geraniol y eugenol en la variedad MM fue significativamente superior a la obtenida en presencia de BgIN y BgIN+RhaA. Este resultado muestra la utilidad de AbfB en combinación con BgIN y RhaA para aumentar la forma libre de estos 4 aglicones en el extracto de glicósidos, y por tanto, sugiere la presencia de posibles diglicósidos de arabinosa en el tomate. Sólo la concentración de bencil alcohol en la variedad Raf, y la de benzaldehído en la variedad MM, obtenida en presencia de BgIN fue significativamente superior con respecto a la obtenida en presencia de $B g I N+R h a A$ y BglN+RhaA+AbfB. La concentración del resto de aglicones, salicilato de metilo en la variedad MM, benzaldehído en la variedad Raf, y linalol y guaiacol en ambas variedades, no fue significativamente diferente entre las 3 incubaciones. De estos resultados se desprende el destacado papel del enzima BgIN y de su combinación con RhaA para incrementar los aglicones en forma libre en el extracto de glicósidos del tomate.

Los aglicones que se detectaron en mayor cantidad tras la hidrólisis enzimática de los extractos de glicósidos en el estado de maduración $\mathrm{P}$ fueron el bencil alcohol y el eugenol en la variedad MM, cuyas concentraciones aumentaron significativamente, con respecto al BLC, hasta un $2755 \%$ y un $5645 \%$, respectivamente, tras incubación en presencia de $\mathrm{BgIN}+\mathrm{RhaA}+\mathrm{AbfB}$. En menor cantidad se detectaron el trans2-hexenal, benzaldehído, nerol, geraniol, y guaiacol en la variedad MM, el bencil alcohol y eugenol en la variedad Raf, y el linalol en ambas variedades. Se alcanzaron incrementos de hasta un $358 \%$ para el linalol y hasta un 1038 \% para el eugenol, en la variedad Raf tras incubación con BgIN+RhaA+AbfB. Finalmente, los aumentos de hexanal, 3-metil-1butanol, 6-metil-5-heptén-2-ol, y salicilato de metilo en la variedad MM, y los de trans-2-hexenal, benzaldehído, nerol, guaiacol, y 2-feniletanol en la variedad Raf, fueron menores y llegaron a ser hasta un $123 \%$ superiores para el trans-2-hexenal tras incubación con BgIN y hasta un $246 \%$ 
superiores para el 6-metil-5-heptén-2-ol en presencia de $\mathrm{BgIN}+\mathrm{RhaA}+\mathrm{AbfB}$, con respecto al BLC.

En el estado de maduración $P$, se obtuvieron concentraciones significativamente superiores, con respecto al BLC, para un mayor número de aglicones tras la incubación de los extractos de glicósidos de la variedad $M M$, en orden descendente, en presencia de $B g I N+R h a A+A b f B$, BglN+RhaA, y BgIN. Y en la variedad Raf, en orden descendente, en presencia de $\mathrm{BgIN}$, BgIN+RhaA+AbfB, y BgIN+RhaA. Este resultado muestra la distinta utilidad de las combinaciones enzimáticas para aumentar los compuestos libres en los extractos de glicósidos en función de la variedad, por lo que distintas variedades podrían tener la mismos aglicones pero formando parte de distintos glicósidos. Tras la incubación con RhaA no aumentó significativamente ningún aglicón.

\subsection{Perfil de aglicones en el estado de maduración maduro}

En la Tabla 20 se muestran los 18 aglicones detectados en las variedades MM y Raf en el estado de maduración $M$, así como las diferencias estadísticamente significativas entre las 4 combinaciones enzimáticas analizadas (BgIN, RhaA, BgIN+RhaA, y BgIN+RhaA+AbfB) y los extractos de glicósidos incubados sin enzimas (BLC). De acuerdo con el análisis estadístico, 12 aglicones mostraron concentraciones estadísticamente superiores, con respecto al BLC, en el estado M. Estos aglicones fueron 3-metil-1-butanol, 6-metil-5-heptén-2-ol, linalol, $\beta$ citronelol, salicilato de metilo, nerol, geraniol, y bencil alcohol en ambas variedades; guaiacol y eugenol en la variedad MM; y benzaldehído y 2feniletanol en la variedad Raf. La concentración de salicilato de metilo en la variedad $\mathrm{MM}$ fue significativamente superior, con respecto al $B L C$, únicamente tras incubación con adición de BgIN. En las muestras tratadas con las combinaciones de enzimas que incluían BgIN también se observaron aumentos de estos compuestos, aunque no fueron 
estadísticamente significativos, al igual que ocurrió en los estados de maduración $V$ y $P$.

Tabla 20. Concentración $(\mu \mathrm{g} / \mathrm{L})$ de los aglicones detectados tras la incubación del extracto de glicósidos de las variedades Moneymaker (MM) y Raf en el estado de maduración $M$ en presencia de BgIN (E1), RhaA (E2), BgIN+ RhaA (E3), BgIN+ RhaA+AbfB (E4), y sin adición de enzimas (BLC).

\begin{tabular}{|c|c|c|c|c|c|c|c|c|c|c|}
\hline Aglicones & BLC & E1 & $\begin{array}{l}\text { MM } \\
\text { E2 }\end{array}$ & E3 & E4 & BLC & E1 & $\begin{array}{l}\text { Raf } \\
\text { E2 }\end{array}$ & E3 & E4 \\
\hline Hexanal & $192.8 \mathrm{a}$ & $189.1 \mathrm{a}$ & $199.5 \mathrm{a}$ & $205.5 a$ & $191.1 \mathrm{a}$ & $150.1 \mathrm{a}$ & $152.8 \mathrm{a}$ & $148.3 \mathrm{a}$ & $152.4 \mathrm{a}$ & $155.0 \mathrm{a}$ \\
\hline 3-Metil-1-butanol & $202.3 \mathrm{a}$ & $685.2 \mathrm{~b}$ & $171.5 \mathrm{a}$ & $847.6 \mathrm{~b}$ & $920.4 \mathrm{~b}$ & $86.17 \mathrm{a}$ & $194.7 \mathrm{~b}$ & $64.94 \mathrm{a}$ & $225.8 \mathrm{~b}$ & $320.9 \mathrm{c}$ \\
\hline trans -2-hexenal & $87.38 \mathrm{a}$ & $82.99 a$ & $69.27 \mathrm{a}$ & $113.2 \mathrm{a}$ & $81.33 \mathrm{a}$ & $126.6 \mathrm{a}$ & $116.1 \mathrm{a}$ & $115.9 \mathrm{a}$ & $130.6 \mathrm{a}$ & $106.0 \mathrm{a}$ \\
\hline 1-Hexanol & $8.682 \mathrm{a}$ & $10.74 \mathrm{a}$ & $9.627 \mathrm{a}$ & $11.18 \mathrm{a}$ & $10.73 \mathrm{a}$ & $7.064 \mathrm{a}$ & $9.512 \mathrm{a}$ & $6.900 \mathrm{a}$ & $8.682 \mathrm{a}$ & $9.440 \mathrm{a}$ \\
\hline Nonanal & $\operatorname{tr}$ & $\operatorname{tr}$ & $\operatorname{tr}$ & $\operatorname{tr}$ & $\operatorname{tr}$ & $\operatorname{tr}$ & $\operatorname{tr}$ & $\operatorname{tr}$ & $\operatorname{tr}$ & $\operatorname{tr}$ \\
\hline 6-Metil-5-heptén-2-ol & $0.506 \mathrm{a}$ & $5.733 \mathrm{~b}$ & $0.439 a$ & $6.476 \mathrm{~b}$ & $6.953 \mathrm{~b}$ & $0.316 \mathrm{a}$ & $10.51 \mathrm{~b}$ & $0.292 \mathrm{a}$ & $10.69 \mathrm{~b}$ & $14.35 \mathrm{c}$ \\
\hline 2-Etil-1-hexanol & $2.178 \mathrm{a}$ & $2.803 \mathrm{a}$ & $2.570 \mathrm{a}$ & $1.858 \mathrm{a}$ & $2.806 \mathrm{a}$ & $2.515 a$ & $2.367 \mathrm{a}$ & $2.385 a$ & $3.429 a$ & $2.817 \mathrm{a}$ \\
\hline Benzaldehído & $10.55 \mathrm{a}$ & $19.44 \mathrm{a}$ & $8.935 a$ & $19.57 \mathrm{a}$ & $19.20 \mathrm{a}$ & $9.836 \mathrm{a}$ & $14.79 \mathrm{~b}$ & $9.836 \mathrm{a}$ & $18.48 \mathrm{c}$ & $19.09 \mathrm{c}$ \\
\hline Linalol & $3.051 \mathrm{a}$ & $10.31 \mathrm{~b}$ & $3.532 \mathrm{a}$ & $10.96 \mathrm{~b}$ & $12.34 \mathrm{~b}$ & $3.147 \mathrm{a}$ & $8.361 \mathrm{~b}$ & $3.628 \mathrm{a}$ & $9.205 \mathrm{~b}$ & $10.19 b$ \\
\hline$\alpha$-Terpineol & $2.744 \mathrm{a}$ & $3.711 \mathrm{a}$ & $3.188 a$ & $3.750 \mathrm{a}$ & $3.619 a$ & $2.962 \mathrm{a}$ & $3.606 \mathrm{a}$ & $3.066 \mathrm{a}$ & $3.916 \mathrm{a}$ & $4.186 \mathrm{a}$ \\
\hline$\beta$-Citronelol & $0.190 \mathrm{a}$ & $1.155 \mathrm{~b}$ & $0.139 a$ & $2.014 \mathrm{c}$ & $2.151 \mathrm{c}$ & $0.076 \mathrm{a}$ & $3.049 \mathrm{~b}$ & $0.153 \mathrm{a}$ & $3.142 \mathrm{~b}$ & $5.044 \mathrm{c}$ \\
\hline Salicilato de metilo & $0.905 a$ & $2.115 b$ & $0.931 \mathrm{a}$ & $1.411 \mathrm{ab}$ & $1.657 \mathrm{ab}$ & $1.652 \mathrm{a}$ & $2.341 \mathrm{ab}$ & $1.855 \mathrm{a}$ & $2.624 a b$ & $3.728 b$ \\
\hline Nerol & $0.478 \mathrm{a}$ & $2.001 \mathrm{~b}$ & $0.476 \mathrm{a}$ & $2.112 \mathrm{~b}$ & $2.130 \mathrm{~b}$ & $0.427 \mathrm{a}$ & $1.561 \mathrm{~b}$ & $0.555 a$ & $2.175 \mathrm{~b}$ & $3.185 \mathrm{c}$ \\
\hline Geraniol & $0.729 a$ & $2.771 \mathrm{~b}$ & $0.773 \mathrm{a}$ & $2.782 \mathrm{~b}$ & $2.963 \mathrm{~b}$ & $0.601 \mathrm{a}$ & $2.274 \mathrm{~b}$ & $0.720 a$ & $2.888 \mathrm{~b}$ & $2.883 \mathrm{~b}$ \\
\hline Guaiacol & $9.355 a$ & $21.82 b$ & $9.658 \mathrm{a}$ & $25.19 \mathrm{~b}$ & $26.36 \mathrm{~b}$ & $9.507 \mathrm{a}$ & $14.51 \mathrm{a}$ & $8.635 a$ & $13.52 \mathrm{a}$ & $17.08 \mathrm{a}$ \\
\hline Bencil a & 95.34 a & $1413 \mathrm{~b}$ & $91.74 \mathrm{a}$ & 1972 b & $1971 \mathrm{~b}$ & $143.2 \mathrm{a}$ & $669.1 \mathrm{~b}$ & $97.33 \mathrm{a}$ & $1446 \mathrm{c}$ & $1817 \mathrm{~d}$ \\
\hline & $.1 \mathrm{a}$ & $120.2 \mathrm{a}$ & $15 a$ & $111.3 \mathrm{a}$ & & $6.84 \mathrm{a}$ & $102.3 a b$ & $87.39 a$ & & $271.6 \mathrm{~b}$ \\
\hline & $2 \mathrm{a}$ & $66.80 \mathrm{~b}$ & $2.506 \mathrm{a}$ & $64.86 \mathrm{~b}$ & 69.8 & $0.713 a$ & $16.49 \mathrm{a}$ & $1.247 \mathrm{a}$ & $22.92 \mathrm{a}$ & $26.32 \mathrm{a}$ \\
\hline
\end{tabular}

tr: concentración $<0.1 \mu \mathrm{g} / \mathrm{L}$.

Diferentes letras para cada compuesto indican diferencias significativas entre los tratamientos enzimáticos ensayados respecto al BLC para cada variedad según el Test de Tukey's HSD aplicado con un intervalo de confianza del 95\% a 3 repeticiones. La letra "a" se asigna a la menor concentración de un compuesto.

La concentración de salicilato de metilo y 2-feniletanol en la variedad Raf fue significativamente superior únicamente tras incubación con BgIN+RhaA+AbfB. La concentración del resto de aglicones aumentó significativamente tras incubación en presencia de $B g I N$, BgIN+RhaA, y $\mathrm{BgIN}+\mathrm{RhaA}+\mathrm{AbfB}$. En la variedad MM, sólo la concentración de $\beta$-citronelol fue significativamente diferente tras la incubación entre estas 3 combinaciones de enzimas. Su concentración tras incubación con $B g I N+R h a A$ y $B g I N+R h a A+A b f B$ fue significativamente superior a la obtenida en presencia de BgIN.

En la variedad Raf, la concentración de 3-metil-1-butanol, 6-metil-5heptén-2-ol, $\beta$-citronelol, y nerol, obtenida tras incubación en presencia de $\mathrm{BgIN}+\mathrm{RhaA}+\mathrm{AbfB}$ fue significativamente superior a la obtenida con $\mathrm{BgIN}$ y 
BgIN+RhaA. Este resultado muestra la utilidad de $A b f B$ en combinación con BgIN y RhaA para aumentar la forma libre de estos 4 aglicones en el extracto de glicósidos, y por tanto, sugiere la presencia de posibles diglicósidos de arabinosa en el tomate. No se registraron diferencias significativas en la concentración de benzaldehído y de bencil alcohol entre la incubación con adición de BgIN+RhaA y $B g I N+R h a A+A b f B$ en la variedad Raf, pero su concentración tras incubación en presencia de ambas combinaciones fue significativamente superior a la obtenida con BgIN. De estos resultados se desprende el destacado papel del enzima BgIN y de su combinación con RhaA para incrementar aglicones particularmente interesantes desde un punto de vista sensorial en forma libre en el extracto de glicósidos del tomate, como lo son el $\beta$-citronelol en la variedad $\mathrm{MM}$, y el benzaldehído y el bencil alcohol en la variedad Raf. No se observaron diferencias significativas en la concentración de linalol, salicilato de metilo, geraniol y eugenol entre la incubación con las combinaciones enzimáticas BgIN, BgIN+RhaA, y BgIN+RhaA+AbfB en ninguna de las variedades consideradas.

Los aglicones que se detectaron en mayor cantidad tras la hidrólisis enzimática de los extractos de glicósidos en el estado de maduración $\mathrm{M}$ fueron el 6-metil-5-heptén-2-ol y el $\beta$-citronelol en la variedad Raf, y el bencil alcohol y el eugenol en la variedad MM. Sus concentraciones aumentaron significativamente, con respecto al BLC, hasta un $2068 \%$ para el bencil alcohol y hasta un $6632 \%$ para el $\beta$-citronelol tras incubación en presencia de $B g I N+R h a A+A b f B$. En menor cantidad se detectaron el 6metil-5-heptén-2-ol y $\beta$-citronelol en la variedad $M M, y$ el nerol y bencil alcohol en la variedad Raf, cuyas concentraciones fueron hasta $746 \%$ superiores para el nerol en la variedad Raf y hasta un $1374 \%$ para el 6metil-5-heptén-2-ol en la variedad $M M$, tras incubación con $\mathrm{BgIN}+\mathrm{RhaA}+\mathrm{AbfB}$. Finalmente, los aumentos de 3-metil-1-butanol, linalol, salicilato de metilo, y geraniol en ambas variedades, los de benzaldehído y 
2-feniletanol en la variedad Raf, y los de nerol y guaiacol en la variedad MM, fueron menores y llegaron a ser hasta un $194 \%$ superiores para el benzaldehído tras incubación con $\mathrm{BgIN}+\mathrm{RhaA}+\mathrm{AbfB}$ y hasta un $480 \%$ superiores para el geraniol en presencia de $\mathrm{BgIN}+\mathrm{RhaA}$, con respecto al BLC.

En el estado de maduración $M$, se obtuvieron concentraciones significativamente superiores respecto al BLC para un mayor número de aglicones tras la incubación de los extractos de glicósidos, en orden descendente, en presencia de $B g I N+R h a A+A b f B, B g I N$, y BgIN+RhaA. Ningún aglicón aumentó significativamente, con respecto al BLC, tras la incubación en presencia de RhaA.

\subsection{Perfil de azúcares en distintos estados de maduración}

La Figura 30 muestra los 3 azúcares detectados tras la incubación de los extractos de glicósidos de las variedades Moneymaker (MM) y Raf en presencia de BgIN, RhaA, BgIN+RhaA, y BgIN+RhaA+AbfB, en los estados de maduración $\mathrm{V}, \mathrm{P}$, y $\mathrm{M}$, así como las diferencias estadísticamente significativas encontradas entre los azúcares en cada uno de los estados de maduración considerados. Estos azúcares fueron la glucosa, la ramnosa, y la arabinosa. El análisis cromatográfico confirmó, como era de esperar, la presencia sólo de glucosa tras la incubación de los extractos de glicósidos con BgIN, sólo la de ramnosa tras la incubación con RhaA, la de glucosa y ramnosa al incubar con BgIN+RhaA, y la de glucosa, ramnosa, y arabinosa al hacerlo con BgIN+RhaA+AbfB. 

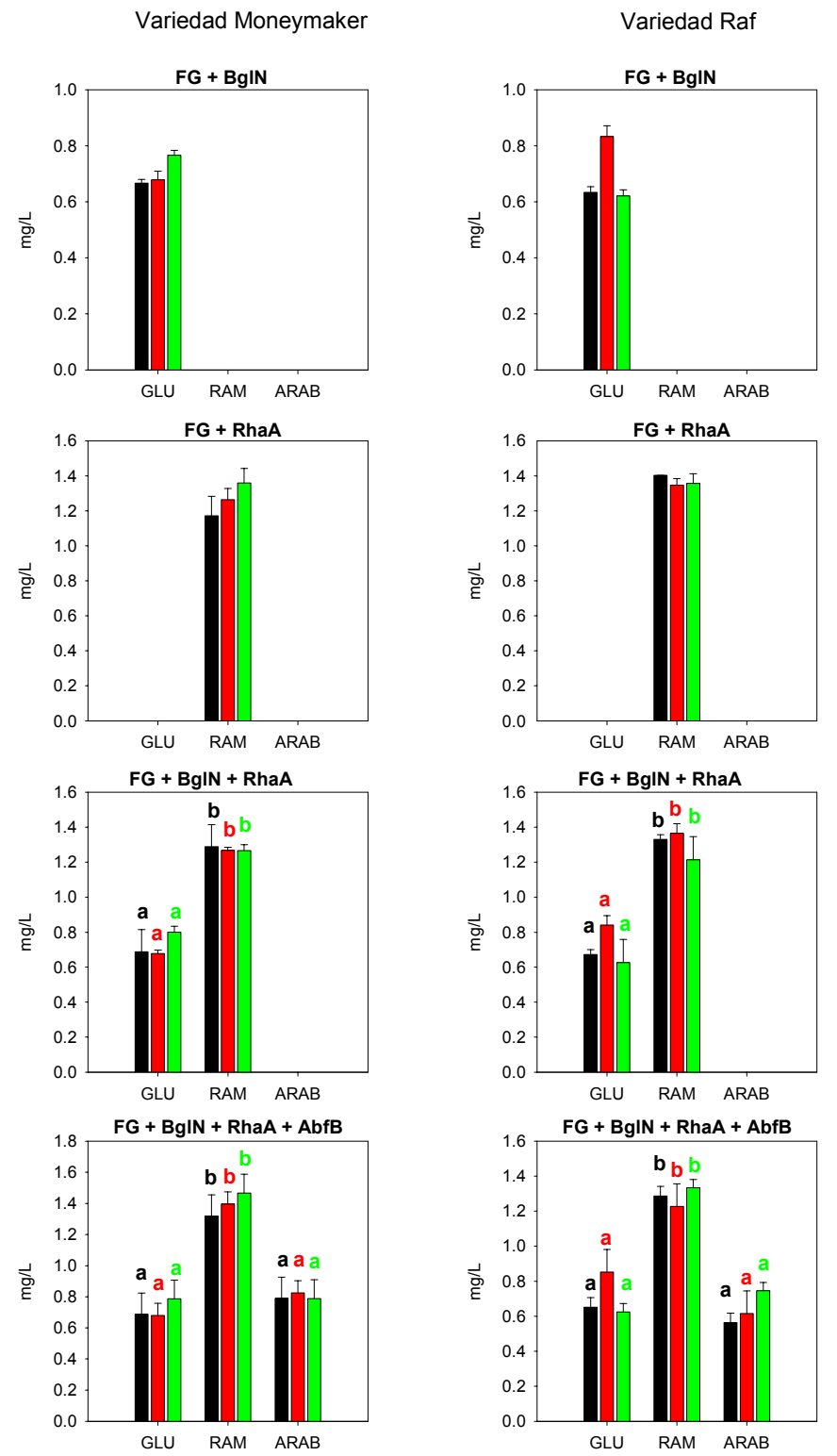

Figura 30. Concentración de glucosa (GLU), ramnosa (RAM), y arabinosa (ARAB) detectadas tras la incubación del extracto de glicósidos de las variedades Moneymaker (MM) y Raf en los estados de maduración V (negro), P (rojo), y M (verde) en presencia de $\mathrm{BgIN}$, RhaA, BgIN+ RhaA, BglN+RhaA+AbfB. Diferentes letras para cada estado de maduración indican diferencias significativas entre los azúcares según el Test de Tukey's HSD aplicado con un intervalo de confianza del $95 \%$ a 3 repeticiones. 
Las concentraciones de cada uno de los azúcares fueron muy similares independientemente de la combinación enzimática con la que se incubara el extracto de glicósidos, y para ambas variedades. Por ejemplo, la concentración de glucosa osciló entre 0.68 y $0.80 \mathrm{mg} / \mathrm{L}$ en la variedad $\mathrm{MM}$, y entre 0.62 y $0.85 \mathrm{mg} / \mathrm{L}$ en la variedad Raf, en función del tratamiento enzimático considerado. $\mathrm{Y}$ la de ramnosa varió entre 1.17 y $1.47 \mathrm{mg} / \mathrm{L}$ en la variedad $\mathrm{MM}$, y entre 1.21 y $1.36 \mathrm{mg} / \mathrm{L}$ en la variedad Raf, en función del tratamiento enzimático considerado. Además, tampoco se registraron cambios significativos en las cantidades de cada uno de los azúcares entre los 3 estados de maduración considerados. El análisis estadístico sí mostró diferencias significativas entre los 3 azúcares detectados. La concentración de ramnosa fue significativamente mayor que la del resto de azúcares en ambas variedades y en los 3 estados de maduración. Mientras que entre las concentraciones de glucosa y arabinosa no se encontraron diferencias significativas. La ramnosa fue el azúcar mayoritario en los 3 estados de maduración considerados y para las 2 variedades. Esto concuerda con que los tratamientos en los que se incluye el enzima RhaA han dado lugar a un mayor aumento de compuestos volátiles libres.

\section{Discusión}

\subsection{Empleo de glicosidasas para la liberación de compuestos volátiles glicosilados del tomate}

El uso de glicosidasas para liberar compuestos volátiles glicosilados ha sido ampliamente estudiado (Straubinger et al., 1998; Parada et al., 2000; Morales et al., 2000; Ly et al., 2002; Lalel et al., 2003; Osorio et al., 2003), y alcanzado con éxito, por ejemplo en la mejora del aroma del vino (Abbott et al., 1991; Francis et al., 1992; Gueguen et al., 1996; Francis et al., 1998; Cabaroglu et al., 2003; Sánchez-Palomo et al., 2005). La caracterización de la fracción volátil, libre y glicosilada, del tomate ha confirmado el potencial de la FG como fuente natural para incrementar el 
aroma de este fruto. A continuación se discute la utilidad de las glicosidasas fúngicas BgIN, Exg1, RhaA, y AbfB para liberar compuestos glicosilados del tomate. Del conjunto de resultados obtenidos se desprende que el uso de estas enzimas puede ser interesante como herramienta para abordar la mejora del aroma del tomate. Finalmente, se ha realizado un estudio sobre la composición de los glicósidos del tomate a partir de la incubación de extractos de glicósidos con las glicosidasas fúngicas específicas.

\subsubsection{Efecto de la adición de $\beta$-glucosidasas al zumo de tomate}

Las $\beta$-glucosidasas hidrolizan el enlace $\beta$-1,4-glicosídico que se establece entre el grupo alcohol de un aglicón y el grupo carbonilo de un residuo de glucosa. Existen evidencias del aumento significativo de los niveles de linalol, bencil alcohol, y 2-feniletanol en el zumo de ciertas frutas como melocotón, cereza, fresas, fruta de la pasión, naranja, manzana, o papaya, por la acción de la $\beta$-glucosidasa de Candida molischiana (para revisión ver Sarry y Günata, 2004). En este trabajo, el zumo de las variedades p73, Jorge, y Durinta fue incubado en presencia de los enzimas con actividad $\beta$-glucosidasa BgIN de C. molischiana (Sánchez-Torres et al., 1998), y Exg1 de Saccharomyces cerevisiae (Gil et al., 2005), cuyas capacidades para liberar compuestos volátiles desde sus respectivos precursores glicosilados en mosto de uva y en vino han sido contrastadas previamente en trabajos anteriores (Genovés et al., 2003; Gil et al., 2005).

Tras la incubación del zumo sin adición de enzimas (BLC), en presencia de BgIN, o de Exg1 se detectaron los mismos 24 compuestos en todas las variedades (Tabla 14), los cuales coincidieron además con los detectados al caracterizar la FVL de estas variedades (Capítulo 1, Tabla 7).

De acuerdo con el análisis estadístico (Tabla 14), 10 compuestos experimentaon aumentos estadísticamente significativos (Figura 21), y 6 
disminuciones significativas (Figura 22). Entre los compuestos cuyas concentraciones aumentaron significativamente, fueron especialmente relevantes por la magnitud del aumento y por su posible repercusión organoléptica positiva, el linalol, nerol, 2-feniletanol, y eugenol. Estos resultados confirman el aumento significativo constatado por Gueguen et al. (1996) de los niveles de linalol y 2-feniletanol en los zumos de frutas tratados con la $\beta$-glucosidasa de C. molischiana (BgIN). El nerol aumentó significativamente tras la incubación del zumo extraído de la variedad Durinta sólo en presencia de Exg1. El linalol, que fue mucho más abundante en la FG que en la FVL de las 3 variedades consideradas, y especialmente en las variedades Jorge y Durinta (Capítulo 1, Figura 8), experimentó aumentos significativos sólo tras la incubación del zumo extraído de la variedad p73 con BgIN. Estos resultados indican la posible distinta especificidad de sustrato de los enzimas $\beta$-glucosídicos Exg1 y BgIN. La concentración de eugenol aumentó significativamente tras la incubación con adición de ambos enzimas en una misma variedad, la variedad Jorge. El aumento alcanzado por el eugenol en la variedad Jorge fue máximo tras incubación en presencia de Exg1, mientras que en la variedad p73 este compuesto sólo aumentó tras incubación en presencia de BgIN. Estos resultados sugieren que quizá el eugenol puede proceder de glicósidos con distinta estructura en ambas variedades de tomate, y que BgIN y Exg1 poseerían diferentes especificidades de sustrato. Por otra parte, sólo la concentración de 3-metil-1-butanol y 2-feniletanol experimentó aumentos significativos en las 3 variedades consideradas, el primero sólo al incubar el zumo con BgIN, y el segundo tras incubar con ambos enzimas.

El 2-feniletanol fue además el compuesto que experimentó los mayores aumentos tras incubación con ambos enzimas (Figura 21). Estos aumentos se tradujeron en un cambio en el signo de su LogU (Tabla 15), desde valores negativos en el BLC hasta positivos en la FVL tras 
incubación de los zumos en presencia de BgIN y Exg1. Conocidas las bondades y limitaciones de este parámetro, el cambio en el signo de LogU indica que al aumentar su concentración, el 2-feniletanol, asociado a notas florales, a "rosas" (Berna et al., 2005a), habría aumentado igualmente su participación en el aroma final del tomate. Cómo se traduciría esta aportación desde un punto de vista sensorial podría ser objeto de otro trabajo.

Además de aumentar significativamente, tras la incubación de los zumos extraídos de las variedades p73, Jorge, y Durinta en presencia de los enzimas, BglN y Exg1, la concentración de 6 compuestos también disminuyó significativamente con respecto al BLC (Figura 22). Estos compuestos fueron la 3-octanona, decanal, 1-octanol, guaiacol, bencil alcohol, y $\beta$-ionona. La hipótesis más probable es que las disminuciones constatadas podrían estar relacionadas con posibles interacciones entre la matriz zumo de tomate, y el sulfato de amonio con el que fueron adicionados los extractos enzimáticos (Papadopoulou y Frazier, 2004; Papadopoulou et al., 2005). Las disminuciones se centraron en compuestos volátiles no especialmente abundantes (Capítulo 1, Tabla 7), y que por tanto reflejaron en sus concentraciones estas posibles interacciones.

Existen numerosos trabajos de caracterización de la FVL del tomate pero muy pocos se han centrado en su FG, y especialmente escasa es la información que se dispone sobre el posible impacto que tendría la liberación de los compuestos volátiles glicosilados sobre el flavor final del tomate (Buttery et al., 1990a; Marlatt et al., 1992). Los resultados obtenidos en este trabajo han puesto de manifiesto nuevamente la relevancia de la FG del tomate como una potencial fuente natural de compuestos volátiles, y la utilidad de los enzimas con actividad $\beta$-glucosidasa como una 
herramienta para liberar compuestos glicosilados particularmente relevantes en el aroma del tomate, de acuerdo con la bibliografía, como el linalol, nerol, 2-feniletanol, y eugenol. Resulta especialmente interesante, de cara a una posible aplicación biotecnológica, que el enriquecimiento en compuestos volátiles de la FVL se pueda obtener con la intervención de una única actividad enzimática, pues supone una aproximación más simple y asequible que el empleo de una mezcla de enzimas. Según los resultados obtenidos, el enzima BgIN adicionado individualmente es el que mostró mayor capacidad para incrementar la FVL.

\subsubsection{Efecto de la adición de mezclas de glicosidasas al zumo de tomate en distintos estados de maduración}

La mayoría de los precursores de compuestos volátiles identificados hasta el momento en productos vegetales y sus derivados son glicósidos, principalmente del tipo O- $\beta$-D-glicósidos y O-diglicósidos (Sarry y Günata, 2004). Los $O-\beta-D$-glucósidos son hidrolizados por $\beta$-glucosidasas. La hidrólisis de los O-diglicósidos requiere en un primer paso una exoglicosidasa, que libera el monosacárido unido a la unidad de glucosa quedando el $\beta$-D-glucósido, y en un segundo paso es una $\beta$-glucosidasa la que actuando sobre el enlace $\beta$-1,4-glicosídico libera el aglicón y la unidad de glucosa correspondiente (Günata et al., 1988; Sarry y Günata, 2004). Para profundizar en el conocimiento del potencial de la FG, una vez conocido el efecto de la adición de actividades $\beta$-glucosidasa al zumo, se abordó la utilización de mezclas de glicosidasas capaces de realizar la hidrólisis secuencial de diglicósidos. En este sentido, se ensayaron 4 enzimas, 2 con actividad $\beta$-glucosidasa (BgIN, $\beta$-glucosidasa de Candida molischiana, y Exg1, exoglucanasa de Saccharomyces cerevisiae), y 2 con actividad exoglicosidasa (RhaA, $\alpha$-L-ramnosidasa de Aspergillus aculeatus, y AbfB, $\alpha$-L-arabinofuranosidasa de Aspergillus niger), adicionadas al zumo individualmente $y$ en combinaciones (BgIN, Exg1, RhaA, AbfB, 
BglN+RhaA, BglN+AbfB, BglN+RhaA+AbfB, Exg1+RhaA, Exg1+AbfB, y Exg1+RhaA+AbfB). Se utilizó el zumo limpio extraído de las variedades Moneymaker (MM) y Raf, variedades de tomate económica y organolépticamente interesantes, en 3 momentos del proceso de maduración del fruto, $\mathrm{V}, \mathrm{P}, \mathrm{y} \mathrm{M}$.

Tras incubar los zumos en presencia de los enzimas o de las combinaciones enzimáticas analizadas se detectaron los mismos 24 compuestos volátiles (Tabla 16 y Tabla 17) descritos en la caracterización de la FVL de estas variedades, y los compuestos cis-óxido de linalol y geraniol, previamente identificados en este trabajo como componentes de la FG de las variedades MM y Raf (Capítulo 1, Tabla 12). La concentración de estos 2 compuestos no mostró diferencias significativas respecto al zumo incubado sin adición de enzimas (BLC), por lo que probablemente ambos compuestos aparecieron en la FVL como consecuencia del proceso de incubación y no de la hidrólisis enzimática de la FG.

De acuerdo con el análisis estadístico, las concentraciones de 11 y 12 compuestos en la FVL de las variedades MM y Raf, respectivamente, experimentaron diferencias estadísticamente significativas respecto al BLC tras incubación en presencia de alguna de las 10 combinaciones enzimáticas analizadas. En general, estas diferencias se tradujeron en aumentos estadísticamente significativos pero también se observaron algunas disminuciones significativas.

La concentración de 3-metil-1-butanol, trans-2-hexenal, 1-hexanol, linalol, 3,5-dimetil benzaldehído, salicilato de metilo, y 2-feniletanol en ambas variedades, la de 3-octanona, 2-etil-1-hexanol y nerol en la variedad MM, y la de octanal, cis-4-decenal y 1-octanol en la variedad Raf, aumentó significativamente, respecto al BLC, tras incubación en presencia de alguna de las 10 mezclas enzimáticas analizadas (Figura 23, Figura 24, Figura 26, Figura 27). Entre estos compuestos, fueron especialmente relevantes el 3-metil-1-butanol, linalol, y 2-feniletanol en ambas variedades, 
y nerol en la variedad $\mathrm{MM}$, tanto por la magnitud de su aumento, que osciló entre un $22 \%$ para el nerol en la variedad MM en presencia de BgIN+AbfB y un $994 \%$ para el 3-metil-1-butanol en ambas variedades con BglN+RhaA+AbfB, como por su interesante potencial repercusión organoléptica para el tomate. El 3-metil-1-butanol se encuentra entre los compuestos con LogU positivo definidos por Buttery (1993), y por tanto se considera que ejerce una contribución destacada al flavor del tomate. Linalol y nerol, están asociados a notas florales o frutales, y 2-feniletanol a olor a rosas (Berna et al., 2005a). El aumento significativo de la concentración de estos 4 compuestos fue constatado anteriormente en este trabajo al incubar los zumos extraídos de las variedades p73, Jorge, y Durinta con adición de los enzimas BgIN o Exg1 (Figura 21). El aumento de la concentración de linalol y de 2-feniletanol en tomate, además, está de acuerdo con el descrito por Gueguen et al (1996) en otras frutas en presencia de BgIN. El 3-metil-1-butanol fue el único compuesto cuya concentración aumentó significativamente en los 3 estados de maduración considerados y en ambas variedades tras la incubación con los distintos enzimas analizados y sus combinaciones. Fue además el compuesto que experimentó los máximos aumentos, particularmente en el estado $\mathrm{V}$, aumentando su concentración hasta un $679 \%$ y un $994 \%$ en las variedades MM y Raf, respectivamente, tras incubación con $\mathrm{BgIN}+\mathrm{RhaA}+\mathrm{AbfB}$.

Los compuestos 3,5-dimetil benzaldehído y cis-4-decenal no fueron detectados en el Capítulo 1 como componentes de la FG de las variedades MM y Raf (Tabla 12), sin embargo se encuentran entre los compuestos cuya concentración aumentó significativamente tras la incubación en presencia de las mezclas enzimáticas analizadas. Probablemente las actividades utilizadas en las mezclas enzimáticas, así como las condiciones experimentales de las incubaciones, sean más eficientes para la hidrólisis de estos compuestos que el tratamiento con el preparado 
comercial AR2000 utilizado para la caracterización de la FG en el Capítulo 1.

La concentración de salicilato de metilo aumentó significativamente en ambas variedades tras incubación en presencia de las combinaciones enzimáticas analizadas (Figura 24 y Figura 27). El aumento en la concentración de este compuesto en el estado de maduración $\mathrm{M}$ del fruto quizá no tenga una repercusión organoléptica positiva pues, como ha sido comentado, se trata de un compuesto característico del estado de maduración verde, que en el caso del tomate es menos apreciado organolépticamente.

Por otro lado, fue en el estado de maduración $V$ en el que aumentó significativamente la concentración de un mayor número de compuestos en ambas variedades (Figura 23, Figura 24, Figura 26, Figura 27) tras incubación en presencia de alguno de los enzimas o de sus mezclas. La posibilidad de aumentar la concentración de 3-metil-1-butanol, linalol, y 2feniletanol, compuestos que pueden ejercer un efecto sensorial positivo según la bibliografía, en estados tempranos del desarrollo del fruto puede ser especialmente interesante para aumentar características de tomate maduro en tomates verdes o en estados más tempranos de maduración.

Los aumentos estadísticamente significativos fueron más numerosos $\mathrm{y}$, en general, de mayor magnitud en los zumos incubados con BgIN y Exg1 combinados con las exoglicosidasas RhaA y AbfB, que en los zumos incubados con los enzimas individualmente. La combinación enzimática $\mathrm{BgIN}+\mathrm{RhaA}+\mathrm{AbfB}$ fue la que consiguió aumentar significativamente la concentración de un mayor número de compuestos, alcanzando también los máximos aumentos. Esta combinación enzimática en teoría es capaz de hidrolizar un abanico más amplio de glicósidos, tanto monoglicósidos como diglicósidos de ramnosa y de arabinosa, por lo que al parecer, este tipo de glicósidos serían relativamente abundantes en el zumo de tomate. A la incubación en presencia de $B g I N+R h a A+A b f B$, le siguen, en orden 
descendente, en cuanto al número de compuestos cuya concentración aumentó significativamente las combinaciones BglN+RhaA, Exg1+RhaA, Exg1+RhaA+AbfB, RhaA, BglN, y BglN+AbfB.

La incubación del zumo con AbfB no produjo aumentos significativos en la concentración de ninguno de los compuestos detectados en la FVL de las variedades MM y Raf. El salicilato de metilo fue el único compuesto que aumentó significativamente tras incubación en presencia de Exg1 y de Exg1+AbfB en el estado $V$ de la variedad Raf (Figura 27). Estos resultados indican que la actividad arabinosidasa es útil para liberar compuestos volátiles glicosilados en presencia de la mezcla $B g I N+R h a A+A b f B$, aunque no resultó útil en solitario tal y como cabría esperar si no existen monoglicósidos de arabinosa. Tampoco resultó útil su adición combinada con la actividad $\beta$-glucosidasa de Exg1, pero sí con la de BgIN. El conjunto de estos resultados indica la distinta especificidad de sustrato entre las $\beta$ glucosidasa BgIN y Exg1, mostrándose más útil a la hora de incrementar los componentes de la fracción volátil en el zumo de tomate el enzima BgIN.

La $\beta$-glucosidasa BgIN destacó por su papel en el aumento de compuestos volátiles tan interesantes organolépticamente para el tomate como el linalol, el nerol, y el 2-feniletanol, participando tanto en la hipotética liberación de aglicones a partir de monoglucósidos como de diglicósidos cuando se emplea en combinación con otros enzimas. Por ejemplo, la concentración de linalol aumentó tras incubación en presencia de BgIN en ambas variedades, y alcanzó sus máximos aumentos tras incubación en presencia de $\mathrm{Bg} I \mathrm{~N}+\mathrm{RhaA}$ en la variedad $\mathrm{MM}$, y en presencia de $\mathrm{BgIN}+\mathrm{AbfB}$ en la variedad Raf.

Los compuestos que aumentaron tras incubación en presencia de RhaA sólo aumentaron además tras incubación con BgIN y Exg1 combinados con RhaA y RhaA+AbfB. A partir de estos resultados se ha podido constatar que la ramnosidasa (RhaA) juega un papel relevante para 
el enriquecimiento en compuestos volátiles del zumo de tomate, tanto individualmente como en combinación. El enzima RhaA utilizado en este trabajo posee un $0.24 \%$ de actividad $\beta$-glucosidasa respecto a su actividad principal que, aunque prácticamente despreciable, podría ayudar a explicar los aumentos experimentados tras incubación del zumo en presencia de RhaA individualmente como consecuencia de la hidrólisis secuencial de diglicósidos de ramnosa con glucosa. Tampoco se descarta la posibilidad de que existan monoglicósidos de ramnosa en tomate, aunque no se han sido descritos en vegetales, o que la hidrólisis química que puede darse para algunos glicósidos durante la incubación sea más favorable para los diglicósidos de ramnosa.

Tras la incubación del zumo extraído de las variedad MM y Raf en presencia de las mezclas de enzimas también se observaron disminuciones significativas de las concentraciones de salicilato de metilo, y hexanal en ambas variedades, y de nonanal y octanal en la variedad Raf (Figura 24, Figura 25, Figura 27, y Figura 28). Las concentraciones de estos compuestos son muy bajas y por tanto cualquier leve variación derivada de las posibles interacciones entre la propia matriz del tomate, los enzimas adicionados, y las condiciones de incubación puede ser causa de los descensos significativos.

Para valorar el efecto de las incubaciones del zumo con las distintas mezclas enzimáticas sobre el conjunto de la FVL de las variedades Moneymaker (MM) y Raf se calculó la suma de las concentraciones ponderadas, respecto al zumo incubado sin enzima (BLC), de todos los compuestos volátiles (Figura 29). Esta suma se obtuvo otorgando el valor de referencia 1 para cada componente en el BLC y calculando el valor proporcional para el resto de mezclas enzimáticas. De esta forma se elimina la influencia de los órdenes de magnitud de las concentraciones 
respectivas de cada componente permitiendo ver los efectos estadísticamente significativos que podrían pasar desaparercibidos en el estudio individual de cada componente. Así, la suma total ponderada consigue reflejar mejor los incrementos totales alcanzados en la FVL tras las incubaciones y ver con mayor claridad la contribución de todos los componentes. A partir del análisis estadístico, no se observaron disminuciones significativas de la suma ponderada. El conjunto ponderado de los compuestos detectados en la FVL alcanzó sus máximos aumentos tras incubación en presencia de $B g I N+R h a A+A b f B$, y particularmente en el estado de maduración $\mathrm{V}$ de ambas variedades. El análisis de los valores obtenidos con esta suma de compuestos volátiles refuerza los efectos individuales de las mezclas enzimáticas ya comentados sobre cada compuesto, de manera que se comprueba con mayor claridad los tratamientos enzimáticos más útiles para el incremento de la concentración de volátiles que, según estos resultados, en orden descendente fueron BgIN+RhaA+AbfB, BgIN+RhaA, Exg1+RhaA, Exg1+RhaA+AbfB ó RhaA, y $B g I N+A b f B$.

En este trabajo se ha demostrado la capacidad de los enzimas glicosídicos para aumentar la concentración de compuestos volátiles organolépticamente interesantes para el tomate. Definir el efecto concreto que tendría el aumento de estos compuestos mediante estudios sensoriales bien diseñados sería de suma importancia para conocer el alcance comercial de esta herramienta biotecnológica para la mejora del aroma del tomate. De la misma forma, sería necesario profundizar en la forma de aplicación de los enzimas para hacerlo compatible con los procesos industriales de fabricación de derivados de tomate procesado o la generación de plantas transgénicas que expresen las actividades de mayor interés. 


\subsubsection{Análisis de la composición de los glicósidos}

Dada la escasa información disponible en la literatura sobre la composición de los precursores glicosilados en tomate, se decidió llevar a cabo un estudio que permitiera arrojar algo de luz acerca de la composición de los glicósidos del tomate mediante el análisis cromatográfico de los aglicones y de los azúcares liberados tras incubar los extractos de glicósidos en condiciones tamponadas en presencia de enzimas glicosídicos específicos. A partir de los resultados obtenidos tanto de la caracterización del perfil aromático como de la adición de glicosidasas al zumo de tomate, se decidió incubar los extractos de glicósidos de las variedades Moneymaker (MM) y Raf, en 3 momentos del proceso de maduración del fruto, en presencia del preparado enzimático comercial AR2000, y de las mezclas enzimáticas BgIN, RhaA, BgIN+RhaA, y $\mathrm{BgIN}+\mathrm{RhaA}+\mathrm{AbfB}$.

Tras incubar los extractos de glicósidos en presencia de AR2000 en los estados de maduración $\mathrm{V}, \mathrm{P}$, y $\mathrm{M}$, se detectaron, por un lado, 30 aglicones (Capítulo 1, Tabla 12), resultados que ya se discutieron en el Capítulo 1. Y por otro, 4 azúcares, glucosa, xilosa, ramnosa, y arabinosa (Capítulo 1, Figura 14). Especialmente llamativa es la presencia de xilosa en los extractos de glicósidos del tomate. Este azúcar no ha sido descrito en uva como parte de glicósidos de compuestos volátiles, y su existencia ha sido comprobada como parte de diglicósidos en el té (para revisión ver Sarry y Günata, 2004). El azúcar más abundante fue la ramnosa, en los 3 estados de maduración considerados y en ambas variedades. Todos los azúcares alcanzaron su máxima concentración en el estado $\mathrm{P}$ o M, aunque sus concentraciones no fueron significativamente diferentes entre los 3 estados de maduración considerados.

Por otro lado, tras la incubación de los extractos de glicósidos con BglN, RhaA, BglN+RhaA, o BgIN+RhaA+AbfB, en los 3 estados de maduración considerados, se detectaron, por un lado, los mismos 18 
aglicones entre los que se encontraban aldehídos, alcoholes, y terpenos (Tabla 18, Tabla 19, y Tabla 20), y por otro, 3 azúcares, glucosa, ramnosa, y arabinosa (Figura 30). El azúcar más abundante también fue la ramnosa. Los tratamientos enzimáticos en presencia de los cuales se liberó un mayor número de aglicones fueron $\mathrm{BgIN}, \mathrm{BgIN}+\mathrm{RhaA}+\mathrm{AbfB}$, y $\mathrm{Bg} I \mathrm{~N}+\mathrm{RhaA}$, dependiendo la mayor utilidad de uno u otro del estado de maduración y de la variedad considerados. El papel de RhaA y de AbfB en la liberación de compuestos volátiles en combinación con los otros enzimas se reveló fundamental. Este resultado confirma la utilidad de la combinación de enzimas $\mathrm{BglN}+\mathrm{RhaA}+\mathrm{AbfB}$ para liberar compuestos volátiles con una repercusión sensorial positiva, según la blibliografía, y en particular de la $\beta$ glucosidasa BgIN y de la ramnosidasa RhaA, y sugiere la posible abundancia de diglicósidos en el tomate.

El conjunto de estos resultados avala la hipótesis de que en la composición de los glicósidos del tomate participan los azúcares glucosa, xilosa, ramnosa, y arabinosa, y que los glicósidos de ramnosa y la ramnosidasa juegan un importante papel en la composición de los glicósidos y en su hidrólisis, respectivamente. Si la ramnosa sólo puede estar formando parte de diglicósidos, no resulta esperable el hecho de que la concentración de glucosa sea inferior a la de ramnosa. Existen dos explicaciones que no han podido ser comprobadas, que pueden existir monoramnósidos, algo no descrito hasta el momento en ningún vegetal, o que la hidrólisis con ramnosidasa puede dar lugar a monoglucósidos que quedan sin hidrolizar en el extracto incubado.

Entre los aglicones que forman parte de los glicósidos en tomate se encuentran aldehídos, alcoholes, y terpenos. En general, son compuestos de gran relevancia organoléptica para el tomate, y convierten a la FG en una interesante potencial fuente de aroma. En algunos casos se ha obsevado la distinta naturaleza o cuantía de algunos de los aglicones liberados a partir de los extractos de glicósidos entre las variedades 
consideradas y en función del estado de maduración. En otros casos se ha podido constatar la liberación de los mismos aglicones en ambas variedades pero tras incubación en presencia de distintas combinaciones enzimáticas. Estos resultados sugieren y confirman, como ya se discutió en el Capítulo 1, la influencia que parece ejercer la variedad y el estado de maduración sobre la composición de la FG del tomate.

Finalmente, los resultados de este trabajo, acompañados del adecuado análisis sensorial, pueden suponer un punto de partida para abordar la mejora biotecnológica del aroma del tomate, por ejemplo a través de la construcción de plantas de tomate modificadas genéticamente para sobrexpresar enzimas específicos de mayor interés o de la incorporación de estos enzimas en los procesos industriales de fabricación de derivados de tomate procesado. Posiblemente, los verdaderos avances en el área de la mejora de la calidad organoléptica de frutas y verduras, y en particular del tomate, sólo se consigan integrando un abordaje multidisciplinar donde se aúnen los conocimientos en técnicas de cultivo, biología molecular, fisiología post-cosecha, tecnología de alimentos, y genética. 



\section{CONCLUSIONES}

Del conjunto de resultados de esta Tesis Doctoral se pueden extraer las siguientes conclusiones:

1.- Se ha caracterizado la fracción volátil libre de las variedades de tomate p73, Jorge, Durinta, Moneymaker y Raf centrándose en los compuestos más relevantes para la calidad organoléptica y en los susceptibles de estar en forma glicosilada. La caracterización ha mostrado diferencias significativas entre la composición de la fracción volátil libre de cada variedad que podrían permitir, como ha sido propuesto en trabajos anteriores, utilizar el perfil aromático del tomate como herramienta para la identificación de variedades.

2.- Se ha caracterizado la fracción volátil glicosilada de las mismas cinco variedades, detectándose hasta 10 compuestos glicosilados que no habían sido detectados en forma libre.

3.- Se ha descrito por primera vez las presencia de los compuestos 1-heptanol, 2-etil-1-hexanol, 1-octanol, salicilato de metilo, guaiacol, y 2metoxi-4-vinilfenol en forma glicosilada en el tomate.

4.- La fracción glicosilada del tomate puede suponer una fuente potencial para conseguir incrementar la concentración de determinados compuestos volátiles en forma libre. De entre los compuestos glicosilados detectados, trans-2-hexenal, cis-óxido de linalol, trans-óxido de linalol, benzaldehído, linalol, $\alpha$-terpineol, $\beta$-citronelol, geraniol, 2-feniletanol, y eugenol han sido descritos como compuestos con repercusión organoléptica positiva en el aroma del tomate. 
5.- A través del cálculo del logaritmo de las unidades de olor (LogU) se desprende que un número limitado de compuestos influyen de una forma esencial en el aroma de tomate, tal y como han propuesto otros autores, y que la hidrólisis y liberación de determinados compuestos a partir de sus formas glicosiladas podría convertirlos en relevantes desde el punto de vista organoléptico.

6.- Los compuestos volátiles tanto libres como glicosilados tienden en general a aumentar su concentración a medida que avanza la maduración del fruto con algunas excepciones. El salicilato de metilo es más abundante en el estado de maduración verde y se detecta a baja concentración en el tomate maduro, aunque con diferencias importantes en función de la variedad.

7.- La adición individual al zumo de tomate de las enzimas BgIN o Exg1, ambas con actividad $\beta$-glucosidasa, ha dado lugar a incrementos significativos en compuestos de la fracción volátil libre, entre los que cabe destacar por su posible repercusión organoléptica el linalol, nerol, 2feniletanol, y eugenol.

8.- La adición al zumo de tomate de combinaciones de diversas actividades glicosídicas, capaces de hidrolizar diglicósidos, ha dado lugar a incrementos significativos en compuestos de la fracción volátil libre. La combinación de las actividades BgIN o Exg1 con las actividades ramnosidasa $(\mathrm{RhaA})$ o arabinosidasa $(\mathrm{AbfB})$ dio lugar a incrementos en la concentración de un mayor número de compuestos que la incubación con cada uno de estos enzimas individualmente. Los tratamientos con presencia de la ramnosidasa (RhaA) combinada con BgIN o con BgIN y AbfB fueron los que lograron el mayor número de aumentos en la concentración compuestos volátiles y en general los de mayor cuantía. 
Destacan los incrementos en la concentración de 3-metil-1-butanol, linalol, 2-feniletanol y nerol por su posible repercusión organoléptica.

9.- Se ha detectado la presencia de glucosa, ramnosa, arabinosa y xilosa como parte de los azúcares componentes de los glicósidos del tomate. De acuerdo con los productos de las hidrólisis detectados tras las incubaciones con cada enzima, en el tomate coexistirían monoglicósidos y diglicósidos, siendo los de ramnosa los más abundantes.

10.- Se ha demostrado la utilidad de los tratamientos enzimáticos para incrementar la concentración de ciertos compuestos volátiles del tomate, algunos de ellos con posible repercusión organoléptica positiva. Esto puede servir de base para abordar la mejora biotecnológica de la planta de tomate o el estudio de la aplicación industrial de los enzimas durante la elaboración de productos derivados de tomate. 




\section{BIBLIOGRAFÍA}

Abbott, N. A.; Coombe, B. G. y Williams, P. J. 1991. The contribution of hydrolyzed flavor precursors to quality differences in Shiraz juice and wines: an investigation by sensory descriptive analysis. American Journal of Enology and Viticulture, 42: 167-174.

Abegaz, E. G.; Tandon, K. S.; Scott, J. W.; Baldwin, E. A. y Shewfelt, R. L. 2000. Partitioning taste from aromatic flavor notes of fresh tomato (Lycopersicon esculentum, Mill.) to develop predictive models as a function of volatile and nonvolatile components. Postharvest Biology and Technology, 20: 261-268.

Abegaz, E. G.; Tandon, K. S.; Scott, J. W.; Baldwin, E. A. y Shewfelt, R. L. 2004. Partitioning taste from aromatic flavor notes of fresh tomato (Lycopersicon esculentum, Mill.) to develop predictive models as a function of volatile and nonvolatile components. Postharvest Biology and Technology, 20: 261-268.

Alexander, L. y Grierson, D. 2002. Ethylene biosynthesis and action in tomato: a model for climateric fruit ripening. Journal of Experimental Botany, 53 (377): 2039-2055.

Anuario de estadística agroalimentaria- M.A.P.A. 2006. http://mapa.es/es/estadistical

Aubert, C.; Ambid, C.; Baumes, R. y Günata, Z. 2003. Investigation of bound aroma constituents of Yellow-Freshed nectarines (Prunus persica L. Cv Springbright). Changes in bound aroma profile during maturation. Journal of Agriculture and Food Chemistry, 51: 6280-6286.

Baek, H. H. y Cadwallader, K. R. 1999. Contribution of free and glycosidically bound volatile compounds to the aroma of Muscadine Grape Juice. Journal of Food Science, 64 (3): 441-444.

Baldwin, E. A. 2004. Flavor. En The Commercial Storage of Fruits, Vegetables, and Florist and Nursery Stocks. Agriculture Handbook Number 66. Gross, K.; Wang, C. y Saltveit, M. (Eds.). Agricultural Research Service, Washington D.C. http://usna.usda.gov/hb66/023flavor.pdf. 
Baldwin, E. A.; Goodner, K.; Plotto, A.; Pritchett, K. y Einstein, M. 2004. Effect of Volatiles and their Concentration on Perception of Tomato Descriptors. Journal of Food Science, 69 (8): 310-318.

Baldwin, E. A.; Nisperos-Carriedo, M. O.; Baker, R. y Scout, J. W. 1991a. Qualitative analysis of flavor parameters in six Florida tomato cultivariedades Journal of Agriculture and Food Chemistry, 39: 11351140.

Baldwin, E. A.; Nisperos-Carriedo, M. O. y Moshomas, M. G. 1991b. Quantitative analysis of flavor and other volatiles and for certain constituents of two tomato cultivars during ripening. Journal of the American Society for Horticultural Science, 116 (2): 265-269.

Baldwin, E. A. y Scott, J. W. 2002. Update on tomato flavor. Proc. Fla. Tomato Institute, PRO 519: 7-13.

Baldwin, E. A.; Scott, J. W.; Einstein, M. A.; Malundo, M. M.; Carr, B. T.; Shewfelt, R. L. y Tandon, K. S. 1998. Relationship between sensory and instrumental analysis for tomato flavor. Journal of the American Society for Horticultural Science, 123: 906-915.

Baldwin, E. A.; Scott, J. W.; Shewmaker, C. K. y Schuch, W. 2000. Flavor trivia and tomato aroma: biochemistry and possible mechanisms for control of important aroma components. HortScience, 35 (6): 1013-1022.

Baldwin, E. A. y Thompson, K. 2000. Effect of sugar type and concentration on perception of tomato sweetness. Proceedings of the Florida State Horticultural Society, 113: 287-289.

Baldwin, I. T.; Halitschke, R.; Paschold, A.; HDahl, C. y Preston, C. 2006. Volatile signalling in plant-plant interactions: "talking trees" in genomica era. Science, 311: 812-814.

Beltran, J.; Serrano, E.; López, F. J.; Peruga, A.; Valcarcel, M. y Rosello, S. 2006. Comparison of two quantitative GC-MS methods for analysis of tomato aroma based on purge-and-trap and on solid-phase microextraction. Anal Bional Chem. Special issue paper, 385: 12551264. 
Berna, A. Z.; Buysens, S.; di Natale, C.; Grün, I. U.; Lammertyn, J. y Nicolaï, B. M. 2005a. Relating sensory analysis with electronic nose and headspace fingerprint MS for tomato aroma profiling. Postharvest Biology and Technology, 36: 143-155.

Berna, A. Z.; Lammertyn, J.; Buysens, S.; di Natale, C. y Nicolaï, B. M. 2005b. Mapping consumer liking of tomatoes with fast aroma profiling techniques. Postharvest Biology and Technology, 38: 115-127.

Berna, A. Z.; Lammertyn, J.; Saevels, S.; di Natale, C. y Nicolaï, B. M. 2004. Electronic nose systems to study shelf life and cultivar effect on tomato aroma profile. Sensors and Actuators B, 97: 324-333.

Besford, R. T. y Hobson, G. E. 1975. Effect of potassium nutrition on some enzymes from ripening Lycopersicon esculentum fruit. Phytochemistry, 14: $57-59$.

Bezman, Y.; Mayer, F.; Takeoka, G. R.; Buttery, R. G.; Ben-Oliel, G.; Rabinowitch, H. D. y Naim, M. 2003. Differential effects of tomato (Lycopersicon esculentum Mill) matrix on the volatility of important aroma compounds. Journal of Agriculture and Food Chemistry, 51: 722726.

Bird, C. R.; Ray, J. A.; Fletcher, J. D.; Boniwell, J. M.; Bird, A. S.; Teulieres, C.; Blain, I.; Bramley, P. M. y Schuch, W. 1991. Using antisense RNA to study gene function: Inhibition of carotenoid biosynthesis in transgenic tomatoes. Bio/Technology, 9: 635-639.

Bleecker, A. B. y Schaller, G. E. 1996. The mechanism of ethylene perception. Plant Physiology, 111: 653-660.

Boulanger, R. y Crouzet, J. 2001. Changes on volatile compounds during heating of Bacuri pulp. Journal of Agriculture and Food Chemistry, 49: 5911-5915.

Bramley, P. M. 2002. Regulation of carotenoid formation during tomato fruit ripening and development. Journal of Experimental Botany, 53 (377): 2107-2113.

Brauss, M. S.; Linforth, R. S. y Taylor, A. J. 1998. Effect of variety, time of eating, and fruit-to-fruit variation on volatile release during eating of 
tomato fruits (Lycopersicon esculentum). Journal of Agriculture and Food Chemistry, 46 (6): 2287-2292.

Bricout, J. 1992. Spectrométrie de masse: couplage avec la chromatographie en phase gazeuse. En Les arômes alimentaires. Richard, H. y Multon, J. L. (Eds.). TEC \& DOC - LAVOISIER, Paris, pp. 356-375.

Brossard, C.; Rousseau, F. y Dumont, J.-P. 2007. Perceptual interactions between characteristic notes smelled above aqueous solutions of odorant mixtures. Chemical Senses, 32: 319-327.

Bruhn, C. M.; Feldmann, N.; Garlitz, C.; Harwood, J.; Ivans, E.; Marshall, M.; Riley, A.; Thurber, D. y Willamson, E. 1991. Consumer perceptions of quality: apricots, cantaloupes, peaches, pears, strawberries, and tomatoes. Journal of Food Quality, 14: 187-195.

Bruno-Bárcena, J. M.; Lucca, M. E.; Siñeriz, F. y Ramón, D. 2002. pH regulation of enzyme production in Aspergillus nidulans growing in aerobic batch fermenter. Biotechnology Letters, 24: 567-572.

Bucheli, P.; Voirol, E.; de la Torre, R.; López, J.; Rytz, A.; Tanksley, S. D. y Pétiard, V. 1999. Definition of Nonvolatile Markers for Flavor of Tomato (Lycopersicon esculentum Mill.) as Tools in Selection and Breeding. Journal of the Science of Food and Agriculture, 47: 659-664.

Burdock, G. A. 2002. Feranoli's Handbook of Flavor Ingredients. CRC Press LLC, Boca Raton, Florida.

Buttery, R. G. 1993. Quantitative and sensory aspects af flavor of tomato and other vegetables and fruits. En Flavor Science: Sensible Principles and Techniques. Acree, T. E. y Teranishi, R. (Eds.). Amer. Chem. Soc., Washington, D.C., pp. 259-281.

Buttery, R. G.; Seifert, R. M.; Guadagni, D. G. y Ling, L. C. 1971. Characterisation of additional volatile components of tomato. Journal of Agriculture and Food Chemistry, 19 (3): 524-529.

Buttery, R. G.; Takeoka, G.; Teranishi, R. y Ling, L. C. 1990a. Tomato aroma components: identification of glycoside hydrolysis volatiles. Journal of Agriculture and Food Chemistry, 38: 2050-2053. 
Buttery, R. G.; Takeoka, G. R. y Ling, L. C. 1995. Furaneol: odor threshold and importance to tomato aroma. Journal of Agriculture and Food Chemistry, 43: 1638-1640.

Buttery, R. G.; Teranishi , R.; Ling, L. C.; Flath, R. A. y Stern, D. J. 1988a. Quantitative studies on origins of fresh tomato aroma volatiles. Journal of Agriculture and Food Chemistry, 36 (6): 1247-1250.

Buttery, R. G.; Teranishi, R. y Ling, L. C. 1987. Fresh tomato aroma volatiles: a quantitative study. Journal of Agriculture and Food Chemistry, 35 (4): 540-544.

Buttery, R. G.; Teranishi, R.; Ling, L. C. y Turnbaugh, J. G. 1990b. Quantitative and sensory studies on tomato paste volatiles. Journal of Agriculture and Food Chemistry, 38 (1): 336-340.

Buttery, R. G.; Turnbaugh, J. G. y Ling, L. C. 1988b. Contribution of volatiles to rice aroma. Journal of Agriculture and Food Chemistry, 36 (5): 1006-1009.

Cabaroglu, T.; Selli, S.; Canbas, A.; Lepoutre, J. P. y Güanata, Z. 2003. Wine flavor enhancement through the use of exogenous fungal glycosidases. Enzyme and Microbial Technology, (33): 581-587.

Canene-Adams, K.; Campbell, J. K.; Zaripheh, S.; Jeffery, E. H. y Erdman, J. W. 2005. The tomato as a functional food. The journal of nutrition, 135 (5): 1226-1230.

Carbonell-Barrachina, A. A.; Agustí, A. y Ruíz, J. J. 2006. Analysis of flavour volatile compounds by dynamic headspace in traditional and hybrid cultivars of Spanish tomatoes. European Food Research and Technology, 222 (5-6): 536-542.

Causse, M.; Saliba-Colombani, V.; Lecomte, L.; Duffé, P.; Rousselle, P. y Buret, M. 2002. QTL anlysis of fruit quality in fresh market tomato: a few chromosome regions control the variation of sensory and instrumental traits. Journal of Experimental Botany, 53 (377): 2089-2098.

Costell, E. 1983. The sensory panel as an analytical tool. Revista de Agroquímica y Tecnología de Alimentos, 23: 1-10. 
Costell, E. y Durán, L. 1981. Sensory analysis in the quality-control of foods .1. Introduction. Revista de Agroquímica y Tecnología de Alimentos, 21: 1-10.

Crouzett, J. 1992. La biogénèse des arômes. En Les arômes alimentaires. Richard, H. y Multon, J. L. (Eds.). TEC \& DOC - LAVOISIER, Paris, pp. 80-97.

Dalal, K. B.; Olson, L. E.; Yu, M. H. y Salunkhe, D. K. 1967. Gas chromatography of the field-, glass- greenhouse-grown, and artificially ripened tomatoes. Phytochemistry, 6: 155-157.

Davidovich-Rikanati, R.; Sitrit, Y.; Tadmor, Y.; lijima, Y.; Bilenko, N.; Bar, E.; Carmona, B.; Fallik, E.; Dudai, N.; Simon, J. E.; Pichersky, E. y Lewinsohn, E. 2007. Enrichment of tomato flavor by diversion of the early plastidial terpenoid pathway. Nature Biotechnology, 25 (8): 899901.

de Prado Ruíz-Santaella, J. L. 2002. Tipos y especificaciones de calidad en el cultivo del tomate. Vida Rural, 148: 1016-1020.

Dicke, M. y Bruin, J. 2001. Chemical information transfer between plants: back to the future. Biochemical Systematics and Ecology, 29: 981-994.

Dijksterhuis, G. B. 1997. Multivariate data analysis in sensory and consumer science. Food and Nutrition Press, Inc., Trumbull, Connecticut.

Dudareva, N.; Pichersky, E. y Gershenzon, J. 2004. Biochemistry of plant volatiles. Plant Physiology, 135: 1893-1902.

Dudareva, N.; Piechulla, B. y Pichersky, E. 2000. Biogenesis of floral scent. Horticultural Reviews, 24: 31-53.

FAO. 2006. http://faostat.fao.org/

Fazzalari, F. A. 1978. Compilation of odor and taste threshold values data. American Society for Testing and Materials, Philadelphia. 
Ferrie, B. J.; Beaudoin, N.; Burkhart, W.; Bowsher, C. G. y Rothstein, S. J. 1994. The cloning of two tomato lipoxygenase genes and their differential expression during fruit ripening. Plant Physiology, 106: 109118.

Fisher, C. y Scott, T. R. 2000. Flavores de los alimentos. Biología y química. ACRIBIA, Zaragoza.

Foolad, M. R. 2007. Genome Mapping and Molecular Breeding of Tomato. International Journal of Plant Genomics Review Article, Artículo ID 64358: 52 páginas.

Francis, I. L.; Kassara, S.; Noble, A. C. y Williams, P. J. 1998. The contribution of glycoside precursors to Cabernet Sauvignon and Merlot aroma: sensory and compositional studies. En Chemistry of Wine Flavour. Waterhouse, A. L. y Ebeler, S. E. (Eds.). ACS Symp. Ser, $\mathrm{n}^{\circ}$ 714. American Chemical Society, New York, pp. 13-30.

Francis, I. L.; Sefton, M. A. y Williams, P. J. 1992. Sensory descriptive analysis of the aroma of hydrolysed flavour precursor fractions from Semillon, Chardonnay, and Sauvignon blanc grape juices. Journal of the Science of Food and Agriculture, 59: 511-520.

Fulton, T. M.; Bucheli, P.; Voirol, E.; López, J.; Pétiard, V. y Tanksley, S. D. 2002. Quantitative trait loci (QTL) affecting sugars, organic acids and other biochemical properties possibly contributing to flavor, identified in four advanced backcross populations of tomato. Euphytica, 127: 163177.

Galliard, T.; Matthew, J. A.; Wright, A. J. y Fishwick, J. 1977. The enzimic breakdown of lipids to volatile and non-volatile carbonyl fragments in disrupted tomato fruits. Journal of the Science of Food and Agriculture, 28: 863-868.

Gao, H. Y.; Zhu, B. Z.; Zhang, Y. L.; Xie, Y. H.; Li, Y. C. y Luo, Y. B. 2007. Effect of suppression of ethylene biosynthesis on flavor products in tomato fruits. Russian Journal of Plant Physiology, 54 (1): 80-88.

Gardner, J. W. y Bartlett, P. N. 1999. Electronic Noses: Principles and Applications. Oxford University Press, New York. 
Genovés, S.; Gil, J. V.; Manzanares, P.; Aleixandre, J. L. y Vallés, S. 2003. Candida molischiana $\beta$-glucosidase production by Saccharomyces cerevisiae and its application in winemaking. Journal of Food Microbiology and Safety, 68 (6): 2096-2100.

Gil, J. V.; Manzanares, P.; Genovés, S.; Vallés, S. y González-Candelas, L. 2005. Over-production of the major exoglucanase of Saccharomyces cerevisiae leads to an increase in the aroma of wine. International Journal of Food Microbiology, 103: 57-68.

Gil, J. V. y Vallés, S. 2001. Effect of macerating enzymes on red wine aroma at laboratory scale: exogenous addition or expression by transgenic wine yeasts. Journal of Agriculture and Food Chemistry, 49: 5515-5523.

Godshall, M. A. 1997. How carbohydrates influence food flavor. Food technology, 51 (1): 63-67.

Gray, D. A.; Prestage, S.; Linforth, R. S. T. y Taylor, A. J. 1999. Fresh tomato specific fluctuations in the composition of lipoxygenasegenerated C6 aldehydes. Food Chemistry, 64: 149-155.

Griffiths, A.; Barry, C. S.; Alpuche-Solis, A. G. y Grierson, D. 1999. Ethylene and developmental signals regulate expression of lipoxygenase genes during tomato fruit ripening. Journal of Experimental Botany, 50: 793-798.

Guadagni, D. G.; Buttery, R. G. y Harris, J. 1966. Odor intensities of hop oil components. Journal of the Science of Food and Agriculture, 17: 142144.

Gueguen, Y.; Chemardin, P.; Janbon, G.; Arnaud, A. y Galzy, P. 1996. A very efficient $\beta$-glucosidase catalyst for the hydrolysis of flavor precursors of wine and fruit juices. Journal of Agriculture and Food Chemistry, 44 (8): 2336-2340.

Günata, Z.; Bitteur, S.; Brillouet, J. M.; Bayonove, C. L. y Cordonnier, R. 1988. Sequential enzymic hydrolysis of potentially aromatic glycosides from grape. Carbohydrate Research, 184: 139-149. 
Hansson, A.; Leufvén, A.; Pehrson, K. y Stenlöf, B. 2002. Multivariate analysis of the influence of pectin, white syrup, and citric acid on aroma concentration in the headspace above pectin gels. Journal of Agriculture and Food Chemistry, 50 (13): 3803-3809.

Hernández-Gómez, A.; Hu, G.; Wang, J. y García-Pereira, A. 2006. Evaluation of tomato maturity by electronic nose. Computers and electronics in agriculture, 54: 44-52.

Ibáñez, E.; López-Sebastián, S.; Ramos, E.; Tabera, J. y Reglero, G. 1998. Analysis of volatile fruit components by headspace solid-phase microextraction. Food Chemistry, 63 (2): 281-286.

Imre, B. 2002. Gas cromatography-olfactometry in food aroma analysis. En Flavor, Fragance and Odor Analysis. Marsili, R. (Ed.). Marcel Dekker, Inc., New York, pp. 297-331.

Ito, Y. y Kubota, K. 2005. Sensory evaluation of the synergism among odorants present in concentrations below their odor threshold in a Chinese jasmine green tea infusion. Molecular Nutrition and Food Research, 49: 61-68.

Jiang, L.; Kojima, H.; Yamada, K.; Kobayashi, A. y Kubota, K. 2001. Isolation of some glycosides as aroma precursors in young leaves of Japanese Pepper (Xanthoxylum piperitum DC.). Journal of Agriculture and Food Chemistry, 49: 5888-5894.

Jones, R. A. y Scott, S. J. 1984. Genetic potential to improve tomato flavor in commercial $F_{1}$ hybrids. Journal of the American Society for Horticultural Science, 109 (3): 318-321.

Jung, D.-M.; de Ropp, J. S. y Ebeler, S. E. 2000. Study of interactions between food phenolics and aromatic flavors using One- and TwoDimensional ${ }^{1} \mathrm{H}$ NMR Spectroscopy. Journal of Agriculture and Food Chemistry, 48 (2): 407-412.

Kader, A. A.; Morris, L. L.; Stevens, M. A. y Albright-Holton, M. 1978. Composition and flavor quality of fresh market tomatoes as influenced by some postharvest handling procedures. Journal of Agriculture and Food Chemistry, 103 (1): 6-13. 
Kader, A. A.; Stevens, M. A.; Albright-Holton, M.; Morris, L. L. y Algazi, M. 1977. Effect of fruit ripeness when picked on flavor and composition in fresh market tomatoes. Journal of the American Society for Horticultural Science, 102 (6): 724-731.

Kazeniac, S. J. y Hall, R. M. 1970. Flavor chemistry of tomato volatiles. Journal of Food Science, 35: 519-529.

Kessler, A. y Baldwin, I. T. 2001. Defensive function of herbivore-induced plant volatile emissions in nature. Science, 291: 2141-2144.

Kirk, O.; Vedel, T. y Fuglsang, C. C. 2002. Industrial enzyme applications. Current Opinion in Biotechnology, 13: 345-351.

Knudsen, J. T.; Tollsten, L. y Bergstrom, G. 1993. Floral Scents: a check list of volatile compounds isolated by headspace techniques.

Phytochemistry, 33: 253-280.

Kramer, M.; Sanders, R.; Bolkan, H.; Waters, C.; Sheeny, R. E. y Hiatt, W. R. 1992. Postharvest evaluation of transgenic tomatoes with reduced levels of polygalacturonase: processing, firmness and disease resistance. Postharvest Biology and Technology, 1 (3): 241-255.

Krammer, G. E.; Takeoka, G. R. y Buttery, R. 1994. Isolation and identification of 2,5-dimethyl-4-hydroxy-3(2H)-furanone glucoside from tomatoes. Journal of Agriculture and Food Chemistry, 42 (8): 1595-1597.

Krammer, G. E.; Winterhalter, P.; Schwab, M. y Schreier, P. 1991. Glycosidically bound aroma compounds in the fruits of Prunus species: apricot $(P$. armeniaca, L.), peach ( $P$. persica, L.), yellow plum $(P$. domestica, L. ssp. syriaca). Journal of Agriculture and Food Chemistry, 39 (4): 778-781.

Krumbein, A. y Auerswald, H. 1998. Characterization of aroma volatiles in tomatoes by sensory analyses. Nahrung, 42 (6): 395-399.

Krumbein, A.; Peters, P. y Brückner, B. 2004. Flavour compounds and a quantitative descriptive analysis of tomatoes (Lycopersicon esculentum Mill.) of different cultivars in short-term storage. Postharvest Biology and Technology, 32: 15-28. 
Kumar, S. y Ramón, D. 1996. Purification and regulation of the synthesis of a $\beta$-xylosidase from Aspergillus nidulans. FEMS Microbiology Letters, 135: 287-293.

Lalel, H. J. D.; Singh, Z. y Tan, S. C. 2003. Glycosidically-bound aroma volatile compounds in the skin and pulp of "Kensington Pride" mango fruit at different stages of maturity. Postharvest Biology and Technology, 29: $205-218$.

Lamparsky, D. 1992b. Méthodes instrumentales d'analyse des arômes: chromatographie en phase gazeuse. En Les arômes alimentaires. Richard, H. y Multon, J. L. (Eds.). TEC \& DOC - LAVOISIER, Paris, pp. 278-313.

Lamparsky, D. 1992a. Méthodes instrumentales d'analyse des arômes: résonance magnetique nucléaire. En Les arômes alimentaires. Richard, H. y Multon, J. L. (Eds.). TEC \& DOC - LAVOISIER, Paris, pp. 338-353.

Langlois, D.; Etièvant, P. X.; Pierron, P. y Jorrot, A. 1996. Sensory and instrumental characterisation of commercial tomato varieties. $Z$. Lebensm. Unters. Forsch., 203: 534-540.

Lawless, H. T. 1986. Sensory interactions in mixtures. Journal of Sensory Studies, 1: 259-274.

Lecas, M.; Günata, Z. Y.; Sapis, J.-C. y Bayonove, C. L. 1991. Purification and partial characterization of $\beta$-glucosidase from grape. Phytochemistry, 30 (2): 451-454.

Leland, J. V. 1997. Flavor interactions:the greater whole. Food technology, 51 (1): 75-80.

Lewinsohn, E.; Schalechet, F.; Wilkinson, J.; Matsui, K.; Tadmor, Y.; Nam, KH.; Amar, O.; Lastochkin, E.; Larkov, O.; Ravid, U.; Hiatt, W.; Gepstein, S. y Pichersky, E. 2001. Enhanced levels of the aroma and flavor compound S-linalool by metabolic engineering of the terpenoid pathway in tomato fruits. Plant Physiology, 127: 1256-1265.

Lewinsohn, E.; Sitrit, Y.; Bar, E.; Azulay, Y.; Ibdah, M.; Meir, A.; Yosef, E.; Zamir, D. y Tadmor, Y. 2005a. Not just colors- carotenoid degradation 
as a link between pigmentation and aroma in tomato and watermelon fruit. Trends in Food Science and technology, 16: 407-415.

Lewinsohn, E.; Sitrit, Y.; Bar, E.; Azulay, Y.; Meir, A.; Zamir, D. y Tadmor, Y. 2005b. Carotenoid pigmentation affects the volatile composition of tomato and watermelon fruits, as revealed by comparative genetic analyses. Journal of Agriculture and Food Chemistry, 53 (8): 3142-3148.

Loughrin, J. H.; Hamilton-Kemp, T. R.; Burton, H. R.; Andersen, R. A. y Hildebrand D.F. 1992. Glycosidically bound volatile components os Nicotiana sylvestris and N. aveolens flowers. Phytochemistry, 31 (5): 1537-1540.

Ly, T. N.; Yamauchi, R.; Shimoyamada, M. y Kato, K. 2002. Isolation and structural elucidation of some glycosides from the rhizomes of Smaller Galanga (Alpinia officinarum Hance). Journal of Agriculture and Food Chemistry, 50: 4919-4924.

MacCabe, A.; Orejas, M.; Tamayo, E. N.; Villanueva, A. y Ramón, D. 2002. Improving extracellular production of food-use enzymes from Aspergillus nidulans. Journal of Biotechnology, 96: 43-54.

Mahmoud, S. S. y Croteau, R. B. 2002. Strategies for transgenic manipulation of monoterpene biosynthesis in plants. Trends in Plant Science, 7: 366-373.

Malundo, M. M.; Shewfelt, R. L. y Scott, J. W. 1995. Flavor quality of fresh tomato (Lycopersicon esculentum Mill.)as affected by sugar and acid levels. Postharvest Biology and Technology, 6: 103-110.

Manzanares, P.; Orejas, M.; Gil, J. V.; de Graaff, L. H.; Visser, J. y Ramón, D. 2003. Construction of a genetically modified wine yeast strain expressing the Aspergillus aculeatus rhaA gene, encoding an $\alpha-L-$ rhamnosidase of enological interest. Applied and Environmental Microbiology, 69 (12): 7558-7562.

Manzanares, P.; van den Broeck, H. C.; de Graaff, L. H. y Visser, J. 2001. Purification and characterisation of two different $\alpha$-L-rhamnosidases, RhaA and RhaB, from Aspergillus aculeatus. Applied and Environmental Microbiology, 67 (5): 2230-2234. 
Marais, J. 1983. Principaux monotérpenols odorants du cépage Muscatés. South Africa Journal of Enology and Viticulture, 4: 49-58.

Markovic, K.; Vahcic, N.; Kovacevic, K. y Banovic, M. 2007. Aroma volatiles of tomatoes and tomato products evaluated by solid-phase microextraction. Flavour and fragrance journal, 22: 395-400.

Marlatt, C.; Ho, C. y Chien, M. 1992. Studies of aroma constituents bound as glycosides in tomato. Journal of Agriculture and Food Chemistry, 40: 249-252.

Marriott, J. 1980. Bananas: Physiology and biochemistry of storage and ripening for optimum quality. CRC Critical Reviews in Food Science and Nutrition, 13: 41-88.

Mattiacci, L.; Dicke, M. y Posthumus, M. A. 1995. $\beta$-Glucosidase: an elicitor of herbivore-induced plant odor that attracts host-searching parasitic wasps. Proceedings of the National Academy of Sciences of the United States of America, 92: 2036-2040.

Maul, F.; Sargent, S. A.; Balaban, M. O.; Baldwin, E. A.; Huber, D. J. y Sims C.A. 1998. Aroma volatile profiles from ripe tomatoes are influenced by physiological maturity al harvest; an application for electronic nose technology. Journal of the American Society for Horticultural Science, 123: 1094-1101.

Maul, F.; Sargent, S. A.; Sims C.A.; Baldwin, E. A.; Balaban, M. O. y Huber, D. J. 2000. Tomato flavour and aroma quality as affected by storage temperature. Journal of Food Science, 65: 1228-1237.

McDonald, R. E.; McCollum, T. G. y Baldwin, E. A. 1999. Temperature of water heat treatments influences tomato fruit quality following lowtemperature storage. Postharvest Biology and Technology, 16: 147-155.

McGlasson, W. B.; Last, J. H.; Shaw, K. J. y Meldrum, S. K. 1987. Influence of the non-ripening mutants rin and nor on the aroma of tomato fruit. HortScience, 22 (4): 632-634.

McGorrin, R. J. 2002. Character Impact Compounds: Flavors and OffFlavors in Foods. En Flavor, Fragance and Odor Analysis. Marsili, R. (Ed.). Marcel Dekker, Inc., New York, pp. 375-413. 
Mizutani, M.; Nakanishi, H.; Ema, J.; Ma, S.-J.; Noguchi, E.; InoharaOchiai, M.; Fukuchi-Mizutani, M.; Nakao, M. y Sakata, K. 2002. Cloning of $\beta$-primeverosidase from tea leaves, a key enzyme in tea aroma formation. Plant Physiology, 130: 2164-2176.

Morales, A. L.; Duque, C. y Bautista, E. 2000. Identification of free and glycosidically bound volatiles and glycosides by capillary GC and capillary GC-MS in "Lulo del Chocó" (Solanum topiro). Journal of High Resolution Chromatography, 23 (5): 379-385.

Morin, P. H. y Richard, H. 1992. Méthodes instrumentales d'analyse des arômes: chromatographie en phase liquide. En Les arômes alimentaires. Richard, H. y Multon, J. L. (Eds.). TEC \& DOC - LAVOISIER, Paris, pp. 318-336.

Nahon, D. F.; Navarro y Koren, P. A.; Roozen, J. P. y Posthumus, M. A. 1998. Flavor release from mixtures of sodium cyclamate, sucrose, and an orange aroma. Journal of Agriculture and Food Chemistry, 46 (12): 4963-4968.

Nonier, M.-F.; Vivas de Gaulejac, N.; Vivas, N. y Vitry, C. 2005.

Glycosidically bound flavour compounds in Quercus petraea Liebl. wood. Flavour and fragrance journal, 20: 567-572.

Oeller, P. W.; Lu, M. W.; Taylor, L. P.; Pike, D. A. y Theologis, A. 1991. Reversible inhibition of tomato fruit senescence by antisense RNA. Science, 254: 437-439.

Ogawa, K.; Ijima, Y.; Guo, W.; Watanabe, N.; Usui, T.; Dong, S.; Tong, Q. y Sakata, K. 1997. Purification of a $\beta$-primeverosidase concerned with alcoholic aroma formation in tea leaves (cv. Shuixian) to be processed to oolong tea. Journal of Agriculture and Food Chemistry, 45 (3): 877-882.

Ohloff, G. 1994. Scent and fragrances, the fascination of odors and their chemical perspectives. En Perfumer and Flavorist. Springer-Verlag, Heidelberg, Germany, pp. 154-158.

Ortiz-Serrano, P. y Gil, J.V. 2007. Quantitation of free and glycosidically bound volatiles in and effect of glycosidase addition on three tomato varieties. Journal of Agriculture and Food Chemistry, 55 (22): 91709176. 
Osorio, C.; Duque, C. y Batista-Viera, F. 2003. Studies on aroma generation in lulo (Solanum quitoense): enzymatic hydrolysis of glycosides from leaves. Food Chemistry, 80: 333-340.

Papadopoulou, A. y Frazier, R. A. 2004. Characterization of proteinpolyphenol interactions. Trends in Food Science and technology, 15: 186-190.

Papadopoulou, A.; Green, R. J. y Frazier, R. A. 2005. Interaction of flavonoids with Bovine Serum Albumin: a fluorescence quenching study. Journal of Agriculture and Food Chemistry, 53: 158-163.

Parada, F.; Duque, C. y Fujimoto, Y. 2000. Free and bound volatile composition and characterization of some glucoconjugates as aroma precusors in Melón de Olor fruit pulp (Sicana odorifera). Journal of Agriculture and Food Chemistry, 48: 6200-6204.

Paré, P. W. y Tumlinson, J. H. 1997. De novo biosynthesis of volatiles induced by insect herbivory in cotton plants. Plant Physiology, 114: 1161-1167.

Parolari, G. 1996. Sensory evaluation techniques. En Handbook of Food Analysis. Volume 1. Nollet, L. M. L. (Ed.). Marcel Dekker, Inc., New York, pp. 163-196.

Pattnaik, S.; Subramanyam, V. R.; Bapaji, M. y Kole, C. R. 1997. Antibacterial and antifungal activity of aromatic constituents of essential oils. Microbios, 89: 39-46.

Paul, F. 1992. Spectrométrie infrarouge et couplage avec la chromatographie en phase gazeuse. En Les arômes alimentaires. Richard, H. y Multon, J. L. (Eds.). TEC \& DOC - LAVOISIER, Paris, pp. 378-401.

Peñuelas, J. y Llusià, J. 2. 2001. The complexity of factors driving volatile organic compounds emissions by plants. Biologia Plantarum, 44: 481487.

Pérez-González, J. A.; van Peij, N. N. M. E.; Bezoen, A.; MacCabe, A. P.; Ramón, D. y de Graaff, L. H. 1998. Molecular cloning and transcriptional 
regulation of the Aspergillus nidulans $x \ln D$ gene encoding a $ß$ xylosidase. Applied and Environmental Microbiology, 64 (4): 1412-1419.

Pétro-Turza, M. 1987. Flavor of tomato and tomato products. Food Reviews International, 2 (3): 309-351.

Pichersky, E. y Gershenzon, J. 2002. The formation and function of plant volatiles: perfumes for pollinator attraction and defense. Current Options of Plant Biology, 5: 237-243.

Pichersky, E.; Noel, J. P. y Dudareva, N. 2006. Biosíntesis of plant volatiles: Natire's diversity and ingenuity. Science, 311: 808-811.

Piechulla, B. y Pott, M. B. 2003. Plant scents - mediators of inter-and intraorganismic communication. Planta, 217: 687-689.

Pino, J. A. y Mesa, J. 2006. Contribution of volatile compounds to mango (Mangifera indica L.) aroma. Flavour and fragrance journal, 21: 207-213.

Plotto, A.; Barnes, K. W. y Goodner, K. 2006. Specific anosmia observed for $\beta$-ionone, but not for $\alpha$-ionone: significance for flavor research. Journal of Food Science, 71 (5): 401-406.

Plotto, A.; Margaría, C. A.; Goodner, K. L.; Goodrich, R. y Baldwin, E. A. 2004. Odour and flavour thresholds for key aroma components in an orange juice matrix: terpenes and aldehydes. Flavour and fragrance journal, 19: 491-498.

Pogorzelski, E. y Wilkowska, A. 2007. Flavour enhancement through the enzymatic hydrolysis of glycosidic aroma precursors in juices and wine beverages: a review. Flavour and fragrance journal, 22: 251-254.

Prasanna, V.; Prabha, T. N. y Tharanathan, R. N. 2007. Fruit ripening phenomena - An overview. Critical Reviews in Food Science and Nutrition, 47: 1-19.

Pszczola, D. E. 2001. From soybeans to spaghetti: the broadening use of enzymes. Food technology, 55: 54-62. 
Raguso, R. A. y Pichersky, E. 1999. A day in the life of a linalool molecule: chemical communication in a plant-pollinator system. Part 1: linalool biosynthesis in flowering plants. Plant Species Biology, 14: 95-120.

Richard, H. 1992. Connaissance de la nature des arômes alimentaires. En Les arômes alimentaires. Richard, H. y Multon, J. L. (Eds.). TEC \& DOC - LAVOISIER, Paris, pp. 22-37.

Riley, J. C. M. y Thompson, J. E. 1998. Ripening-induced acceleration of volatile aldehyde generation following tissue disruption in tomato fruit. Physiologia Plantarum, 104: 571-576.

Riu-Aumatell, M.; Castellari, M.; López-Tamames, E.; Galassi, S. y Buxaderas, S. 2004. Characterisation of volatile compounds of fruit juices and nectars by HS/SPME and GC/MS. Food Chemistry, 87 (4): 627-637.

Rogacheva, S.; Espinosa-Díaz, M. A. y Voilley, A. 1999. Transfer of aroma compounds in water-lipid systems: binding tendency of $\beta$-lactoglobulin. Journal of Agriculture and Food Chemistry, 47 (1): 259-263.

Ruíz, J. J.; Alonso, A.; García-Marínez, S.; Valero, M.; Blasco, P. y RuízBevia, F. 2005. Quantitative analysis of flavour volatiles detects differences among closely related traditional cultivars of tomato. Journal of the Science of Food and Agriculture, 85: 54-60.

Runyon, J. B.; Mescher, M. C. y de Moraes, C. M. 2006. Volatile chemical cues guide host location and host selection by parasitic plants. Science, 313: 1964-1967.

Sakho, M.; Chassangne, D. y Crouzet, J. 1997. African mango glycosidically bound volatile compounds. Journal of Agriculture and Food Chemistry, 45 (3): 883-888.

Sánchez-Palomo, E.; Díaz-Maroto Hidalgo, M. C.; González-Viñas, M. A. y Pérez-Coello, M. S. 2005. Aroma enhancement in wines from different grape varieties using exogenous glycosidases. Food Chemistry, 92: 627-635. 
Sánchez-Torres, P.; González-Candelas, L. y Ramón, D. 1996. Expression in a wine yeast strain of the Aspergillus niger abfB gene. FEMS Microbiology Letters, 145: 189-194.

Sánchez-Torres, P.; Gónzalez-Candelas, L. y Ramón, D. 1998. Heterologous expression of a Candida molischiana anthocyanin- $\beta$ glucosidase in a wine yeast strain. Journal of Agriculture and Food Chemistry, 46 (1): 354-360.

Sarry, JE. y Günata, Z. 2004. Plant and microbial glycoside hydrolases: volatile release from glycosidic aroma precursors. Food Chemistry, 87: 509-521.

Serrano-Megías, M. y López-Nicolás, J. M. 2006. Application of agglomerative hierarchical clustering to identify consumer tomato preferences: influence of physicochemical and sensory characteristics on consumer response. Journal of the Science of Food and Agriculture, 86: 493-499.

Servili, M.; Selvaggini, R.; Taticchi, A.; Begliomini, A. L. y Montedoro, GF. 2000. Relationships between the volatile compounds evaluated by solid phase microextraction and the thermal treatment of tomato juice: optimization of the blanching parameters. Food Chemistry, 71: 407-415.

Simkin, A. J.; Schwartz, S. H.; Auldridge, M.; Taylor, M. G. y Klee, H. J. 2004. The tomato carotenoid cleavage dioxygenase 1 genes contribute to the formation of the flavor volatiles $\beta$-ionone, pseudoionone, and geranylacetone. The Plant Journal, 40: 882-892.

Soares-Chaves, A. L. y de Mello-Farias, P. C. 2006. Ethylene and fruit ripening: from illumination gas to the control of gene expression, more than a century of discoveries. Genetics and Molecular Biology, 29 (3): 508-515.

Song, J.; Fan, L. y Beaudry, R. M. 1998. Application of solid phase microextraction and gas chromatography/time-of-flight mass spectrometry for rapid analysis of flavor volatiles in tomato and strawberry fruits. Journal of Agriculture and Food Chemistry, 46: 37213726. 
Sozzi, G. O.; Fraschina, A. A.; Navarro, A. A.; Cascone, O.; Greve, L. C. y Labavitch, J. M. 2002. $\alpha$-L-Arabinofuranosidase activity during development and ripening of normal and ACC synthase antisense tomato fruit. HortScience, 37 (3): 564-566.

Speirs, J.; Lee, E.; Holt, K.; Yong-Duk, K.; Scott, N. S.; Loveys, B. y Schuch, W. 1998. Genetic manipulation of alcohol dehydrogenase levels in ripening tomato fruit affect the balance of some flavor aldehydes and alcohols. Plant Physiology, 117: 1047-1058.

Stern, D. J.; Buttery, R. G.; Teranishi, R.; Ling, L. C.; Scott, K. y Cantwell, M. 1994. Effect of storage an d ripening on fresh tomato quality, Partl. Food Chemistry, 49: 225-231.

Stevens, M. A. 1970. Relationship between polyene-carotene content and volatile compound composition in tomatoes. Journal of the American Society for Horticultural Science, 95: 461-464.

Stevens, M. A. 1972. Relationships between components contributing to quality variation among tomato lines. Journal of the American Society for Horticultural Science, 97 (1): 70-73.

Stevens, M. A.; Kader, A. A. y Albright-Holton, M. 1979. Potential for increasing tomato flavor via increased sugar and acid content. Journal of the American Society for Horticultural Science, 104 (1): 40-42.

Stevens, M. A.; Kader, A. A.; Albright-Holton, M. y Algazi, M. 1977. Genotypic variation for flavor and composition in fresh market tomatoes. Journal of the American Society for Horticultural Science, 102 (5): 680689.

Straubinger, M.; Bau, B.; Eckstein, S.; Fink, M. y Winterhalter, P. 1998. Identification of novel glycosidic aroma precursors in Saffron (Crocus sativus L.). Journal of Agriculture and Food Chemistry, 46: 3238-3243.

Suárez, M.; Duque, C.; Wintoch, H. y Schreier, P. 1991. Glycosidically bound aroma compounds from the pulp and the peelings of Lulo fruit (Solanum vestissimum D.). Journal of Agriculture and Food Chemistry, 39 (9): 1643-1645. 
Tadmor, Y.; Fridman, E.; Gur, A.; Larkov, O.; Lastochkin, E.; Ravid, U.; Zamir, D. y Lewinsohn, E. 2002. Identification of malodorous, a wild species allele affecting tomato aroma that was selected against during domestication. Journal of Agriculture and Food Chemistry, 50: 20052009.

Tandon, K. S.; Baldwin, E. A.; Scott, J. W. y Shewfelt, R. L. 2003. Linking Sensory Descriptors to Volatile and Nonvolatile Components of Fresh Tomato Flavor. Sensory and Nutritive Qualities of Food, 68 (7): 23662371.

Tandon, K. S.; Baldwin, E. A. y Shewfelt, R. L. 2000. Aroma perception of individual volatile compounds in fresh tomatoes (Lycopersicon esculentum, Mill.) as affected by the medium of evaluation. Postharvest Biology and Technology, 20: 261-268.

Theologis, A. 1992. One rotten apple spoils the whole Bushel:the role of ethylene in fruit ripening. Cell, 70: 181-184.

Thybo, A. K.; Bechmann, I. E. y Brandt, K. 2005. Integration of sensory and objective measurements of tomato quality: quantitative assessment of the effect of harvest date as compared with growth medium (soil versus rockwool), electrical conductivity, variety and maturity. Journal of the Science of Food and Agriculture, 85: 2289-2296.

Thybo, A. K.; Edelenbos, M.; Christensen, L. P.; Sorensen, J. N. y ThorupKristensen, K. 2006. Effect of organic growing systems on sensory quality and chemical composition of tomatoes. $L W T, 39: 835-843$.

Tieman, D.; Zeigler, M.; Schmelz, E.; Taylor, M.; Bliss, P.; Kirst, M. y Klee, $H$. 2006. Identification of loci affecting flavour volatile emissions in tomato fruits. Journal of Experimental Botany, 57 (4): 887-896.

Tsuruhami, K.; Mori, S.; Amarume, S.; Saruwatari, S.; Murata, T.; Hirakake, J.; Sakata, K. y Usui, T. 2006. Isolation and characterization of a $\beta$ primeverosidase-like enzyme from Penicillium multicolor. Bioscience Biotechnology and Biochemistry, 70 (3): 691-698.

van Beilen, J. B. y Li, Z. 2002. Enzyme technology: an overview. Current Opinion in Biotechnology, 13: 338-344. 
Vasserot, Y.; Arnaud, A. y Galzy, P. 1995. Monoterpenol glycosides in plants and their biotechnological transformation. Acta Biotechnol., 15 (1): 77-95.

Verhoeyen, M. E.; Bovy, A.; Collins, G.; Muir, S.; Robinson, S.; de Vos, C. H. R. y Colliver, S. 2002. Increasing antioxidant levels in tomatoes through modification of the flavonoid biosynthetic pathway. Journal of Experimental Botany, 53 (377): 2099-2106.

Volante, M.; Pontello, M.; Volante, L.; Cattaneo, M.; Bianchi, M. y Colzani, L. 2000. Applications of SPME to the Analysis of Pesticide Residues in Vegetables. Pest Management Science, 56: 618-636.

Wang, C.; Chin, C. K.; Ho, C. T.; Hwang, C. F.; Polashock, J. J. y Martin, C. E. 1996. Changes of fatty acids and fatty acid-derived flavor compuonds by expressing the yeast $\Delta-9$ desaturase gene in tomato. Journal of Agriculture and Food Chemistry, 44: 3399-3402.

Wang, D.; Kubota, K.; Kobayashi, A. y Juan, I. M. 2001. Analysis of glycosidically bound aroma precursors in tea Leaves.3. Change in the glycoside content of tea leaves during the Oolong tea manufacturing process. Journal of Agriculture and Food Chemistry, 49: 5391-5396.

Wang, M.; Shao, Y.; Huang, TC.; Wei, GJ. y Ho, CT. 1998. Isolation and structural elucidation of aroma constituents bound as glycosides from Sage (Salvia officinalis). Journal of Agriculture and Food Chemistry, 46: 2509-2511.

Watada, A. E. y Aulenbach, B. B. 1979. Chemical and sensory qualities of fresh market tomatoes. Journal of Food Science, 44: 1013-1016.

Watanabe, S.; Hashimoto, I.; Hayashi, K.; Yagi, K.; Asai, T.; Knapp, H.; Straubinger, M.; Winterhalter, P. y Watanabe, N. 2001. Isolation and identification of 2-phenylethyl disaccharide glycosides and mono glycosides from Rose flowers, and theis potential role in scent formation. Bioscience Biotechnology and Biochemistry, 65 (2): 442-445.

Wei, S.; Marton, I.; Dekel, M.; Shalitin, D.; Lewinsohn, E.; Bravdo, B.-A. y Shoseyov, O. 2004. Manipulating volatile emission in tobacco leaves by expressing Aspergillus niger $\beta$-glucosidase in different subcellular compartments. Plant Biotechnology Journal, 2: 341-350. 
Weisburger, J. H. 1999. Mechanisms of action of antioxidants as exemplified in vegetables, tomatoes and tea. Food and Chemical Toxicology, 37: 943-948.

Werkhoff, P.; Brennecke, S.; Bretschneider, W. y Bertram, H. J. 2002. Modern Methods for Isolating and Quantifying Volatile Flavor and Fragance Compounds. En Flavor, Fragance and Odor Analysis. Marsili, R. T. (Ed.). Marcel Dekker, Inc., New York, pp. 139-204.

White, P. J. 2002. Recent advances in fruit development and ripening: an overview. Journal of Experimental Botany, 53 (377): 1995-2000.

Williams, P. J. 1993. Hydrolitic flavor release in fruit and wines through hydrolysis of nonvolatile precursors. En Flavor Science: Sensible Principles and Techniques. Acree, T. E. y Teranishi, R. (Eds.). Amer. Chem. Soc., Washington, D.C., pp. 287-308.

Wittig de Penna, E. 2001. Evaluación Sensorial. Una metodología actual para tecnología de alimentos. Biblioteca digital de la Universidad de Chile. http://mazinger.sisib.uchile.cl/repositorio/lb/ciencias quimicas y farmaceuticas/ wittinge01/index.html.

Wright, D. H. y Harris, N. D. 1985. Effect of nitrogen and potassium fertilization on tomato flavor. Journal of Agriculture and Food Chemistry, 33 (3): 355-358.

Yang, X. y Peppard, T. 1994. Solid-phase microextraction for flavor analysis. Journal of Agriculture and Food Chemistry, 42: 1925-1930.

Yilmaz, E. 2001. Oxylipin Pathway in the Biosynthesis of Fresh Tomato Volatiles. Mini Review. Turkish Journal of Biology, 25: 351-360.

Yilmaz, E.; Baldwin, E. A. y Shewfelt, R. L. 2002a. Enzymatic modification of tomato homogenate and its effect on volatile flavor compounds. Food Chemistry and Toxicology, 67 (6): 2122-2125.

Yilmaz, E.; Scott, J. W. y Shewfelt, R. L. 2002b. Effects of harvesting maturity and off-plant ripening on the activities of lipoxygenase, hydroperoxide lyase, and alcohol deshydrogenase enzymes in fresh tomato. Journal of Food Biochemistry, 26: 443-457. 
Yilmaz, E.; Tandon, K. S.; Scott, J. W.; Baldwin, E. A. y Shewfelt, R. L. 2001. Absence of a clear relationship between lipid pathway enzymes and volatile compounds in fresh tomatoes. Journal of Plant Physiology, 158: 1111-1116.

Zhu, H. L.; Zhu, B. Z.; Fu, D. Q.; Xie, Y. H.; Hao, Y. L. y Luo, Y. B. 2005.

Role of ethylene in the biosynthetic pathways of aroma volatiles in ripening fruit. Russian Journal of Plant Physiology, 52 (5): 776-780. 
